\title{
Tritium Movement and Accumulation in the NGNP System Interface and Hydrogen Plant
}

Hirofumi Ohashi

Steven R. Sherman

June 2007

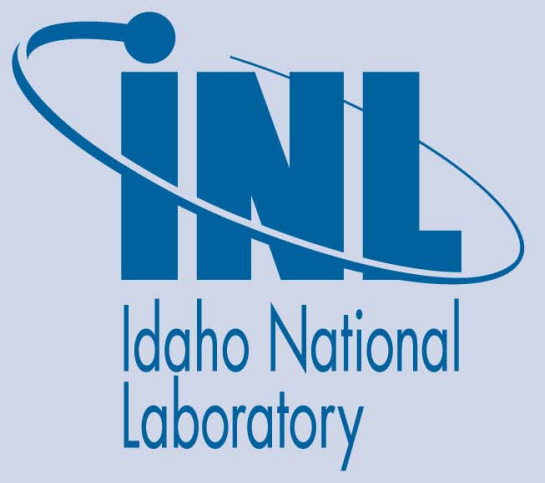

The INL is a U.S. Department of Energy National Laboratory operated by Battelle Energy Alliance 


\title{
Tritium Movement and Accumulation in the NGNP System Interface and Hydrogen Plant
}

\author{
Hirofumi Ohashi ${ }^{1}$ \\ Steven R. Sherman ${ }^{2}$
}

1JAEA

${ }^{2}$ INL

June 2007

Idaho National Laboratory
Idaho Falls, Idaho 83415

http://www.inl.gov

Prepared for the

U.S. Department of Energy

Office of Nuclear Energy

Under DOE Idaho Operations Office

Contract DE-AC07-05ID14517 


\section{ABSTRACT}

Tritium movement and accumulation in a Next Generation Nuclear Plant with a hydrogen plant using a high-temperature electrolysis (HTE) process and a thermochemical water-splitting Sulfur-Iodine (SI) process are estimated by the numerical code THYTAN as a function of design, operational, and material parameters. Estimated tritium concentrations in the hydrogen product and in process chemicals in the hydrogen plant of the Next Generation Nuclear Plant using the HTE process are slightly higher than the drinking water limit defined by the U.S. Environmental Protection Agency and the limit in the effluent at the boundary of an unrestricted area of a nuclear plant as defined by the U.S. Nuclear Regulatory Commission. However, these concentrations can be reduced to within the limits through use of some designs and modified operations. Tritium concentrations in the Next Generation Nuclear Plant using the SI process are significantly higher as calculated and are affected by parameters with large uncertainties (i.e., tritium permeability of the process heat exchanger, the hydrogen concentration in the heat transfer and process fluids, the equilibrium constant of the isotope exchange reaction between $\mathrm{HT}$ and $\mathrm{H}_{2} \mathrm{SO}_{4}$ ). These parameters, including tritium generation and the release rate in the reactor core, should be more accurately estimated in the near future to improve the calculations for the NGNP using the SI process. Decreasing the tritium permeation through the heat exchanger between the primary and secondary circuits may be an an effective measure for decreasing tritium concentrations in the hydrogen product, the hydrogen plant, and the tertiary coolant. 


\section{EXECUTIVE SUMMARY}

This study evaluated tritium concentrations in the hydrogen product and in process chemicals in the energy transport systems and the hydrogen plant associated with the Next Generation Nuclear Plant (NGNP). In this work, tritium generation and transport mechansisms in the NGNP are described. The mathematics of these mechanisms are outlined, and are then codified and analyzed using a Japan Atomic Energy Agency (JAEA) analysis code called THYTAN [ $\underline{T}$ ritium and $\underline{H Y}$ drogen Transportation ANalysis code ]. As a preliminary step, the THYTAN code was benchmarked against data available from the Peach Bottom HTGR. After benchmarking, various configurations of the NGNP employing a hightemperature electrolysis (HTE) hydrogen plant and an NGNP employing a Sulfur-Iodine (SI) hydrogen plant were analyzed, and the concentrations of tritium in the process and product streams were compared to current regulatory effluent limits in ground water and in air.

Tritium is generated in the core of the reactor from the ternary fission of nuclear fuel (e.g., e.g., ${ }^{233} \mathrm{U},{ }^{235} \mathrm{U},{ }^{239} \mathrm{Pu}$, and ${ }^{241} \mathrm{Pu}$ ) from thermal neutrons, and from neutron capture reactions with ${ }^{6} \mathrm{Li},{ }^{7} \mathrm{Li}$, ${ }^{3} \mathrm{He}$, and ${ }^{10} \mathrm{~B}$. Tritium from these reactions diffuses from the core materials into the primary coolant, where it can migrate to other parts of the system through bulk transport, diffusion, and isotope exchange mechanisms. Tritium is lost from the system when it diffuses through barrier materials to the outside environment or is entrained or carried away in the loss of bulk fluids (e.g., helium coolant leaks, as a contaminant in a hydrogen product stream, etc.). Tritium not lost to the outside environment accumulates in the process fluids or absorbs into the plant's materials of construction. At steady-state, the tritium creation rate equals the rate of tritium losses to the outside environment, and tritium concentrations in process fluid streams are time-invariant.

Mass balances and a node-link computational scheme were used to represent the various NGNP process units and flow streams. A node is used to represent a process unit or a section of a process unit, while links are used to indicate the flow of materials into and out of a node.

Using this computational scheme and the THYTAN algorithms, a representation of the Peach Bottom HTGR was analyzed, and the results were compared to the data available from Peach Bottom operations in regard to tritium. The comparison of THYTAN results with Peach Bottom data showed that the THYTAN code provided results that were within 5\%, and sometimes much better, of the observed data in most cases.

An NGNP employing HTE was extensively analyzed for tritium. A reference case was examined, and tritium concentrations in the primary, secondary, and tertiery coolants were determined, as were the concentrations of tritium in HTE process chemicals and in the hydrogen and oxygen product. For the reference case, tritium in the hydrogen product was found to be $2.67 \times 10^{-3} \mathrm{~Bq} / \mathrm{cm}^{3}$ [STP], which is below the NRC gaseous effluent limit of $3.7 \times 10^{-3} \mathrm{~Bq} / \mathrm{cm}^{3}$ [STP]. Tritium concentrations in process chemicals and in the primary, secondary, and tertiary coolants exceeded the NRC gaseous effluent limit, and, in the case of liquid-phase chemicals, exceeded the EPA drinking water effluent limit of $37 \mathrm{~Bq} / \mathrm{cm}^{3}$. The amount of tritium in the hydrogen product and process fluid streams could be lowered by reducing the heat exchanger material permeabilities, increasing the hydrogen purification system flow rates, and by injecting additional hydrogen into the primary, secondary, or tertiary helium loops to affect tritium permeation chemistry at the heat exchanger surfaces, and the degree of tritium reduction in each process stream is dependent upon the extent of the measures taken.

An NGNP employing a Sulfur-Iodine (SI) hydrogen production process was also extensively analyzed for tritium. A reference case was examined, and tritium concentrations in the coolant loops and 
process chemicals were determined. For the reference case, the tritium concentration in the hydrogen product was found to be $1.23 \mathrm{~Bq} / \mathrm{cm}^{3}$ [STP], which exceeds the NRC gaseous effluent limit by a factor of 305. Tritium concentration in the gaseous flash drum (S301) of the SI process reaches $18.95 \mathrm{~Bq} / \mathrm{cm}^{3}$ [STP] and is $1.77 \mathrm{~Bq} / \mathrm{cm}^{3}[\mathrm{STP}]$ in the tertiery helium coolant. Tritium in the liquid process chemicals also exceeds the liquid effluent limit by a large margin. Reducing heat exchanger permeabilities, increasing the helium purification sytem flow rates, and injecting hydrogen into the primary, secondary, or tertiary helium coolants lowers tritium concentrations in the hydrogen plant, but more drastic measures are needed to achieve the desired effluent limits than are required by an NGNP using an HTE hydrogen production process.

A third configuration of the NGNP with either an HTE or SI hydrogen plant was analyzed that did not include a tertiary loop. It was determined that the presence or absence of a tertiary loop does not make a significant difference in the concentration of tritium in the hydrogen plant process streams.

Additional data is needed to determine more accurately the tritium concentrations in the NGNP. These data include information about the tritium permeability of non-metallic heat exchanger materials and for non-metallic surface coatings, a better understanding of tritium release rates from NGNP core graphite and other materials, and measurements of the tritium isotope exchange rates and equilibrium constants for the interactions between tritium and key process chemicals (e.g., $\mathrm{H}_{2} \mathrm{SO}_{4}, \mathrm{HI}$ ). Additional modeling work is needed for the NGNP configurations of interest, as is further model development, as the THYTAN code is JAEA-proprietary and is not yet openly available for use outside of JAEA. In the actual plant, more development work is needed to define, construct, and test tritium instrumentation. 


\section{CONTENTS}

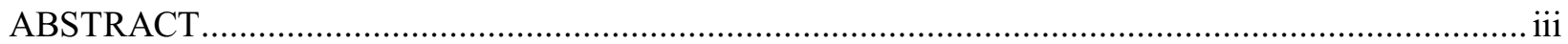

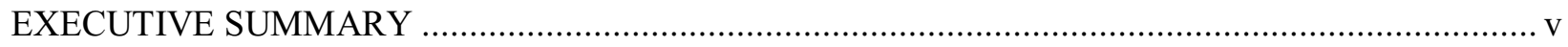

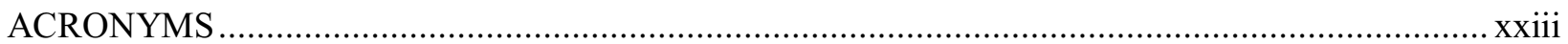

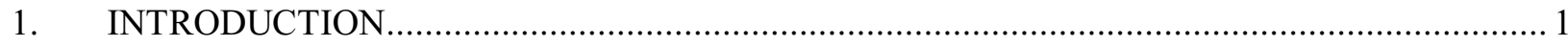

2. TRITIUM SOURCE AND PATHWAY TO PRODUCT HYDROGEN ..................................... 5

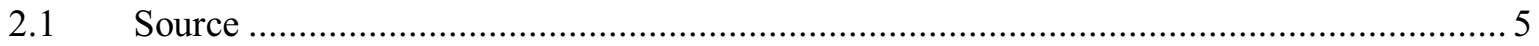

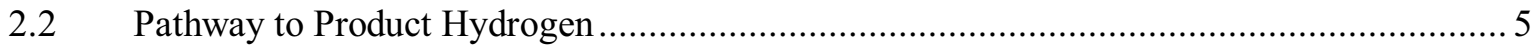

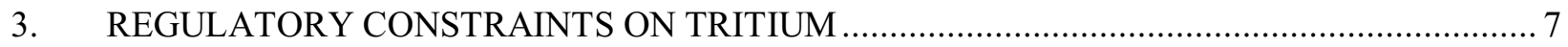

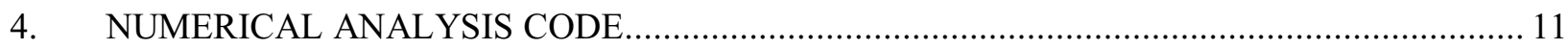

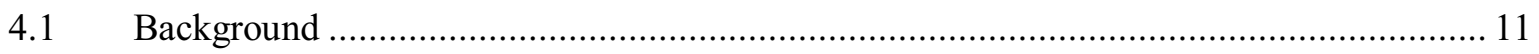

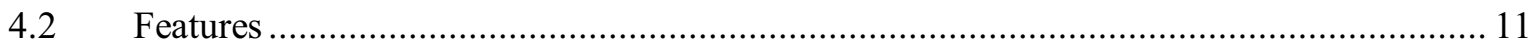

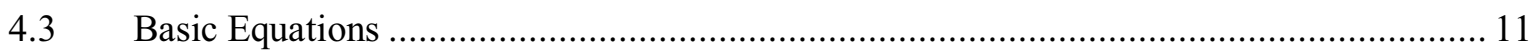

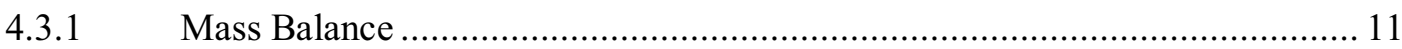

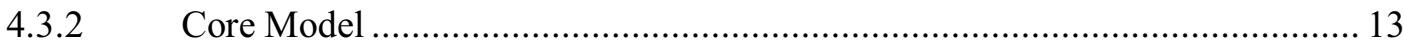

4.3.3 Permeation Model .................................................................................. 16

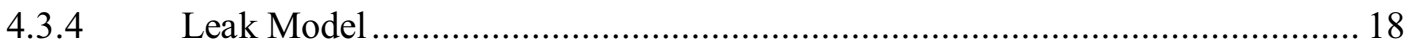

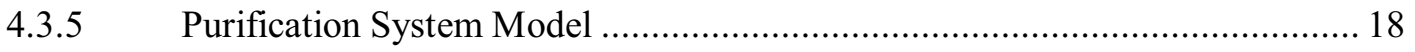

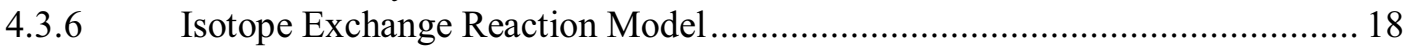

4.3.7 Strategy of Modeling for the Hydrogen Production System........................... 20

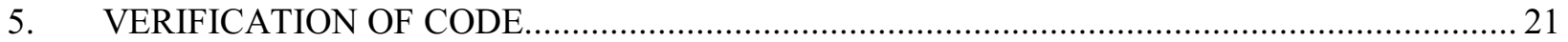

5.1 Brief Description of Peach Bottom High-Temperature Gas-Cooled Reactor .................. 21

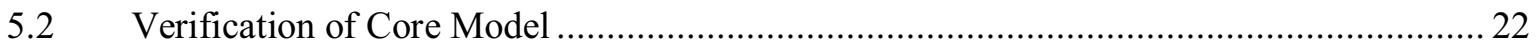

5.2.1 Birth of Tritium by Ternary Fission ...................................................... 22

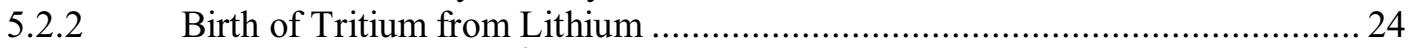

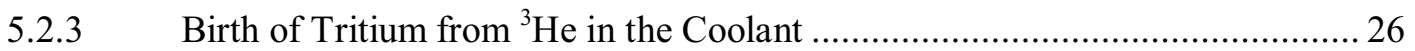

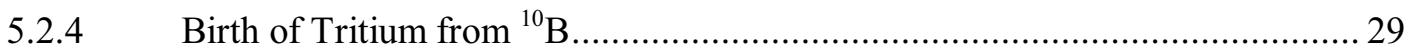

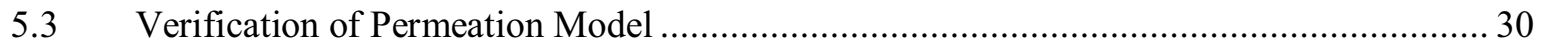

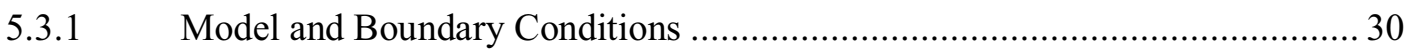

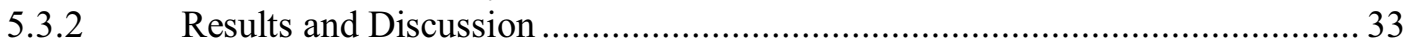

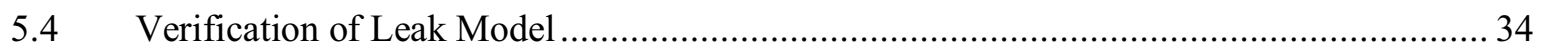

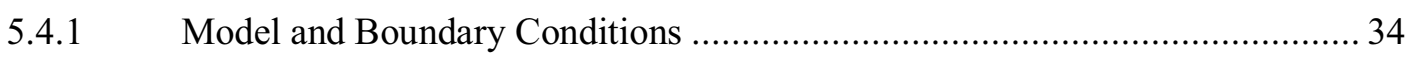

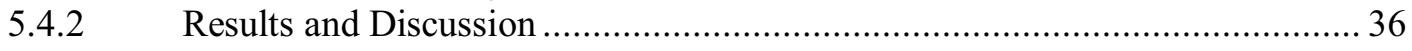




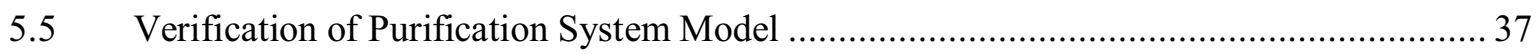

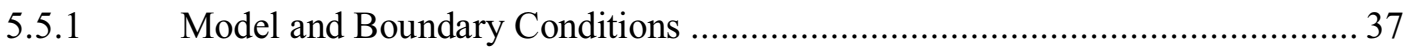

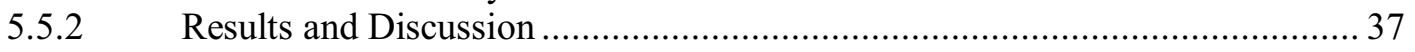

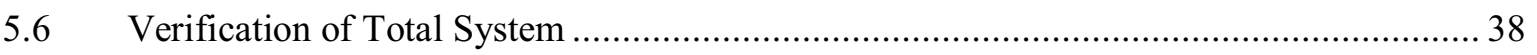

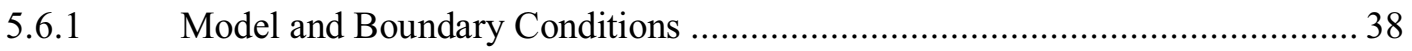

5.6.2 Results and Discussion ............................................................................ 42

6. NUMERICAL ANALYSIS OF THE NEXT GENERATION NUCLEAR PLANT USING HIGH-

TEMPERATURE ELECTROLYSIS PROCESS.................................................................... 45

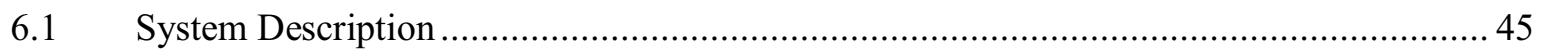

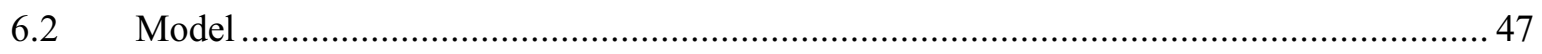

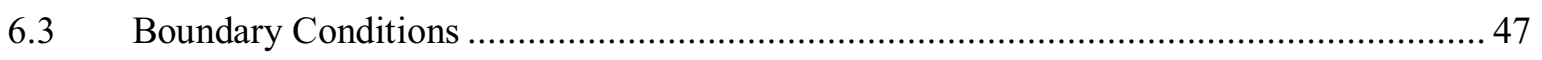

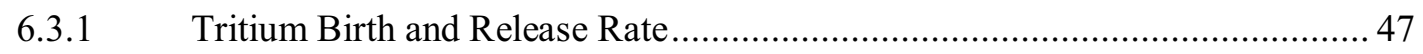

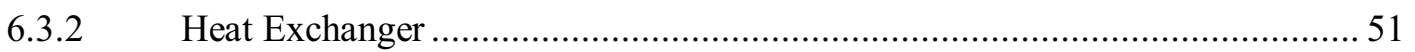

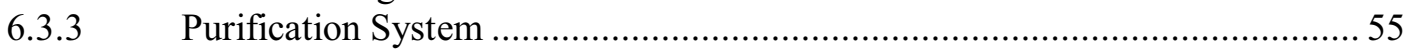

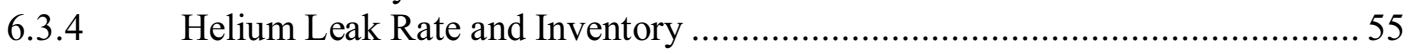

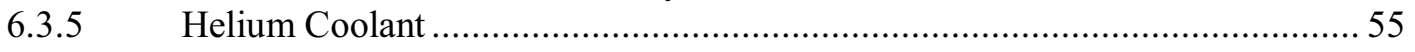

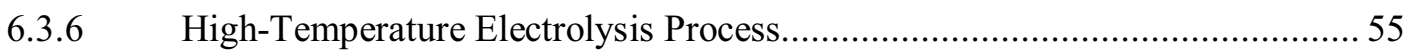

6.4 Calculation Results and Discussion ....................................................................... 59

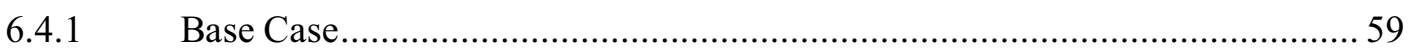

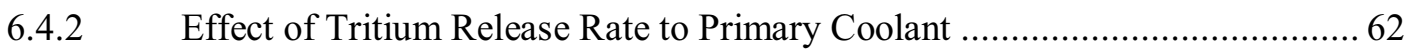

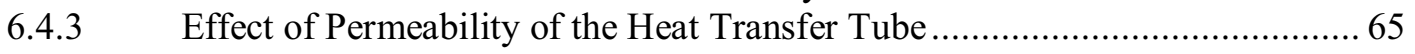

6.4.4 Effect of Helium Flow Rate at Purification System ...................................... 70

6.4.5 Effect of Pressure in Tertiary Loop ...................................................... 75

6.4.6 Effect of Reactor Outlet Temperature .................................................... 78

6.4.7 Effect of Hydrogen Injection in Helium Coolant ....................................... 83

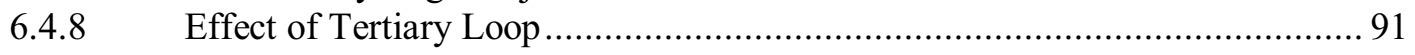

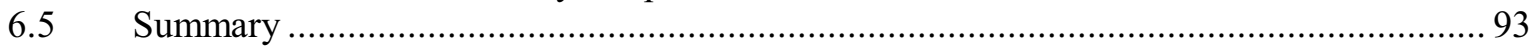

7. NUMERICAL ANALYSIS OF THE NEXT GENERATION NUCLEAR PLANT USING THE

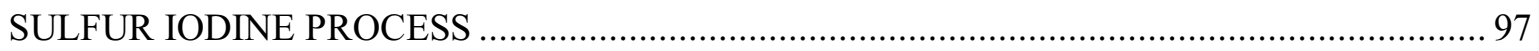

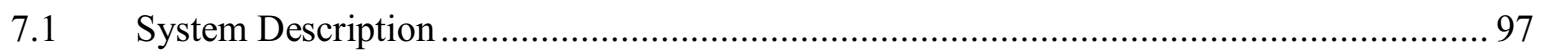

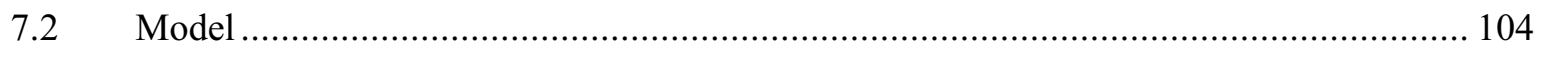

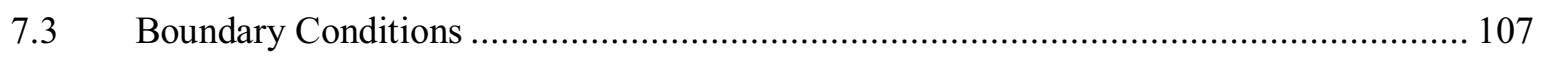

7.3.1 Tritium Release Rate ....................................................................... 107

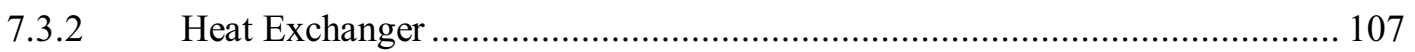

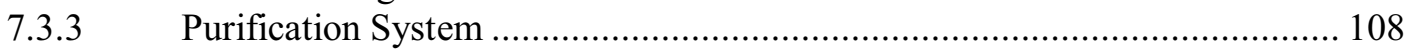

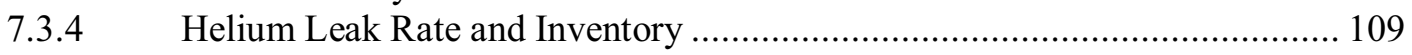

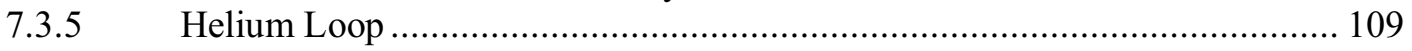

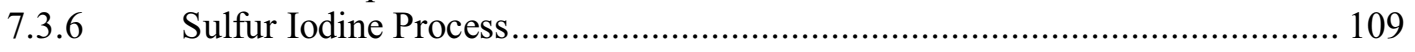

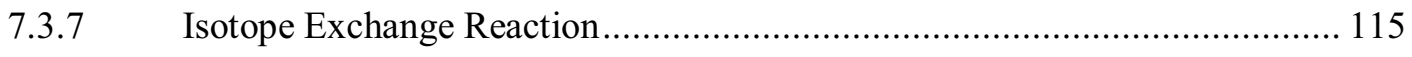




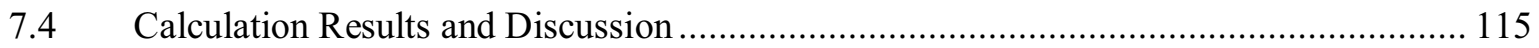

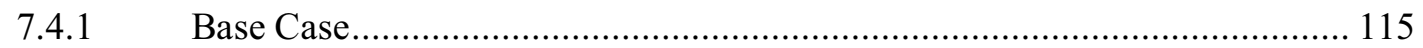

7.4.2 Effect of Equilibrium Constant of the Isotope Exchange Reaction................ 121

7.4.3 Effect of Process Heat Exchanger Permeability ......................................... 124

7.4.4 Effect of Hydrogen Concentration in Helium Coolant ................................ 127

7.4.5 Effect of Primary Coolant Tritium Release Rate ....................................... 131

7.4.6 Effect of Intermediate Heat Exchanger and Secondary Heat Exchanger

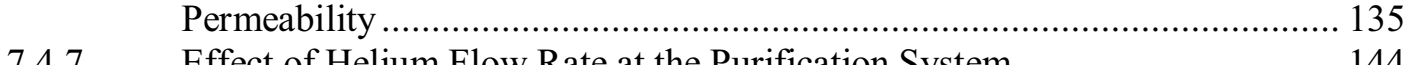

7.4.7 Effect of Helium Flow Rate at the Purification System .............................. 144

7.4.8 Effect of Pressure in Tertiary Loop ....................................................... 159

7.4.9 Effect of Hydrogen Injection in Helium Coolant ...................................... 163

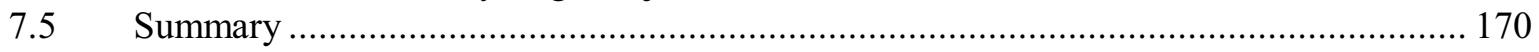

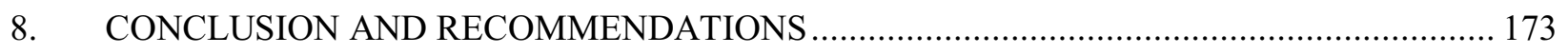

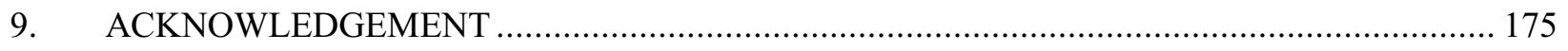

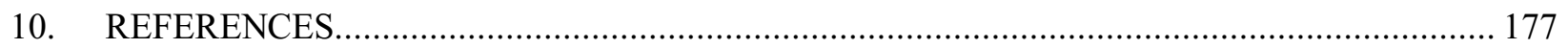




\section{FIGURES}

Figure 1. Diagram of a Next Generation Nuclear Plant facility...................................................... 1

Figure 2. Reference configuration of NGNP showing deployment of SI plant [C.H. Oh et al., 2006]...... 2

Figure 3. Simplified schematic diagram of node and junction in THYTAN. ....................................... 13

Figure 4. Isometric view of the primary coolant system of the Peach Bottom high-temperature gas-cooled

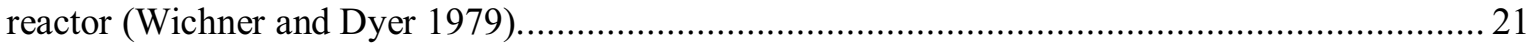

Figure 5. Simplified flowsheet of the Peach Bottom high-temperature gas-cooled reactor, illustrating tritium transport paths (Wichner and Dyer 1979)............................................................ 23

Figure 6. Model nodalization scheme for verification of the permeation model. ................................. 33

Figure 7. Nodalization scheme for verification of the leak model. .................................................... 35

Figure 8. Comparison of tritium concentrations in the containment vessel of the Peach Bottom high-temperature gas-cooled reactor for verification of the leak model..................................... 36

Figure 9. Nodalization scheme for verification of the purification system model. ............................... 37

Figure 10. Analytical and computed solution of tritium concentration for verification of the purification system model.

Figure 12. Calculation result for the annual tritium birth rate in the Peach Bottom high-temperature gas-cooled reactor during the Core 2 operation.

Figure 13. Comparison of tritium concentration, in the Peach Bottom high-temperature gas-cooled reactor, between the observed concentration (reprinted from Wichner and Dyer 1979) and the computed solution from THYTAN.

Figure 14. Tentative flow scheme for the Next Generation Nuclear Plant using the high-temperature electrolysis process.

Figure 15. Nodalization scheme of the Next Generation Nuclear Plant using the high-temperature electrolysis process.

Table 18. Additional calculation results for the tritium birth rate in the high-temperature gas-cooled reactor.

Figure 16. Permeability of Incoloy 800.

Figure 17. Tritium distributions in the Next Generation Nuclear Plant using the high-temperature electrolysis process. 
Figure 18. Effect of varying tritium release rate on the tritium concentration in the hydrogen product for the Next Generation Nuclear Plant using the high-temperature electrolysis process

Figure 19. Effect of varying tritium release rate on the tritium concentration in gaseous process chemicals in the electrolyzer for the Next Generation Nuclear Plant using the high-temperature electrolysis process.

Figure 20. Effect of varying tritium release rate on the tritium concentration in liquid process chemicals in the $\mathrm{H}_{2} / \mathrm{H}_{2} \mathrm{O}$ knockout tank for the Next Generation Nuclear Plant using the high-temperature electrolysis process.

Figure 21. Effect of varying tritium release rate on the tritium concentration in helium coolant for the Next Generation Nuclear Plant using the high-temperature electrolysis process......

Figure 22. Effect of varying permeability on the tritium concentration in the hydrogen product for the Next Generation Nuclear Plant using the high-temperature electrolysis process.

Figure 23. Effect of varying intermediate heat exchanger permeability on tritium permeation rate through the intermediate heat exchanger and the driving force of permeation for the Next Generation Nuclear Plant using the high-temperature electrolysis process.

Figure 24. Effect of varying secondary heat exchanger permeability on tritium permeation rate through the secondary heat exchanger and the driving force of permeation for the Next Generation Nuclear Plant using the high-temperature electrolysis process.

Figure 25. Effect of varying permeability on the tritium concentration in gaseous process chemicals in the electrolyzer for the Next Generation Nuclear Plant using the high-temperature electrolysis process. 67

Figure 26. Effect of varying permeability on the tritium concentration in liquid process chemicals in the $\mathrm{H}_{2} / \mathrm{H}_{2} \mathrm{O}$ knockout tank for the Next Generation Nuclear Plant using the high-temperature electrolysis process.

Figure 27. Effect of varying intermediate heat exchanger permeability on the tritium concentration in the helium coolant for the Next Generation Nuclear Plant using the high-temperature electrolysis process.

Figure 28. Effect of varying secondary heat exchanger permeability on the tritium concentration in the helium coolant for the Next Generation Nuclear Plant using the high-temperature electrolysis process.

Figure 29. Effect of varying process heat exchanger permeability on the tritium concentration in the helium coolant for the Next Generation Nuclear Plant using the high-temperature electrolysis process.

Figure 30. Effect of varying helium flow rate at the purification system on the tritium concentration in the hydrogen product for the Next Generation Nuclear Plant using the high-temperature electrolysis process.

Figure 31. Effect of varying helium flow rate at the purification system on the tritium concentration in the electrolyzer's gaseous process chemicals for the Next Generation Nuclear Plant using the hightemperature electrolysis process. 
Figure 32. Effect of varying helium flow rate at the purification system on the tritium concentration in liquid process chemicals in the $\mathrm{H}_{2} / \mathrm{H}_{2} \mathrm{O}$ knockout tank for the Next Generation Nuclear Plant using the high-temperature electrolysis process.

Figure 33. Effect of varying helium flow rate at the purification system in the primary loop on the tritium concentration in the helium coolant for the Next Generation Nuclear Plant using the hightemperature electrolysis process.

Figure 34. Effect of varying helium flow rate at the purification system in the secondary loop on the tritium concentration in the helium coolant for the Next Generation Nuclear Plant using the hightemperature electrolysis process.

Figure 35. Effect of varying helium flow rate at the purification system in the tertiary loop on the tritium concentration in the helium coolant for the Next Generation Nuclear Plant using the hightemperature electrolysis process.

Figure 36. Effect of varying helium flow rate at the purification system in all loops on the tritium concentration in the helium coolant for the Next Generation Nuclear Plant using the hightemperature electrolysis process.

Figure 37. Effect of varying pressure in tertiary loop on the tritium concentration in the hydrogen product for the Next Generation Nuclear Plant using the high-temperature electrolysis process.

Figure 38. Effect of varying pressure in the tertiary loop on tritium permeation rate for the Next Generation Nuclear Plant using the high-temperature electrolysis process.

Figure 39. Effect of varying pressure in the tertiary loop on the tritium concentration in the electrolyzer's gaseous process chemicals for the Next Generation Nuclear Plant using the high-temperature electrolysis process.

Figure 40. Effect of varying pressure in the tertiary loop on the tritium concentration in the $\mathrm{H}_{2} / \mathrm{H}_{2} \mathrm{O}$ knockout tank's liquid process chemicals for the Next Generation Nuclear Plant using the hightemperature electrolysis process.

Figure 41. Effect of varying pressure in the tertiary loop on tritium concentration in the helium coolant for the Next Generation Nuclear Plant using the high-temperature electrolysis process.

Figure 42. Effect of varying reactor outlet temperature on the tritium concentration in product hydrogen for the Next Generation Nuclear Plant using the high-temperature electrolysis process.....

Figure 43. Effect of varying reactor outlet temperature on the tritium permeation rate for the Next Generation Nuclear Plant using the high-temperature electrolysis process.

Figure 44. Effect of reactor outlet temperature on the the tritium concentration in the electrolyzer's gaseous process chemicals for the Next Generation Nuclear Plant using the high-temperature electrolysis process.

Figure 45. Effect of varying reactor outlet temperature on the tritium concentration in the $\mathrm{H}_{2} / \mathrm{H}_{2} \mathrm{O}$ knockout tank's liquid process chemicals for the Next Generation Nuclear Plant using the hightemperature electrolysis process. 
Figure 46. Effect of varying reactor outlet temperature on the tritium concentration in the helium coolant for the Next Generation Nuclear Plant using the high-temperature electrolysis process.....

Figure 47. Effect of varying hydrogen injection in the helium coolant on the tritium concentration for the hydrogen product for the Next Generation Nuclear Plant using the high-temperature electrolysis process.

Figure 48. Effect of varying hydrogen injection in the primary helium coolant on tritium permeation rate for the Next Generation Nuclear Plant using the high-temperature electrolysis process.

Figure 49. Effect of varying hydrogen injection in the secondary helium coolant on tritium permeation rate for the Next Generation Nuclear Plant using the high-temperature electrolysis process.

Figure 50. Effect of varying hydrogen injection in the tertiary helium coolant on tritium permeation rate for the Next Generation Nuclear Plant using the high-temperature electrolysis process.

Figure 51. Effect of varying hydrogen injection in the primary helium coolant on hydrogen concentration in the helium coolant for the Next Generation Nuclear Plant using the high-temperature electrolysis process.

Figure 52. Effect of varying hydrogen injection in the secondary helium coolant on hydrogen concentration in the helium coolant for the Next Generation Nuclear Plant using the hightemperature electrolysis process.

Figure 53. Effect of varying hydrogen injection in the tertiary helium coolant on hydrogen concentration in the helium coolant for the Next Generation Nuclear Plant using the high-temperature electrolysis process.

Figure 54. Effect of varying hydrogen injection in the helium coolant on the tritium concentration in the electrolyzer's gaseous process chemicals for the Next Generation Nuclear Plant using the hightemperature electrolysis process.

Figure 55. Effect of varying hydrogen injection in the helium coolant on the tritium concentration in the $\mathrm{H}_{2} / \mathrm{H}_{2} \mathrm{O}$ knockout tank's liquid process chemicals for the Next Generation Nuclear Plant using the high-temperature electrolysis process.

Figure 56. Effect of varying hydrogen injection in the primary helium coolant on the tritium concentration of the helium coolant for the Next Generation Nuclear Plant using the high-temperature electrolysis process.

Figure 57. Effect of varying hydrogen injection in the secondary helium coolant on the tritium concentration of the helium coolant for the Next Generation Nuclear Plant using the hightemperature electrolysis process.

Figure 58. Effect of varying hydrogen injection in the tertiary helium coolant on the tritium concentration of the helium coolant for the Next Generation Nuclear Plant using the high-temperature electrolysis process.

Figure 59. Nodalization scheme for the Next Generation Nuclear Plant using the high-temperature electrolysis process without a tertiary loop. 
Figure 60. Section 1 flowsheet for the sulfur iodine process (Richards et al. 2006).

Figure 61. Section 2 flowsheet for the sulfur iodine process (Richards et al. 2006).

Figure 62. Section 3 flowsheet for the sulfur iodine process (Richards et al. 2006). 101

Figure 63. Tentative flow scheme for the Next Generation Nuclear Plant using the sulfur iodine process.102

Figure 64. Helium loop nodalization scheme for the Next Generation Nuclear Plant using the sulfur iodine process. 104

Figure 65. Section 1 nodalization scheme in the sulfur iodine process for Next Generation Nuclear Plant.105

Figure 66. Section 2 nodalization scheme in the sulfur iodine process for the Next Generation Nuclear Plant.

Figure 67. Section 3 nodalization scheme in the sulfur iodine process for the Next Generation Nuclear Plant.

Figure 68. Tritium distributions for the Next Generation Nuclear Plant using the sulfur iodine process. 117

Figure 69. Effect of varying equilibrium constant of isotope exchange reaction between $\mathrm{HT}$ and $\mathrm{H}_{2} \mathrm{SO}_{4}$ on the hydrogen product tritium concentration for the Next Generation Nuclear Plant using the sulfur iodine process.

Figure 70. Effect of varying equilibrium constant of isotope exchange reaction between $\mathrm{HT}$ and $\mathrm{H}_{2} \mathrm{SO}_{4}$ on the tritium concentration in gaseous process chemicals for the Next Generation Nuclear Plant using the sulfur iodine process.

Figure 71. Effect of varying equilibrium constant of the isotope exchange reaction between HT and $\mathrm{H}_{2} \mathrm{SO}_{4}$ on the tritium concentration in liquid process chemicals for the Next Generation Nuclear Plant using the sulfur iodine process.

Figure 72. Effect of varying equilibrium constant of the isotope exchange reaction between HT and $\mathrm{H}_{2} \mathrm{SO}_{4}$ on the tritium concentration in the helium coolant for the Next Generation Nuclear Plant using the sulfur iodine process.

Figure 73. Effect of varying process heat exchanger permeability on the tritium concentration in the hydrogen product for the Next Generation Nuclear Plant using the sulfur iodine process.

Figure 74. Effect of varying process heat exchanger permeability on the tritium concentration in gaseous process chemicals of the flash drum (S301) for the Next Generation Nuclear Plant using the sulfur iodine process.

Figure 75. Effect of varying process heat exchanger permeability on the tritium concentration in liquid process chemicals of the secondary $\mathrm{O}_{2}$ knockout drum (S105) for the Next Generation Nuclear Plant using the sulfur iodine process.

Figure 76. Effect of varying process heat exchanger permeability on the tritium concentration in helium coolant for the Next Generation Nuclear Plant using the sulfur iodine process. 
Figure 77. Effect of varying hydrogen concentration in the helium coolant on the tritium concentration in the hydrogen product for the Next Generation Nuclear Plant using the sulfur iodine process. ..... 128

Figure 78. Effect of varying hydrogen concentration in helium coolant on the tritium concentration in gaseous process chemicals of the flash drum (S301) for the Next Generation Nuclear Plant using the sulfur iodine process.

Figure 79. Effect of varying hydrogen concentration in helium coolant on the tritium concentration in liquid process chemicals of the secondary $\mathrm{O}_{2}$ knockout drum (S105) for the Next Generation Nuclear Plant using the sulfur iodine process.

Figure 80. Effect of varying hydrogen concentration in helium coolant on the tritium concentration in the primary helium coolant for the Next Generation Nuclear Plant using the sulfur iodine process... 130

Figure 81. Effect of varying hydrogen concentration in helium coolant on the tritium concentration in the secondary helium coolant for the Next Generation Nuclear Plant using the sulfur iodine process. 130

Figure 82. Effect of varying hydrogen concentration in helium coolant on the tritium concentration in the tertiary helium coolant for the Next Generation Nuclear Plant using the sulfur iodine process.... 131

Figure 83. Effect of varying tritium release rate on the tritium concentration in the hydrogen product for the Next Generation Nuclear Plant using the sulfur iodine process.

Figure 84. Effect of varying tritium release rate on the tritium concentration in gaseous process chemicals of the flash drum (S301) for the Next Generation Nuclear Plant using the sulfur iodine process. 132

Figure 85. Effect of varying tritium release rate on the tritium concentration in liquid process chemicals of the secondary $\mathrm{O}_{2}$ knockout drum (S105) for the Next Generation Nuclear Plant using the sulfur iodine process.

Figure 86. Effect of varying tritium release rate on the tritium concentration in the primary helium coolant for the Next Generation Nuclear Plant using the sulfur iodine process. 134

Figure 87. Effect of varying tritium release rate on the tritium concentration in the secondary helium coolant for the Next Generation Nuclear Plant using the sulfur iodine process.

Figure 88. Effect of varying tritium release rate on the tritium concentration in the tertiary helium coolant for the Next Generation Nuclear Plant using the sulfur iodine process. 135

Figure 89. Effect of varying intermediate heat exchanger permeability on the tritium concentration in the hydrogen product for the Next Generation Nuclear Plant using the sulfur iodine process.

Figure 90. Effect of varying secondary heat exchanger permeability on the tritium concentration in the hydrogen product for the Next Generation Nuclear Plant using the sulfur iodine process.

Figure 91. Effect of varying intermediate heat exchanger permeability on the tritium permeation driving force and tritium permeation rate through the intermediate heat exchanger for the Next Generation Nuclear Plant using the sulfur iodine process. 
Figure 92. Effect of varying secondary heat exchanger permeability on the tritium permeation driving force and tritium permeation rate through the secondary heat exchanger for the Next Generation Nuclear Plant using the sulfur iodine process.

Figure 93. Effect of varying intermediate heat exchanger permeability on the tritium concentration in gaseous process chemicals of the flash drum (S301) for the Next Generation Nuclear Plant using the sulfur iodine process.

Figure 94. Effect of varying secondary heat exchanger permeability on the tritium concentration in gaseous process chemicals of the flash drum (S301) for the Next Generation Nuclear Plant using the sulfur iodine process.

Figure 95. Effect of varying intermediate heat exchanger permeability on the tritium concentration in liquid process chemicals of the secondary $\mathrm{O}_{2}$ knockout drum (S105) for the Next Generation Nuclear Plant using the sulfur iodine process.

Figure 96. Effect of varying secondary heat exchanger permeability on the tritium concentration in liquid process chemicals of the secondary $\mathrm{O}_{2}$ knockout drum (S105) for the Next Generation Nuclear Plant using the sulfur iodine process.

Figure 97. Effect of varying intermediate heat exchanger permeability on the tritium concentration in the primary helium coolant for the Next Generation Nuclear Plant using the sulfur iodine process... 141

Figure 98. Effect of varying intermediate heat exchanger permeability on the tritium concentration in the secondary helium coolant for the Next Generation Nuclear Plant using the sulfur iodine process. 141

Figure 99. Effect of varying intermediate heat exchanger permeability on the tritium concentration in the tertiary helium coolant for the Next Generation Nuclear Plant using the sulfur iodine process.... 142

Figure 100. Effect of varying secondary heat exchanger permeability on the tritium concentration in the primary helium coolant for the Next Generation Nuclear Plant using the sulfur iodine process... 142

Figure 101. Effect of varying secondary heat exchanger permeability on the tritium concentration in the secondary helium coolant for the Next Generation Nuclear Plant using the sulfur iodine process. 143

Figure 102. Effect of varying secondary heat exchanger permeability on the tritium concentration in the tertiary helium coolant for the Next Generation Nuclear Plant using the sulfur iodine process.... 143

Figure 103. Effect of varying helium flow rate at the purification system in the primary loop on the tritium concentration in the hydrogen product for the Next Generation Nuclear Plant using the sulfur iodine process.

Figure 104. Effect of varying helium flow rate at the purification system in the secondary loop on the tritium concentration in the hydrogen product for the Next Generation Nuclear Plant using the sulfur iodine process.

Figure 105. Effect of varying helium flow rate at the purification system in the tertiary loop on the tritium concentration in the hydrogen product for the Next Generation Nuclear Plant using the sulfur iodine process. 
Figure 106. Effect of varying helium flow rate at the purification system in all loops on the tritium concentration in the hydrogen product for the Next Generation Nuclear Plant using the sulfur iodine process.

Figure 107. Effect of varying helium flow rate at the purification system in the primary loop on the tritium concentration in gaseous process chemicals of the flash drum (S301) for the Next Generation Nuclear Plant using the sulfur iodine process.

Figure 108. Effect of varying helium flow rate at the purification system in the secondary loop on the tritium concentration in gaseous process chemicals of the flash drum (S301) for the Next Generation Nuclear Plant using the sulfur iodine process.

Figure 109. Effect of varying helium flow rate at the purification system in the tertiary loop on the tritium concentration in gaseous process chemicals of the flash drum (S301) for the Next Generation Nuclear Plant using the sulfur iodine process.

Figure 110. Effect of varying helium flow rate at the purification system in all loops on the tritium concentration in gaseous process chemicals of the flash drum (S301) for the Next Generation Nuclear Plant using the sulfur iodine process.

Figure 111. Effect of varying helium flow rate at the purification system in the primary loop on the tritium concentration in liquid process chemicals of the secondary $\mathrm{O}_{2}$ knockout drum (S105) for the Next Generation Nuclear Plant using the sulfur iodine process.

Figure 112. Effect of varying helium flow rate at the purification system in the secondary loop on the tritium concentration in liquid process chemicals of the secondary $\mathrm{O}_{2}$ knockout drum (S105) for the Next Generation Nuclear Plant using the sulfur iodine process.

Figure 113. Effect of varying helium flow rate at the purification system in the tertiary loop on the tritium concentration in liquid process chemicals of the secondary $\mathrm{O}_{2}$ knockout drum (S105) for the Next Generation Nuclear Plant using the sulfur iodine process.

Figure 114. Effect of varying helium flow rate at the purification system in all loops on the tritium concentration in liquid process chemicals of the secondary $\mathrm{O}_{2}$ knockout drum $(\mathrm{S} 105)$ for the Next Generation Nuclear Plant using the sulfur iodine process.

Figure 115. Effect of varying helium flow rate at the purification system in the primary loop on the tritium concentration in the primary helium coolant for Next Generation Nuclear Plant using sulfur iodine process

Figure 116. Effect of varying helium flow rate at the purification system in the primary loop on the tritium concentration in the secondary helium coolant for the Next Generation Nuclear Plant using the sulfur iodine process.

Figure 117. Effect of varying helium flow rate at the purification system in the primary loop on the tritium concentration in the tertiary helium coolant for the Next Generation Nuclear Plant using the sulfur iodine process.

Figure 118. Effect of varying helium flow rate at the purification system in the secondary loop on the tritium concentration in the primary helium coolant for the Next Generation Nuclear Plant using the sulfur iodine process. 
Figure 119. Effect of varying helium flow rate at the purification system in the secondary loop on the tritium concentration in the secondary helium coolant for the Next Generation Nuclear Plant using the sulfur iodine process.

Figure 120. Effect of varying helium flow rate at the purification system in the secondary loop on the tritium concentration in the tertiary helium coolant for the Next Generation Nuclear Plant using the sulfur iodine process.

Figure 121. Effect of varying helium flow rate at the purification system in the tertiary loop on the tritium concentration in the primary helium coolant for the Next Generation Nuclear Plant using the sulfur iodine process. 156

Figure 122. Effect of varying helium flow rate at the purification system in the tertiary loop on the tritium concentration in the secondary helium coolant for the Next Generation Nuclear Plant using the sulfur iodine process.

Figure 123. Effect of varying helium flow rate at the purification system in the tertiary loop on the tritium concentration in the tertiary helium coolant for the Next Generation Nuclear Plant using the sulfur iodine process.

Figure 124. Effect of varying helium flow rate at the purification system in all loops on the tritium concentration in the primary helium coolant for the Next Generation Nuclear Plant using the sulfur iodine process

Figure 125. Effect of varying helium flow rate at the purification system in all loops on the tritium concentration in the secondary helium coolant for the Next Generation Nuclear Plant using the sulfur iodine process.

Figure 126. Effect of varying helium flow rate at the purification system in all loops on the tritium concentration in the tertiary helium coolant for the Next Generation Nuclear Plant using the sulfur iodine process.

Figure 127. Effect of varying pressure in the tertiary loop on the tritium concentration in product hydrogen for the Next Generation Nuclear Plant using the sulfur iodine process.

Figure 128. Effect of varying pressure in the tertiary loop on the tritium concentration in the gaseous process chemicals of the flash drum (S301) for the Next Generation Nuclear Plant using the sulfur iodine process.

Figure 129. Effect of varying pressure in the tertiary loop on the tritium concentration in the liquid process chemicals of the secondary $\mathrm{O}_{2}$ knockout drum (S105) for the Next Generation Nuclear Plant using the sulfur iodine process.

Figure 130. Effect of varying pressure in the tertiary loop on the tritium concentration in the primary helium coolant for the Next Generation Nuclear Plant using the sulfur iodine process.

Figure 131. Effect of varying pressure in the tertiary loop on the tritium concentration in the secondary helium coolant for the Next Generation Nuclear Plant using the sulfur iodine process.....

Figure 132. Effect of varying pressure in the tertiary loop on the tritium concentration in the tertiary helium coolant for the Next Generation Nuclear Plant using the sulfur iodine process..... 
Figure 133. Effect of varying hydrogen injection in the primary helium coolant on the tritium concentration in the hydrogen product for the Next Generation Nuclear Plant using the sulfur iodine process.

Figure 134. Effect of varying hydrogen injection in the secondary helium coolant on the tritium concentration in the hydrogen product for the Next Generation Nuclear Plant using the sulfur iodine process.

Figure 135. Effect of varying hydrogen injection in the tertiary helium coolant on the tritium concentration in the hydrogen product for the Next Generation Nuclear Plant using the sulfur iodine process.

Figure 136. Effect of varying hydrogen injection in the primary helium coolant on the hydrogen concentration in the primary helium coolant for the Next Generation Nuclear Plant using the sulfur iodine process

Figure 137. Effect of varying hydrogen injection in the primary helium coolant on the hydrogen concentration in the secondary helium coolant for the Next Generation Nuclear Plant using the sulfur iodine process.

Figure 138. Effect of varying hydrogen injection in the primary helium coolant on the hydrogen concentration in the tertiary helium coolant for the Next Generation Nuclear Plant using the sulfur iodine process.

Figure 139. Effect of varying hydrogen injection in the primary helium coolant on the tritium concentration in gaseous process chemicals of the flash drum (S301) for the Next Generation Nuclear Plant using the sulfur iodine process.

Figure 140. Effect of varying hydrogen injection in the primary helium coolant on the tritium concentration in liquid process chemicals of the secondary $\mathrm{O}_{2}$ knockout drum (S105) for the Next Generation Nuclear Plant using the sulfur iodine process.

Figure 141. Effect of varying hydrogen injection in the primary helium coolant on the tritium concentration in the primary helium coolant for the Next Generation Nuclear Plant using the sulfur iodine process.

Figure 142. Effect of varying hydrogen injection in the primary helium coolant on the tritium concentration in the secondary helium coolant for the Next Generation Nuclear Plant using the sulfur iodine process.

Figure 143. Effect of varying hydrogen injection in the primary helium coolant on the tritium concentration in the tertiary helium coolant for the Next Generation Nuclear Plant using the sulfur iodine process. 


\section{TABLES}

Table 1. Regulatory constraints on tritium in the United States.............................................................. 7

Table 2. Comparison of tritium activity by ternary fission.

Table 3. Comparison of tritium activity from ${ }^{6} \mathrm{Li}$ at the Core 2 operation of the Peach Bottom high-temperature gas-cooled reactor.

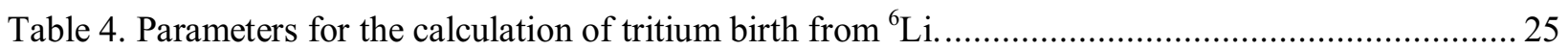

Table 5. Input data of THYTAN for the calculation of tritium birth from ${ }^{6} \mathrm{Li}$..................................... 25

Table 6. Comparison of tritium activity from ${ }^{3} \mathrm{He}$ at the Core 2 operation of the Peach Bottom

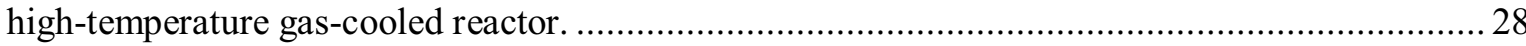

Table 7. Input data of THYTAN for the calculation of tritium birth from ${ }^{3} \mathrm{He}$..................................... 28

Table 8. Input data for the subnode of THYTAN for the calculation of tritium birth from ${ }^{3} \mathrm{He}$.............. 29

Table 9. Comparison of tritium activity from ${ }^{10} \mathrm{~B}$ in the poisoned spine at the Core 2 operation of Peach

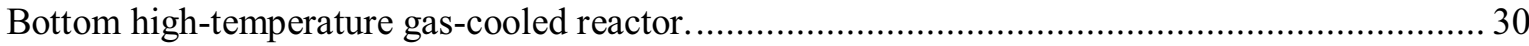

Table 10. Characteristics of the heat transfer tube samples from the steam generator of the Peach Bottom high-temperature gas-cooled reactor.

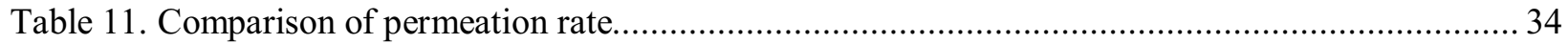

Table 12. Input data of THYTAN for verification of the leak model................................................. 35

Table 13. THYTAN boundary conditions for verification of the purification system model......

Table 14. Boundary condition of the steam generator for the Peach Bottom high-temperature gas-cooled reactor

Table 15. Characteristics of the concentric duct for the Peach Bottom high-temperature gas-cooled reactor.

Table 16. Major specifications for the Next Generation Nuclear Plant using the high-temperature electrolysis process

Table 17. Calculation results for the tritium birth rate in the high-temperature gas-cooled reactor

Table 19. Boundary conditions for heat transfer tube permeability in the Next Generation Nuclear Plant using the high-temperature electrolysis process

Table 21. Helium inventory of the Peach Bottom high-temperature gas-cooled reactor and Fort St. Vrain.55

Table 23. Boundary conditions of temperature and pressure in components. 58 
Table 24. Tritium concentration in the hydrogen product for the base case of the Next Generation Nuclear

Plant using the high-temperature electrolysis process.

Table 25. Tritium concentration in the oxygen for the base case of the Next Generation Nuclear Plant using the high-temperature electrolysis process

Table 26. Tritium concentrations in high-temperature electrolysis process components for the base case of Next Generation Nuclear Plant.

Table 27. Tritium concentration in helium coolant for the base case of the Next Generation Nuclear Plant using the high-temperature electrolysis process

Table 28. Comparison of tritium concentrations for the Next Generation Nuclear Plant using the high-temperature electrolysis process with and without the tertiary loop.

Table 29. Conditions for decreasing tritium concentrations to below gaseous and liquid limits.

Table 30. Major specifications for the Next Generation Nuclear Plant using the sulfur iodine process. . 103

Table 31. Boundary conditions of the heat transfer tube for the Next Generation Nuclear Plant using the sulfur iodine process. 108

Table 32. Flow rate boundary condition for each link in the sulfur iodine process.

Table 33. Boundary conditions of temperature and pressure in components of the sulfur iodine process.112

Table 34. Tritium concentration in the hydrogen product in the base case for the Next Generation Nuclear Plant using the sulfur iodine process.

Table 35. Tritium concentration in the oxygen product in the base case for the Next Generation Nuclear Plant using the sulfur iodine process.

Table 36. Tritium concentrations in the sulfur iodine process components for the base case of the Next Generation Nuclear Plant using the sulfur iodine process.

Table 37. Tritium concentrations in the helium coolant for the base case of the Next Generation Nuclear

Plant using the sulfur iodine process. 



\section{ACRONYMS}

\begin{tabular}{|c|c|}
\hline ALARA & as low as reasonably achievable \\
\hline EPA & U.S. Environmental Protection Agency \\
\hline HTE & high-temperature electrolysis \\
\hline HTGR & high-temperature gas-cooled reactor \\
\hline IHX & intermediate heat exchanger \\
\hline NGNP & Next Generation Nuclear Plant \\
\hline NRC & U.S. Nuclear Regulatory Commission \\
\hline PHX & process heat exchanger \\
\hline SHX & secondary heat exchanger \\
\hline SI & sulfur iodine \\
\hline THYTAN & 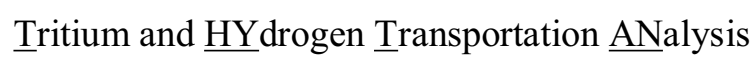 \\
\hline
\end{tabular}




\section{Tritium Movement and Accumulation in the NGNP System Interface and Hydrogen Plant}

\section{INTRODUCTION}

Hydrogen is a clean energy medium that does not release $\mathrm{CO}_{2}$ when consumed or burned. A high-temperature gas-cooled reactor (HTGR) can produce a massive amount of high-temperature thermal energy without a controlled release of any $\mathrm{CO}_{2}$. Thermal energy from an HTGR can be used to produce heat and electricity that can be used to split water into hydrogen and oxygen. Therefore, the HTGR can be considered a suitable energy source for producing a huge amount of hydrogen with no corresponding $\mathrm{CO}_{2}$ emissions. Recently, aggressive research and development of HTGR designs have been carried out throughout the world (e.g., U.S.A. [Public Law 109-58 2005], France [Billot and Barbier 2004], South Africa [Matzner 2004], Republic of Korea [Shin et al. 2005], China [Zhang and Yu 2002], and Japan [Fujikawa et al. 2004]).

The U.S. Department of Energy is developing the technologies to enable the construction and operation of a very high-temperature gas-cooled reactor (VHTR) and an advanced large-scale hydrogen plant that will be capable of producing hydrogen from water using nuclear power. The first-of-a-kind (FOAK) plant consisting of the combination of a VHTR and a hydrogen plant is known as the Next Generation Nuclear Plant (NGNP). Figure 1 shows a diagram of the proposed NGNP facility. The VHTR provides nuclear process heat to the hydrogen production plant through a high-temperature heat transfer loop. Research and development on hydrogen production technologies and high-temperature heat transport technologies between a nuclear reactor and hydrogen plant is being carried out by the U.S. Department of Energy's Nuclear Hydrogen Initiative.

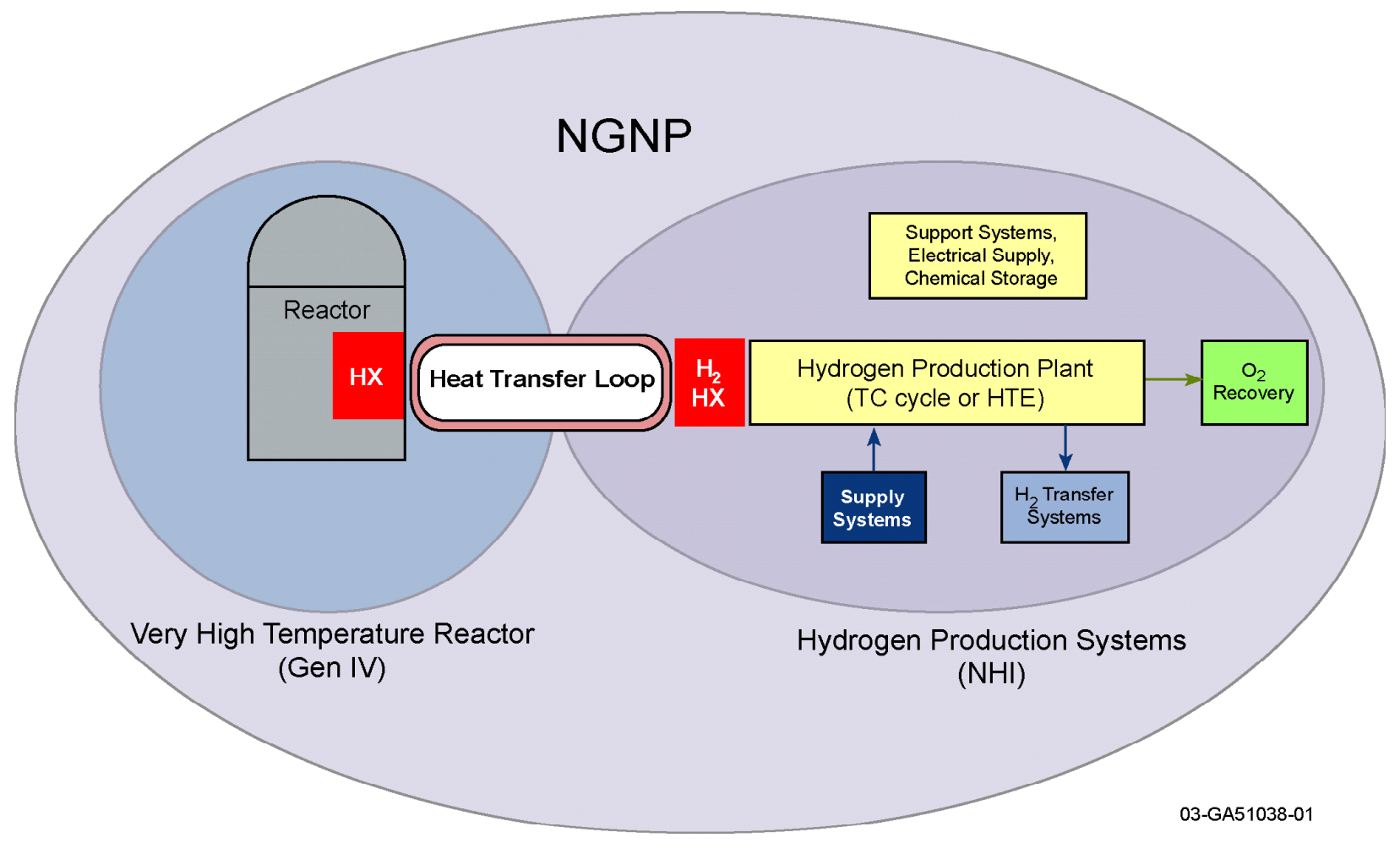

Figure 1. Diagram of a Next Generation Nuclear Plant facility. 
This study has assumed a particular configuration of the NGNP that employs a helium-filled primary cooling loop, a full-sized intermediate heat exchanger (IHX), a helium-filled secondary loop containing the electricity power conversion unit (PCU), and a tertiery helium-filled loop to transport thermal energy to the hydrogen production plant. The nuclear plant produces is assumed to produce 600 $\mathrm{MWt}$, and the tertiary loop is assumed to carry $55 \mathrm{MWt}$ to the hydrogen production plant with the balance of the thermal energy used to produce electricity. A schematic of this reference configuration that employs a Sulfur-Iodine Process hydrogen plant is shown in Figure 2.

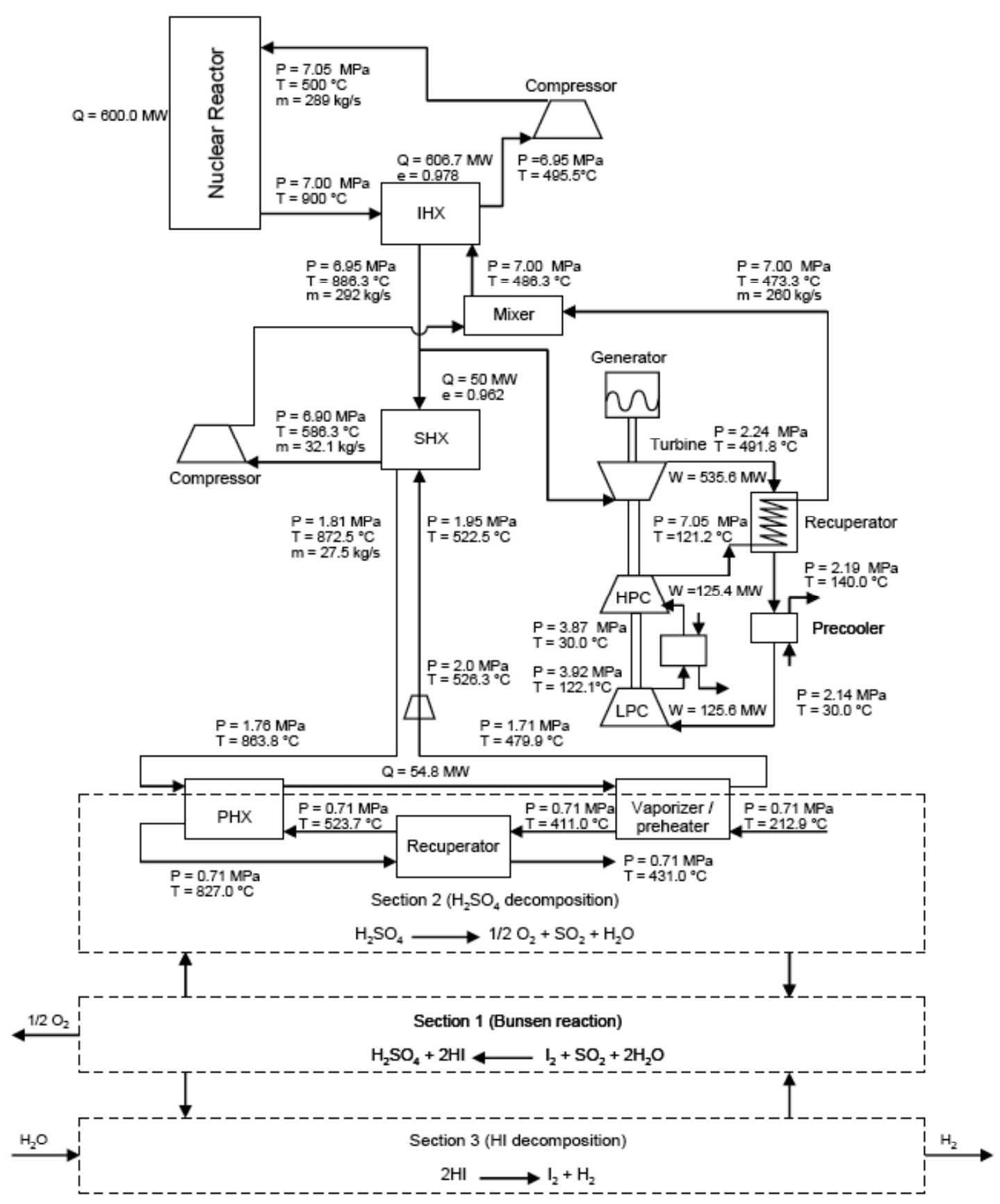

Figure 2. Reference configuration of NGNP showing deployment of SI plant [C.H. Oh et al., 2006]. 
One potential problem with using a VHTR as the high-temperature heat source for the hydrogen production plant is transmission of tritium from the primary coolant to the hydrogen product by permeation through the heat transfer surfaces. Tritium behavior in HTGRs was evaluated in several countries in the 1970s (e.g., the Dragon reactor in England [Forsyth 1972], the Peach Bottom HTGR in the U.S. [Wichner and Dyer 1979], and AVR in Germany [Steinwarz, Rohrig, and Nieder 1980]). Data from the operation of HTGRs and from laboratory experiments revealed the mechanisms of tritium production, transport, and release to the environment from these HTGRs. In his review of tritium behavior in an HTGR system, Gainey (1976) concluded from the available data that tritium releases should be well within the present Federal guidelines for a nuclear plant. For example, the estimated maximum dose to an average adult for a typical 3,000-MWt HTGR with a cooling tower is $0.38 \mathrm{milliRem} / \mathrm{year}$, which is slightly more than one-tenth of the maximum annual dose allowed (Gainey 1976). As a result of this conclusion, no further laboratory-scale work on tritium was required or performed at that time. However, the NGNP will produce hydrogen for industry or individual users, while former HTGRs were not used as a heat source for process heat applications. The migration of tritium to down-stream processes cannot be ignored, and additional calculations and experiments are needed to determine the expected values of tritium in the hydrogen plant fluids and products. In any case, tritium concentrations must still fall within regulatory guidelines in all materials released to the customer or the environment if the hydrogen plant is to remain in the non-nuclear-regulated domain.

This study evaluated tritium concentrations in the hydrogen product and in process chemicals in the hydrogen plant that is part of the NGNP. Section 2 of this study describes a general tritium source and pathway to product hydrogen. Section 3 summarizes regulatory constraints on tritium in the U.S. Tritium transport behavior in the the NGNP was estimated by using a numerical analysis code (i.e., Tritium and

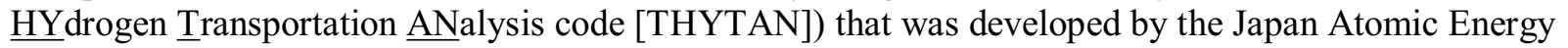
Agency. Section 4 shows the features and basic equations of THYTAN. Before evaluating the NGNP, the verification of THYTAN was carried out using the reported experimental and analytical tritium study results in the Peach Bottom HTGR (the first HTGR in the U.S.). Section 5 describes the code verification results. Section 6 summarizes the calculation model and analysis results for the NGNP using the HTE process. Section 7 describes the calculation model and analysis results for NGNP using the SI process. Section 8 summarizes the recommendations and future research and development items. 


\section{TRITIUM SOURCE AND PATHWAY TO PRODUCT HYDROGEN}

\subsection{Source}

The tritium generation mechanisms are well described in Gainey (1976). The primary tritium birth mechanism is ternary fission of fuel (e.g. ${ }^{233} \mathrm{U},{ }^{235} \mathrm{U},{ }^{239} \mathrm{Pu}$, and ${ }^{241} \mathrm{Pu}$ ) due to thermal neutrons. Tritium is also generated in HTGR from ${ }^{6} \mathrm{Li},{ }^{7} \mathrm{Li},{ }^{3} \mathrm{He}$, and ${ }^{10} \mathrm{~B}$ by neutron capture reactions as the following:

${ }^{6} \mathrm{Li}(\mathrm{n}, \alpha){ }^{3} \mathrm{H}$

${ }^{7} \operatorname{Li}(\mathrm{n}, \mathrm{n} \alpha){ }^{3} \mathrm{H}$

${ }^{3} \mathrm{He}(\mathrm{n}, \mathrm{p}){ }^{3} \mathrm{H}$

${ }^{10} \mathrm{~B}(\mathrm{n}, 2 \alpha){ }^{3} \mathrm{H}$

${ }^{10} \mathrm{~B}(\mathrm{n}, \alpha){ }^{7} \mathrm{Li}$.

${ }^{6} \mathrm{Li}$ and ${ }^{7} \mathrm{Li}$ are impurities in the core graphite material (e.g., sleeve, spine, reflector, and fuel matrix). ${ }^{3} \mathrm{He}$ is an impurity in the reactor coolant helium. Because the helium coolant leaks from the primary loop to the containment vessel, ${ }^{3} \mathrm{He}$ is supplied along with helium to the primary coolant. ${ }^{10} \mathrm{~B}$ exists in the control rods, burnable poison, and reflector. Tritium is produced directly from ${ }^{10} \mathrm{~B}$ via Equation (4) or via the chain of reaction in Equations (2) and (5).

\subsection{Pathway to Product Hydrogen}

Tritium generated in the fuel particles by ternary fission mechanisms can escape into the primary coolant after permeating the barrier layers of the fuel particles. In addition, tritium born from ${ }^{10} \mathrm{~B}$ and ${ }^{6} \mathrm{Li}$ can pass into the primary coolant. The principal chemical form for tritium in the reactor coolant was reported as HT due to the isotope exchange reaction between $\mathrm{T}_{2}$ and $\mathrm{H}_{2}$ (Wichner and Dyer 1979). Some of the tritium in the primary coolant is removed by a purification system installed in the primary loop. Some of the tritium can escape to the outside environment by permeation through the components and piping and by leakage of the bulk primary helium coolant. The remainder of the tritium in the primary coolant permeates through the heat transfer tubes or surfaces of the intermediate heat exchanger (IHX) and is mixed into the secondary coolant.

In the secondary loop, some of the tritium is removed by the purification system or escapes to the outside environment by permeation or bulk leakage. The remainder of the tritium in the secondary coolant permeates through the heat transfer surfaces and is mixed into the tertiary coolant. Once in the tertiary loop, tritium permeates through the heat transfer surfaces of the process heat exchanger(s) and is mixed into the process chemicals of the hydrogen plant.

Once in the hydrogen plant fluids, tritium can react with hydrogen-containing process chemicals through isotope exchange reactions. For example, the HTE process contains $\mathrm{H}_{2} \mathrm{O}$. Tritium can undergo an isotope exchange reaction with the $\mathrm{H}_{2} \mathrm{O}$ to form HTO. Once formed, gaseous HTO and unreacted HT can escape from the HTE process as impurities in the hydrogen and oxygen products. Another loss mechanism for HTO is through the removal or leakage of contaminated liquid water from the process. The remainder of the HTO circulates in the plant with the rest of the recycled water and accumulates until the overall input and output rates of tritium to and from the HTE process are equalized. The SI process contains $\mathrm{H}_{2} \mathrm{O}, \mathrm{H}_{2} \mathrm{SO}_{4}$, and $\mathrm{HI}$ as circulating chemicals, and these can undergo isotope exchange mechansisms to produce HTO, $\mathrm{HTSO}_{4}$, and TI. Since tritium losses from the SI process occur only from 
the occasional leaks of process chemicals and contamination of the hydrogen and oxygen products, these tritium-containing chemicals accumulate in the process until the tritium input rate by permeation equals the tritium loss rate through these other mechanisms. 


\section{REGULATORY CONSTRAINTS ON TRITIUM}

In the U.S., the U.S. Nuclear Regulatory Commission (NRC) is continuously evaluating the latest radiation protection recommendations from international and national scientific bodies to ensure the adequacy of the standards they use. Among those standards, the NRC and the U.S. Environmental Protection Agency (EPA) have established three layers of radiation protection limits to protect the public against potential health risks from exposure to radioactive liquid discharges (effluents) from nuclear power plant operations. Table 1 summarizes the regulatory constraints on tritium.

Table 1. Regulatory constraints on tritium in the United States.

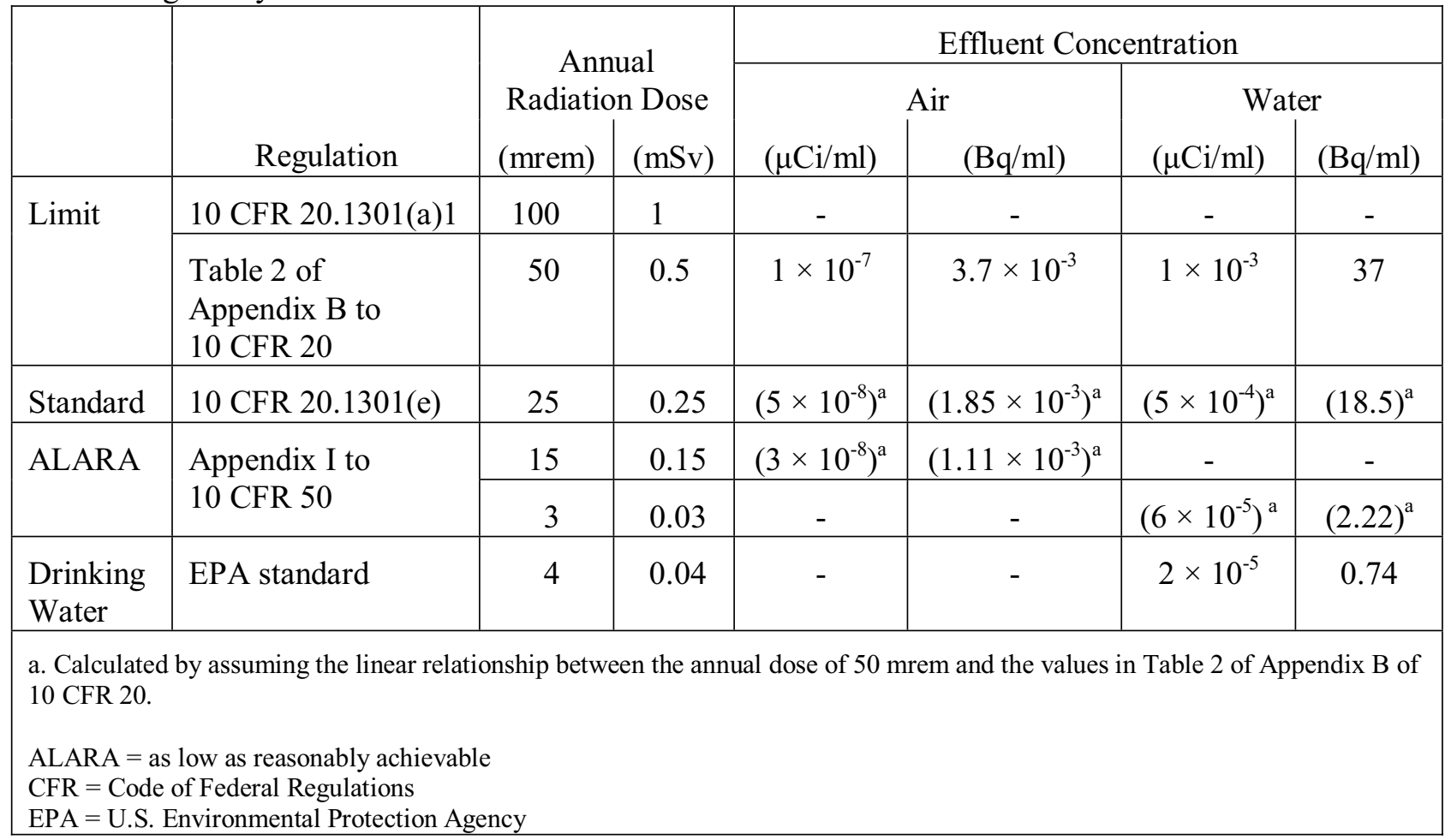

Layer 1: As Low as Reasonable Achievable (ALARA) Objective-Appendix I of 10 CFR 50

Tritium in gaseous effluent: 15 mrem per year

Liquid tritium effluent: 3 mrem per year.

The NRC imposes specific requirements for nuclear power reactors for airborne and waterborne effluent release. These requirements are contained in 10 CFR 50.36a and detailed in Appendix I of 10 CFR 50. These requirements are structured to maintain the dose to members of the public from all radioactive effluent releases to levels that are ALARA. Controls imposed on licensees are not based on the quantity or concentration of radioactive material released, but is based on the calculated dose to members of the public. The licensee's Radiological Effluent Technical Specifications contain dose values for the maximally exposed member of the public living near a nuclear power plant. For tritium in gaseous effluents, the ALARA annual offsite dose objective is $15 \mathrm{mrem}$ to the thyroid (or other organ). For liquid effluent release, such as diluted tritium, the ALARA annual offsite dose objective is 3 mrem total body or 10 mrem to any organ. This ALARA objective is $3 \%$ of the annual public radiation dose limit of $100 \mathrm{mrem}$. 
Layer 2: Standard-10 CFR 20.1301(e)

Tritium in gaseous effluent: 25 mrem per year

Liquid tritium effluent: 25 mrem per year.

In 1979, EPA developed a radiation dose standard of 25 mrem to whole body, 75 mrem to the thyroid, and $25 \mathrm{mrem}$ to any other organ of an individual member of the public. The NRC incorporated these EPA standards, 40 CFR 190, into its regulations in 1981, and all nuclear power plants must now meet these requirements.

Layer 3: Limit—10 CFR 20.1301(a)1

Tritium in gaseous effluent: 100 mrem per year

Liquid tritium effluent: 100 mrem per year.

The NRC's final layer of protection for public health and safety is a dose limit of 100 mrem per year to an individual member of the public. This limit is universally applied to everyone, regardless of work duties (e.g., medical worker, nuclear operator, etc.). The NRC adopted the 100-mrem per year dose limit from the 1990 Recommendations of the International Commission on Radiological Protection. The U.S. National Commission on Radiological Protection and Measurements also recommends the dose limit of 100 mrem per year.

For gas and liquid effluents, including tritiated water, any licensee can demonstrate compliance with the 100-mrem per year dose standard by not exceeding the concentration values specified in Table 2 of Appendix B of 10 CFR 20. These concentration values, if inhaled or ingested over the course of a year, would produce a total effective dose of $50 \mathrm{mrem}$. For tritium, the effluent concentration in air and water are $1.0 \times 10^{-7} \mu \mathrm{Ci} / \mathrm{ml}$ (or $3.7 \times 10^{-3} \mathrm{~Bq} / \mathrm{ml}$ ) and $1.0 \times 10^{-3} \mu \mathrm{Ci} / \mathrm{ml}($ or $37 \mathrm{~Bq} / \mathrm{ml}$ ), respectively.

In the United State, EPA sets Federal legal limits for contaminants in drinking water under the authority of the Safe Drinking Water Act. These limits are called maximum containment levels, and water suppliers must provide water that meets these standards. The EPA's drinking water standards do not apply to private drinking water wells, including those that may be impacted by tritium that is inadvertently released from nuclear power plants. However, many State authorities have adopted the EPA's drinking water standards as legally enforceable groundwater protection standards and those standards are often used in assessing laboratory test results of water from private wells.

In 1976, EPA established a dose-based drinking water standard of 4 mrem per year to avoid undesirable future contamination of public water supplies as a result of controllable human activities. The EPA set a maximum contamination level of $20,000 \mathrm{pCi} / \mathrm{L}$ for tritium. This level is assumed to yield a dose of 4 mrem per year.

Since that time, the calculation methods to equate tritium concentrations in drinking water to the radiation does in people (in mrem) have improved. In 1991, EPA calculated that a larger tritium concentration of $60,900 \mathrm{pCi} / \mathrm{L}$ yields a 4-mrem per year dose; this is a threefold increase from the maximum contaminant level of $20,000 \mathrm{pCi} / \mathrm{L}$ established in 1976 . However, EPA kept the 1976 value of $20,000 \mathrm{pCi} / \mathrm{L}$ for tritium in its latest regulations.

Hydrogen produced by NGNP may be used in a petroleum refiner, a chemical production system, or in fuel cell applications, and legal limits for tritium in the hydrogen for these applications do not exist. 
In the absence of industry-established tritium limits, the dose to people must be the governing limit. Therefore, tritium levels and limits will be evaluated and defined by considering hydrogen usage and a tritium pathway to the human body. 


\section{NUMERICAL ANALYSIS CODE \\ 4.1 Background}

The numerical analysis code, THYTAN, was developed by the Japan Atomic Energy Research Institute (a former organization of the Japan Atomic Energy Agency). THYTAN was developed in the late 1990s as a tool for estimating tritium transportation in the HTGR hydrogen production system. THYTAN was originally developed for the HTGR hydrogen production system for use with steam reforming of methane. In 2006, it was modified for the HTGR hydrogen production system using the SI process and the HTE process. The new version of THYTAN can calculate the isotope exchange reaction between tritium-containing chemicals and hydrogen-containing chemicals of the SI process and the HTE process. It enables estimates of tritium contamination in process chemicals of the hydrogen production plant. The original version of THYTAN was written by FORTRAN 77. During the course of this work it was converted into Fortran 95, which may simplify future modification and implementation.

\subsection{Features}

THYTAN is a dynamic simulation code that calculates mass balances of the tritium-containing chemicals HT, HTO, $\mathrm{HTSO}_{4}$, and TI, and hydrogen in the HTGR hydrogen production system (i.e., the primary and intermediate loops of the hydrogen production plant). THYTAN is capable of modeling simplified representations of the SI process and the HTE process in the hydrogen production plant. In THYTAN, the following phenomena are taken into account:

1. Tritium birth by ternary fission in the fuel particle and through neutron absorption reactions of ${ }^{6} \mathrm{Li}$, ${ }^{7} \mathrm{Li},{ }^{10} \mathrm{~B}$, and ${ }^{3} \mathrm{He}$ in the core and tritium release to the primary coolant helium

2. Tritium and hydrogen permeation through the heat transfer surfaces of the heat exchanger (e.g., IHX), the chemical reactor, and the recuperator

3. Tritium and hydrogen permeation assuming a co-axial pipe in the primary and intermediate loops

4. Tritium and hydrogen permeation to the outside through the outer walls of components and piping

5. Tritium and hydrogen removal by the purification system installed in the primary and secondary loops

6. Tritium and hydrogen leakage to the atmosphere or to another loop that accompanies general bulk helium leakage

7. Isotope exchange reaction between tritium-containing and hydrogen-containing chemicals.

\subsection{Basic Equations}

\subsubsection{Mass Balance}

In THYTAN, a node and link are employed to calculate the mass balance of tritium-containing chemicals and hydrogen. Each component of the HTGR hydrogen production system is expressed by a node. The mass balance of tritium-containing chemicals and hydrogen in each node is calculated using the following basic equations: 


$$
\begin{aligned}
& V_{j} \frac{d C_{i, j}}{d t}=\sum\left(F_{\text {total }, j-1} \cdot C_{i, j-1}\right)-F_{\text {total }, j} \cdot C_{i, j}-S_{i, j} \\
& S_{i, j}=-R_{\text {core }, i, j}+R_{H X, i, j}+R_{\text {copipe }, i, j}+R_{\text {comp }, i, j}+R_{\text {leak }, i, j}+R_{P F, i, j}+R_{\text {reaction }, i, j}
\end{aligned}
$$

where

$$
\begin{array}{ll}
V_{j} & =\text { the volume of node } j\left[\mathrm{~m}^{3}(\mathrm{STP})\right] \\
C_{i, j} & =\text { the volume fraction of chemical } i \text { in node } j\left[\mathrm{~m}^{3}(\mathrm{STP}) / \mathrm{m}^{3}(\mathrm{STP})\right] \\
t & =\text { time }[\mathrm{s}] \\
F_{\text {total }, j} & =\text { the volumetric flow rate of all chemicals in node } j\left[\mathrm{~m}^{3}(\mathrm{STP}) / \mathrm{s}\right] \\
S_{i, j} & =\text { the total amount of volume change rate of chemical } i \text { in node } j \text { by considering } \\
& \text { generation, release, permeation, removal, leakage, and isotope exchange reactions } \\
& {\left[\mathrm{m}^{3}(\mathrm{STP}) / \mathrm{s}\right]} \\
R_{\text {core }, i, j} & =\text { volumetric release rate from the core to the primary coolant }\left[\mathrm{m}^{3}(\mathrm{STP}) / \mathrm{s}\right] \\
R_{H X, i, j} & =\text { volumetric permeation rate at heat exchanger }\left(\mathrm{i}=\mathrm{H}_{2} \text { and } \mathrm{HT}\right)\left[\mathrm{m}^{3}(\mathrm{STP}) / \mathrm{s}\right] \\
R_{\text {copipe }, i, j} & =\text { volumetric permeation rate at co-axial pipe }\left(\mathrm{i}=\mathrm{H}_{2} \text { and } \mathrm{HT}\right)\left[\mathrm{m}^{3}(\mathrm{STP}) / \mathrm{s}\right] \\
R_{\text {comp }, i, j} & =\text { volumetric permeation rate to outside }\left(\mathrm{i}=\mathrm{\textrm {H } _ { 2 }} \text { and } \mathrm{HT}\right)\left[\mathrm{m}^{3}(\mathrm{STP}) / \mathrm{s}\right] \\
R_{\text {leak }, i, j} & =\text { volumetric leak rate with helium leakage }\left(i=\mathrm{H}_{2}, \mathrm{HT} \text { and } \mathrm{HTO}\right)\left[\mathrm{m}^{3}(\mathrm{STP}) / \mathrm{s}\right] \\
R_{P F, i, j} & =\text { volumetric removal rate by purification system }\left(i=\mathrm{H}_{2}, \mathrm{HT} \text { and } \mathrm{HTO}\right)\left[\mathrm{m}^{3}(\mathrm{STP}) / \mathrm{s}\right] \\
R_{\text {reaction }, i, j} & =\text { volumetric reaction rate by isotope exchange reactions } \\
& \left(i=\mathrm{H}_{2}, \mathrm{HT}, \mathrm{HTO}, \mathrm{HTSO} 4 \text { and TI }\right)\left[\mathrm{m}^{3}(\mathrm{STP}) / \mathrm{s}\right] .
\end{array}
$$

Each node is connected using links, and the separation and junction of each chemical are represented using links (see Figure 3). 


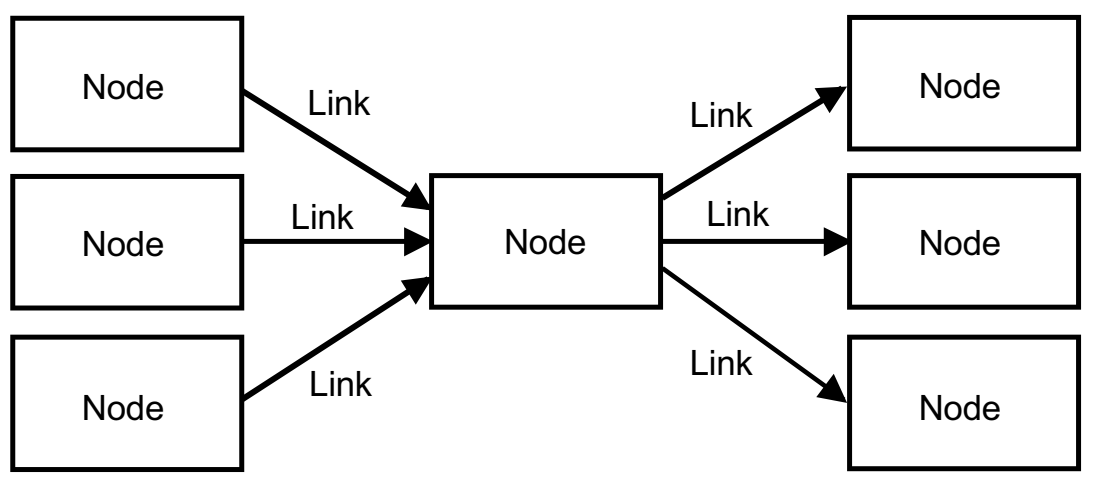

Figure 3. Simplified schematic diagram of node and junction in THYTAN.

\subsubsection{Core Model}

1. Ternary fission

$\frac{d\left(N_{T(T e r)}\right)}{d t}=K \cdot P \cdot Y-\lambda \cdot N_{T(T e r)}$

where

$$
\begin{array}{ll}
N_{T(T e r)} \quad=\text { number of tritium atoms due to ternary fission } \\
K \quad=\text { fission rate per thermal megawatt [fission/MW/s] } \\
P \quad=\text { reactor power }[\mathrm{MW}] \\
Y \quad=\text { average yield per fission [1/fission] } \\
\lambda \quad=\text { tritium decay constant }[1 / \mathrm{s}]
\end{array}
$$

2. Birth from ${ }^{6} \mathrm{Li}$

$$
\begin{aligned}
& \frac{d\left(N_{L i 6}\right)}{d t}=-\phi_{t h} \cdot \sigma_{L i 6 T} \cdot N_{L i 6} \\
& \frac{d\left(N_{T(L i 6)}\right)}{d t}=\phi_{t h} \cdot \sigma_{L i 6 T} \cdot N_{L i 6}-\lambda \cdot N_{T(L i 6)}
\end{aligned}
$$

where

$$
\begin{aligned}
& N_{L i 6}=\text { number of }{ }^{6} \mathrm{Li} \text { atoms } \\
& N_{T(L i 6)} \quad=\text { number of tritium atoms from }{ }^{6} \mathrm{Li} \\
& \left.\phi_{t h}=\text { thermal neutron flux [neutrons } / \mathrm{cm}^{2} / \mathrm{s}\right] \\
& \sigma_{L i 6 T}=\text { effective cross section for }{ }^{6} \mathrm{Li}(\mathrm{n}, \alpha){ }^{3} \mathrm{H}\left[\mathrm{cm}^{2}\right] .
\end{aligned}
$$


3. Birth from ${ }^{7} \mathrm{Li}$

$\frac{d\left(N_{L i 7}\right)}{d t}=-\phi_{f} \cdot \sigma_{L i 7 H 3} \cdot N_{L i 7}$

$\frac{d\left(N_{T(L i 7)}\right)}{d t}=\phi_{f} \cdot \sigma_{L i 7 T} \cdot N_{L i 7}-\lambda \cdot N_{T(L i 7)}$

where

$$
\begin{aligned}
& N_{L i 7}=\text { number of }{ }^{7} \mathrm{Li} \text { atoms, excluding }{ }^{10} \mathrm{~B} \text { source } \\
& N_{T(L i 7)} \quad=\text { number of tritium atoms from }{ }^{7} \mathrm{Li} \text {, excluding birth from }{ }^{10} \mathrm{~B} \\
& \left.\phi_{f} \quad=\text { fast neutron flux [neutrons } / \mathrm{cm}^{2} / \mathrm{s}\right] \\
& \sigma_{L i 7 T}=\text { effective cross section for }{ }^{7} \mathrm{Li}(\mathrm{n}, \mathrm{n} \alpha){ }^{3} \mathrm{H}\left[\mathrm{cm}^{2}\right] .
\end{aligned}
$$

4. Birth from ${ }^{3} \mathrm{He}$

$$
\begin{aligned}
& \frac{d\left(N_{H e 3}\right)}{d t}=f \cdot N_{H e 3}^{\circ}-f \cdot N_{H e 3}-\phi_{H e} \cdot \sigma_{H e 3 T} \cdot N_{H e 3} \\
& \frac{d\left(N_{T(H e 3)}\right)}{d t}=\phi_{H e} \cdot \sigma_{H e 3 T} \cdot N_{H e 3}-\lambda \cdot N_{T(H e 3)} \\
& \phi_{H e}=\frac{W_{\text {core }}}{W_{\text {total }}} \cdot \phi_{t h}
\end{aligned}
$$

where

$$
\begin{aligned}
& N_{\mathrm{He3}}=\text { number of }{ }^{3} \mathrm{He} \text { atoms } \\
& N_{T(\mathrm{He} 3)} \quad=\text { number of tritium atoms from }{ }^{3} \mathrm{He} \\
& f \quad=\text { fractional supply rate of helium coolant }[1 / \mathrm{s}] \\
& N_{H e 3}^{\circ}=\text { number of }{ }^{3} \mathrm{He} \text { atoms in the supply helium } \\
& \sigma_{H e 3 T}=\text { effective cross section for }{ }^{3} \mathrm{He}(\mathrm{n}, \mathrm{p}) \mathrm{T}\left[\mathrm{cm}^{2}\right] \\
& \phi_{H e} \quad=\text { average thermal neutron flux experienced by the total primary helium inventory }\left[\mathrm{n} / \mathrm{cm}^{2} / \mathrm{s}\right] \\
& W_{\text {core }}=\text { helium inventory in core }[\mathrm{kg}] \\
& W_{\text {total }}=\text { total primary helium inventory }[\mathrm{kg}] .
\end{aligned}
$$


5. Birth from ${ }^{10} \mathrm{~B}$

$$
\begin{aligned}
& \frac{d\left(N_{B 10}\right)}{d t}=-\left(\phi_{t h} \cdot \sigma_{B 10 L i 7}+\phi_{f} \cdot \sigma_{B 10 T}\right) \cdot N_{B 10} \\
& \frac{d\left(N_{L i 7(B 10)}\right)}{d t}=\phi_{t h} \cdot \sigma_{B 10 L i 7} \cdot N_{B 10}-\phi_{f} \cdot \sigma_{L i 7 T} \cdot N_{L i 7(B 10)} \\
& \frac{d\left(N_{T(B 10)}\right)}{d t}=\phi_{f} \cdot \sigma_{L i 7 T} \cdot N_{L i 7(B 10)}+\phi_{f} \cdot \sigma_{B 10 T} \cdot N_{B 10}-\lambda \cdot N_{T(B 10)}
\end{aligned}
$$

where

$$
\begin{aligned}
& N_{B 10}=\text { number of }{ }^{10} \mathrm{~B} \text { atoms } \\
& N_{L i 7(B 10)} \quad=\text { number of }{ }^{7} \mathrm{Li} \text { atoms from }{ }^{10} \mathrm{~B} \\
& N_{T(B 10)} \quad=\text { number of tritium from }{ }^{10} \mathrm{~B} \\
& \sigma_{B 10 L i 7} \quad=\text { effective cross section for }{ }^{10} \mathrm{~B}(\mathrm{n}, \alpha){ }^{7} \mathrm{Li}\left[\mathrm{cm}^{2}\right] \\
& \sigma_{B 10 T}=\text { effective cross section for }{ }^{10} \mathrm{~B}(\mathrm{n}, 2 \alpha){ }^{3} \mathrm{H}\left[\mathrm{cm}^{2}\right] .
\end{aligned}
$$

6. Tritium release rate

In the core model, the node of the reactor core can be divided into subnodes in order to take into account distribution of neutron flux and the release rate of tritium from each component. Therefore, the tritium release rate from the core to the primary coolant, $R_{c o r e, H T, j}\left[\mathrm{~m}^{3}(\mathrm{STP}) / \mathrm{s}\right]$, is calculated by using the following equations:

$$
\begin{aligned}
\frac{N_{T(\text { total })}}{d t}= & \sum\left\{\alpha_{\text {Ter }} \frac{d\left(N_{T(\text { Ter })}\right)}{d t}\right\}+\sum\left[\alpha_{L i}\left\{\frac{d\left(N_{T(\text { Lib })}\right)}{d t}+\frac{d\left(N_{T(\text { Li7) }}\right)}{d t}\right\}\right] \\
& +\sum\left\{\alpha_{H e 3} \frac{d\left(N_{T(H e 3)}\right)}{d t}\right\}+\sum\left\{\alpha_{B 10} \frac{d\left(N_{T(B 10)}\right)}{d t}\right\} \\
R_{\text {core }, H T, j}= & \frac{N_{T(\text { total })}}{d t} \times \frac{1}{N_{A}} \times \frac{R \cdot T_{0}}{P_{0}}
\end{aligned}
$$

where

$$
\begin{aligned}
& N_{T(\text { release })} \quad=\text { number of tritium atoms released to the primary coolant } \\
& \alpha_{T e r}=\text { fractional release ratio of tritium produced due to ternary fission } \\
& \alpha_{L i}=\text { fractional release ratio of tritium produced from }{ }^{6} \mathrm{Li} \text { and }{ }^{7} \mathrm{Li} \\
& \alpha_{\mathrm{He} 3}=\text { fractional release ratio of tritium produced from }{ }^{3} \mathrm{He}
\end{aligned}
$$




$$
\begin{array}{ll}
\alpha_{B 10} & =\text { fractional release ratio of tritium produced from }{ }^{10} \mathrm{~B} \\
N_{A} & =\text { Avogadro constant } \\
R & =\text { gas constant }(8.314) \\
T_{0} & =\text { standard temperature }(273.15 \mathrm{~K}) \\
P_{0} & =\text { standard pressure }\left(1.01325 \times 10^{5} \mathrm{~Pa}\right) .
\end{array}
$$

\subsubsection{Permeation Model}

The permeation rate of $\mathrm{H}_{2}$ at the heat exchanger, $R_{H X, H 2}\left[\mathrm{~m}^{3}(\mathrm{STP}) / \mathrm{s}\right]$, and at the co-axial pipe (hot pipe inside the cold pipe), $R_{\text {copipe,H } 2}\left[\mathrm{~m}^{3}(\mathrm{STP}) / \mathrm{s}\right]$, is estimated using the following equation:

$$
R_{H X, H 2, j}\left(\text { or } \quad R_{\text {copipe }, H 2, j}\right)=\frac{A}{l} \cdot k_{p, H} \cdot\left(\sqrt{P_{H 2, h}}-\sqrt{P_{H 2, l}}\right)
$$

where

$$
\begin{aligned}
& A=\text { heat transfer area or surface area }\left[\mathrm{m}^{2}\right] \\
& l \quad=\text { thickness of heat transfer tube or component casing }[\mathrm{m}] \\
& k_{p, H}=\text { permeability of hydrogen }\left[\mathrm{m}^{3}(\mathrm{STP}) / \mathrm{m} / \mathrm{s} / \mathrm{Pa}^{0.5}\right] \\
& P_{H 2, h}=\text { partial pressure of } \mathrm{H}_{2} \text { at high pressure side }[\mathrm{Pa}] \\
& P_{H 2, l}=\text { partial pressure of } \mathrm{H}_{2} \text { at low pressure side }[\mathrm{Pa}] \\
& l \text { is calculated by the following relation: }
\end{aligned}
$$

$$
l=r_{o} \cdot \ln \left(\frac{r_{o}}{r_{i}}\right)
$$

where

$$
\begin{aligned}
& r_{o}=\text { outer radius of heat transfer tube }[\mathrm{m}] \\
& r_{i} \quad=\text { inner radius of heat transfer tube }[\mathrm{m}]
\end{aligned}
$$


Permeability is calculated by using the Arrhenius equation:

$$
k_{p}=f \cdot \exp \left(\frac{-E}{R T}\right)
$$

where

$$
\begin{aligned}
f & =\text { pre-exponential factor of permeability }\left[\mathrm{m}^{3}(\mathrm{STP}) / \mathrm{m} / \mathrm{s} / \mathrm{Pa}^{0.5}\right] \\
E & =\text { activation energy }[\mathrm{J} / \mathrm{mol}] \\
R & =\text { ideal gas constant }[\mathrm{J} / \mathrm{mol}-\mathrm{K}] \\
T & =\text { temperature }[\mathrm{K}] .
\end{aligned}
$$

The permeation rate of $\mathrm{H}_{2}$ though the outer wall of the component and piping, $R_{\text {comp }, H 2}$, is calculated by excluding the $\mathrm{H}_{2}$ partial pressure at the low pressure side as follows:

$$
R_{\text {comp }, H 2, j}=\frac{A}{l} \cdot k_{p, H} \cdot \sqrt{P_{H 2, h}}
$$

The permeation rate of HT at the heat exchanger, $R_{H X, H 2}\left[\mathrm{~m}^{3}(\mathrm{STP}) / \mathrm{s}\right]$, and at the co-axial pipe, $R_{\text {copipe }, H 2}\left[\mathrm{~m}^{3}(\mathrm{STP}) / \mathrm{s}\right]$, is estimated by considering the effect of the existence of hydrogen on the adsorption-dissociation and recombination-desorption step as follows:

$$
R_{H X, H T, j}\left(\text { or } \quad R_{\text {copipe }, H T, j}\right)=\frac{A}{l} \cdot k_{p, T} \cdot\left(1-\frac{P_{H 2, l}}{P_{T o t a l, l}}\right)\left(\frac{P_{H T, h}}{\sqrt{P_{H 2, h}+P_{H T, h}}}-\frac{P_{H T, l}}{\sqrt{P_{H 2, l}+P_{H T, l}}}\right)
$$

where

$$
\begin{aligned}
& k_{p, T}=\text { permeability of tritium }\left[\mathrm{m}^{3}(\mathrm{STP}) / \mathrm{m} / \mathrm{s} / \mathrm{Pa}^{0.5}\right] \\
& P_{H T, h}=\text { partial pressure of } \mathrm{HT} \text { at high pressure side }[\mathrm{Pa}] \\
& P_{H T, l}=\text { partial pressure of HT at low pressure side }[\mathrm{Pa}] \\
& P_{\text {Total }, l} \quad=\text { total pressure at low pressure side }[\mathrm{Pa}] .
\end{aligned}
$$

The permeation rate of HT through the outer wall of the component and piping, $R_{\text {comp }, H T}$, is calculated by using the following equation:

$$
R_{\text {comp }, H T, j}=\frac{A}{l} \cdot k_{p, T} \cdot \frac{P_{H T, h}}{\sqrt{P_{H 2, h}+P_{H T, h}}} \text {. }
$$




\subsubsection{Leak Model}

The leak rate of helium from the loop, $R_{\text {leak }, H e}\left[\mathrm{~m}^{3}(\mathrm{STP}) / \mathrm{s}\right]$, can be expressed by the following equation:

$$
R_{\text {leak }, \text { He }}=V_{\text {total }} \cdot L_{R}
$$

where

$$
\begin{aligned}
& V_{\text {total }}=\text { total inventory in loop }\left[\mathrm{m}^{3}(\mathrm{STP})\right] \\
& L_{R} \quad=\text { fractional helium leak rate }[1 / \mathrm{s}]
\end{aligned}
$$

The leak rate of $\mathrm{H}_{2}$, HT, and HTO with helium leakage in node $\mathrm{j}, R_{\text {leak }, i, j}$, is calculated by using the following equation:

$$
R_{\text {leak }, i, j}=V_{\text {total }} \cdot L_{R} \cdot \bar{C}_{i} \cdot \frac{V_{j}}{V_{\text {leak }}}\left(i=\mathrm{H}_{2}, \mathrm{HT} \text { and HTO }\right)
$$

where

$$
\begin{aligned}
& \bar{C}_{i}=\text { average concentration of chemical i in nodes with helium leak } \\
& V_{\text {leak }}=\text { sum of the inventory of nodes with helium leak. }
\end{aligned}
$$

\subsubsection{Purification System Model}

The removal rate, $R_{P F}$, of hydrogen and tritium-containing chemicals in the primary and intermediate loop by the purification system is expressed by the following equation:

$$
R_{P F, i, j}=F_{P F, H e} \cdot \eta_{i} \cdot C_{i, j} \quad\left(i=\mathrm{H}_{2}, \mathrm{HT}, \text { and } \mathrm{HTO}\right)
$$

where

$$
\begin{aligned}
& F_{P F, H e} \quad=\text { helium flow rate at purification system }\left[\mathrm{m}^{3}(\mathrm{STP}) / \mathrm{s}\right] \\
& \eta_{i} \quad=\text { fractional efficiency of purification system for removing component i. }
\end{aligned}
$$

\subsubsection{Isotope Exchange Reaction Model}

The SI process contains $\mathrm{H}_{2}, \mathrm{H}_{2} \mathrm{O}, \mathrm{H}_{2} \mathrm{SO}_{4}$, and $\mathrm{HI}$ and the $\mathrm{HTE}$ process contains $\mathrm{H}_{2}$ and $\mathrm{H}_{2} \mathrm{O}$ as hydrogen-containing chemicals. The primary and intermediate coolants also contain $\mathrm{H}_{2}$ and $\mathrm{H}_{2} \mathrm{O}$ as impurities. The following isotope exchange reactions between tritium-containing chemicals and hydrogen-containing chemicals are taken into account as elementary reactions:

$$
\begin{aligned}
& \mathrm{HT}+\mathrm{H}_{2} \mathrm{O}=\mathrm{H}_{2}+\mathrm{HTO} \\
& \mathrm{HT}+\mathrm{H}_{2} \mathrm{SO}_{4}=\mathrm{H}_{2}+\mathrm{HTSO}_{4}
\end{aligned}
$$


$\mathrm{HT}+\mathrm{HI}=\mathrm{H}_{2}+\mathrm{TI}$

$\mathrm{HTO}+\mathrm{H}_{2} \mathrm{SO}_{4}=\mathrm{H}_{2} \mathrm{O}+\mathrm{HTSO}_{4}$

$\mathrm{HTO}+\mathrm{HI}=\mathrm{H}_{2} \mathrm{O}+\mathrm{TI}$.

The reaction rate of Equation (30) is known to be relatively slow without catalysts. Though the kinetics of the other reactions are relatively unknown, it is assumed here that all isotope exchange reactions proceed to equilibrium in order to calculate the tritium concentration in the liquid phase of the hydrogen production plant. This is a conservative assumption, as concentrations of tritium-containing liquid chemicals (i.e., HTO, $\mathrm{HTSO}_{4}$, and TI) in the liquid phase will be at their highest values at equilibrium. Mass balances at equilibrium of the isotope exchange reactions from Equations (30) through (34) can be expressed by the following equations:

$$
\begin{aligned}
& K_{1}=\frac{F_{H 2, e q} \cdot F_{H T O, e q}}{F_{H T, e q} \cdot F_{H 2 O, e q}} \\
& K_{2}=\frac{F_{H 2, e q} \cdot F_{H T S O 4, e q}}{F_{H T, e q} \cdot F_{H 2 S O 4, e q}} \\
& K_{3}=\frac{F_{H 2, e q} \cdot F_{T I, e q}}{F_{H T, e q} \cdot F_{H I, e q}} \\
& K_{4}=\frac{K_{2}}{K_{1}}=\frac{F_{H 2 O, e q} \cdot F_{H T S O 4, e q}}{F_{H T O, e q} \cdot F_{H 2 S O 4, e q}} \\
& K_{5}=\frac{K_{3}}{K_{1}}=\frac{F_{H 2 O, e q} \cdot F_{T I, e q}}{F_{H T O, e q} \cdot F_{H I, e q}}
\end{aligned}
$$

where

$$
\begin{aligned}
& K=\text { equilibrium constant of each isotope exchange reaction } \\
& F_{i, e q}=\text { volumetric flow rate of each chemical at equilibrium }\left[\mathrm{m}^{3}(\mathrm{STP}) / \mathrm{s}\right] .
\end{aligned}
$$

In Equations (12) through (16), the mass balances under the equilibrium state can be calculated using the flow rate and equilibrium constants of the reaction in Equations (30), (31), and (32) (i.e., $K_{1}$, $K_{2}$, and $K_{3}$ ). The equilibrium constant of the reaction in Equation (30), $K_{1}$, can be expressed in the following equation (Atomic Energy Society of Japan 1982):

$\log K_{1}=0.292 \log T+(336.5 / T)-1.055$

The equilibrium constant of the reaction in Equation (32), $K_{3}$, also appeared in the Atomic Society of Japan (1982) and can be expressed as the following approximate equation:

$$
\ln K_{3}=-1.13+1.07 \times 10^{-2} T-2.26 \times 10^{-5} T^{2}+2.10 \times 10^{-8} T^{3}-7.25 \times 10^{-12} T^{4} .
$$


However, the equilibrium constant $K_{2}$ of the reaction in Equation (31), which is the isotope exchange reaction between HT and $\mathrm{H}_{2} \mathrm{SO}_{4}$, was not provided in the Atomic Society of Japan (1982).

Alternatively, the reaction rate of each chemical, $R_{\text {reaction }, i, j}$, can be expressed by the following equation:

$$
R_{\text {reaction }, i, j}=\sum F_{i, j-1}-F_{i, e q}\left(i=\mathrm{H}_{2}, \mathrm{HT}, \mathrm{HTO}, \mathrm{HTSO}_{4} \text { and TI }\right) .
$$

\subsubsection{Strategy of Modeling for the Hydrogen Production System}

In the numerical analysis model for the SI process developed for this study, the following strategies and assumptions were proposed:

1. $\mathrm{H}_{2}, \mathrm{H}_{2} \mathrm{O}, \mathrm{H}_{2} \mathrm{SO}_{4}, \mathrm{SO}_{3}, \mathrm{SO}_{2}, \mathrm{O}_{2}, \mathrm{I}_{2}$, and $\mathrm{HI}$ are treated as process chemicals; the flow rates of each chemical are set as constant boundary conditions.

2. Chemical reactions without tritium-containing chemicals are not calculated.

3. The mass change of $\mathrm{H}_{2} \mathrm{O}, \mathrm{H}_{2} \mathrm{SO}_{4}$, and $\mathrm{HI}$ by the isotope exchange reactions is not considered. The mass change of $\mathrm{H}_{2}$ in the $\mathrm{HI}$ section also is not considered because the amounts of these process chemicals are much higher than those of tritium-containing chemicals.

4. HT, HTO, $\mathrm{HTSO}_{4}$, and TI are treated as the tritium-containing chemicals and the mass balances of each chemical are calculated. The mass balance of $\mathrm{H}_{2}$ is calculated only in the components where $\mathrm{H}_{2}$ does not exist as process chemicals.

5. The separation ratio of flow rate of $\mathrm{HTO}, \mathrm{HTSO}_{4}$, and TI for some links is assumed to be dependent on the flow rates of $\mathrm{H}_{2} \mathrm{O}, \mathrm{H}_{2} \mathrm{SO}_{4}$, and $\mathrm{HI}$, respectively. The separation ratio of the $\mathrm{HT}$ flow rate for some links is assumed to be dependent on the flow rate of $\mathrm{H}_{2}$ as the process chemical or $\mathrm{O}_{2}$ in the case of no $\mathrm{H}_{2}$ flow as the process chemical.

6. Dissolution of $\mathrm{H}_{2}$ and $\mathrm{HT}$ in liquid process chemicals (i.e., $\mathrm{H}_{2} \mathrm{O}, \mathrm{H}_{2} \mathrm{SO}_{4}, \mathrm{I}_{2}$, and $\mathrm{HI}$ ) is not considered.

7. In the electrolyzer of the HTE process, HTO is decomposed to HT and $1 / 2 \mathrm{O}_{2}$. The decomposition efficiency is assumed to be the same value as steam electrolysis efficiency (i.e., $\mathrm{H}_{2} \mathrm{O}=\mathrm{H}_{2}+1 / 2 \mathrm{O}_{2}$ ). 


\section{VERIFICATION OF CODE}

\subsection{Brief Description of Peach Bottom High-Temperature Gas-Cooled Reactor}

The Peach Bottom Atomic Power Station Unit No. 1 (Scheffel, Baldwin, and Tomlin 1976; Wichner and Dyer 1979) was the first installation of an HTGR in the United States. The plant operated from 1967 to 1974. In 1974, it was shut down for decommissioning. The Peach Bottom HTGR was a helium-cooled, graphite-moderated, $115 \mathrm{MWt}$ reactor. The fuel compacts contained pyrolytic carbon-coated thorium and fully enriched uranium carbide fuel particles. Core 1 fuel particles were coated with a single layer of pyrolytic graphite, solely to prevent hydrolysis during manufacture. The improved BISO (fuel coated with two ceramic layers) coatings on the Core 2 fuel particles were designed to retain gaseous fission products during the life of Core 2 (i.e., from July 1970 to October 1974).

A schematic of the Peach Bottom primary loop is shown in Figure 4. The primary circuit consisted of two loops, each containing a helium compressor and steam generator. The total helium flow of $210,000 \mathrm{~kg} / \mathrm{h}$ was divided equally between the two loops. Coolant temperatures at the core inlet and outlet of the rector vessel were 345 and $714^{\circ} \mathrm{C}$, respectively, and the primary loop pressure was approximately $2.4 \mathrm{MPa}(335 \mathrm{psig})$. The reactor and steam generator were connected by a concentric duct. Coolant exited from the reactor flows in the inner pipe of the concentric duct. The steam generators were forced-recirculation, drum-type boilers that have pendant U-tube economizer, evaporator, and superheater sections.

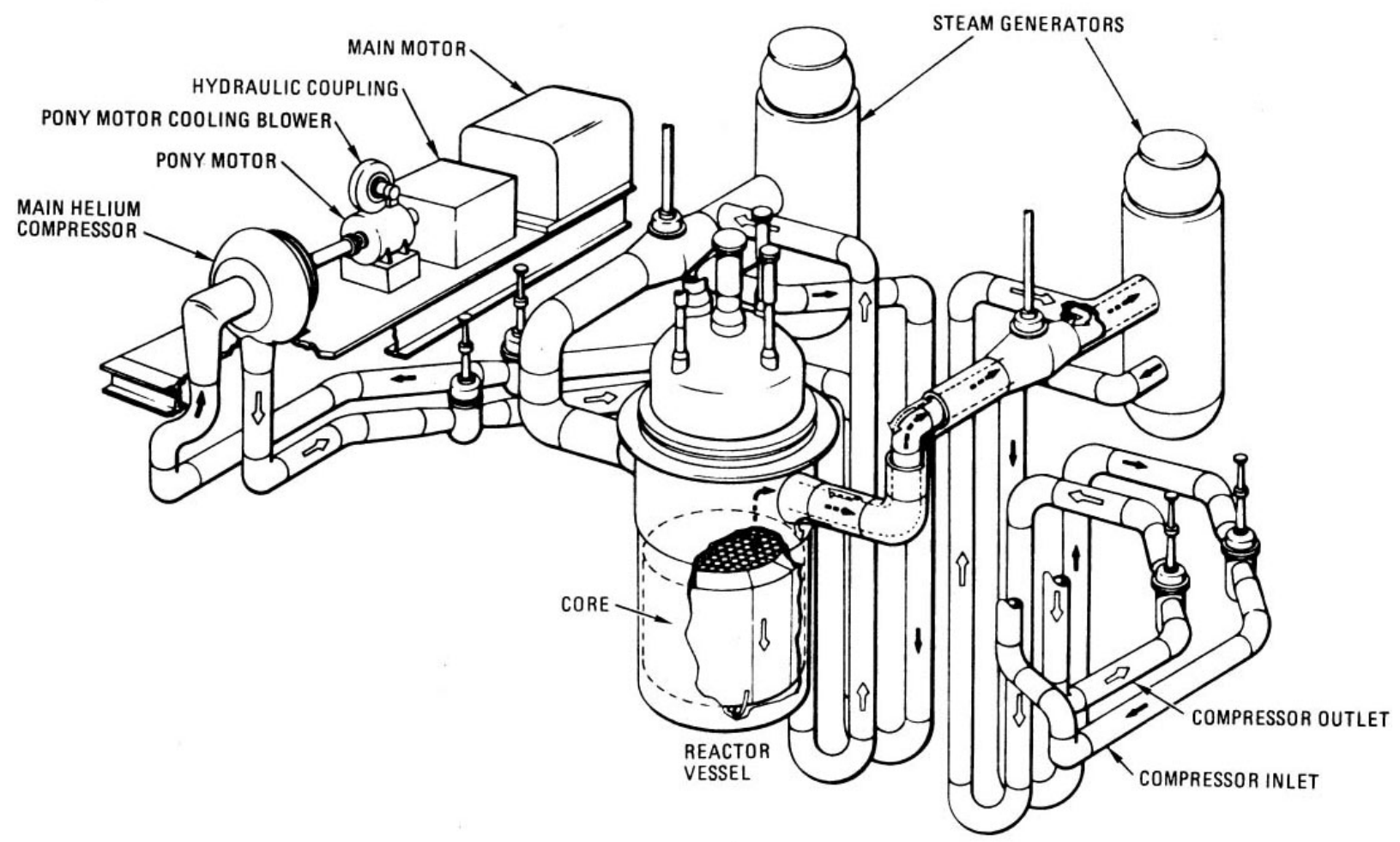

Figure 4. Isometric view of the primary coolant system of the Peach Bottom high-temperature gas-cooled reactor (Wichner and Dyer 1979). 
The simplified flowsheet of the reactor primary circuit and cleanup systems of the Peach Bottom HTGR are shown in Figure 5. A small portion of the tritium picked up by the fuel element purge flow (i.e., $454 \mathrm{~kg} / \mathrm{h}[1,000 \mathrm{lb} / \mathrm{h}]$ ) was permanently retained in the fission product traps that are located within the base of each fuel element. However, a major portion of the tritium left the core in the purge stream and entered the fission product trapping system. It was concluded that the water and Freon-cooled delay beds in the fission product trapping system did not play a significant role in the disposition of tritium in the reactor. About $10 \%$ of the purified helium leaving the Freon-cooled bed was diverted to a liquid nitrogen trap and (liquid nitrogen-cooled charcoal beds). It was confirmed that tritium was effectively captured in these traps. A smaller helium purge flow (i.e., $91 \mathrm{~kg} / \mathrm{h}[200 \mathrm{lb} / \mathrm{h}]$ ) was drawn from the steam generator to the chemical cleanup system, which consisted of an oxidizer unit and a molecular-sieve dehydrator. Gaseous HT was converted to HTO in the oxidizer and drawn off to the waste disposal drain tank from the condenser downstream from the unit. Additional HTO was removed by the molecular-sieve dehydrator downstream from the oxidizer. Purified helium that exited from the chemical cleanup system entered the fission product trapping system upstream from the liquid nitrogen trap.

\subsection{Verification of Core Model}

The tritium birth in the Peach Bottom HTGR during Core 2 operation was evaluated by Wichner and Dyer (1979). The numerical analysis results from THYTAN on the tritium birth due to ternary fission and from ${ }^{3} \mathrm{He}, \mathrm{Li}$, and ${ }^{10} \mathrm{~B}$ were compared with the reported values.

\subsubsection{Birth of Tritium by Ternary Fission}

In order to estimate the tritium birth in fuel by ternary fission, an average power, $\bar{P}$, assumed constant over the life of Core 2, was used instead of the actual time-dependent power level due to the complex power history of the Peach Bottom HTGR. $\bar{P}$ was calculated using the following equation:

$$
\bar{P}=P_{\text {rated }}\left(E F P D / t_{f}\right)
$$

where

$$
P_{\text {rated }}=\text { rated power }(115 \mathrm{MWt})
$$

$E F P=$ equivalent full power days at EOL (897 days)

$t_{f}=$ duration of Core 2 operation, including shutdown $\left(1.34 \times 10^{8} \mathrm{~s}\right.$ or 1550 days $)$.

Tritium birth was estimated using the calculated $\bar{P}(66.6 \mathrm{MWt})$ and the following equation:

$$
N_{T}\left(t_{f}\right)=K \cdot \bar{P} \cdot Y\left(\frac{1-\exp \left(-\lambda \cdot t_{f}\right)}{\lambda}\right)
$$

where

$$
\begin{aligned}
& N_{T}\left(t_{f}\right) \quad=\text { atoms of tritium at time } t_{f} \\
& K \quad=\text { fission rate per thermal megawatt }\left(3.121 \times 10^{16} \text { fissions/MW/s }\right) \\
& Y \quad=\text { average yield per fission }\left(1 \times 10^{-4}\right) \\
& \lambda \quad=\text { tritium decay constant }\left(1.793 \times 10^{-9} \mathrm{~s}^{-1}\right) .
\end{aligned}
$$




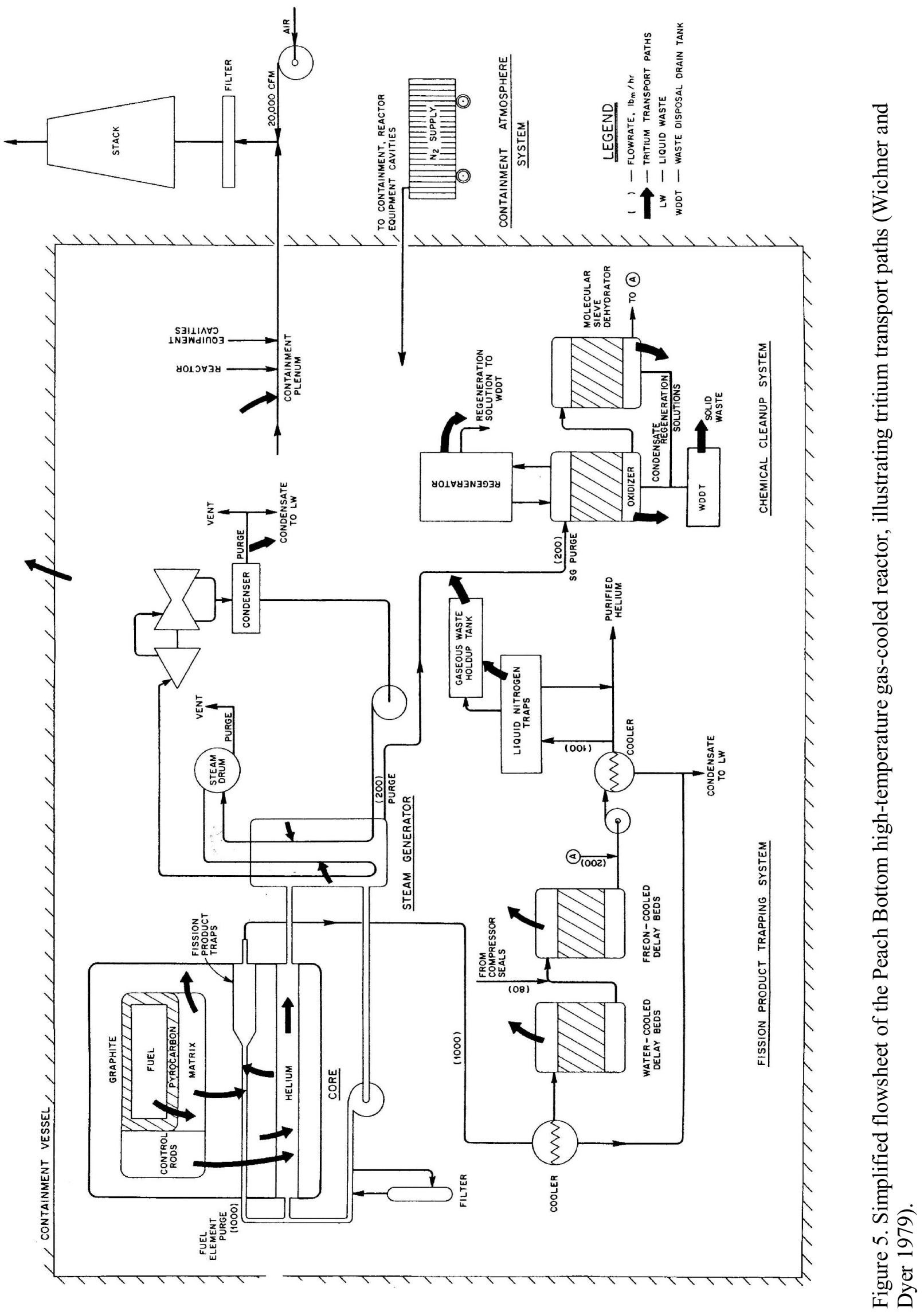


The reported tritium birth by ternary fission during 1,550 days was $1,210 \mathrm{Ci}$ (or $4.43 \times 10^{13} \mathrm{~Bq}$ ). The analytical solution of Equation (44) and the computed solution from THYTAN are listed in Table 2. The variance between the analytical solution and the computed solutions from THYTAN was calculated using the following equation:

Variance $=\frac{(\text { computed solution from THYTAN })-(\text { Analytical solution })}{(\text { Analytical solution })}$.

The calculation by THYTAN when using the above parameters yields $4.42 \times 10^{13} \mathrm{~Bq}$ of the tritium birth by ternary fission. This agreed well with the reported and analytical values.

Table 2. Comparison of tritium activity by ternary fission.

\begin{tabular}{|c|c|c|c|c|}
\hline \multicolumn{2}{|c|}{ Activity } \\
\hline \multicolumn{2}{|c|}{} & \begin{tabular}{c} 
Analytical \\
Solution \\
\multicolumn{2}{|c|}{ Reported Value }
\end{tabular} & $\begin{array}{c}\text { Computed Solution from } \\
\text { THYTAN }\end{array}$ & \\
$(\mathrm{Ci})$ & $(\mathrm{Bq})$ & $(\mathrm{Bq})$ & Variance \\
\hline 1,210 & $4.43 \times 10^{13}$ & $4.43 \times 10^{13}$ & $4.42 \times 10^{13}$ & 0.0030 \\
\hline
\end{tabular}

\subsubsection{Birth of Tritium from Lithium}

Reported values of the tritium birth from ${ }^{6} \mathrm{Li}$ contained in graphite are listed in Table 3 . Because the tritium activity was reported by using the unit of $\mathrm{Ci}$, the values expressed by the unit of $\mathrm{Bq}$ are also listed in Table 3.

Table 3. Comparison of tritium activity from ${ }^{6} \mathrm{Li}$ at the Core 2 operation of the Peach Bottom high-temperature gas-cooled reactor.

\begin{tabular}{|l|c|c|c|c|c|}
\hline & \multicolumn{4}{|c|}{ Activity } & \\
\hline $\begin{array}{c}\text { Graphite } \\
\text { Component }\end{array}$ & \multicolumn{2}{|c|}{$\begin{array}{c}\text { Reported Value } \\
(\mathrm{Ci})\end{array}$} & $\begin{array}{c}\text { Analytical } \\
\text { Solution } \\
(\mathrm{Bq})\end{array}$ & $\begin{array}{c}\text { Computed Solution } \\
\text { from THYTAN } \\
(\mathrm{Bq})\end{array}$ & Variance \\
\hline Sleeve & 14.0 & $5.13 \times 10^{11}$ & $5.12 \times 10^{11}$ & $5.12 \times 10^{11}$ & 0.0004 \\
\hline Spine & 1.0 & $3.66 \times 10^{10}$ & $3.78 \times 10^{10}$ & $3.78 \times 10^{10}$ & 0.0003 \\
\hline $\begin{array}{l}\text { Removal radial } \\
\text { reflector }\end{array}$ & 16.4 & $6.01 \times 10^{11}$ & $5.76 \times 10^{11}$ & $5.75 \times 10^{11}$ & -0.0023 \\
\hline $\begin{array}{l}\text { Permanent radial } \\
\text { reflector }\end{array}$ & 18.8 & $6.89 \times 10^{11}$ & $6.72 \times 10^{11}$ & $6.69 \times 10^{11}$ & -0.0045 \\
\hline Axial reflector & 9.2 & $3.37 \times 10^{11}$ & $3.42 \times 10^{11}$ & $3.42 \times 10^{11}$ & 0.0004 \\
\hline Fuel matrix & 13.1 & $4.80 \times 10^{11}$ & $5.68 \times 10^{11}$ & $5.68 \times 10^{11}$ & 0.0004 \\
\hline
\end{tabular}

The values shown in Table 3 were calculated by using the following equation:

$$
N_{T}\left(t_{f}\right)=\left(\frac{\phi_{t h} \cdot \sigma_{L i 6 T} \cdot N_{6}(0)}{\lambda-\phi_{t h} \cdot \sigma_{L i 6 T}}\right) \cdot\left[\exp \left(-\phi_{t h} \cdot \sigma_{L i 6 T} \cdot t_{f}\right)-\exp \left(-\lambda \cdot t_{f}\right)\right]
$$


where

$$
\begin{aligned}
& N_{T}\left(t_{f}\right) \quad=\text { atoms of tritium from }{ }^{6} \mathrm{Li} \text { at time } t_{f} \\
& \sigma_{L i 6 T}=\text { effective cross section for }{ }^{6} \mathrm{Li}(\mathrm{n}, \alpha) \mathrm{T}\left(4.08 \times 10^{-22} \mathrm{~cm}^{2}\right) \\
& N_{6}(0)=\text { initial amount of }{ }^{6} \mathrm{Li} \text { atoms. }
\end{aligned}
$$

The parameters for the calculation of each graphite component are listed in Table 4. The tritium birth is also calculated using these parameters and Equation (46). The radial reflectors were not replaced at the end of the Core 1 operation. Therefore, the tritium activities in the removable radial reflector and the permanent radial reflector are calculated sequentially: first with the Core 1 parameters of flux and time $\left(7.36 \times 10^{7} \mathrm{~s}\right.$ or 852 days) and then with Core 2 parameters. Results are listed in Table 3 as an analytical solution. Tritium activity was calculated by THYTAN using the same procedure (i.e., sequential calculation using Core 1 and Core 2 parameters for the removable radial reflector and the permanent radial reflector). Parameters for each subnode of THYTAN are listed in Table 5. The thermal neutron flux listed in Table 4 was used for the calculation of THYTAN. The graphite weight for the input data of THYTAN was adjusted to maintain the initial amount of ${ }^{6} \mathrm{Li}$ the same as the value listed in

\begin{tabular}{|c|c|c|}
\hline Component & $\begin{array}{c}\text { Thermal Neutron Flux } \\
\text { (neutrons } / \mathrm{cm}^{2} / \mathrm{s} \text { ) }\end{array}$ & $\begin{array}{c}\text { Initial Amount of }{ }^{6} \mathrm{Li} \\
\text { (moles) }\end{array}$ \\
\hline Sleeve & $2.82 \times 10^{13}$ & $6.99 \times 10^{-4}$ \\
\hline Spine & $2.82 \times 10^{13}$ & $5.17 \times 10^{-5}$ \\
\hline \multirow[t]{2}{*}{ Removal radial reflector } & Core 1: $2.57 \times 10^{13}$ & \multirow[t]{2}{*}{$7.56 \times 10^{-4}$} \\
\hline & Core 2: $2.82 \times 10^{13}$ & \\
\hline \multirow[t]{2}{*}{ Permanent radial reflector } & Core 1: $1.28 \times 10^{13}$ & \multirow[t]{2}{*}{$1.12 \times 10^{-3}$} \\
\hline & Core 2: $1.41 \times 10^{13}$ & \\
\hline Axial reflector & $1.41 \times 10^{13}$ & $6.74 \times 10^{-4}$ \\
\hline Fuel matrix & $2.82 \times 10^{13}$ & $7.76 \times 10^{-4}$ \\
\hline
\end{tabular}
Table 4 using a lithium concentration from Table 5.

Table 4. Parameters for the calculation of tritium birth from ${ }^{6} \mathrm{Li}$.

Table 5. Input data of THYTAN for the calculation of tritium birth from ${ }^{6} \mathrm{Li}$.

\begin{tabular}{|l|c|c|}
\hline \multicolumn{1}{|c|}{ Component } & $\begin{array}{c}\text { Lithium Concentration } \\
(\mathrm{ppm})\end{array}$ & $\begin{array}{c}\text { Graphite Weight } \\
(\mathrm{kg})\end{array}$ \\
\hline Sleeve & 0.007 & $9.37 \times 10^{3}$ \\
\hline Spine & 0.001 & $4.85 \times 10^{3}$ \\
\hline Removal radial reflector & 0.007 & $1.01 \times 10^{4}$ \\
\hline Permanent radial reflector & 0.007 & $1.50 \times 10^{4}$ \\
\hline Axial reflector & 0.007 & $9.03 \times 10^{3}$ \\
\hline Fuel matrix & 0.010 & $7.28 \times 10^{3}$ \\
\hline
\end{tabular}


There were discrepancies between the reported values and the analytical solution, especially in the result for the fuel matrix. The reported value and analytical solution should agree because they use the same equation to calculate tritium production. However, the reason for the discrepancy is unknown. On the other hand, the computed solutions from THYTAN agree well with the analytical solutions of each component.

\subsubsection{Birth of Tritium from ${ }^{3} \mathrm{He}$ in the Coolant}

Wichner and Dyer (1979) calculated tritium birth from ${ }^{3} \mathrm{He}$ existing in the coolant space (including the purge gaps) and graphite void source locations (i.e., in the sleeve graphite, the removal reflector, the permanent reflector, and the axial reflector).

For the coolant space, including the purge flow gaps, the following equation is used:

$N_{T 1}=\frac{\left(V_{1}+V_{7}\right) \cdot \phi_{t h} \cdot \sigma_{H e 3 T} \cdot N_{3}}{Q+\lambda \cdot V}$

for the sleeve graphite, the following equation is used:

$N_{T 2}\left(t_{f}\right)=\frac{V_{3}}{V} \cdot \phi_{t h} \cdot \sigma_{H e 3 T} \cdot N_{3}\left[\frac{1-\exp \left(-\lambda \cdot t_{f}\right)}{\lambda}\right]$

for the removal radial reflector, the following equation is used:

$N_{T 3}\left(t_{f}\right)=\frac{V_{4}}{V} \cdot \phi_{t h} \cdot \sigma_{H e 3 T} \cdot N_{3}\left[\frac{1-\exp \left(-\lambda \cdot t_{f}\right)}{\lambda}\right]$

for the permanent radial reflector, the following equation is used:

$N_{T 4}\left(t_{f}\right)=\frac{V_{6}}{V} \cdot \phi_{t h, 3} \cdot \sigma_{H e 3 T} \cdot N_{3}\left[\frac{1-\exp \left(-\lambda \cdot t_{f}\right)}{\lambda}\right]$

for the axial reflector, the following equation is used:

$N_{T 5}\left(t_{f}\right)=\frac{V_{5}}{V} \cdot \phi_{t h, 2} \cdot \sigma_{H e 3 T} \cdot N_{3}\left[\frac{1-\exp \left(-\lambda \cdot t_{f}\right)}{\lambda}\right]$

where

$$
\begin{aligned}
& N_{T 1}=\text { total moles of tritium circulating in the reactor with the coolant } \\
& N_{T 2}=\text { total moles of tritium born in the sleeve graphite from }{ }^{3} \mathrm{He} \\
& N_{T 3}=\text { total moles of tritium born in the removal radial reflector from }{ }^{3} \mathrm{He} \\
& N_{T 4}=\text { total moles of tritium born in the permanent reflector from }{ }^{3} \mathrm{He}
\end{aligned}
$$




$$
\begin{aligned}
& N_{T 5}=\text { total moles of tritium born in the axial reflector from }{ }^{3} \mathrm{He} \\
& V_{1} \quad=\text { volume of coolant passage in core }\left(1.77 \times 10^{6} \mathrm{~cm}^{3}\right) \\
& V_{2}=\text { ex-core primary system volume }\left(1.88 \times 10^{8} \mathrm{~cm}^{3}\right) \\
& V_{3}=\text { connected porosity in sleeve graphite }\left(3.44 \times 10^{5} \mathrm{~cm}^{3}\right) \\
& V_{4}=\text { connected porosity in removal radial reflector }\left(8.46 \times 10^{5} \mathrm{~cm}^{3}\right) \\
& V_{5}=\text { connected porosity in axial reflector }\left(3.92 \times 10^{5} \mathrm{~cm}^{3}\right) \\
& V_{6}=\text { connected porosity in permanent radial reflector }\left(2.32 \times 10^{6} \mathrm{~cm}^{3}\right) \\
& V_{7} \quad \text { = purge flow volume within the fuel elements }\left(6.32 \times 10^{5} \mathrm{~cm}^{3}\right) \\
& V \quad=\text { effective helium volume of the primary system } \\
& \left(V_{1}+V_{2}+V_{3}+V_{4}+V_{5}+V_{6}\left[1.94 \times 10^{8} \mathrm{~cm}^{3}\right]\right) \\
& \phi_{t h}=\text { average thermal neutron flux in core and removal radial reflector, } \\
& \text { Core } 2\left(2.82 \times 10^{13} \text { neutrons } / \mathrm{cm}^{2} / \mathrm{s}\right) \\
& \phi_{t h, 2}=\text { average thermal neutron flux in axial reflector }\left(1.41 \times 10^{13} \text { neutrons } / \mathrm{cm}^{2} / \mathrm{s}\right) \\
& \phi_{t h, 3}=\text { average thermal neutron flux in permanent radial reflector }\left(1.41 \times 10^{13} \text { neutrons } / \mathrm{cm}^{2} / \mathrm{s}\right) \\
& \sigma_{H e 3 T}=\text { effective cross section for }{ }^{3} \mathrm{He}(\mathrm{n}, \mathrm{p}) \mathrm{T}\left(2.28 \times 10^{-21} \mathrm{~cm}^{2}\right) \\
& Q \quad=\text { flow to chemical cleanup system plus } 10 \% \text { of fuel element purge flow } \\
& \left(Q_{1}\left(2.40 \times 10^{4} \mathrm{~cm}^{3} / \mathrm{s}\right)\right)+\text { leakage flow rate from primary system }\left(Q_{2}\left[25.5 \mathrm{~cm}^{3} / \mathrm{s}\right]\right) \text {. }
\end{aligned}
$$

equation:

The total moles of ${ }^{3} \mathrm{He}$ in the primary system, $N_{3}$, is governed by the relation in the following

$$
\frac{d N_{3}}{d t}=-\sigma_{H e 3 T} \cdot N_{3}\left\{\left(\frac{V_{1}+V_{3}+V_{4}+V_{7}}{V}\right) \cdot \phi_{t h}+\left(\frac{V_{5}+V_{6}}{V}\right) \cdot \phi_{t h, 2}\right\}+Q_{2}\left(\left[{ }^{3} \mathrm{He}\right]_{i}-\left[{ }^{3} \mathrm{He}\right]\right)
$$

\section{where}

$\left[{ }^{3} \mathrm{He}\right]_{i} \quad={ }^{3} \mathrm{He}$ concentration in makeup helium $\left(5.78 \times 10^{-11} \mathrm{moles} / \mathrm{cm}^{3}\right.$ based on $0.16 \mathrm{ppm}$ ${ }^{3} \mathrm{He}$ in helium)

$\left[{ }^{3} \mathrm{He}\right] \quad={ }^{3} \mathrm{He}$ concentration in primary $\operatorname{system}\left(=N_{3} / V\right)$. 
Reported values of tritium birth from ${ }^{3} \mathrm{He}$ in the Core 2 operation are listed in Table 6. Tritium birth is also calculated using Equations (47) through (52); the results are listed in Table 6 as the analytical solution. The parameters for THYTAN are summarized in Tables 7 and 8 . The tritium birth in each region is modeled using five subnodes (i.e., in the circulating coolant, in the sleeve graphite, in the removal radial reflector, in the permanent radial reflector, and in the axial reflector). Helium inventories in each subnode and in the primary system are calculated based on an average primary loop temperature of $809 \mathrm{~K}$ and a pressure of $23 \mathrm{~atm}$. The fraction of ${ }^{3} \mathrm{He}$ in each region is calculated using the helium inventories. In THYTAN, the effects of tritium being removed by the purification system and leakage from the primary coolant, expressed by the term Q in Equation (47), are not considered as part of the core model but are included in the purification system model and the leak model. Therefore, THYTAN's computed solution on the activity in the circulating coolant does not include the effect of tritium removal. Reported values are larger than both analytical and computed solutions in the range of about 1.1 to 1.6 times. The reason is unknown. However, the analytical and computed solutions show good agreement.

Table 6. Comparison of tritium activity from ${ }^{3} \mathrm{He}$ at the Core 2 operation of the Peach Bottom high-temperature gas-cooled reactor.

\begin{tabular}{|c|c|c|c|c|c|}
\hline \multirow[b]{3}{*}{ Region } & \multicolumn{4}{|c|}{ Activity } & \multirow[b]{3}{*}{ Variance } \\
\hline & \multicolumn{2}{|c|}{ Reported Value } & \multirow{2}{*}{$\begin{array}{c}\text { Analytical } \\
\text { Solution } \\
(\mathrm{Bq})\end{array}$} & \multirow{2}{*}{$\begin{array}{c}\text { Computed } \\
\text { Solution from } \\
\text { THYTAN } \\
(\mathrm{Bq})\end{array}$} & \\
\hline & $(\mathrm{Ci})$ & $(\mathrm{Bq})$ & & & \\
\hline In circulating coolant & $3.6 \times 10^{-3}$ & $1.32 \times 10^{8}$ & $6.17 \times 10^{7}$ & - & - \\
\hline $\begin{array}{l}\text { In circulating coolant } \\
\text { (without tritium removing) }\end{array}$ & - & - & $9.09 \times 10^{11}$ & $8.78 \times 10^{11}$ & -0.0358 \\
\hline In sleeve graphite & 5.4 & $1.98 \times 10^{11}$ & $1.31 \times 10^{11}$ & $1.26 \times 10^{11}$ & -0.0460 \\
\hline In removal radial reflector & 13.5 & $4.95 \times 10^{11}$ & $3.20 \times 10^{11}$ & $3.09 \times 10^{11}$ & -0.0358 \\
\hline $\begin{array}{l}\text { In permanent radial } \\
\text { reflector }\end{array}$ & 15.5 & $5.68 \times 10^{11}$ & $5.43 \times 10^{11}$ & $5.24 \times 10^{11}$ & -0.0358 \\
\hline In axial reflector & 3.1 & $1.14 \times 10^{12}$ & $9.17 \times 10^{11}$ & $8.86 \times 10^{11}$ & -0.0358 \\
\hline
\end{tabular}

Table 7. Input data of THYTAN for the calculation of tritium birth from ${ }^{3} \mathrm{He}$.

\begin{tabular}{|l|c|c|}
\hline \multicolumn{1}{|c|}{ Parameter } & Unit & Value \\
\hline Effective cross section for ${ }^{3} \mathrm{He}(\mathrm{n}, \mathrm{p}) \mathrm{T}$ & $\mathrm{cm}$ & $2.28 \times 10^{-21}$ \\
\hline${ }^{3} \mathrm{He}$ concentration in makeup helium & $\mathrm{ppm}$ & 0.16 \\
\hline Helium inventory in primary system & $\mathrm{kg}$ & 269 \\
\hline
\end{tabular}


Table 8. Input data for the subnode of THYTAN for the calculation of tritium birth from ${ }^{3} \mathrm{He}$.

\begin{tabular}{|l|c|c|}
\hline \multicolumn{1}{|c|}{ Subnode } & $\begin{array}{c}\text { Thermal Neutron Flux } \\
\left(\text { neutrons } / \mathrm{cm}^{2} / \mathrm{s}\right)\end{array}$ & $\begin{array}{c}\text { Helium Inventory } \\
(\mathrm{kg})\end{array}$ \\
\hline In circulating coolant & $2.82 \times 10^{13}$ & 3.33 \\
\hline In sleeve graphite & $2.82 \times 10^{13}$ & 0.477 \\
\hline In removal radial reflector & $2.82 \times 10^{13}$ & 1.17 \\
\hline In permanent radial reflector & $1.41 \times 10^{13}$ & 3.22 \\
\hline In axial reflector & $1.41 \times 10^{13}$ & 0.543 \\
\hline
\end{tabular}

\subsubsection{Birth of Tritium from ${ }^{10} \mathrm{~B}$}

The tritium birth from ${ }^{10} \mathrm{~B}$ in the poisoned spine was evaluated by the following equation:

$$
\begin{aligned}
\frac{N_{T}\left(t_{f}\right)}{N_{10}(0)}= & \frac{b \cdot a}{(b-a) \cdot(\lambda-a)}\left(\exp \left(-a \cdot t_{f}\right)-\exp \left(-\lambda \cdot t_{f}\right)\right) \\
& -\frac{b \cdot a}{(b-a) \cdot(\lambda-b)}\left(\exp \left(-b \cdot t_{f}\right)-\exp \left(-\lambda \cdot t_{f}\right)\right) \\
& +\frac{c}{(\lambda-a)}\left(\exp \left(-a \cdot t_{f}\right)-\exp \left(-\lambda \cdot t_{f}\right)\right)
\end{aligned}
$$

where

$$
\begin{aligned}
& a \quad=\beta \cdot \phi_{t h} \cdot \sigma_{B 10 L i 7} \\
& b=\phi_{f} \cdot \sigma_{L i 7 T} \\
& c \quad=\phi_{f} \cdot \sigma_{B 10 T} \\
& \beta \quad=\text { self-shielding factor }(0.0141) \\
& \phi_{t h}=\text { average thermal neutron flux }\left(2.82 \times 10^{13} \text { neutrons } / \mathrm{cm}^{2} / \mathrm{s}\right) \\
& \phi_{f} \quad=\text { average fast neutron flux }\left(2.26 \times 10^{13} \text { neutrons } / \mathrm{cm}^{2} / \mathrm{s}\right) \\
& \sigma_{B 10 L i 7}=\text { effective cross section for }{ }^{10} \mathrm{~B}(\mathrm{n}, \alpha){ }^{7} \mathrm{Li}\left(1.63 \times 10^{-21} \mathrm{~cm}^{2}\right) \\
& \sigma_{L i 7 T}=\text { effective cross section for }{ }^{7} \mathrm{Li}(\mathrm{n}, \mathrm{n} \alpha)^{3} \mathrm{H}\left(1.53 \times 10^{-25} \mathrm{~cm}^{2}\right) \\
& \sigma_{B 10 T}=\text { effective cross section for }{ }^{10} \mathrm{~B}(\mathrm{n}, 2 \alpha){ }^{3} \mathrm{H}\left(5.00 \times 10^{-26} \mathrm{~cm}^{2}\right) \\
& N_{10}(0) \quad=\text { initial amount of }{ }^{10} \mathrm{~B} \text { atoms (20.15 moles). }
\end{aligned}
$$


Tritium from ${ }^{10} \mathrm{~B}$ was produced in the poisoned spine and in the control rod. However, tritium formed in the control rods was estimated by a different procedure because the control rod position varied with time. Therefore, only the tritium birth from ${ }^{10} \mathrm{~B}$ in the poisoned spine is compared with the computed solution from THYTAN. For the THYTAN calculation, the concentration of ${ }^{10} \mathrm{~B}$ and the weight of the poisoned spine in the input data of THYTAN are set as adequate values to maintain the initial amount of ${ }^{10} \mathrm{~B}$ atoms the same as the reported value. The calculation result and reported values are shown in Table 9. All tritium activities show nearly the same values.

Table 9. Comparison of tritium activity from ${ }^{10} \mathrm{~B}$ in the poisoned spine at the Core 2 operation of Peach Bottom high-temperature gas-cooled reactor.

\begin{tabular}{|c|c|c|c|c|}
\hline \multicolumn{5}{|c|}{ Activity } \\
\hline \multicolumn{2}{|c|}{ Reported Value } & $\begin{array}{c}\text { Analytical } \\
\text { Solution } \\
(\mathrm{Bq})\end{array}$ & $\begin{array}{c}\text { Computed } \\
\text { Solution from } \\
\text { THYTAN } \\
(\mathrm{Bq})\end{array}$ & Variance \\
\hline 85.7 & $(\mathrm{~Bq})$ & $3.19 \times 10^{12}$ & $3.18 \times 10^{12}$ & -0.0028 \\
\hline
\end{tabular}

\subsection{Verification of Permeation Model}

\subsubsection{Model and Boundary Conditions}

The tritium permeation rate of the heat transfer tubing obtained from the Peach Bottom HTGR steam generator at the end-of-life was reported by Yang, Baugh, and Baldwin (1977). THYTAN's permeation model was verified using this experimental data. The reported permeation rate, $J$, of the as-received Incoloy-800 superheater tubing, silicon-low-carbon steel evaporator tubing, and low-carbon steel economizer are as follows:

for the economizer:

$$
J=7.78 \times 10^{1} \cdot \exp (-4500 / T)(493 \mathrm{~K}-623 \mathrm{~K})\left[\mu \mathrm{Ci} / \mathrm{m}^{2} / \mathrm{h}\right]
$$

for the evaporator:

$$
J=6.97 \times 10^{3} \cdot \exp (-6830 / T)(573 \mathrm{~K}-693 \mathrm{~K})\left[\mu \mathrm{Ci} / \mathrm{m}^{2} / \mathrm{h}\right]
$$

for the superheater:

$$
J=1.72 \times 10^{3} \cdot \exp (-6440 / T)(673 \mathrm{~K}-973 \mathrm{~K})\left[\mu \mathrm{Ci} / \mathrm{m}^{2} / \mathrm{h}\right] .
$$

The experimental condition of the tritium activity and the hydrogen impurity contents in the feed helium were prepared similarly to those in the Peach Bottom HTGR coolant $-6 \times 10^{2} \mu \mathrm{Ci} / \mathrm{m}^{3}$ (STP) and $20 \mathrm{~Pa}$, respectively. These values correspond to $0.461 \mathrm{ppb}$ and $199 \mathrm{ppm}$ by volume, respectively.

Wichner and Dyer (1979) used the following equation to estimate the tritium permeation through the steam generator of the Peach Bottom HTGR:

$$
J=K \cdot[T]_{H e}^{1 / 2}
$$


where

$K=$ permeability $\left([\mu \mathrm{Ci} / \mathrm{cm}]^{1 / 2} / \mathrm{h}\right.$ or $\left.\mathrm{Ncc} \mathrm{cm} / \mathrm{cm}^{2} / \mathrm{Pa}^{1 / 2} / \mathrm{h}\right)$

$[T]_{H e}=$ tritium concentration on the helium side $\left(\mu \mathrm{Ci} / \mathrm{cm}^{3}\right)$.

Equations (58), (59), and (60) provided the values for the economizer, evaporator, and superheater, respectively:

$$
\begin{aligned}
& K=0.318 \cdot \exp (-4500 / T)\left((\mu \mathrm{Ci} / \mathrm{cm})^{1 / 2} / \mathrm{h}\right) \\
& K=28.5 \cdot \exp (-6830 / T)\left((\mu \mathrm{Ci} / \mathrm{cm})^{1 / 2} / \mathrm{h}\right) \\
& K=7.02 \cdot \exp (-6440 / T)\left((\mu \mathrm{Ci} / \mathrm{cm})^{1 / 2} / \mathrm{h}\right) .
\end{aligned}
$$

These values are converted to SI units and normalized using the thickness of each heat transfer tube calculated by an outer and inner radius as listed in Table 10. The results are calculated using Equations (61), (62), and (63) for the economizer, evaporator, and superheater, respectively.

$$
\begin{aligned}
& K=4.40 \times 10^{-15} \cdot \exp \left(-37.4 \times 10^{3} / R / T\right)\left(\mathrm{m}^{3}(\mathrm{STP}) / \mathrm{m} / \mathrm{s} / \mathrm{Pa}^{0.5}\right) \\
& K=5.50 \times 10^{-13} \cdot \exp \left(-56.8 \times 10^{3} / R / T\right)\left(\mathrm{m}^{3}(\mathrm{STP}) / \mathrm{m} / \mathrm{s} / \mathrm{Pa}^{0.5}\right) \\
& K=2.07 \times 10^{-13} \cdot \exp \left(-53.5 \times 10^{3} / R / T\right)\left(\mathrm{m}^{3}(\mathrm{STP}) / \mathrm{m} / \mathrm{s} / \mathrm{Pa}^{0.5}\right)
\end{aligned}
$$

where

$$
R \quad=\text { gas constant }(8.314 \mathrm{~J} / \mathrm{mol} / \mathrm{K})
$$

Instead of Equation (57), the relation of permeation, including the effect of impurity hydrogen as defined by Equation (25), is used in THYTAN as a basic equation. The following permeability can be obtained using the experimental data of the permeation rate, experimental conditions, and the definition of permeation rate:

for the economizer:

$$
K=2.89 \times 10^{-12} \cdot \exp \left(-37.4 \times 10^{3} / R / T\right)\left(\mathrm{m}^{3}(\mathrm{STP}) / \mathrm{m} / \mathrm{s} / \mathrm{Pa}^{0.5}\right)
$$

for the evaporator:

$$
K=3.62 \times 10^{-10} \cdot \exp \left(-56.8 \times 10^{3} / R / T\right)\left(\mathrm{m}^{3}(\mathrm{STP}) / \mathrm{m} / \mathrm{s} / \mathrm{Pa}^{0.5}\right)
$$

for the superheater:

$$
K=1.36 \times 10^{-10} \cdot \exp \left(-53.5 \times 10^{3} / R / T\right)\left(\mathrm{m}^{3}(\mathrm{STP}) / \mathrm{m} / \mathrm{s} / \mathrm{Pa}^{0.5}\right) .
$$


Note that the value of the permeability is varied due to whether the effect of impurity hydrogen is considered in the definition of the permeation rate. The permeability obtained by using Equation (57) can only yield the correct tritium permeation rate at the same hydrogen impurity condition of the experimental (i.e., about 200 ppm).

Calculation of the tritium permeation rate for the superheater, evaporator, and economizer was carried out by THYTAN using both permeation rates obtained from Equations (25) and (57) (the permeation rate from Equation 57 recognizes the presence of tritium in the hydrogen, while Equation 25 does not). Figure 6 shows a nodalization scheme of THYTAN for the verification of the permeation model. Nodes No. 1 and No. 2 express a feed side chamber and a permeation chamber, respectively. Tritium permeation through the heat transfer tube is considered by the permeation model associated with nodes No. 1 and No. 2. The experimental conditions (i.e., the tritium concentration in the feed side of $0.461 \mathrm{ppb}$, feed helium pressure of $0.1013 \times 10^{5} \mathrm{~Pa}$, and the permeation chamber pressure of $1.33 \times 10^{-3} \mathrm{~Pa}$ ) were employed as boundary conditions. The boundary condition of hydrogen concentration in helium was set at 0 for the calculation using the permeability obtained from Equation (57) to eliminate the effect of impurity hydrogen, because the basic equation of permeation rate in THYTAN includes the effect of impurity hydrogen. For the calculation using the permeability obtained by Equation (25), the hydrogen concentration of $199 \mathrm{ppm}$ is used for the boundary condition for the node No. 1. Characteristics of the heat transfer tube samples for the input data of THYTAN are summarized in Table 10. 


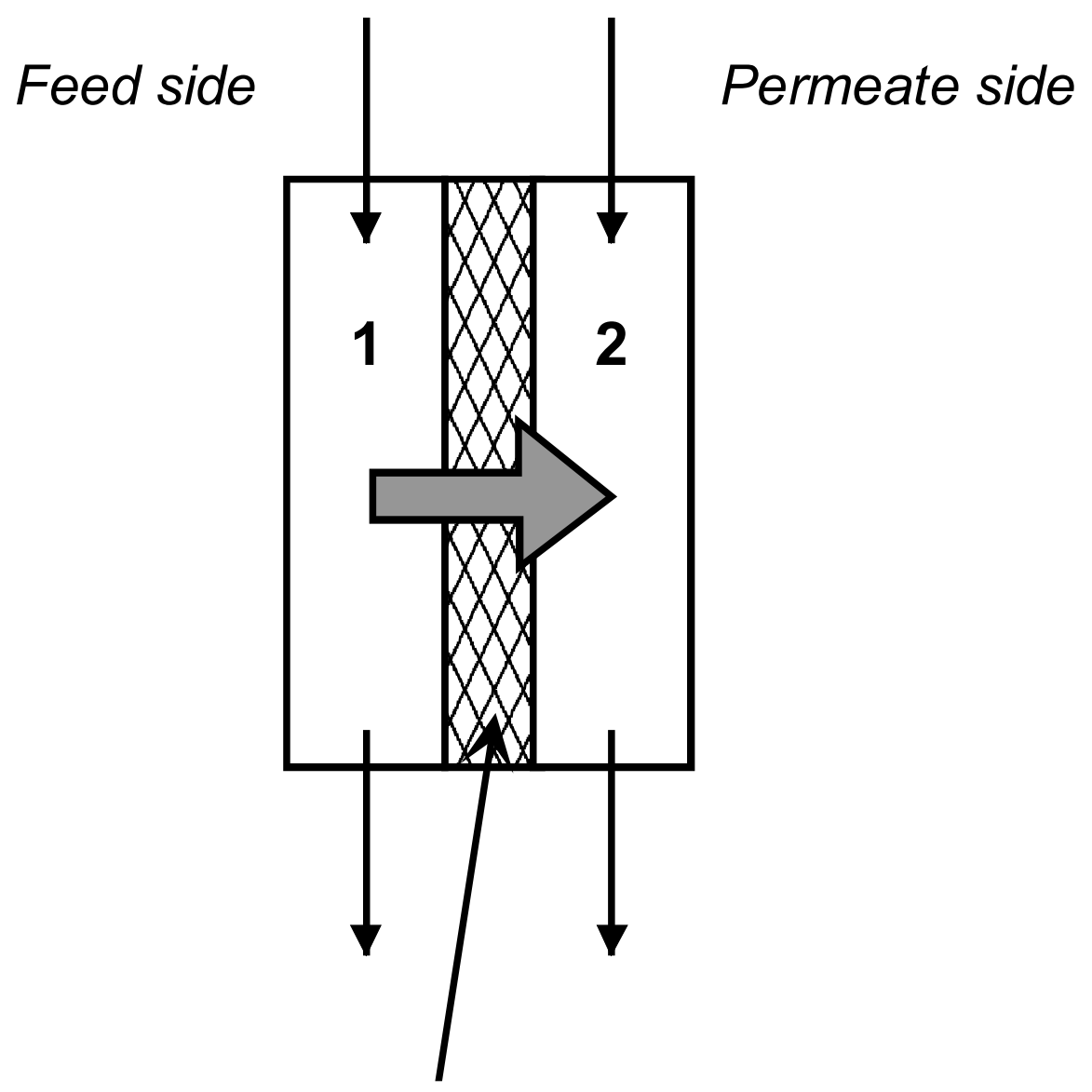

\section{Heat transfer tube}

Figure 6. Model nodalization scheme for verification of the permeation model.

Table 10. Characteristics of the heat transfer tube samples from the steam generator of the Peach Bottom high-temperature gas-cooled reactor.

\begin{tabular}{|l|c|c|c|}
\hline \multicolumn{1}{|c|}{ Sample } & $\begin{array}{c}\text { Effective Area } \\
\left(\mathrm{m}^{2}\right)\end{array}$ & $\begin{array}{c}\text { Outer Radius } \\
(\mathrm{m})\end{array}$ & $\begin{array}{c}\text { Inner Radius } \\
(\mathrm{m})\end{array}$ \\
\hline Economizer (inlet) & $103.47 \times 10^{-4}$ & $9.525 \times 10^{-3}$ & $7.300 \times 10^{-3}$ \\
\hline Evaporator (inlet) & $68.34 \times 10^{-4}$ & $6.350 \times 10^{-3}$ & $4.775 \times 10^{-3}$ \\
\hline Superheater (inlet) & $90.16 \times 10^{-4}$ & $9.525 \times 10^{-3}$ & $6.350 \times 10^{-3}$ \\
\hline
\end{tabular}

\subsubsection{Results and Discussion}

The analytical solutions of the permeation rate calculated by Equations (54) through (56) are listed in Table 11. The computed solutions from THYTAN using Equations (61) through (66) are also listed in Table 11. Both computed solutions agree well with the analytical solutions. 
Table 11. Comparison of permeation rate.

\begin{tabular}{|c|c|c|c|c|c|c|}
\hline \multirow[b]{3}{*}{ Sample } & \multirow[b]{3}{*}{$\begin{array}{c}\text { Temp. } \\
(\mathrm{K})\end{array}$} & \multirow{3}{*}{$\begin{array}{c}\text { Analytical } \\
\text { Solution Using } \\
\text { Equations }(54) \\
\text { through }(56) \\
\text { Permeation Rate } \\
\left(\mu \mathrm{Ci} / \mathrm{m}^{2} / \mathrm{h}\right)\end{array}$} & \multicolumn{4}{|c|}{ Computed Solution from THYTAN } \\
\hline & & & \multicolumn{2}{|c|}{$\begin{array}{l}\text { Using Equations (61) } \\
\text { through (63) }\end{array}$} & \multicolumn{2}{|c|}{$\begin{array}{l}\text { Using Equations (64) } \\
\text { through (66) }\end{array}$} \\
\hline & & & $\begin{array}{l}\text { Permeation rate } \\
\left(\mu \mathrm{Ci} / \mathrm{m}^{2} / \mathrm{h}\right)\end{array}$ & Variance & $\begin{array}{c}\text { Permeation rate } \\
\left(\mu \mathrm{Ci} / \mathrm{m}^{2} / \mathrm{h}\right)\end{array}$ & Variance \\
\hline \multirow{3}{*}{$\begin{array}{l}\text { Superheater } \\
\text { (inlet) }\end{array}$} & 673 & $1.202 \times 10^{-1}$ & $1.202 \times 10^{-1}$ & 0.00054 & $1.202 \times 10^{-1}$ & 0.00057 \\
\hline & 823 & $6.873 \times 10^{-1}$ & $6.876 \times 10^{-1}$ & 0.00043 & $6.876 \times 10^{-1}$ & 0.00047 \\
\hline & 973 & 2.298 & 2.297 & 0.00036 & 2.297 & 0.00039 \\
\hline \multirow{3}{*}{$\begin{array}{l}\text { Evaporator } \\
\text { (inlet) }\end{array}$} & 573 & $4.640 \times 10^{-2}$ & $4.644 \times 10^{-2}$ & 0.00073 & $4.644 \times 10^{-2}$ & 0.00072 \\
\hline & 633 & $1.436 \times 10^{-1}$ & $1.437 \times 10^{-1}$ & 0.00066 & $1.437 \times 10^{-1}$ & 0.00065 \\
\hline & 693 & $3.656 \times 10^{-1}$ & $3.658 \times 10^{-1}$ & 0.00061 & $3.658 \times 10^{-1}$ & 0.00062 \\
\hline \multirow{3}{*}{$\begin{array}{l}\text { Economizer } \\
\text { (inlet) }\end{array}$} & 493 & $8.450 \times 10^{-3}$ & $8.454 \times 10^{-3}$ & 0.00056 & $8.454 \times 10^{-3}$ & 0.00056 \\
\hline & 558 & $2.447 \times 10^{-2}$ & $2.448 \times 10^{-2}$ & 0.00050 & $2.448 \times 10^{-2}$ & 0.00050 \\
\hline & 623 & $5.676 \times 10^{-2}$ & $5.678 \times 10^{-2}$ & 0.00044 & $5.678 \times 10^{-2}$ & 0.00044 \\
\hline
\end{tabular}

\subsection{Verification of Leak Model}

\subsubsection{Model and Boundary Conditions}

Experimental data from the Peach Bottom HTGR reported that an average leakage rate was $0.1 \%$ /day from the approximately $2.04 \times 10^{4} \mathrm{~m}^{3}$ of nitrogen in the containment vessel and was $3.2 \mathrm{~kg}$ /day from the approximately $232 \mathrm{~m}^{3}$ of primary helium. The special tritium survey showed typical tritium concentrations of $2 \times 10^{-5} \mu \mathrm{Ci} / \mathrm{cm}^{3}$ in the primary coolant and $5 \times 10^{-7} \mu \mathrm{Ci} / \mathrm{cm}^{3}$ in the containment atmosphere for the nominal reactor conditions of temperature and pressure. Note that Wichner and Dyer (1979) emphasized that these concentrations were correct at least during that period in 1971 when the measurements were obtained.

In order to verify the leak model of THYTAN, the tritium concentration in the containment vessel was estimated by THYTAN using the reported leak rate and the tritium concentration in the primary loop. Then the numerical analysis result from THYTAN on the tritium concentration in the containment vessel was compared with the experimental result and the reported analytical solution. Figure 7 shows a nodalization scheme of THYTAN for calculation of leakage in the Peach Bottom HTGR. Nodes No. 1 and No. 2 and nodes No. 3 and No. 4 expressed the primary loop and the containment vessel, respectively. Leakage from the primary loop to the containment vessel is considered by the model of leakage from node No. 1 to node No. 3 and that from node No. 2 to node No. 4, respectively. Leakage from the containment vessel to the atmosphere is also considered by the model of leakage from node No. 3 and node No. 4. 


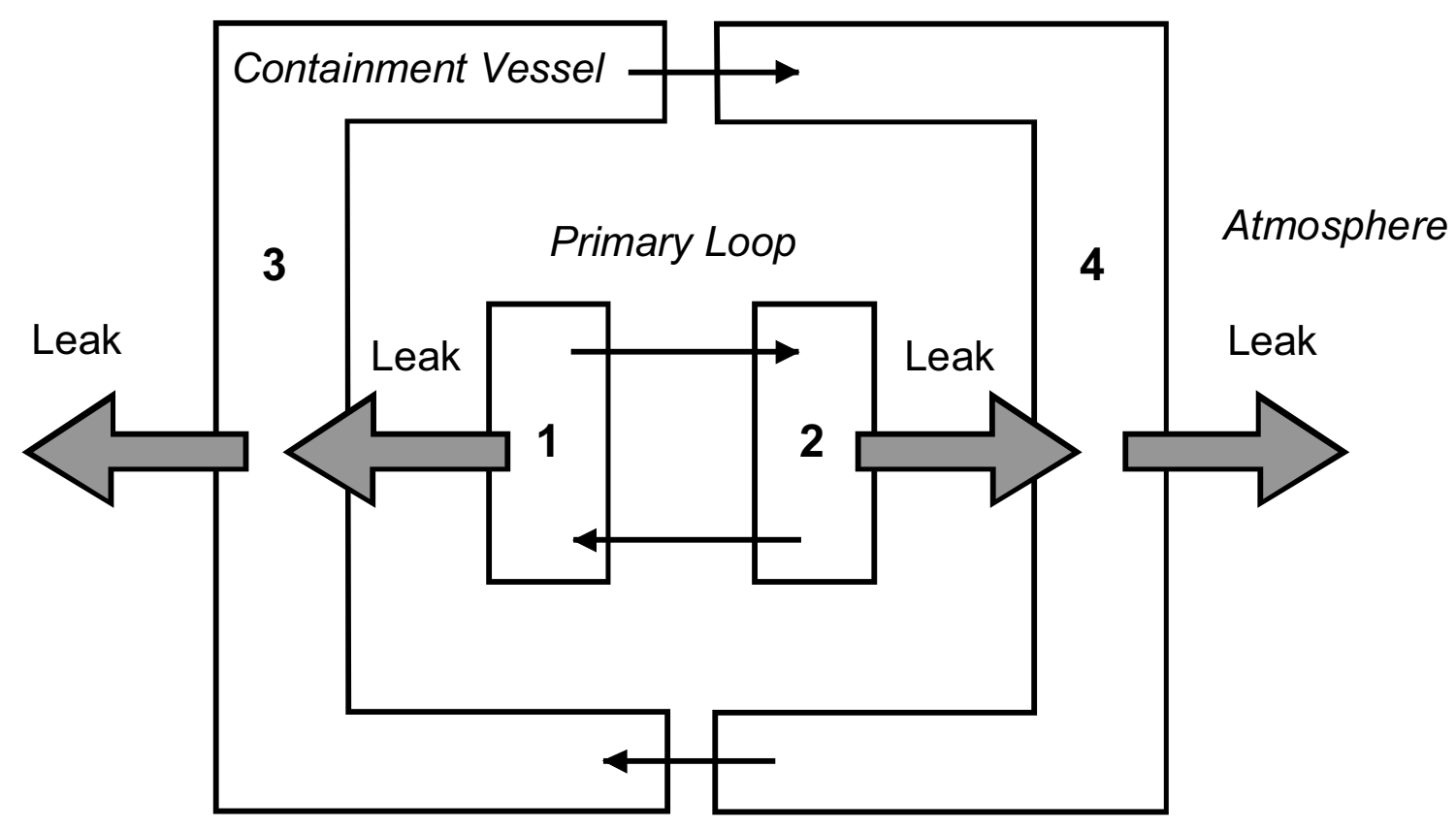

Figure 7. Nodalization scheme for verification of the leak model.

The input data of THYTAN is summarized in Table 12. Because information on the containment vessel temperature is not available, the average containment vessel temperature is assumed to be $323 \mathrm{~K}$. The tritium concentration in the primary loop of $2 \times 10^{-5} \mu \mathrm{Ci} / \mathrm{cm}^{3}$ corresponds to $1.98 \times 10^{-3} \mathrm{ppb}$ under the reported average temperature of $809 \mathrm{~K}$ and a pressure of $23 \mathrm{~atm}$ in the primary coolant. In order to keep the tritium concentration in the primary coolant $1.98 \times 10^{-3} \mathrm{ppb}$, the tritium release rate to the primary coolant was adjusted by the core model. The initial concentration of tritium in the containment vessel was set at 0 .

Table 12. Input data of THYTAN for verification of the leak model.

\begin{tabular}{|c|c|c|}
\hline Parameter & Unit & Value \\
\hline Leak rate from primary to containment vessel & $1 / \mathrm{h}$ & $4.15 \times 10^{-4 \mathrm{a}}$ \\
\hline Primary loop volume & $\mathrm{m}^{3}$ & 232 \\
\hline Primary loop pressure & $\mathrm{Pa}$ & $2.33 \times 10^{6 \mathrm{~b}}$ \\
\hline Primary loop temperature & $\mathrm{K}$ & 809 \\
\hline Leak rate from containment vessel to atmosphere & $1 / \mathrm{h}$ & $4.17 \times 10^{-4} \mathrm{c}$ \\
\hline Containment vessel volume & $\mathrm{m}^{3}$ & $1.56 \times 10^{4 \mathrm{~d}}$ \\
\hline Containment vessel pressure & $\mathrm{Pa}$ & $1.57 \times 10^{5 \mathrm{e}}$ \\
\hline Containment vessel temperature & $\mathrm{K}$ & $323^{\mathrm{f}}$ \\
\hline \multicolumn{3}{|c|}{$\begin{array}{l}\text { a. Based on } 3.2 \mathrm{~kg} / \text { day. } \\
\text { b. Based on } 23 \mathrm{~atm} \text {. } \\
\text { c. Based on } 0.1 \% \text { day. } \\
\text { d. Based on a nitrogen volume of } 2.04 \times 104 \mathrm{~m}^{3} \text { at a pressure of } 1.57 \times 10^{5} \mathrm{~Pa} \text { and assumed temperature of } 323 \mathrm{~K} \text {. } \\
\text { e. Based on } 8 \text { psig. } \\
\text { f. Assumed. }\end{array}$} \\
\hline
\end{tabular}




\subsubsection{Results and Discussion}

The solid lines in Figure 8 show THYTAN's computed solutions of the tritium concentrations in the primary coolant and in the containment vessel, respectively. The horizontal axis indicates the elapsed time of the operation. It was confirmed that the tritium concentration in the primary coolant was well adjusted to the experimental result of $1.98 \times 10^{-3} \mathrm{ppb}$. The experimental result of the tritium concentration in the containment vessel at $5 \times 10^{-7} \mu \mathrm{Ci} / \mathrm{cm}^{3}$ corresponds to $5.0 \times 10^{-4} \mathrm{ppb}$ under the containment vessel pressure of $1.57 \times 10^{5} \mathrm{~Pa}$ and the assumed temperature of $323 \mathrm{~K}$. Because information on the relationship between operating time and the tritium concentration in the containment vessel is not available, experimental data on the tritium concentration in the containment vessel is shown by a broken line as a constant value.

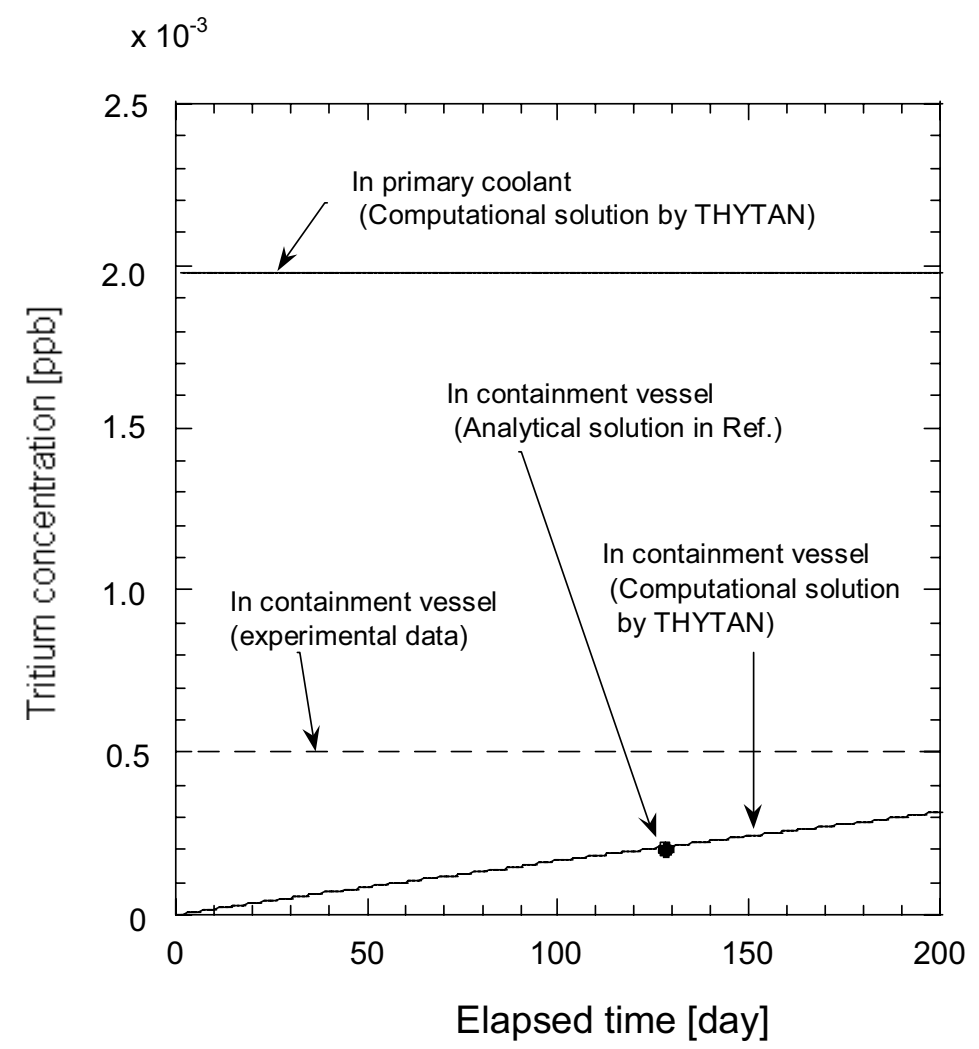

Figure 8. Comparison of tritium concentrations in the containment vessel of the Peach Bottom high-temperature gas-cooled reactor for verification of the leak model.

The containment vessel's deinerting operation was carried out approximately every 127 days. The reported analytical solution for the tritium concentration in the containment vessel at the end of 127 days was $2.1 \times 10^{-7} \mu \mathrm{Ci} / \mathrm{cm}^{3}$. This equivalent to $2.1 \times 10^{-4} \mathrm{ppb}$ at the containment vessel pressure of $1.57 \times 10^{5} \mathrm{~Pa}$ and the assumed temperature of $323 \mathrm{~K}$. This is shown in Figure 8 by a solid circle. The containment vessel's concentration calculated by THYTAN increased with the operating time and showed $2.1 \times 10^{-4} \mathrm{ppb}$ at the end of 127 days. This agreed well with the reported analytical solution. However, both the reported analytical and the computed solution by THYTAN were less than the experimental value observed in 1971 during the special tritium survey. This may indicate that the concentration in the primary coolant and containment vessel might not be stable during operation. 


\subsection{Verification of Purification System Model}

\subsubsection{Model and Boundary Conditions}

Because suitable experimental and analytical data on tritium removal by the purification system does not exist, verification of the purification model was carried out by comparison with an analytical solution from a simple model. Figure 9 shows a THYTAN nodalization scheme for verification of the purification system model. The simplest model was prepared using two nodes, because THYTAN cannot model only a single node (a node must be linked to another node in a closed system) with only one node. Both nodes make up the purification system model. The boundary conditions of both nodes are the same and are listed in Table 13. The HT concentration in each node was calculated during 3,000 s using this model and boundary conditions.

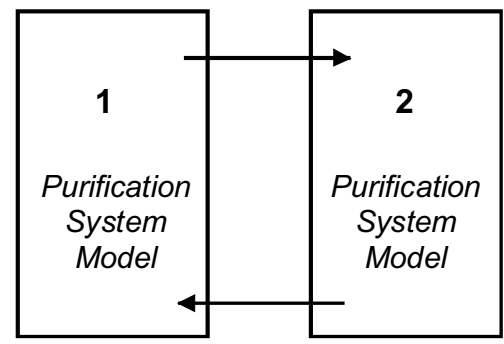

Figure 9. Nodalization scheme for verification of the purification system model.

Table 13. THYTAN boundary conditions for verification of the purification system model.

\begin{tabular}{|l|c|c|c|}
\hline \multicolumn{1}{|c|}{ Parameter } & Symbol & Unit & Value \\
\hline Inventory & $V_{j}$ & $\mathrm{~m}^{3}(\mathrm{STP})$ & 1 \\
\hline $\begin{array}{l}\text { Helium flow rate at purification } \\
\text { system }\end{array}$ & $F_{P F, H e}$ & $\mathrm{~m}^{3}(\mathrm{STP})$ & $1.0 \times 10^{-3}$ \\
\hline $\begin{array}{l}\text { Fractional efficiency of purification } \\
\text { system for HT }\end{array}$ & $\eta_{H T}$ & - & 0.9 \\
\hline \begin{tabular}{l} 
Initial concentration of HT \\
\hline
\end{tabular} & $C_{0, H T, j}$ & $\mathrm{~m}^{3}(\mathrm{STP}) / \mathrm{m}^{3}(\mathrm{STP})$ & $1.0 \times 10^{-9}$ \\
\hline
\end{tabular}

\subsubsection{Results and Discussion}

Because the boundary conditions of both nodes are the same, the mass balance of each node can be expressed in the following equation:

$$
\begin{aligned}
V_{j} \frac{d C_{i, j}}{d t} & =-R_{P F, i, j} \\
& =-F_{P F, H e} \cdot \eta_{i} \cdot C_{i, j}
\end{aligned}
$$

The solution for $C_{i, j}$ is found in the following equation:

$$
C_{i, j}(t)=C_{0, i, j} \cdot \exp \left(-\frac{F_{P F, H e} \cdot \eta_{i}}{V_{j}} \cdot t\right)
$$


where

$C_{0, i, j}=$ initial concentration of chemical $\mathrm{i}$ in node $\mathrm{j}\left[\mathrm{m}^{3}(\mathrm{STP}) / \mathrm{m}^{3}(\mathrm{STP})\right]$.

The analytical solution from Equation (68) and the computed solution from THYTAN are plotted in Figure 10. Both the analytical solution and the computed solution show same-time dependency.

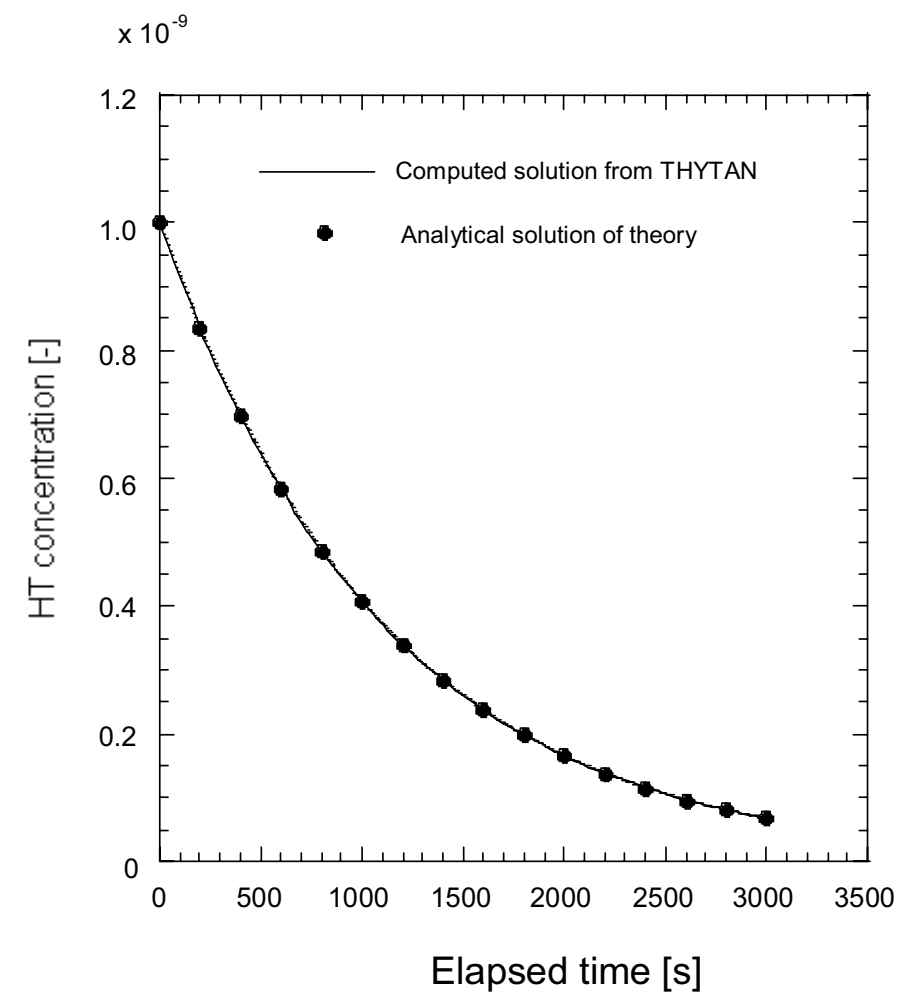

Figure 10. Analytical and computed solution of tritium concentration for verification of the purification system model.

\subsection{Verification of Total System}

\subsubsection{Model and Boundary Conditions}

Model. Figure 11 shows the nodalization scheme of the Peach Bottom HTGR. Nodes No. 1 and No. 2 correspond to the main helium flow and the fuel element purge flow in the core, respectively. Tritium release to nodes No. 1 and No. 2 is calculated by the core model. Helium flow channels in both steam generators were represented by nodes No. 4 through No. 18 and No. 21 through No. 35, respectively. Each section of the steam generator (i.e., the superheater, the evaporator, and the economizer) was modeled using 5 nodes. Steam flow channels in both steam generators were also represented by nodes No. 52 through No. 66 and No. 68 through No. 82, respectively. Tritium permeation from the primary helium coolant to water was considered in each node in the steam generator. Two concentric ducts between the reactor and the steam generator are modeled using nodes No. 3 and No. 19, and No. 20 and 
No. 36, respectively. Tritium permeations from the hot helium in the inner pipe to the cold helium in the outer pipe are considered by the permeation model from node No. 3 through No. 19 and from No. 20 through No. 36, respectively. Two effective traps (i.e., the liquid nitrogen traps in the fission product trapping system and the chemical cleanup system for tritium removal) were modeled by nodes No. 43 and No. 40 associated with the purification system model, respectively. The atmosphere in the containment vessel was represented using nodes No. 85 and 86. The leakage of tritium contained within the bulk helium that leaks from the primary coolant to the containment vessel is considered leakage from nodes No. 19 through No. 85 and from No. 36 through No. 86, respectively. The tritium leak from the containment vessel to outside was considered leakage from node No. 85 and No. 86 using the leak model.

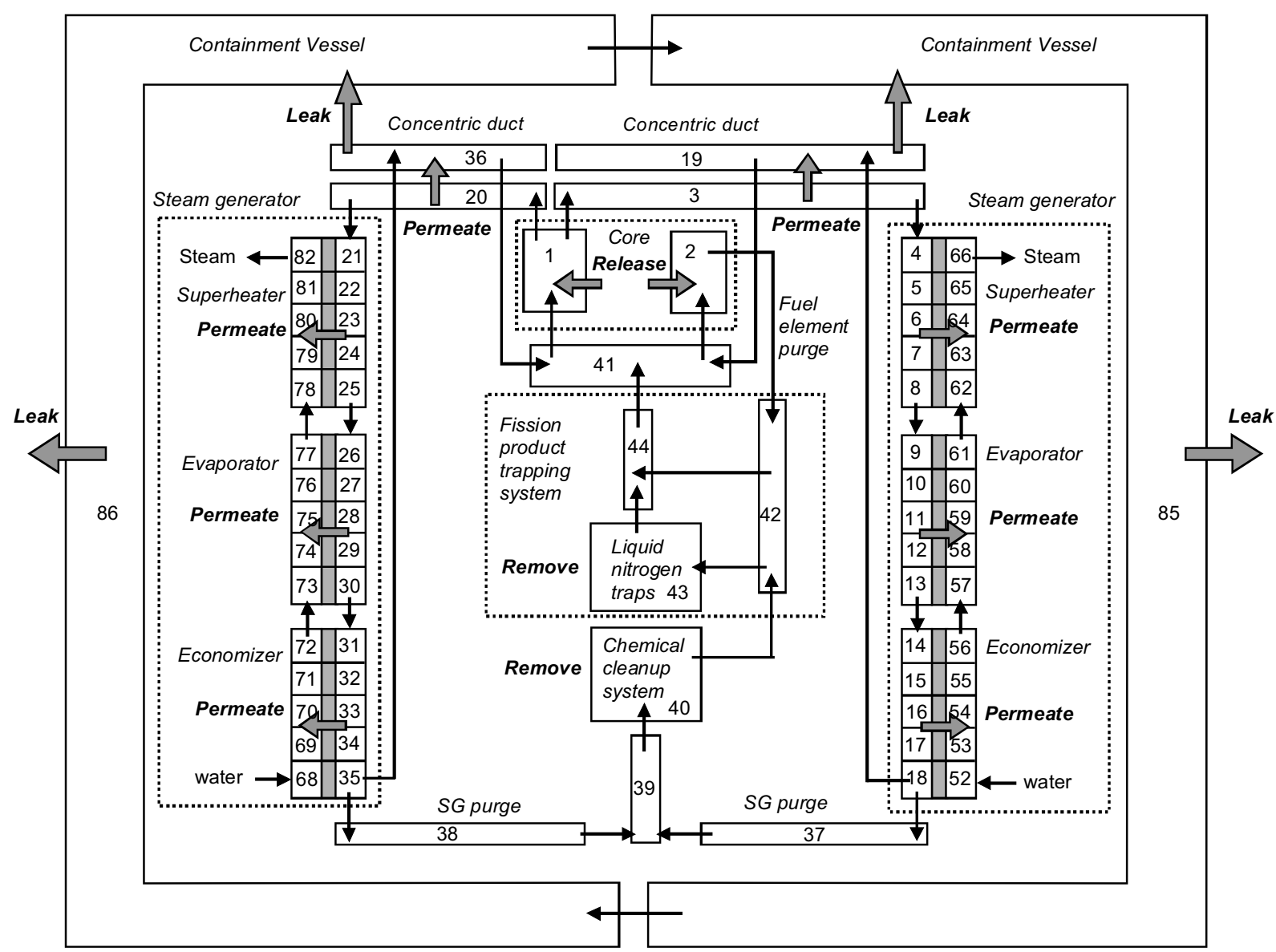

Figure 11. Nodalization scheme of the Peach Bottom high-temperature gas-cooled reactor.

Boundary condition of node temperature, pressure, and volume. Because no information is available on the inventory of each component of the Peach Bottom HTGR, the total volume of the primary coolant (i.e., $232 \mathrm{~m}^{3}$ ) is divided into the number of the nodes; the temperature and pressure of each node is set as the reported average temperature of $809 \mathrm{~K}$ and average pressure of $23 \mathrm{~atm}$. These parameters have no effect on the tritium concentration at steady state, and the metal temperature of the steam generator and the concentric duct, which does affect the permeation rate, was set adequately using the operating data as described in the following sections.

Boundary condition of tritium release rate. The total tritium birth was estimated as $2,200 \mathrm{Ci}$ $\left(8.14 \times 10^{13} \mathrm{~Bq}\right)$ during the Core 2 operation of 1,550 days. Leakage to the fission product trapping system via the fuel element purge flow was also estimated as $310 \mathrm{Ci}\left(1.15 \times 10^{13} \mathrm{~Bq}\right)$. On the other hand, the estimated tritium activity in the core based on measured concentration, meaning the unreleased tritium 
to the primary coolant, was $997 \mathrm{Ci}\left(3.69 \times 10^{13} \mathrm{~Bq}\right)$. However, this value does not include the tritium trapped in the unmeasured core components (i.e., control rods, poisoned spines, and permanent reflector graphite). Therefore, the amount of tritium released to the primary coolant via the main flow channel in the core is uncertain. The difference (i.e., $893 \mathrm{Ci}$ ) between the estimated total tritium birth of 2,200 Ci and $1,307 \mathrm{Ci}$ (sum of $997 \mathrm{Ci}$ and $310 \mathrm{Ci}$ ) is the possible maximum tritium activity released to the primary coolant via the main flow channel. Therefore, the total amount of tritium released during 1,550 days to the main flow channel was varied between 0 and $893 \mathrm{Ci}\left(3.30 \times 10^{13} \mathrm{~Bq}\right)$.

Figure 12 shows the THYTAN calculation results for the annual tritium birth rate in the Peach Bottom HTGR during the Core 2 operation. Tritium birth from ${ }^{10} \mathrm{~B}$ in the control rods was calculated using the same thermal and fast neutron fluxes as for the poisoned spine and assumed adequate initial moles of ${ }^{10} \mathrm{~B}$ in the control rod to obtain the same activity as the reported one (790 $\mathrm{Ci}$ at 1,550 days). The annual tritium birth rate slightly decreased with operating time. However, it is assumed that the tritium birth rate was constant and the ratio of tritium release rate to the tritium birth rate is constant (i.e., the tritium release rate is constant). Applying this assumption, the tritium release rate to the fuel element purge flow was set as $2.70 \times 10^{12} \mathrm{~Bq} / \mathrm{y}$, which corresponds to the total activity of $310 \mathrm{Ci}$ at 1,550 days. The tritium release rate to the main flow channel was varied between 0 and $7.78 \times 10^{12} \mathrm{~Bq} / \mathrm{y}$, which corresponds to the total activity of $0 \mathrm{Ci}$ and $893 \mathrm{Ci}$ at 1,550 days, respectively.

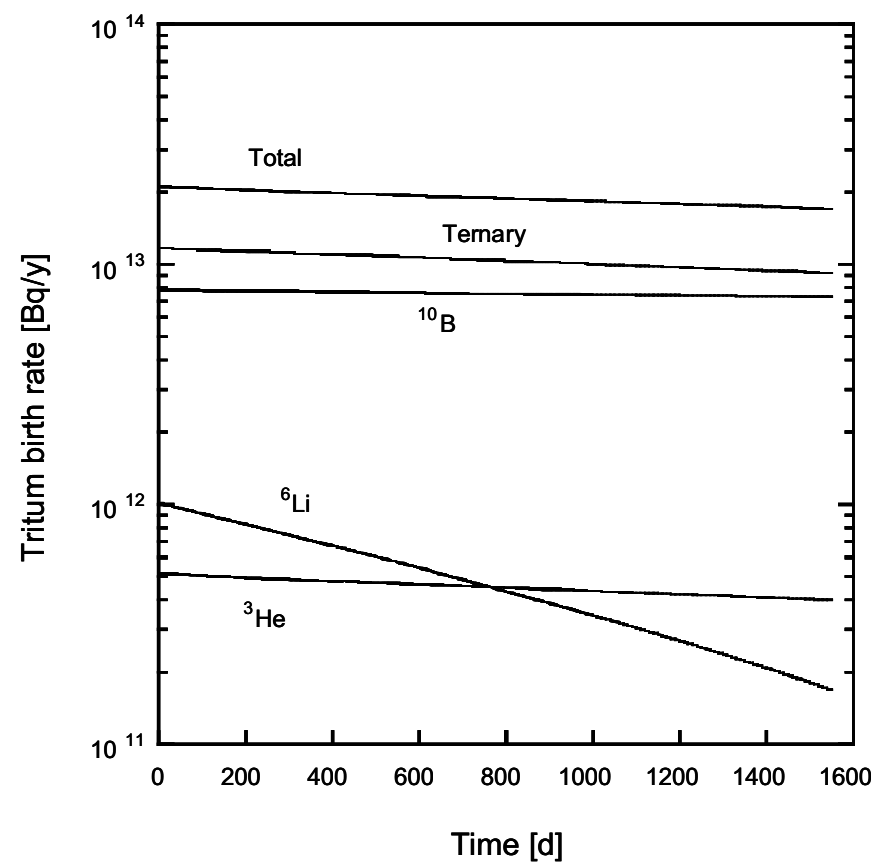

Figure 12. Calculation result for the annual tritium birth rate in the Peach Bottom high-temperature gas-cooled reactor during the Core 2 operation.

Boundary condition for the steam generator. The boundary condition for the steam generator is summarized in Table 14. The metal temperature is assumed to decrease linearly from the inlet to the outlet of helium flow. The total surface area for two steam generators is divided into 10 nodes for each section (i.e., economizer, evaporator, and superheater). Tritium permeability data, with the effect of impurity hydrogen from Equations (64) through (66), are used for each section. Therefore, the hydrogen 
concentration in the primary coolant is adjusted to the experimental data value of approximately $10 \mathrm{ppm}$ $(23 \mathrm{~Pa})$.

Table 14. Boundary condition of the steam generator for the Peach Bottom high-temperature gas-cooled reactor.

\begin{tabular}{|l|c|c|c|c|c|}
\hline & & & & \multicolumn{2}{c|}{$\begin{array}{c}\text { Metal Temperature } \\
\text { (K) }\end{array}$} \\
\cline { 2 - 6 } Section & $\begin{array}{c}\text { Surface Area } \\
\left(\mathrm{m}^{2}\right)\end{array}$ & $\begin{array}{c}\text { Outer Radius } \\
(\mathrm{m})\end{array}$ & $\begin{array}{c}\text { Inner Radius } \\
(\mathrm{m})\end{array}$ & $\begin{array}{c}\text { Helium Side } \\
\text { Outlet }\end{array}$ & $\begin{array}{c}\text { Helium Side } \\
\text { Inlet }\end{array}$ \\
\hline Economizer & 212 & $6.350 \times 10^{-3}$ & $4.775 \times 10^{-3}$ & 513 & 593 \\
\hline Evaporator & 474 & $9.525 \times 10^{-3}$ & $7.305 \times 10^{-3}$ & 593 & 618 \\
\hline Superheater & 275 & $9.525 \times 10^{-3}$ & $6.350 \times 10^{-3}$ & 693 & 853 \\
\hline a. For two steam generators.
\end{tabular}

Boundary condition for the concentric duct. The size of the concentric (co-axial) duct is summarized in Table 15 (General Atomic Company 1978). The metal temperature of the inner pipe is assumed to be similar to the reactor inlet helium temperature of $616 \mathrm{~K}\left(650^{\circ} \mathrm{F}\right)$. The material of the concentric duct is carbon-silicon steel, specification A-212, Grade B (General Atomic Company 1978). The evaporator tubing of the steam generator was also constructed of carbon-silicon steel, specification SA-192 (General Atomic Company 1978). Additionally, the operating temperatures of both tubes are almost the same. Therefore, permeability of the evaporator as defined in Equation (65) is applied to permeability of the concentric duct.

Table 15. Characteristics of the concentric duct for the Peach Bottom high-temperature gas-cooled reactor.

\begin{tabular}{|l|l|}
\hline \multicolumn{1}{|c|}{ Parameter } & Value \\
\hline Length (m) & $7.65^{\mathrm{a}}$ \\
\hline Outer diameter of inner pipe (m) & 0.8064 \\
\hline Inner diameter of inner pipe (m) & $0.7430^{\mathrm{b}}$ \\
\hline $\begin{array}{l}\text { a. Based on } 25 \mathrm{ft} 1 \text { in. } \\
\text { b. Based on thickness of } 3.17 \mathrm{~cm} .\end{array}$ \\
\hline
\end{tabular}

Boundary condition of the purification system model. The fractional tritium removal efficiency of the purification system is assumed to be 1.0 to estimate the amount of tritium removal by the purification system (Wichner and Dyer 1979). In the same way, tritium removal efficiency is set at 1.0 in this study. The flow rate of helium at the liquid nitrogen traps and the chemical cleanup system are set as the operating condition of $45.4 \mathrm{~kg} / \mathrm{h}(100 \mathrm{lb} / \mathrm{h})$ and $90.7 \mathrm{~kg} / \mathrm{h}(200 \mathrm{lb} / \mathrm{h})$, respectively.

Boundary condition for the leak. As for the leak from the primary coolant to the containment vessel and from the containment vessel to outside, the parameters listed in Table 12 are used as the boundary conditions. 


\subsubsection{Results and Discussion}

Calculation results for tritium concentration in the primary coolant, based on the activity of $310 \mathrm{Ci}$ to the purge loop and $0 \mathrm{Ci}$ to the main flow channel (i.e., case of minimum release rate) was $0.389 \mathrm{~Bq} / \mathrm{cm}^{3}$ (STP). This corresponds to $8.16 \times 10^{-5} \mu \mathrm{Ci} / \mathrm{cm}^{3}$ based on the average temperature and pressure of the primary coolant. As for the case based on the tritium activity of $310 \mathrm{Ci}$ to the purge flow and $893 \mathrm{Ci}$ to the main flow channel (i.e., case of maximum release rate), tritium concentration in the primary coolant was calculated as $1.61 \mathrm{~Bq} / \mathrm{cm}^{3}(\mathrm{STP})$ (i.e., $3.38 \times 10^{-4} \mu \mathrm{Ci} / \mathrm{cm}^{3}$ ). The tritium concentration in the primary coolant increased by 4.1 times with the increase of the tritium release rate to the primary coolant from $310 \mathrm{Ci}$ to $1,203 \mathrm{Ci}(310 \mathrm{Ci}+893 \mathrm{Ci}$ ) (i.e., increase by 3.9 times). Reported experimental data on tritium in the primary coolant in 1974 is reprinted as Figure 13 (Wichner and Dyer 1979). Tritium activity in the primary coolant (i.e. main loop HT and HTO) fluctuated in a range from $2 \times 10^{-6} \mu \mathrm{Ci} / \mathrm{cm}^{3}$ to $3 \times 10^{-4} \mu \mathrm{Ci} / \mathrm{cm}^{3}$ during operation in 1974. Calculation results from THYTAN are shown in same figure through use of dotted lines. The calculation result of the tritium concentration in the primary coolant based on $310 \mathrm{Ci}$ is almost the same level as the experimental results. The calculation result based on $310 \mathrm{Ci}$ to the purge flow and $893 \mathrm{Ci}$ to the main flow is slightly larger than the majority of the experimental results. However, the observed maximum value in the experiments matches the computed result. It can be concluded that the computed solution from THYTAN is slightly conservative, but THYTAN has shown itself capable of matching at least some of the experimental data. Note that tritium concentration in the secondary coolant (i.e., HTO in steam generator) could not be precisely estimated due to lack of data for the Peach Bottom HTGR (e.g., inventory of water and water drain rate). 


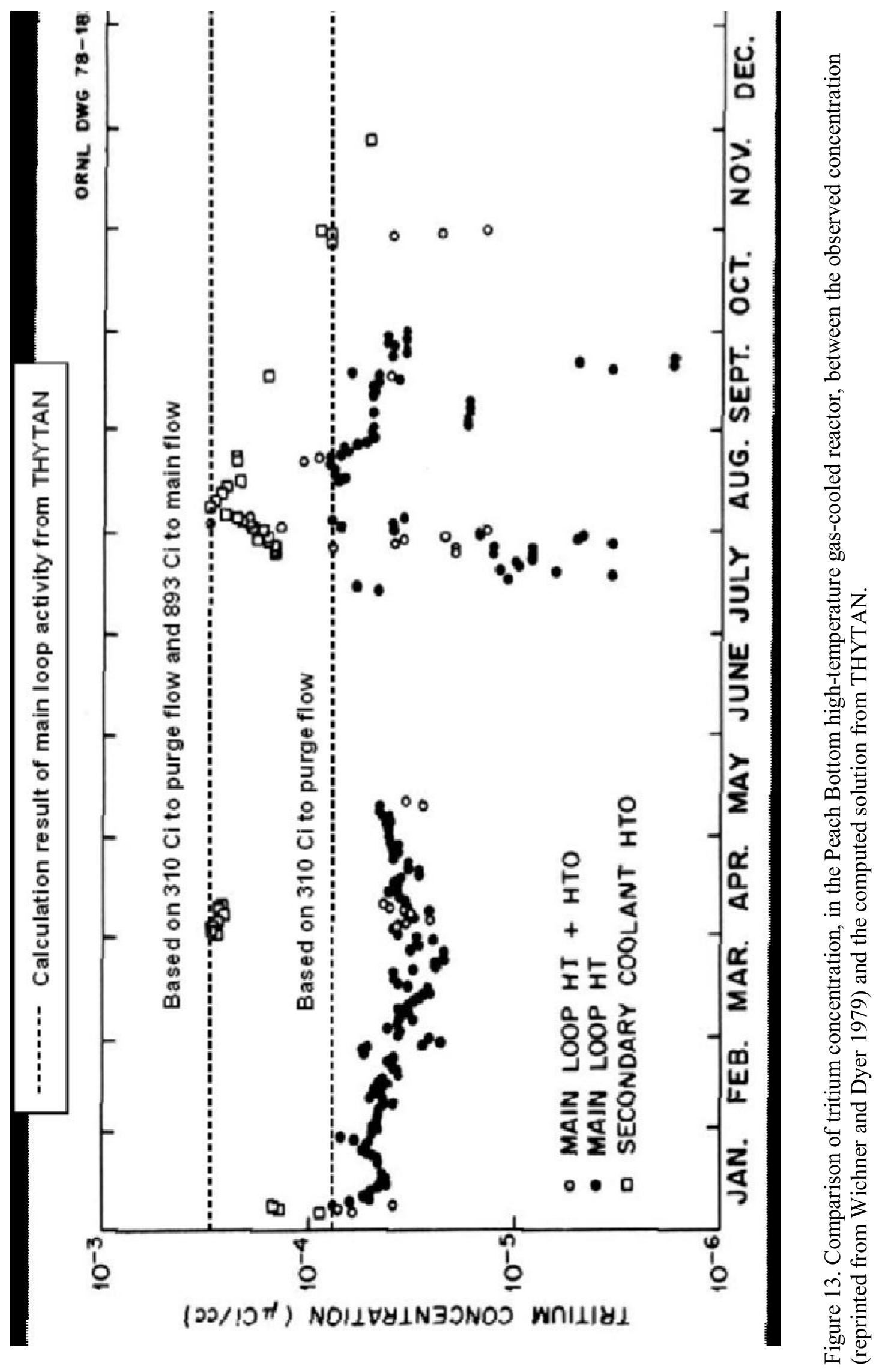




\section{NUMERICAL ANALYSIS OF THE NEXT GENERATION NUCLEAR PLANT USING HIGH-TEMPERATURE ELECTROLYSIS PROCESS}

\subsection{System Description}

Figure 14 shows a tentative flow scheme for the NGNP using the HTE process. The major specifications are listed in Table 16. High-temperature thermal energy of $600 \mathrm{MW}$ from a very high-temperature gas-cooled reactor is transported to the secondary coolant of helium at the IHX. Secondary helium is divided at the exit of the IHX. Approximately $89 \%$ of the secondary helium flows into a gas turbine plant to generate electricity and then returns to the IHX. The remainder of the secondary helium, approximately 11\%, enters a secondary heat exchanger (SHX). The thermal energy of the secondary helium, $50 \mathrm{MW}$, is transported to a tertiary coolant of helium at the SHX. Three process heat exchangers (PHXs) are installed in the tertiary loop to transport thermal energy from the tertiary coolant to the process chemicals in the HTE process. The HTE process is composed of a main process line and a sweep line. Hydrogen is produced in an electrolyzer in the main line by using electricity produced in the gas turbine plant. Oxygen is obtained from the sweep line as a by-product.

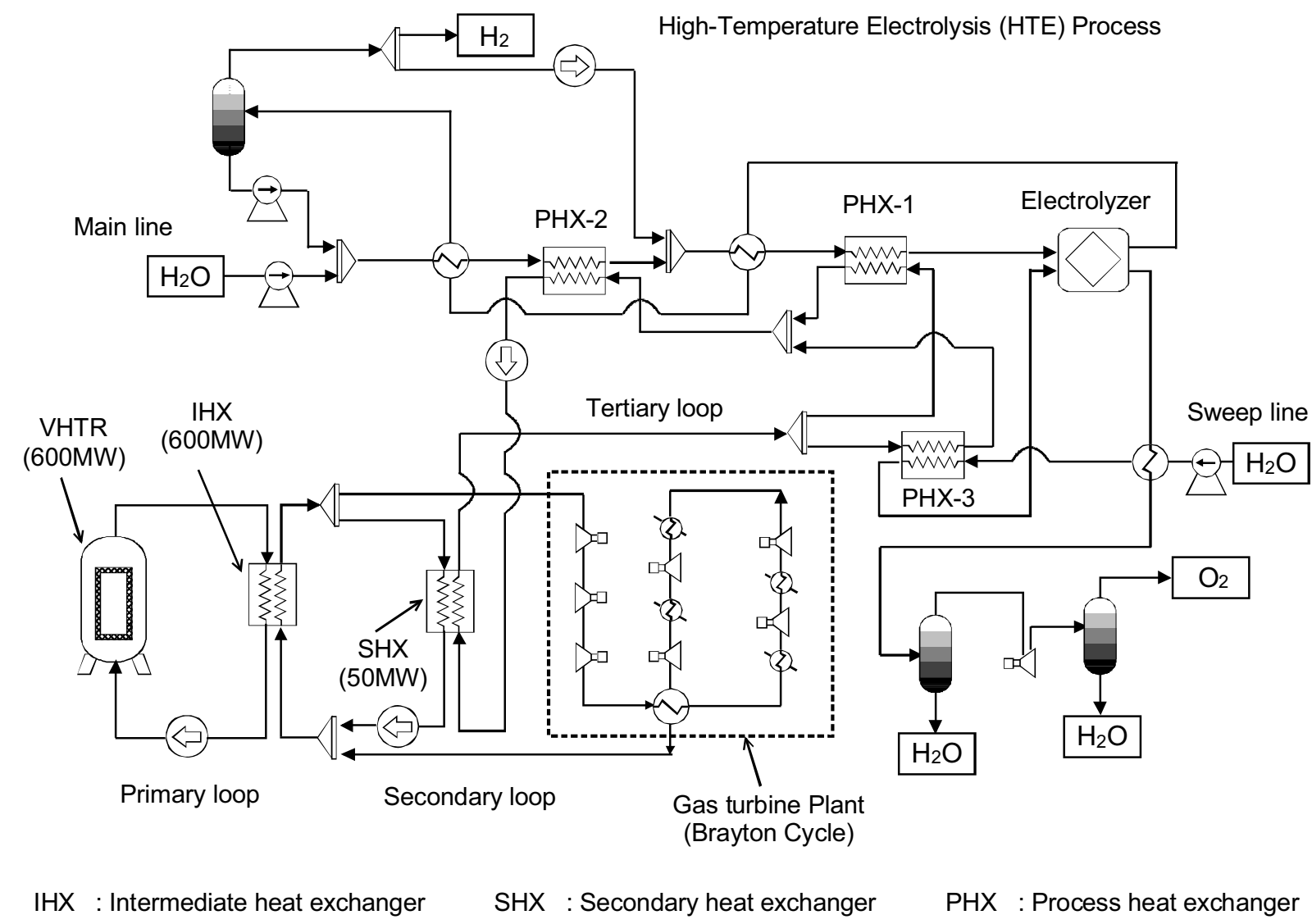

Figure 14. Tentative flow scheme for the Next Generation Nuclear Plant using the high-temperature electrolysis process. 
Table 16. Major specifications for the Next Generation Nuclear Plant using the high-temperature electrolysis process.

\begin{tabular}{|c|c|}
\hline Item & Value \\
\hline Reactor power & $600 \mathrm{MWt}$ \\
\hline Heat transfer rate of IHX & $600 \mathrm{MWt}$ \\
\hline Heat transfer rate of SHX & $50 \mathrm{MWt}$ \\
\hline \multicolumn{2}{|l|}{ Primary coolant } \\
\hline Reactor outlet temperature & $900^{\circ} \mathrm{C}$ \\
\hline Reactor inlet temperature & $495^{\circ} \mathrm{C}$ \\
\hline Flow rate & $289 \mathrm{~kg} / \mathrm{s}$ \\
\hline Pressure & $7.0 \mathrm{MPa}$ \\
\hline \multicolumn{2}{|l|}{ Secondary coolant } \\
\hline \multicolumn{2}{|l|}{ Total } \\
\hline IHX outlet temperature & $885^{\circ} \mathrm{C}$ \\
\hline IHX inlet temperature & $480^{\circ} \mathrm{C}$ \\
\hline Flow rate & $289 \mathrm{~kg} / \mathrm{s}$ \\
\hline Pressure & 7.0 Mpa \\
\hline \multicolumn{2}{|l|}{ Gas turbine plant line } \\
\hline Gas turbine plant inlet temperature & $885^{\circ} \mathrm{C}$ \\
\hline Gas turbine plant outlet temperature & $467^{\circ} \mathrm{C}$ \\
\hline Flow rate & $257 \mathrm{~kg} / \mathrm{s}$ \\
\hline \multicolumn{2}{|l|}{ SHX line } \\
\hline SHX inlet temperature & $885^{\circ} \mathrm{C}$ \\
\hline SHX outlet temperature & $580^{\circ} \mathrm{C}$ \\
\hline Flow rate & $32 \mathrm{~kg} / \mathrm{s}$ \\
\hline \multicolumn{2}{|l|}{ Tertiary coolant } \\
\hline \multicolumn{2}{|l|}{ Total } \\
\hline SHX outlet temperature & $875^{\circ} \mathrm{C}$ \\
\hline SHX inlet temperature & $522^{\circ} \mathrm{C}$ \\
\hline Flow rate & $27.5 \mathrm{~kg} / \mathrm{s}$ \\
\hline Pressure & $2.0 \mathrm{Mpa}$ \\
\hline \multicolumn{2}{|l|}{ For main line of HTE process } \\
\hline PHX-1 inlet temperature & $864^{\circ} \mathrm{C}$ \\
\hline PHX-1 outlet temperature & $447^{\circ} \mathrm{C}$ \\
\hline Flow rate & $20.6 \mathrm{~kg} / \mathrm{s}$ \\
\hline \multicolumn{2}{|l|}{ For sweep line of HTE process } \\
\hline PHX-3 inlet temperature & $864^{\circ} \mathrm{C}$ \\
\hline PHX-3 outlet temperature & $612^{\circ} \mathrm{C}$ \\
\hline Flow rate & $6.9 \mathrm{~kg} / \mathrm{s}$ \\
\hline \multicolumn{2}{|l|}{ HTE process } \\
\hline Hydrogen production rate & $7.5 \times 10^{4} \mathrm{~m}^{3}(\mathrm{STP}) / \mathrm{h}$ \\
\hline $\begin{array}{l}\text { IHX = intermediate heat exchanger } \\
\text { SHX = secondary heat exchanger }\end{array}$ & $\begin{array}{l}\text { changer } \\
\text { re electrolysis }\end{array}$ \\
\hline
\end{tabular}




\subsection{Model}

Figure 15 shows the nodalization scheme for NGNP using the HTE process. Tritium release to the primary coolant is shown at a node expressed by No. (1). Five heat exchangers (i.e., IHX, SHX, PHX-1, PHX-2, PHX-3) are modeled by using 10 nodes in each flow channel. Each node is associated with the permeation model. On the other hand, the precooler and the three intercoolers in the gas turbine plant are not modeled as a heat exchanger due to the lack of design data (e.g., heat transfer and metal temperature). The helium temperature in these components is relatively low (i.e., less than $100^{\circ} \mathrm{C}$ ). Therefore, tritium permeation from the secondary helium to the cooling water through these components is likely not significant. Also, recuperators in the gas turbine plant and in the HTE process are not modeled as a heat exchanger due to the lack of design data. In the recuperator, tritium migrates in the same loop even if tritium permeates the heat transfer tube. Therefore, the effect of tritium permeation at the recuperator also does not seem significant.

Installing the purification system in the primary loop (i.e., split helium coolant from main stream) between the reactor outlet and at the IHX inlet (a high-temperature position) is more effective than installing it at the lowest-temperature position (i.e., between the IHX outlet and the reactor inlet). However, the hot gas duct between the reactor and IHX may be constructed as a concentric or co-axial duct to reduce heat loss, as was done with the the hot gas duct between the reactor and steam generator of the Peach Bottom HTGR. Because high-temperature helium from the reactor would flow inside the inner pipe of the concentric duct in this arrangement, it is technically difficult to split the helium from the inner pipe of the concentric duct. Hot gas ducts between IHX and SHX in the secondary loop, and between SHX and PHX in the tertiary loop, may be constructed as a concentric duct similar to the hot gas duct in the primary loop. As a result of the physical difficulty in installing a purification system in a concentric pipe with the hot pipe in the middle, the purification system is assumed to be installed in the position of the lowest temperature in each helium loop, where the pipes are not assumed to be constructed in a concentric arrangement. Leakage of tritium to the outside of the system with bulk helium leakage is considered in each helium loop. The isotope exchange reaction (i.e., $\mathrm{HT}+\mathrm{H}_{2} \mathrm{O}=\mathrm{H}_{2}+\mathrm{HTO}$ ) is considered in the components of the HTE process.

\subsection{Boundary Conditions}

\subsubsection{Tritium Birth and Release Rate}

Because information is not yet available for the core design of NGNP to estimate tritium birth, the tritium birth and release rate to the primary coolant is estimated from experience on other HTGRs. Reported calculation results on tritium birth rate for different HTGRs are collected in Tables 17 and 18. The tritium birth rates are normalized to the thermal megawatt by using each reactor power under a $100 \%$ service factor. The tritium birth rates are the same order of magnitude and range from $2.14 \times 10^{11}$ to $4.28 \times 10^{11} \mathrm{~Bq} / \mathrm{y} / \mathrm{MWt}$. The discrepancy is due to the period of operation and the evaluation conditions. The tritium birth rate of Fort St. Vrain in the first year at $3.10 \times 10^{11} \mathrm{~Bq} / \mathrm{y} / \mathrm{MWt}$ is the largest for an HTGR in the U.S. 

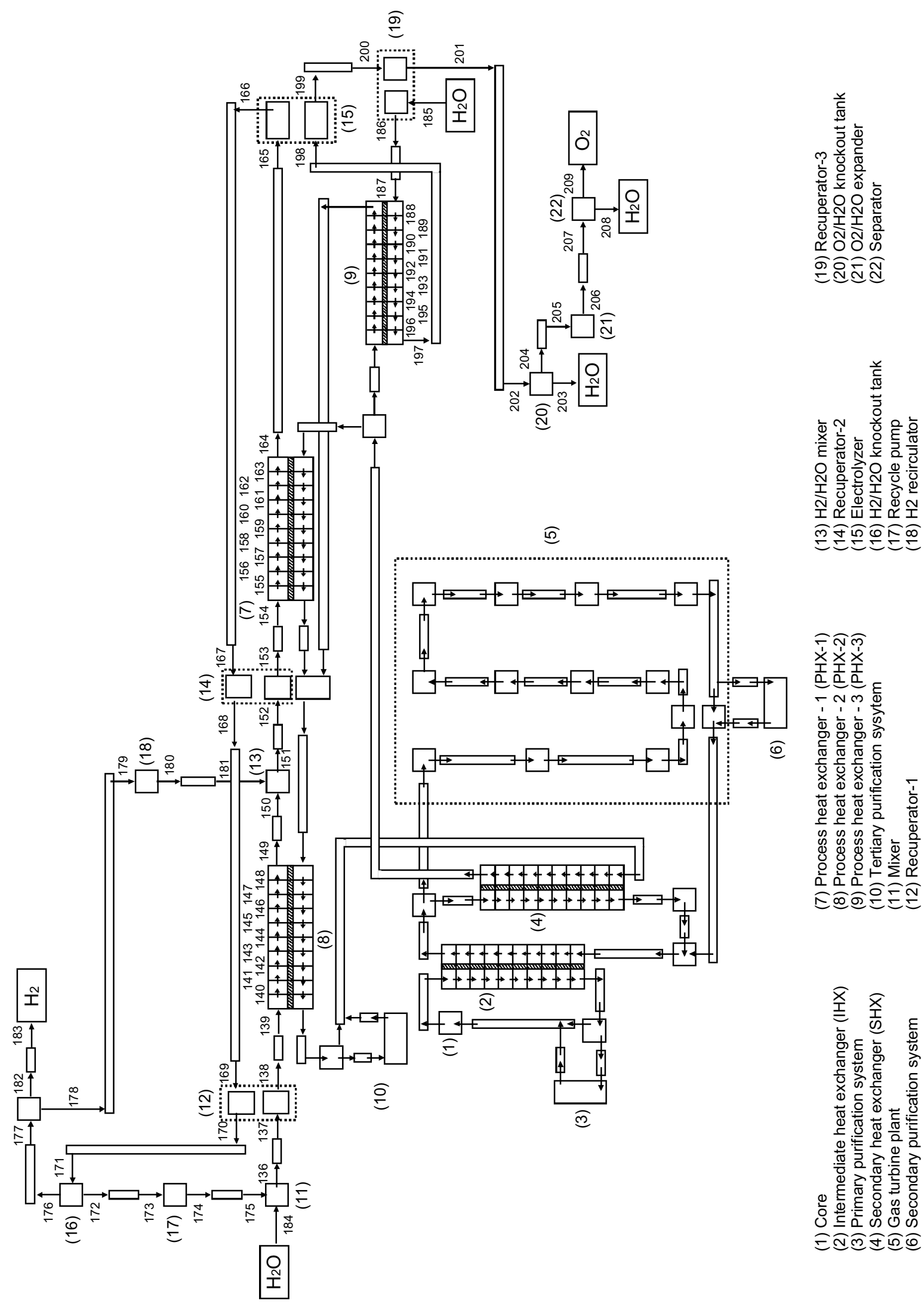

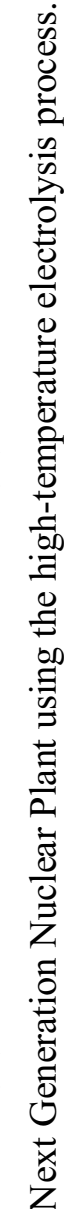

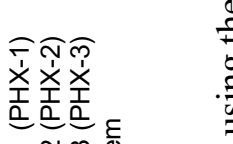

־ N

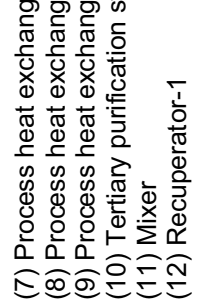

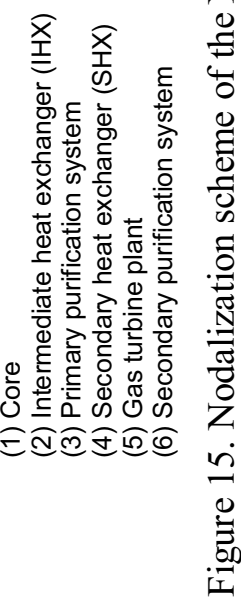




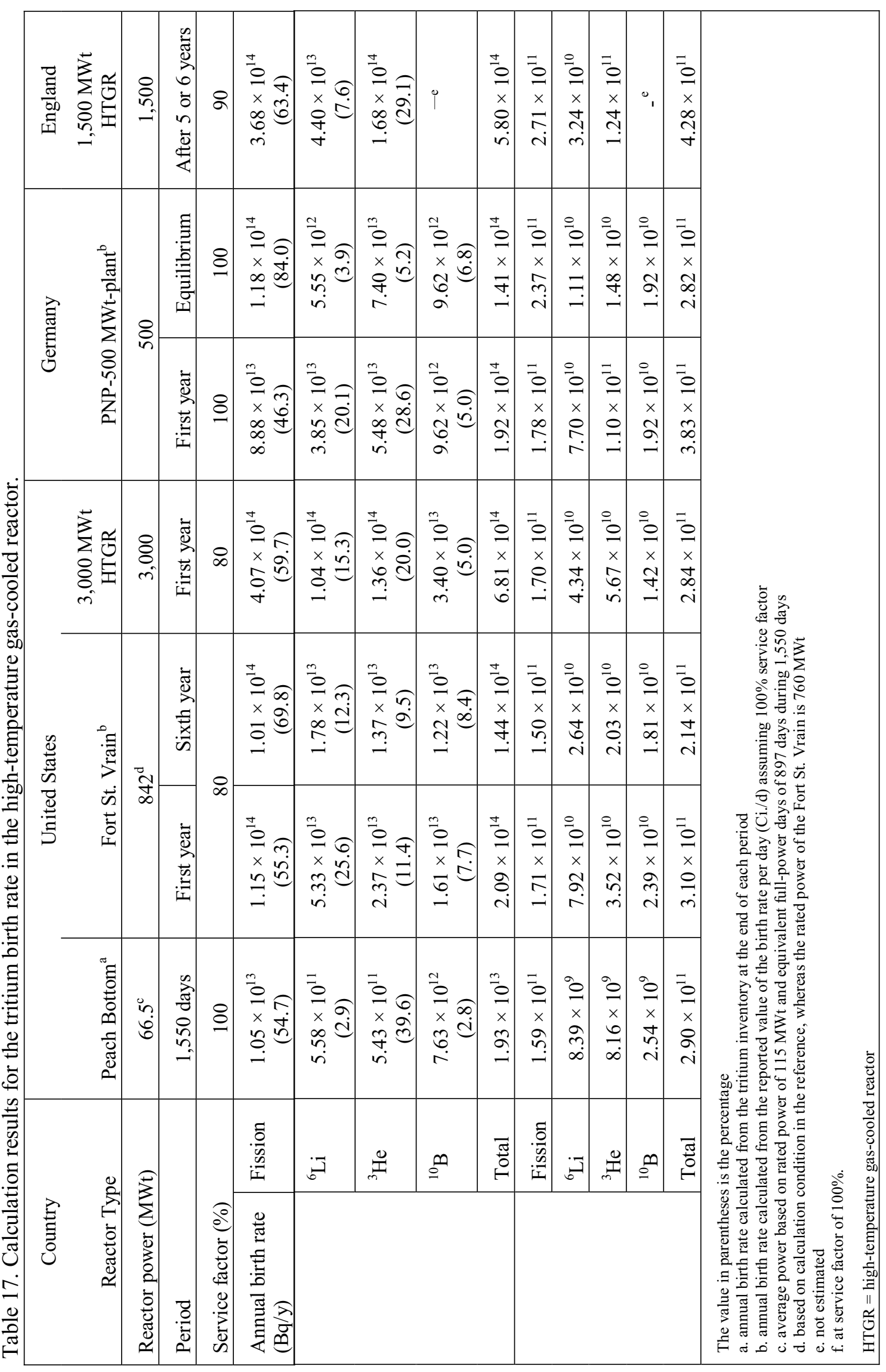




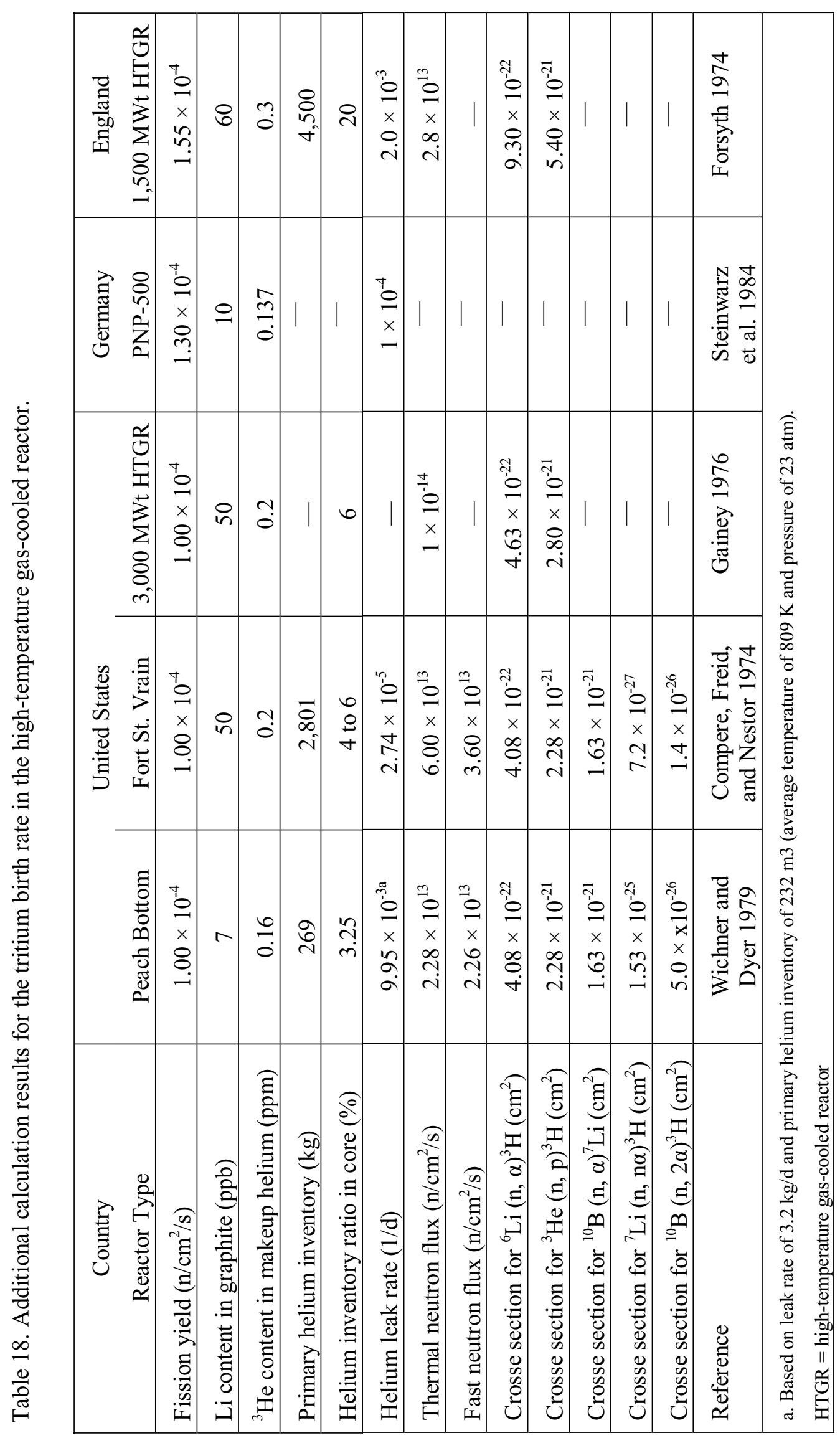


For the release rate of tritium to the primary coolant, operating experience on Dragon (Forsyth 1972) and AVR (Steinwarz, Rohrig, and Nieder 1980) shows that the graphite core retains much of the tritium generated from ${ }^{6} \mathrm{Li}$ and ${ }^{3} \mathrm{He}$. Forsyth (1972) reported that the ability of the core's graphite components to retain tritium depended on their mass and temperature and the hydrogenous impurity content of the coolant. The tritium release rate to the primary coolant from the graphite core in Dragon was about $1 \%$ of the in-graphite generation rate (Forsyth 1972). Investigation of the tritium inventory in the core components of the Peach Bottom HTGR also indicated that the tritium retention capabilities of the fuel elements and the graphite reflector were effective (Wichner and Dyer 1979). The reported tritium release rate for the Peach Bottom HTGR, for an overall release fraction to the primary coolant, was 0.32 during 3 years of operation (Burnette and Baldwin 1980). Therefore, it is known that tritium can be chemisorbed onto graphite at a high temperature. However, the mechanisms holding tritium in graphite are poorly understood. In his review of tritium behavior in the HTGR system, Gainey (1976) concluded that it is not possible to incorporate tritium retention by graphite, or control material, into a model calculation. Additionally, he mentioned that calculations of tritium release to the primary coolant would be conservatively high due to neglecting this phenomenon (Gainey 1976). Because of the difficulty and uncertainties in the material data, Steinwarz et al. (1984) also conservatively neglected the sorption of tritium into the graphite components in their design calculation of the PNP-500 MWt-plant in Germany.

Tritium generated by ternary fission in fuel is retained effectively by a TRISO (fuel contained within three ceramic coating layers) coating system, the buffer, inner pyrolytic carbon, silicon carbide, and outer pyrolytic carbon. However, the core will include regions that operate at temperatures greater than $1,000^{\circ} \mathrm{C}$ for significant periods of time. The fractional tritium release is expected to be about 0.2 if fuel is maintained at $1,300^{\circ} \mathrm{C}$ for 100 days (Richards et al. 2006).

For this study, the tritium release rate of NGNP is assumed to be the tritium birth rate for the Fort St. Vrain (i.e., $3.10 \times 10^{11} \mathrm{~Bq} / \mathrm{y} / \mathrm{MWt}$ ) by conservatively neglecting tritium retained by the graphite core and the TRISO coating system. The tritium release rate to the primary coolant in NGNP (600 MWt) is given by $1.86 \times 10^{14} \mathrm{~Bq} / \mathrm{y}\left(3.10 \times 10^{11} \times 600\right)$.

\subsubsection{Heat Exchanger}

Heat transfer tube permeability. One of the candidate materials for IHX and SHX of NGNP is Inconel 617. No data is available about permeability through Inconel 617. Therefore, permeability of Incoloy 800 is applied to the heat exchangers of NGNP with the HTE process, including PHX. The tritium permeation rate of the superheater of the Peach Bottom HTGR, Incoloy 800, was reported by Yang, Baugh, and Baldwin (1977). Permeability is evaluated in Section 5.2 of this report. The

pre-exponential factor of permeability, $K_{o}$, and activation energy, $E$, of the as-received Incoloy 800 that were evaluated using Equation (25) are found using the following equations:

$$
\begin{aligned}
& K_{o}=1.36 \times 10^{-10}\left(\mathrm{~m}^{3}(\mathrm{STP}) / \mathrm{m} / \mathrm{s} / \mathrm{Pa}^{0.5}\right) \\
& E=53.5 \times 10^{3}(\mathrm{~J} / \mathrm{mol})
\end{aligned}
$$

The tritium permeation rate of the superheater, evaporator, and economizer was measured after removal of surface films formed on the helium-coolant side during reactor operation, and after removal of surface films on both the helium-coolant side and the steam side. Removal of the surface film on the helium-coolant side of the economizer tube had no effect on the tritium permeation rate. However, removal of surface film on the helium-coolant side of the superheater and evaporator tubes lowered the tritium permeation rate. It was concluded that removal of these films allowed for formation of a protective layer having a lower tritium permeation rate by a reaction between the impurities in the tritium source and Incoloy 800 or silicon-low-carbon steel. On the other hand, the tritium permeation rates for 
the superheater, evaporator, and economizer were increased by removing surface film on the steam side by factors of 10, 15, and 6, respectively. However, for the superheater, the tritium permeation rate of the as-received tube is the largest measured for the Incoloy 800 tubes due to the decreasing permeation rate caused by the removal of surface film on the helium-coolant side. The actual tritium permeation rate of Incoloy 800 without surface film formed by steam seems uncertain. However, the permeation rate might be about 10 times larger than that of the as-received tube from these experimental results.

The tritium permeation rate of Incoloy 800 was also described by Richards et al. (2006) when calculating the permeation rate at the IHX as follows:

$$
\text { Flux }=61.02 \cdot C_{t} \sqrt{\frac{P_{a t m}}{C_{H 2}}} \cdot \frac{\exp (-6250 / T)}{t_{m m}}\left[\mu \mathrm{Ci} / \mathrm{m}^{2} / \mathrm{h}\right]
$$

where

$$
\begin{aligned}
& C_{t}=\begin{array}{r}
\text { tritium concentration on the primary coolant, referenced to standard temperature and } \\
\text { pressure }\left(\mu \mathrm{Ci} / \mathrm{m}^{3}\right)
\end{array} \\
& P_{\text {atm }}=\text { total primary-side pressure (atm) } \\
& C_{H 2}=\text { hydrogen impurity concentration in the primary coolant }(\mathrm{ppmv}) \\
& T \quad=\text { IHX wall temperature }(\mathrm{K}) \\
& t_{m m}=\text { IHX wall thickness }(\mathrm{mm}) .
\end{aligned}
$$

It also can be rewritten as the following:

$$
\text { Flux }=5.326 \times 10^{-11} \cdot \frac{P_{t}}{\sqrt{P_{H 2}}} \cdot \frac{\exp \left(-51.94 \times 10^{3} / R / T\right)}{t_{m}}\left[\mathrm{~m}^{3}(\mathrm{STP}) / \mathrm{m} / \mathrm{s} / \mathrm{Pa}^{0.5}\right]
$$

where

$$
\begin{aligned}
& P_{t}=\text { partial pressure of tritium in the primary coolant }(\mathrm{Pa}) \\
& P_{H 2}=\text { partial pressure of hydrogen in the primary coolant }(\mathrm{Pa}) \\
& t_{m} \quad=\text { IHX wall thickness }(\mathrm{m}) .
\end{aligned}
$$

In this result, pre-exponential factors of permeability and activation energy are as follows:

$$
\begin{aligned}
& K_{o}=5.326 \times 10^{-11}\left(\mathrm{~m}^{3}(\mathrm{STP}) / \mathrm{m} / \mathrm{s} / \mathrm{Pa}^{0.5}\right) \\
& E=51.94 \times 10^{3}(\mathrm{~J} / \mathrm{mol}) .
\end{aligned}
$$

Both permeabilities are plotted in Figure 16. The tritium permeation rate reported by Richards et al. (2006) is less than that of the as-received superheater tube of the Peach Bottom HTGR by a factor of about 0.5 . Permeability reported by Richards et al. (2006) includes the effect of surface film formed by steam. 


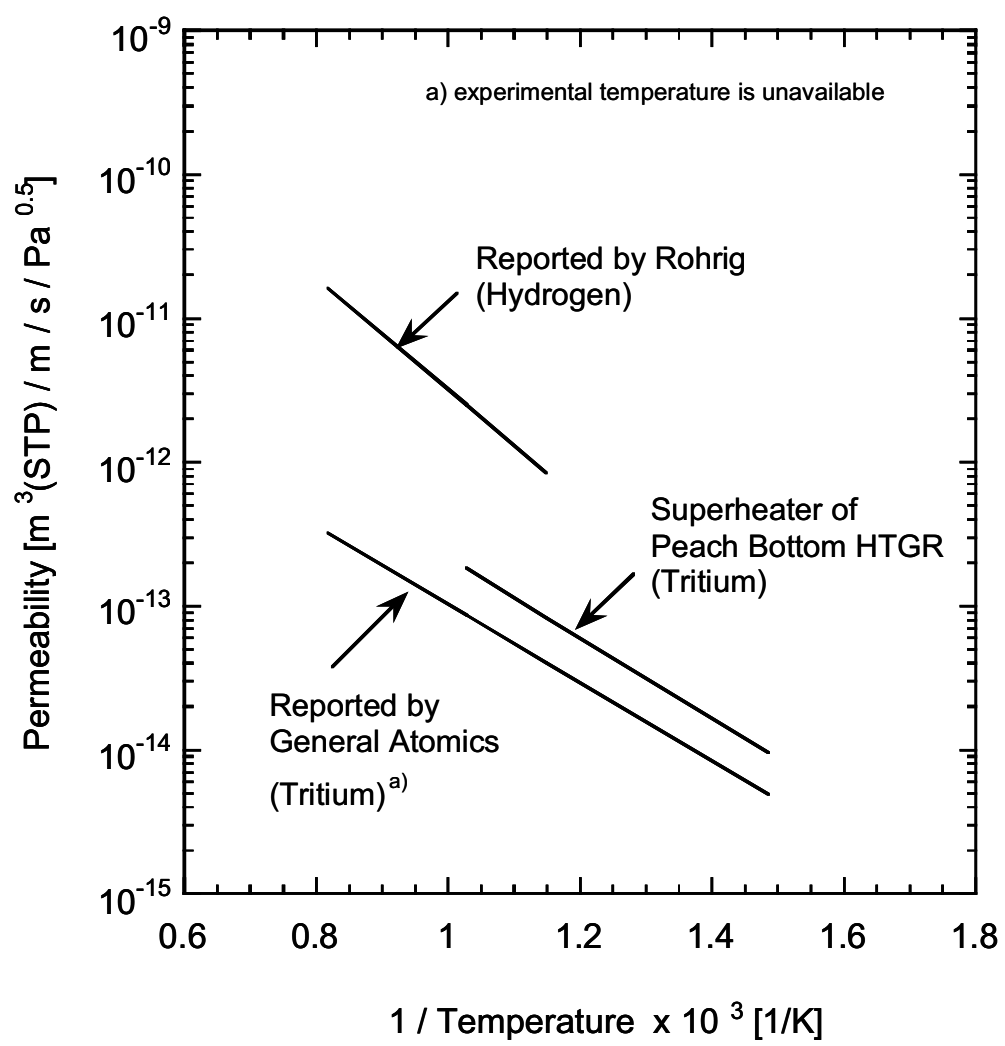

Figure 16. Permeability of Incoloy 800.

Röhrig et al. (1975) reported a hydrogen permeability for Incoloy 800 from 873 to 1,223 K and hydrogen partial pressures from 50 and $5 \times 10^{4} \mathrm{~Pa}$. The pre-exponential factor of permeability and activation energy was reported as the following:

$K_{o}=7.44 \times 10^{-2}\left(\mathrm{~cm}^{3}(\mathrm{STP}) / \mathrm{cm} / \mathrm{s} / \mathrm{bar}^{0.5}\right)$,

$E=17.7(\mathrm{kcal} / \mathrm{mol})$

It also can be rewritten as the following:

$K_{o}=2.35 \times 10^{-8}\left(\mathrm{~m}^{3}(\mathrm{STP}) / \mathrm{m} / \mathrm{s} / \mathrm{Pa}^{0.5}\right)$

$E=74.0 \times 10^{3}(\mathrm{~J} / \mathrm{mol})$

Gainey (1976) compared this value with an experimental result for hydrogen permeation of Incoloy 800 that was measured by Yang, Baugh, and Baldwin (1977) over a range of 700 to $1,000 \mathrm{~K}$ and hydrogen pressures from 47 to $1 \times 10^{5} \mathrm{~Pa}$ (Gainey 1976). It was confirmed that good agreement is observed at a hydrogen pressure below $133 \mathrm{~Pa}$. Hydrogen permeability calculated by Equations (77) and (78) is also shown in Figure 15. The ratio of the square root of tritium molecular weight to that of hydrogen is $1.73(\sqrt{3 / 1})$. Hydrogen permeability reported by Röhrig et al. (1975) is larger than tritium permeability of the as-received superheater tube of the Peach Bottom by a factor of 10.2 and 13.7 at 873 and $973 \mathrm{~K}$, respectively. These results imply that tritium permeability, without surface films formed by steam, might be higher than that of the as-received superheater tube of the Peach Bottom. 
Hydrogen permeability of Incoloy 800 reported by Röhrig et al. (1975) is employed for the hydrogen permeability of IHX and SHX, which are used in the circumstance without steam. Tritium permeability of IHX and SHX is defined as $\sqrt{3}$ times smaller than hydrogen permeability. Because three PHXs will be used under the steam circumstance (similar to the steam generator of the Peach Bottom HTGR), tritium permeability of the as-received Incoloy 800 of the Peach Bottom is directly applied to tritium permeability of PHX. Hydrogen permeability of PHX is calculated as $\sqrt{3}$ times larger than tritium permeability. The values of permeability used in this study are summarized in Table 19.

Table 19. Boundary conditions for heat transfer tube permeability in the Next Generation Nuclear Plant using the high-temperature electrolysis process.

\begin{tabular}{|c|c|c|c|}
\hline \multirow[b]{2}{*}{ Heat Exchanger Type } & \multicolumn{2}{|c|}{$\begin{array}{l}\text { Pre-exponential Factor of Permeability } \\
\qquad\left(\mathrm{m}^{3}(\mathrm{STP}) / \mathrm{m} / \mathrm{s} / \mathrm{Pa}^{0.5}\right)\end{array}$} & \multirow{2}{*}{$\begin{array}{l}\text { Activation Energy } \\
(\mathrm{J} / \mathrm{mol})\end{array}$} \\
\hline & Tritium & Hydrogen & \\
\hline $\begin{array}{l}\text { IHX } \\
\text { (intermediate heat exchanger) }\end{array}$ & $1.36 \times 10^{-8 a}$ & $2.35 \times 10^{-8 b}$ & $74.0 \times 10^{3 b}$ \\
\hline $\begin{array}{l}\text { SHX } \\
\text { (secondary heat exchanger) }\end{array}$ & $1.36 \times 10^{-8 a}$ & $2.35 \times 10^{-8 b}$ & $74.0 \times 10^{3 b}$ \\
\hline $\begin{array}{l}\text { PHX } \\
\text { (process heat exchanger) }\end{array}$ & $1.36 \times 10^{-10 \mathrm{c}}$ & $2.36 \times 10^{-10 \mathrm{~d}}$ & $53.5 \times 10^{3 c}$ \\
\hline \multicolumn{4}{|c|}{$\begin{array}{l}\text { a. } \sqrt{3} \text { times smaller than hydrogen permeability. } \\
\text { b. Reported experimental data (Röhrig et al. 1976). } \\
\text { c. Experimental data for the as-received superheater tube of the Peach Bottom HTGR (Yang, Baugh, and Baldwin 1977). } \\
\text { d. } \sqrt{3} \text { times larger than tritium permeability. }\end{array}$} \\
\hline
\end{tabular}

Heat transfer tube heat transfer area, thickness, and temperature. The tentative value of the heat transfer area, thickness, and temperature for the heat transfer tubes in NGNP using the HTE process are summarized in Table 20. Metal temperature is calculated as the average value of gas temperature between a high-temperature and a low-temperature side, and the values used in this study are given in Table 20.

\begin{tabular}{|l|c|c|c|c|}
\hline $\begin{array}{c}\text { Table 20. Boundary conditions } \\
\text { for the heat transfer tube in the } \\
\text { Next Generation Nuclear Plant } \\
\text { using the high-temperature } \\
\text { electrolysis process.Type }\end{array}$ & $\begin{array}{c}\text { Heat Transfer Area } \\
\left(\mathrm{m}^{2}\right)\end{array}$ & $\begin{array}{c}\text { Thickness } \\
(\mathrm{mm})\end{array}$ & Inlet $^{\mathrm{a}}$ & Outlet $^{\mathrm{a}}$ \\
\hline Intermediate heat exchanger & 50390 & 0.96 & 1,166 & 761 \\
\hline Secondary heat exchanger & 1,924 & 2.82 & 1,148 & 826 \\
\hline Process heat exchanger-1 & 1,287 & 0.90 & 1,119 & 621 \\
\hline Process heat exchanger -2 & 34 & 0.90 & 647 & 635 \\
\hline Process heat exchanger -3 & 2,161 & 0.90 & 1,119 & 801 \\
\hline a. Flow direction of gas on high-temperature side. & & & \\
\hline
\end{tabular}




\subsubsection{Purification System}

The purification system's helium flow rate should be designed by considering its ratio with the total helium inventory flow rate in the stream being treated. The purification rate (i.e., ratio of helium flow rate in purification system to the helium inventory) for the Peach Bottom HTGR and Fort St. Vrain were about $20 \% / \mathrm{h}$ and $12 \% / \mathrm{h}$, respectively. However, information for the primary helium inventory of NGNP is not available. Therefore, the primary helium inventory of NGNP was evaluated using the Peach Bottom HTGR and Fort St. Vrain. The primary helium inventory for the Peach Bottom HTGR and Fort St. Vrain are listed in Table 21. The primary helium inventory per thermal megawatt for both HTGRs is almost same (i.e., 3.96 and $3.69 \mathrm{~kg} / \mathrm{MWt}$, respectively). The primary helium inventory of NGNP, $600 \mathrm{MWt}$, is assumed to be $2,293 \mathrm{~kg}$ using the average value of $3.82 \mathrm{~kg} / \mathrm{MWt}$. The latest design value of the purification rate of $12 \% / \mathrm{h}$ and the assumed primary helium inventory of 2,293 $\mathrm{kg}$ yields the helium flow rate for the purification system at $275 \mathrm{~kg} / \mathrm{h}$. These numbers are used to define the base case for the purification system's helium flow rate in the primary loop.

Table 21. Helium inventory of the Peach Bottom high-temperature gas-cooled reactor and Fort St. Vrain.

\begin{tabular}{|l|c|c|c|}
\hline \multicolumn{1}{|c|}{ Reactor Type } & $\begin{array}{c}\text { Reactor Power } \\
(\mathrm{MWt})\end{array}$ & $\begin{array}{c}\text { Primary Helium Inventory } \\
(\mathrm{kg})\end{array}$ & $\begin{array}{c}\text { Helium Inventory per } \\
\text { Thermal Megawatt } \\
(\mathrm{kg} / \mathrm{MWt})\end{array}$ \\
\hline Peach Bottom & 115 & $455^{\mathrm{a}}$ & 3.96 \\
\hline Fort St. Vrain & 760 & $2,801^{\mathrm{b}}$ & 3.69 \\
\hline $\begin{array}{l}\text { a. Calculated using purification rate of } 20 \% / \mathrm{h} \text { and the helium flow rate of } 91 \mathrm{~kg} / \mathrm{h} \text { at chemical cleanup system. } \\
\text { b. Based on } 6.17 \times 10^{3} \mathrm{lb} \text {. }\end{array}$ \\
\hline
\end{tabular}

It is difficult to estimate the helium inventory for the secondary and the ternary loops without having actual design data. Therefore, a helium flow rate of $275 \mathrm{~kg} / \mathrm{h}$ is also used as a base case for the purification system in the secondary and ternary loops. The tritium removal efficiency by the purification system in each loop is assumed to be 1.0 .

\subsubsection{Helium Leak Rate and Inventory}

The HTGRs' helium leak rates from the primary loop to outside are summarized in Table 17. The measured leak rate of the Peach Bottom HTGR (i.e., $9.95 \times 10^{-3} / \mathrm{d}$ ) and the assumed primary helium inventory of 2,293 kg are used for NGNP to evaluate tritium leak from the primary loop to outside with helium leakage. The leak rate of $9.95 \times 10^{-3} / \mathrm{d}$ is also used for the secondary and the ternary loop. It is possible for the inventory of the tertiary loop to be much larger than the inventory for the primary and secondary loops due to the long length of the tertiary loop (10's to 100's of meters). However, for the purposes of this study, the inventory of the tertiary and secondary loops is assumed to be the same value as that of the primary loop due to lack of design data.

\subsubsection{Helium Coolant} Table 16

Helium boundary conditions (i.e., temperature, flow rate, and pressure) are based on the values in

\subsubsection{High-Temperature Electrolysis Process}

Flow rate boundary conditions for each link in the HTE process are listed in Table 22. The temperature and pressure of each component in the HTE process are listed in Table 23. 
Table 22. Boundary condition of flow rate in each link in high-temperature electrolysis process.

\begin{tabular}{|c|c|c|c|c|}
\hline \multirow[b]{2}{*}{ Line } & \multirow[b]{2}{*}{ Link } & \multicolumn{3}{|c|}{$\begin{array}{c}\text { Flow Rate } \\
(\mathrm{mol} / \mathrm{s})\end{array}$} \\
\hline & & $\mathrm{H}_{2} \mathrm{O}$ & $\mathrm{H}_{2}$ & $\mathrm{O}_{2}$ \\
\hline \multirow[t]{37}{*}{ Main } & 136 & $1,049.108$ & 0.006 & 0 \\
\hline & 137 & $1,049.108$ & 0.006 & 0 \\
\hline & 138 & $1,049.108$ & 0.006 & 0 \\
\hline & 139 & $1,049.108$ & 0.006 & 0 \\
\hline & 140 & $1,049.108$ & 0.006 & 0 \\
\hline & 141 & $1,049.108$ & 0.006 & 0 \\
\hline & 142 & $1,049.108$ & 0.006 & 0 \\
\hline & 143 & $1,049.108$ & 0.006 & 0 \\
\hline & 144 & $1,049.108$ & 0.006 & 0 \\
\hline & 145 & $1,049.108$ & 0.006 & 0 \\
\hline & 146 & $1,049.108$ & 0.006 & 0 \\
\hline & 147 & $1,049.108$ & 0.006 & 0 \\
\hline & 148 & $1,049.108$ & 0.006 & 0 \\
\hline & 149 & $1,049.108$ & 0.006 & 0 \\
\hline & 150 & $1,049.108$ & 0.006 & 0 \\
\hline & 151 & $1,049.385$ & 116.598 & 0 \\
\hline & 152 & $1,049.385$ & 116.598 & 0 \\
\hline & 153 & $1,049.385$ & 116.598 & 0 \\
\hline & 154 & $1,049.385$ & 116.598 & 0 \\
\hline & 155 & $1,049.385$ & 116.598 & 0 \\
\hline & 156 & $1,049.385$ & 116.598 & 0 \\
\hline & 157 & $1,049.385$ & 116.598 & 0 \\
\hline & 158 & $1,049.385$ & 116.598 & 0 \\
\hline & 159 & $1,049.385$ & 116.598 & 0 \\
\hline & 160 & $1,049.385$ & 116.598 & 0 \\
\hline & 161 & $1,049.385$ & 116.598 & 0 \\
\hline & 162 & $1,049.385$ & 116.598 & 0 \\
\hline & 163 & $1,049.385$ & 116.598 & 0 \\
\hline & 164 & $1,049.385$ & 116.598 & 0 \\
\hline & 165 & $1,049.385$ & 116.598 & 0 \\
\hline & 166 & 116.605 & $1,049.448$ & 0 \\
\hline & 167 & 116.605 & $1,049.448$ & 0 \\
\hline & 168 & 116.605 & $1,049.448$ & 0 \\
\hline & 169 & 116.605 & $1,049.448$ & 0 \\
\hline & 170 & 116.605 & $1,049.448$ & 0 \\
\hline & 171 & 116.605 & $1,049.448$ & 0 \\
\hline & 172 & 115.679 & 0.006 & 0 \\
\hline
\end{tabular}


Table 21. (continued).

\begin{tabular}{|c|c|c|c|c|}
\hline \multirow{3}{*}{ Line } & \multirow[b]{2}{*}{ Link } & \multicolumn{3}{|c|}{$\begin{array}{c}\text { Flow Rate } \\
(\mathrm{mol} / \mathrm{s})\end{array}$} \\
\hline & & $\mathrm{H}_{2} \mathrm{O}$ & $\mathrm{H}_{2}$ & $\mathrm{O}_{2}$ \\
\hline & 173 & 115.679 & 0.006 & 0 \\
\hline \multirow[t]{11}{*}{ Main } & 174 & 115.679 & 0.006 & 0 \\
\hline & 175 & 115.679 & 0.006 & 0 \\
\hline & 176 & 0.935 & $1,049.369$ & 0 \\
\hline & 177 & 0.935 & $1,049.369$ & 0 \\
\hline & 178 & 0.104 & 116.602 & 0 \\
\hline & 179 & 0.104 & 116.602 & 0 \\
\hline & 180 & 0.104 & 116.602 & 0 \\
\hline & 181 & 0.104 & 116.602 & 0 \\
\hline & 182 & 0.831 & 932.717 & 0 \\
\hline & 183 & 0.831 & 932.717 & 0 \\
\hline & 184 & 933.651 & 0 & 0 \\
\hline \multirow[t]{26}{*}{ Sweep } & 185 & 555.084 & 0 & 0 \\
\hline & 186 & 555.084 & 0 & 0 \\
\hline & 187 & 555.084 & 0 & 0 \\
\hline & 188 & 555.084 & 0 & 0 \\
\hline & 189 & 555.084 & 0 & 0 \\
\hline & 190 & 555.084 & 0 & 0 \\
\hline & 191 & 555.084 & 0 & 0 \\
\hline & 192 & 555.084 & 0 & 0 \\
\hline & 193 & 555.084 & 0 & 0 \\
\hline & 194 & 555.084 & 0 & 0 \\
\hline & 195 & 555.084 & 0 & 0 \\
\hline & 196 & 555.084 & 0 & 0 \\
\hline & 197 & 555.084 & 0 & 0 \\
\hline & 198 & 555.084 & 0 & 0 \\
\hline & 199 & 555.004 & 0 & 466.313 \\
\hline & 200 & 555.004 & 0 & 466.313 \\
\hline & 201 & 555.004 & 0 & 466.313 \\
\hline & 202 & 555.004 & 0 & 466.313 \\
\hline & 203 & 213.100 & 0 & 0.373 \\
\hline & 204 & 341.925 & 0 & 465.959 \\
\hline & 205 & 341.925 & 0 & 465.959 \\
\hline & 206 & 341.925 & 0 & 465.959 \\
\hline & 207 & 341.925 & 0 & 465.959 \\
\hline & 208 & 330.273 & 0 & 0.001 \\
\hline & 209 & 11.670 & 0 & 465.948 \\
\hline & 210 & 11.670 & 0 & 465.948 \\
\hline
\end{tabular}


Table 23. Boundary conditions of temperature and pressure in components.

\begin{tabular}{|c|c|c|c|}
\hline Line & Component & Temperature $(\mathrm{K})$ & Pressure (MPa) \\
\hline \multirow{30}{*}{ main } & Mixer & 295.3 & 5.08 \\
\hline & Recuperator-1 (to electrolyzer) & 406.9 & 5.07 \\
\hline & \multirow[t]{10}{*}{ PHX-2 } & 518.6 & 5.06 \\
\hline & & 520.0 & 5.06 \\
\hline & & 521.5 & 5.06 \\
\hline & & 523.0 & 5.05 \\
\hline & & 524.5 & 5.05 \\
\hline & & 526.0 & 5.05 \\
\hline & & 527.5 & 5.05 \\
\hline & & 529.0 & 5.04 \\
\hline & & 530.5 & 5.04 \\
\hline & & 532.0 & 5.04 \\
\hline & $\mathrm{H}_{2} / \mathrm{H}_{2} \mathrm{O}$ mixer & 490.6 & 5.04 \\
\hline & Recuperator-2 (to electrolyzer) & 506.8 & 5.03 \\
\hline & \multirow[t]{10}{*}{ PHX-1 } & 523.0 & 5.02 \\
\hline & & 587.1 & 5.02 \\
\hline & & 651.2 & 5.02 \\
\hline & & 715.3 & 5.01 \\
\hline & & 779.4 & 5.01 \\
\hline & & 843.6 & 5.01 \\
\hline & & 907.7 & 5.01 \\
\hline & & 971.8 & 5.00 \\
\hline & & $1,035.9$ & 5.00 \\
\hline & & $1,100.1$ & 5.00 \\
\hline & Electrolyzer & $1,115.6$ & 5.00 \\
\hline & Recuperator-2 (from electrolyzer) & 922.3 & 4.99 \\
\hline & Recuperator-1 (from electrolyzer) & 506.8 & 4.97 \\
\hline & $\mathrm{H} 2 / \mathrm{H} 2 \mathrm{O}$ knockout tank & 300.3 & 4.96 \\
\hline & Recycle pump & 300.3 & 5.08 \\
\hline & $\mathrm{H} 2$ recirculator & 302.2 & 5.04 \\
\hline \multirow[t]{16}{*}{ sweep } & Recuperator-3 (to electrolyzer) & 505.9 & 5.02 \\
\hline & \multirow[t]{10}{*}{ PHX-3 } & 717.2 & 5.01 \\
\hline & & 759.7 & 5.01 \\
\hline & & 802.2 & 5.01 \\
\hline & & 844.8 & 5.01 \\
\hline & & 887.3 & 5.01 \\
\hline & & 929.9 & 5.00 \\
\hline & & 972.4 & 5.00 \\
\hline & & $1,015.0$ & 5.00 \\
\hline & & $1,057.5$ & 5.00 \\
\hline & & $1,100.1$ & 5.00 \\
\hline & Electrolyzer & $1,115.6$ & 5.00 \\
\hline & Recuperator-3 (from electrolyzer) & 807.1 & 5.00 \\
\hline & $\mathrm{O}_{2} / \mathrm{H}_{2} \mathrm{O}$ knockout tank & 483.1 & 4.99 \\
\hline & $\mathrm{O}_{2} / \mathrm{H}_{2} \mathrm{O}$ expander & 345.1 & 0.10 \\
\hline & Separator & 294.3 & 0.10 \\
\hline
\end{tabular}




\subsection{Calculation Results and Discussion}

Regulatory constraints on the tritium concentration in the hydrogen product are not defined. Therefore, the calculation result for the tritium concentration in product hydrogen is tentatively compared with the existing limit described in Section 3. The strategy of licensing the hydrogen plant as a non-nuclear plant has not been discussed from the viewpoint of radioactive material (i.e., tritium) in the hydrogen plant. Therefore, tritium concentrations in the components of the hydrogen plant also are tentatively compared with the tritium concentration limit in gaseous and liquid effluents at the boundary of an unrestricted area of a nuclear plant. Tertiary helium flows inside of the PHX, which is a part of hydrogen plant. The tritium concentration limit in tertiary helium to avoid regulating the hydrogen plant as a radioactive facility should be discussed in the near future. In order to provide information for this discussion, the tritium concentration in the tertiary helium also is tentatively compared with the gaseous effluent limit at the boundary of an unrestricted area of a nuclear plant.

The design of the NGNP is immature at this stage (i.e., some parameters are not yet determined). Therefore, the effect of these parameters on the tritium concentration is estimated by parametric calculation.

\subsubsection{Base Case}

Tritium distribution. Figure 17 shows the base case calculation result for tritium distribution in the NGNP using the HTE process at steady state. Tritium flow rates are normalized by the tritium release rate to the primary coolant $(1.86 \times 1014 \mathrm{~Bq} / \mathrm{y})$. In the primary helium loop, $30.742 \%$ of the tritium released from the core is removed by the purification system. A small portion of the tritium (i.e., $0.106 \%$ ) leaks to the outside from the primary loop with helium leakage. The remainder of the tritium (i.e., $69.152 \%$ ) permeates into the secondary helium loop through the IHX. For the secondary helium loop, $30.341 \%$ of the tritium (i.e., about half of the permeated tritium from the primary loop) is removed by the purification system. A small portion of tritium (i.e., $0.105 \%$ ) leaks to outside of the coolant.

Consequently, $38.705 \%$ of tritium permeates from the secondary helium loop to the tertiary loop through the SHX. In the tertiary loop, almost all of the tritium permeated from the secondary loop is removed by the purification system. Tritium permeation rates from the tertiary loop to the main line and to the sweep line of the HTE process are $0.946 \%$ and $2.499 \%$, respectively. Note that the amount of tritium permeated to the main line is lower than that permeated to the sweep line because the heat transfer area of PHX-1 is smaller than that of PHX-3 (see Table 20). Hydrogen product is obtained from the main line. The ratio of tritium in they hydrogen product is $0.946 \%$ compared to the tritium release rate to the primary coolant. The dominant form of tritium in product hydrogen is HT. However, product oxygen obtained from the sweep line contains only $0.053 \%$ of tritium because almost all the tritium permeated from the tertiary loop to the sweep line flows out with the drain water as a form of HTO.

Tritium concentration. Tritium concentrations in hydrogen and oxygen products are summarized in Tables 24 and 25, respectively. Tritium concentration in gaseous hydrogen $\left(2.67 \times 10^{-3} \mathrm{~Bq} / \mathrm{cm}^{3}[\mathrm{STP}]\right)$ is slightly less than the gaseous effluent limit $\left(3.7 \times 10^{-3} \mathrm{~Bq} / \mathrm{cm}^{3}[\mathrm{STP}]\right)$. The tritium concentration in liquid hydrogen was calculated using the density of liquid hydrogen (i.e., $0.077 \mathrm{~g} / \mathrm{cm}^{3}$ ). The tritium concentration in liquid hydrogen (i.e., $2.30 \mathrm{~Bq} / \mathrm{ml})$ is also less than the liquid effluent limit $(37 \mathrm{~Bq} / \mathrm{ml})$. However, the concentration is greater than the drinking water limit of $0.74 \mathrm{~Bq} / \mathrm{ml}$, which corresponds to $20,000 \mathrm{pCi} / \mathrm{L}$. 


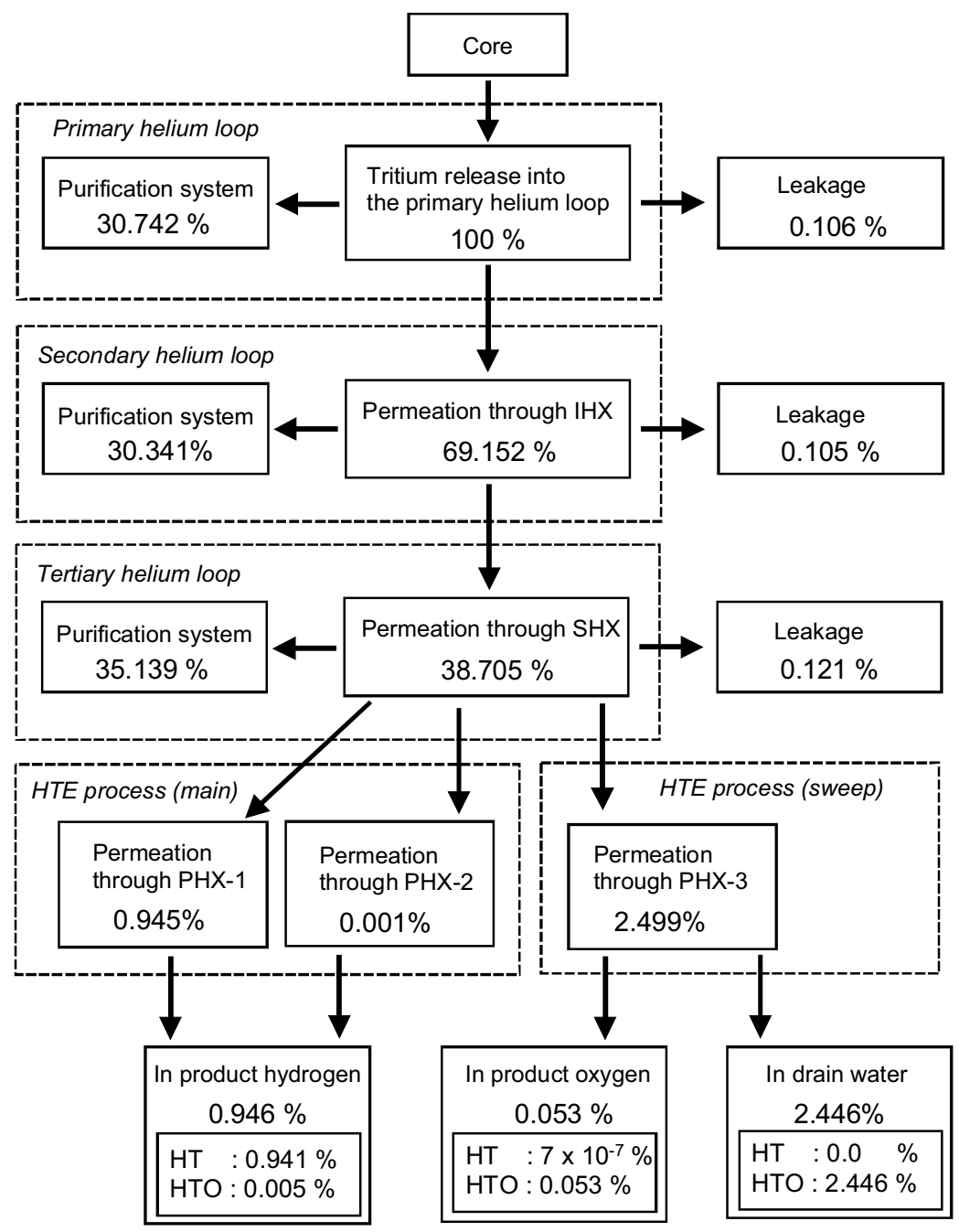

Figure 17. Tritium distributions in the Next Generation Nuclear Plant using the high-temperature electrolysis process.

Table 24. Tritium concentration in the hydrogen product for the base case of the Next Generation Nuclear Plant using the high-temperature electrolysis process.

\begin{tabular}{|c|c|c|c|c|c|c|}
\hline \multicolumn{3}{|c|}{ In Gaseous Hydrogen } & \multicolumn{2}{c|}{ In Liquid Hydrogen } & \multicolumn{2}{c|}{ Weight Base } \\
$(\mathrm{ppb})$ & $\left(\mu \mathrm{Ci} / \mathrm{cm}^{3}[\mathrm{STP}]\right)$ & $\left(\mathrm{Bq} / \mathrm{cm}^{3}[\mathrm{STP}]\right)$ & $\left(\mu \mathrm{Ci} / \mathrm{cm}^{3}\right)$ & $\left(\mathrm{Bq} / \mathrm{cm}^{3}\right)$ & $\left(\mu \mathrm{Ci} / \mathrm{g}-\mathrm{H}_{2}\right)$ & $\left(\mathrm{Bq} / \mathrm{g}-\mathrm{H}_{2}\right)$ \\
\hline $5.55 \times 10^{-5}$ & $7.21 \times 10^{-8}$ & $2.67 \times 10^{-3}$ & $6.22 \times 10^{-5}$ & 2.30 & $8.02 \times 10^{-4}$ & 29.7 \\
\hline
\end{tabular}

Table 25. Tritium concentration in the oxygen for the base case of the Next Generation Nuclear Plant using the high-temperature electrolysis process.

\begin{tabular}{|c|c|c|c|c|c|c|}
\hline \multicolumn{3}{|c|}{ In Gaseous Hydrogen } & \multicolumn{2}{c|}{ In Liquid Hydrogen } & \multicolumn{2}{c|}{ Weight Base } \\
$(\mathrm{ppb})$ & $\left(\mu \mathrm{Ci} / \mathrm{cm}^{3}[\mathrm{STP}]\right)$ & $\left(\mathrm{Bq} / \mathrm{cm}^{3}[\mathrm{STP}]\right)$ & $\left(\mu \mathrm{Ci} / \mathrm{cm}^{3}\right)$ & $\left(\mathrm{Bq} / \mathrm{cm}^{3}\right)$ & $\left(\mu \mathrm{Ci} / \mathrm{g}-\mathrm{O}_{2}\right)$ & $\left(\mathrm{Bq} / \mathrm{g}-\mathrm{O}_{2}\right)$ \\
\hline $6.03 \times 10^{-6}$ & $8.02 \times 10^{-9}$ & $2.97 \times 10^{-4}$ & $6.40 \times 10^{-6}$ & $2.37 \times 10^{-1}$ & $5.62 \times 10^{-6}$ & $2.08 \times 10^{-1}$ \\
\hline
\end{tabular}


Tritium activity concentrations in components of the HTE process are summarized in Table 26. The tritium concentration in gaseous process chemicals in the sweep line of the electrolyzer shows maximum concentration of all of the components $\left(6.44 \times 10^{-3} \mathrm{~Bq} / \mathrm{cm}^{3}[\mathrm{STP}]\right)$, and is larger than the gaseous effluent limit $\left(3.7 \times 10^{-3} \mathrm{~Bq} / \mathrm{cm}^{3}[\mathrm{STP}]\right)$. For the main line, the tritium concentration in the electrolyzer shows maximum value of $4.02 \times 10^{-3} \mathrm{~Bq} / \mathrm{cm}^{3}(\mathrm{STP})$; however, it is slightly lower than that in the sweep line. The tritium concentration in liquid process chemicals in the $\mathrm{H}_{2} / \mathrm{H}_{2} \mathrm{O}$ knockout tank installed in the main line shows a maximum concentration of $\left(20.3 \mathrm{~Bq} / \mathrm{cm}^{3}\right)$, and is lower than the drinking water limit of $37 \mathrm{~Bq} / \mathrm{cm}^{3}$.

Table 26. Tritium concentrations in high-temperature electrolysis process components for the base case of Next Generation Nuclear Plant.

\begin{tabular}{|c|c|c|c|c|}
\hline Line & \multicolumn{2}{|c|}{ Component } & $\begin{array}{c}\text { In Gaseous } \\
\text { Process Chemical } \\
\left(\mathrm{Bq} / \mathrm{cm}^{3}[\mathrm{STP}]\right)\end{array}$ & $\begin{array}{c}\text { In Liquid } \\
\text { Process Chemical } \\
\left(\mathrm{Bq} / \mathrm{cm}^{3}\right)\end{array}$ \\
\hline \multirow[t]{12}{*}{ Main } & \multicolumn{2}{|l|}{ Mixer } & $2.84 \times 10^{-4}$ & 2.24 \\
\hline & \multirow[t]{2}{*}{ Recuperator-1 } & to electrolyzer & $2.84 \times 10^{-4}$ & 2.24 \\
\hline & & from electrolyzer & $3.50 \times 10^{-3}$ & 10.9 \\
\hline & \multicolumn{2}{|l|}{ PHX-2 } & $7.52 \times 10^{-4}$ & 2.24 \\
\hline & \multicolumn{2}{|l|}{$\mathrm{H}_{2} / \mathrm{H}_{2} \mathrm{O}$ mixer } & $7.72 \times 10^{-4}$ & 2.51 \\
\hline & \multirow[t]{2}{*}{ Recuperator-2 } & to electrolyzer & $8.03 \times 10^{-4}$ & 2.50 \\
\hline & & from electrolyzer & $4.02 \times 10^{-3}$ & - \\
\hline & \multicolumn{2}{|l|}{ PHX-1 } & $1.60 \times 10^{-3}$ & 3.22 \\
\hline & \multicolumn{2}{|l|}{ Electrolyzer } & $4.02 \times 10^{-3}$ & - \\
\hline & \multicolumn{2}{|c|}{$\mathrm{H}_{2} / \mathrm{H}_{2} \mathrm{O}$ knockout tank } & $2.66 \times 10^{-3}$ & 20.3 \\
\hline & \multicolumn{2}{|l|}{ Recycle pump } & $2.66 \times 10^{-3}$ & 20.3 \\
\hline & \multicolumn{2}{|l|}{$\mathrm{H}_{2}$ recirculator } & $2.67 \times 10^{-3}$ & - \\
\hline \multirow[t]{6}{*}{ Sweep } & \multicolumn{2}{|l|}{ PHX-3 } & $4.40 \times 10^{-3}$ & - \\
\hline & \multicolumn{2}{|l|}{ Electrolyzer } & $6.44 \times 10^{-3}$ & - \\
\hline & \multicolumn{2}{|c|}{ Recuperator-3 (from electrolyzer) } & $1.44 \times 10^{-8}$ & 14.8 \\
\hline & \multicolumn{2}{|c|}{$\mathrm{O}_{2} / \mathrm{H}_{2} \mathrm{O}$ knockout tank } & $8.77 \times 10^{-9}$ & 14.8 \\
\hline & \multicolumn{2}{|c|}{$\mathrm{O}_{2} / \mathrm{H}_{2} \mathrm{O}$ expander } & $5.02 \times 10^{-3}$ & - \\
\hline & \multicolumn{2}{|l|}{ Separator } & $3.62 \times 10^{-9}$ & 14.8 \\
\hline
\end{tabular}

Tritium concentrations in helium coolants are listed in Table 27. The tritium concentration in the primary coolant is $8.83 \times 10^{-2} \mathrm{ppb}$. The tritium concentration in the secondary coolant (i.e., $8.71 \times 10^{-2} \mathrm{ppb}$ ) is slightly lower than that in the primary coolant. However, the tritium concentration in the tertiary coolant $\left(1.01 \times 10^{-1} \mathrm{ppb}\right)$ is higher than that in both the primary and the secondary coolants. The pressure of the tertiary coolant at about $2 \mathrm{MPa}$ is lower than that of the secondary coolant at about $7 \mathrm{MPa}$. Therefore, partial pressure of tritium in the tertiary coolant is lower than that in the secondary. However, tritium concentration in the tertiary coolant is larger than that of the secondary 
coolant. The tritium concentration in the tertiary helium at $4.85 \mathrm{~Bq} / \mathrm{cm}^{3}$ (STP) is larger than the gaseous effluent limit at $3.7 \times 10^{-3} \mathrm{~Bq} / \mathrm{cm}^{3}(\mathrm{STP})$ by a factor of more than 1,000 .

Table 27. Tritium concentration in helium coolant for the base case of the Next Generation Nuclear Plant using the high-temperature electrolysis process.

\begin{tabular}{|l|c|c|c|}
\hline \multirow{2}{*}{ Coolant } & \multicolumn{3}{|c|}{ Tritium concentration } \\
& $(\mathrm{ppb})$ & $\left(\mu \mathrm{Ci} / \mathrm{cm}^{3}[\mathrm{STP}]\right)$ & $\left(\mathrm{Bq} / \mathrm{cm}^{3}[\mathrm{STP}]\right)$ \\
\hline Primary & $8.83 \times 10^{-2}$ & $1.15 \times 10^{-4}$ & 4.24 \\
\hline Secondary & $8.71 \times 10^{-2}$ & $1.13 \times 10^{-4}$ & 4.18 \\
\hline Tertiary & $1.01 \times 10^{-1}$ & $1.31 \times 10^{-4}$ & 4.85 \\
\hline
\end{tabular}

\subsubsection{Effect of Tritium Release Rate to Primary Coolant}

Tritium concentration in product hydrogen. Figure 18 shows the effect of varying the tritium release rate from the nuclear reactor core on the tritium concentration in product hydrogen. A horizontal axis indicates the ratio of the tritium release rate to that of the base case. The tritium activity concentration in product hydrogen decreases linearly with the tritium release rate to the primary coolant. The tritium activity concentration in product hydrogen is less than the drinking water limit in the case where the tritium release rate is less than 0.3 times the base case release rate.

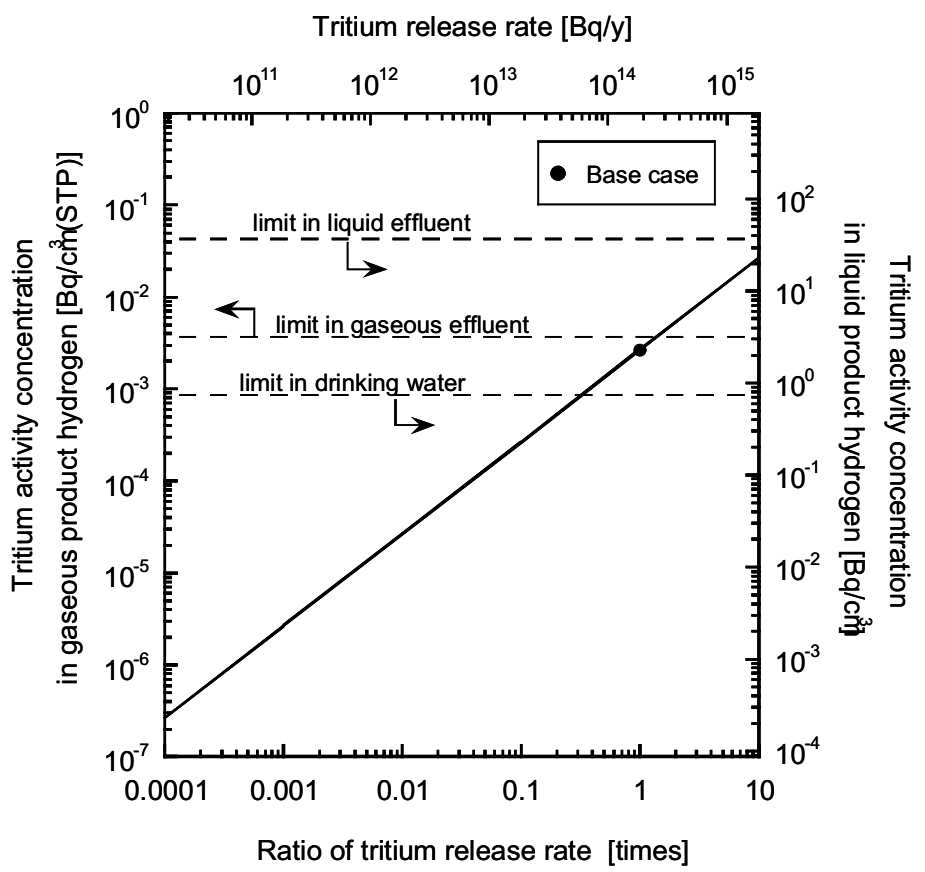

Figure 18. Effect of varying tritium release rate on the tritium concentration in the hydrogen product for the Next Generation Nuclear Plant using the high-temperature electrolysis process.

Tritium concentration in a component of the high-temperature electrolysis process. The tritium activity concentration in the gaseous process chemicals in the electrolyzer shows higher values in HTE components than is released with the product hydrogen. Figure 19 shows the gaseous tritium activity concentration in the electrolyzer, which decreases linearly with a decrease in the the tritium 
release rate. The concentration is less than the gaseous effluent limit when the release rate is less than 0.6 of the base case release limit. The tritium concentration in liquid process chemicals in the $\mathrm{H}_{2} / \mathrm{H}_{2} \mathrm{O}$ knockout tank is the largest of all of the HTE components, and but the concentration of tritium in this component does not exceed the liquid effluent limit unless the release rate exceeds more than 2 times the base case value, as shown in Figure 20.

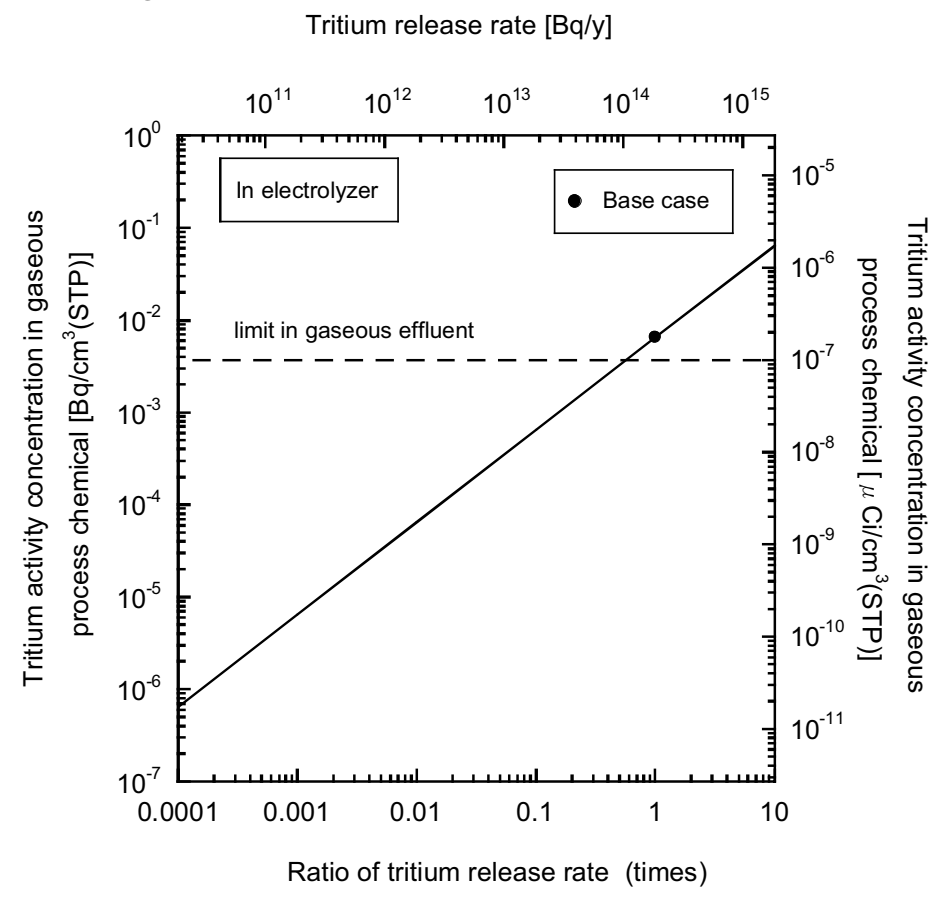

Figure 19. Effect of varying tritium release rate on the tritium concentration in gaseous process chemicals in the electrolyzer for the Next Generation Nuclear Plant using the high-temperature electrolysis process.

Tritium concentration in helium coolant. Figure 21 shows the tritium activity concentration in the primary, secondary and tertiary coolants, respectively, in response to changes in the ratio of the tritium release rate. The tritium concentration in the tertiary coolant is the largest, while that in the secondary coolant is the smallest. All concentrations decrease linearly with a decrease in tritium release rate from the reactor core. The tritium concentration in tertiary helium becomes less than the gaseous effluent limit below about $8 \times 10^{-4}$ times the base case release rate. 


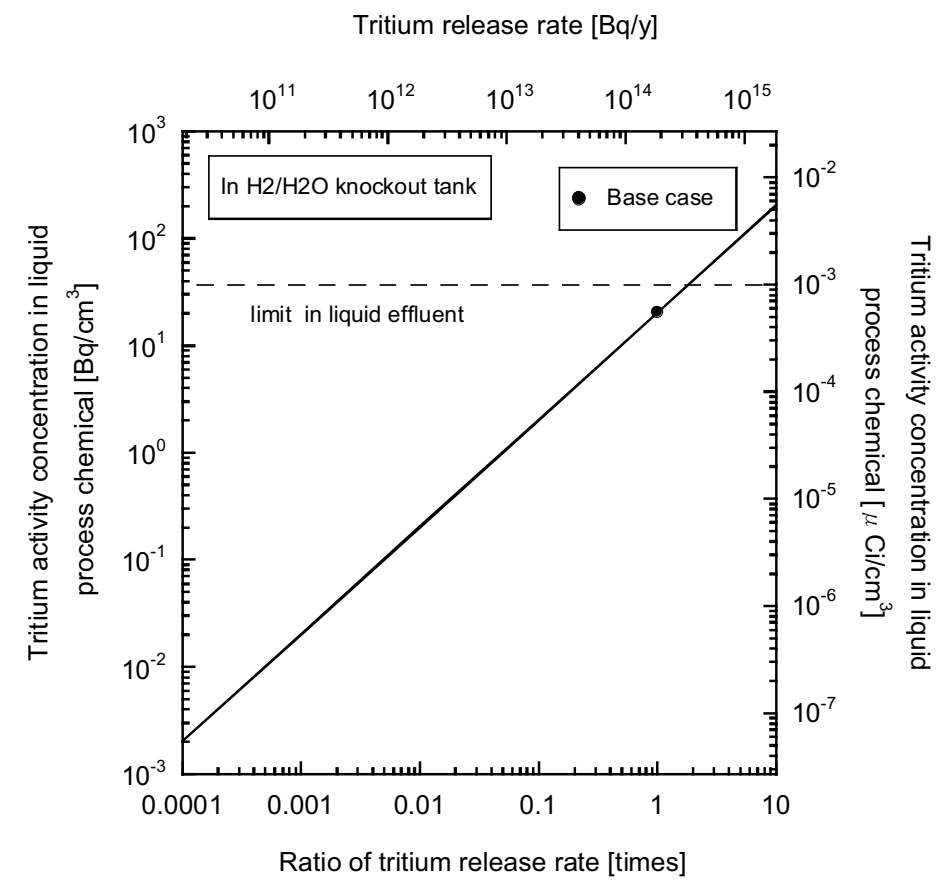

Figure 20. Effect of varying tritium release rate on the tritium concentration in liquid process chemicals in the $\mathrm{H}_{2} / \mathrm{H}_{2} \mathrm{O}$ knockout tank for the Next Generation Nuclear Plant using the high-temperature electrolysis process.

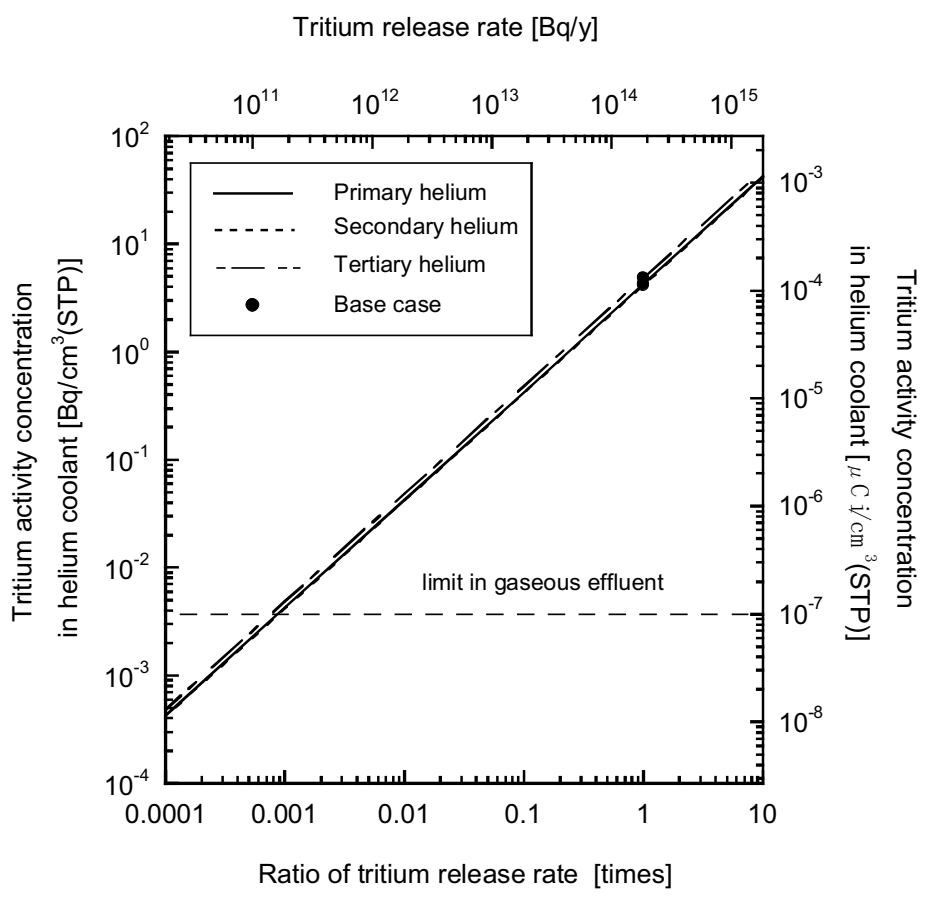

Figure 21. Effect of varying tritium release rate on the tritium concentration in helium coolant for the Next Generation Nuclear Plant using the high-temperature electrolysis process. 


\subsubsection{Effect of Permeability of the Heat Transfer Tube}

Tritium concentration in hydrogen product. Figure 22 shows the effect of varying IHX, SHX, and PHX permeability on the tritium concentration in the hydrogen product. Increasing the IHX permeability above 0.01 times the base case has no effect on the tritium concentration in the hydrogen product. The tritium concentration in the hydrogen product starts to decrease gradually with the decrease of the IHX permeability below about 0.1 times and becomes less than the drinking water limit below about $1 \times 10^{-3}$ times against the base case. The tritium concentration in the hydrogen product decreases with the decrease of the SHX and PHX permeability, even if the permeability values are near the base case values. The heat transfer area per unit heat exchange rate of IHX is about 2.2 times compared with that of SHX. The thickness of the heat transfer tube of the IHX is 0.34 times that of the SHX. The temperature of the heat transfer tubes of the IHX and the SHX are almost the same. Therefore, tritium permeates more easily throug the IHX than the SHX. Figure 23 shows $P_{H T} / \sqrt{P_{H 2}+P_{H T}}$ in the primary and secondary coolants in the IHX and the tritium permeation rate through the IHX. The difference between the value of $P_{H T} / \sqrt{P_{H 2}+P_{H T}}$ between the primary coolant and secondary coolant the driving force for tritium permeation through the IHX. Figure 24 also shows $P_{H T} / \sqrt{P_{H 2}+P_{H T}}$ in the secondary and tertiary coolants in the SHX and the tritium permeation rate through the SHX. The difference of the value of $P_{H T} / \sqrt{P_{H 2}+P_{H T}}$ across the IHX in the base case is extremely small compared with that of the SHX. In the case where there is a small difference in the value of $P_{H T} / \sqrt{P_{H 2}+P_{H T}}$ between the primary and secondary coolants, the driving force for tritium permeation (i.e., difference of $P_{H T} / \sqrt{P_{H 2}+P_{H T}}$ ) increases lineally with the decrease of permeability. Therefore, the permeation rate through IHX is almost constant around the base case.

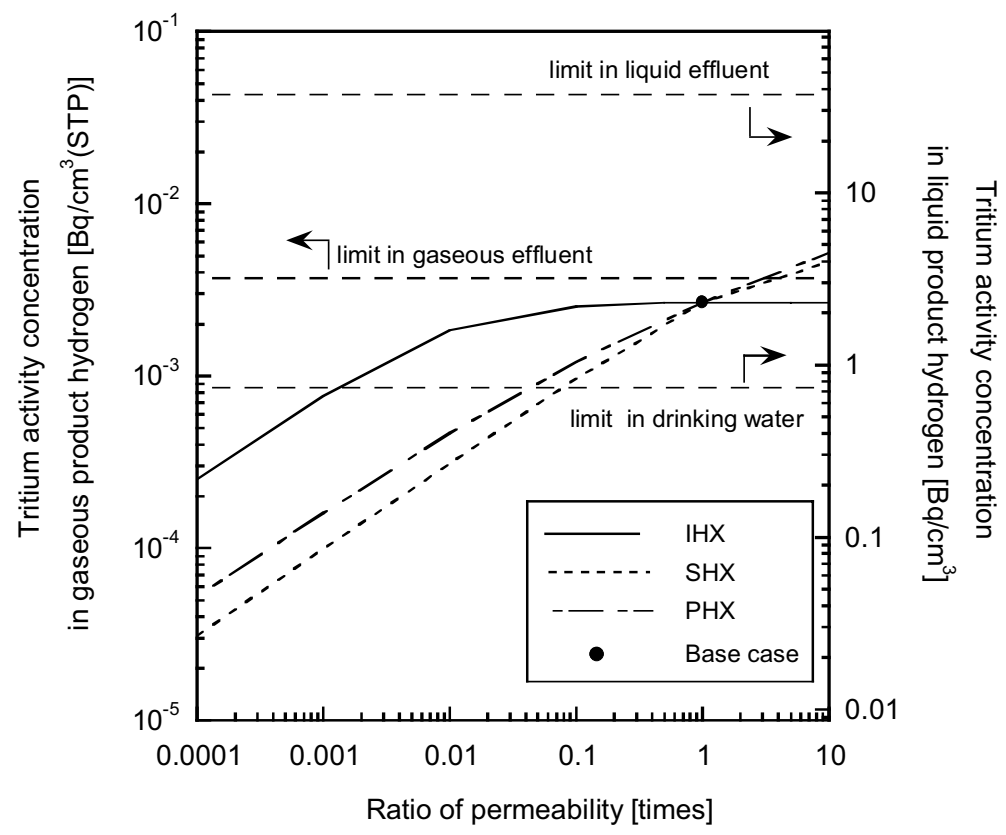

Figure 22. Effect of varying permeability on the tritium concentration in the hydrogen product for the Next Generation Nuclear Plant using the high-temperature electrolysis process. 


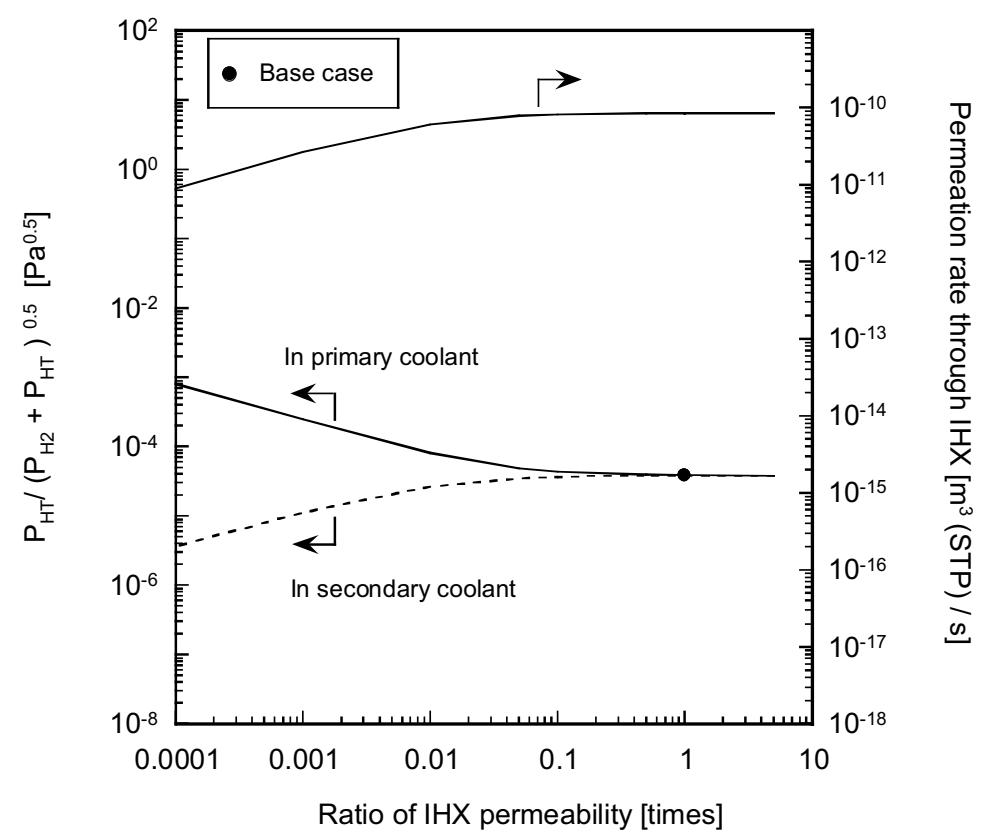

Figure 23. Effect of varying intermediate heat exchanger permeability on tritium permeation rate through the intermediate heat exchanger and the driving force of permeation for the Next Generation Nuclear Plant using the high-temperature electrolysis process.

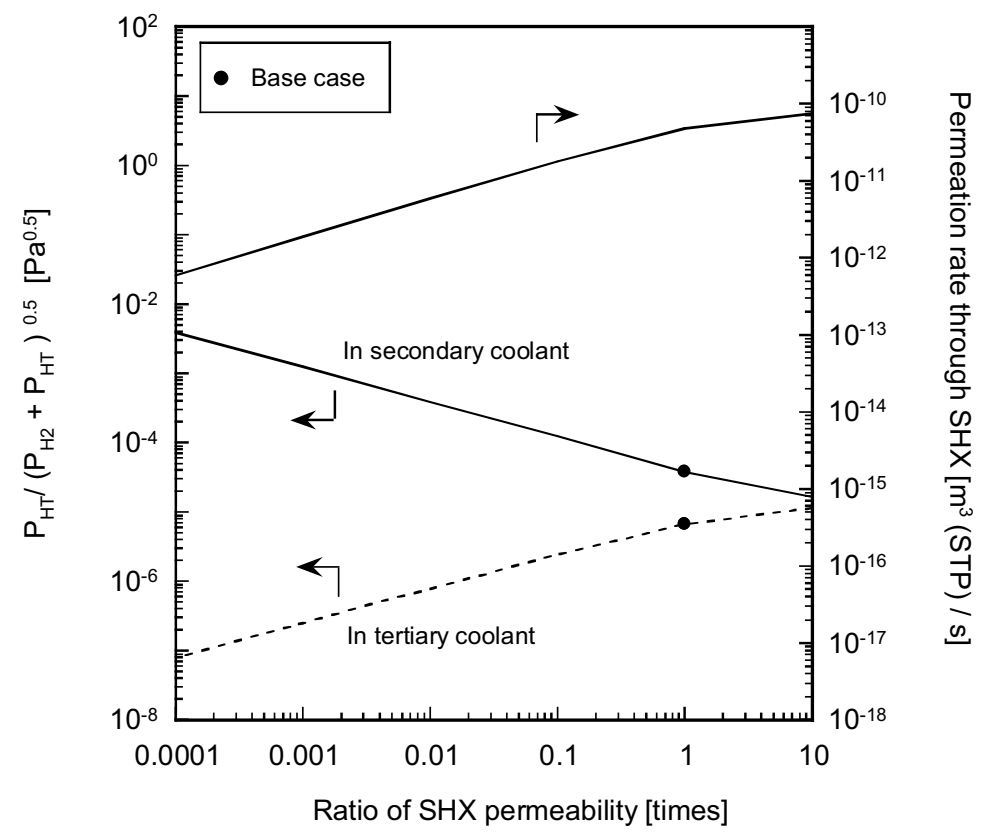

Figure 24. Effect of varying secondary heat exchanger permeability on tritium permeation rate through the secondary heat exchanger and the driving force of permeation for the Next Generation Nuclear Plant using the high-temperature electrolysis process. 
Decreasing SHX permeability is more effective for decreasing the tritium concentration in the product hydrogen compared with decreasing PHX permeability as shown in Figure 22. Tritium concentrations in the product hydrogen become less than the drinking water limit below 0.08 times of SHX and 0.04 times of PHX against the base case.

In order to decrease the tritium concentration in the product hydrogen by a factor of 0.1 from the base case, the permeability of IHX, SHX and PHX must be decreased by a factor of more than about $1 \times 10^{-4}$ times, $7 \times 10^{-3}$ times, and $3 \times 10^{-3}$ times, respectively, the base case permeabilities.

Tritium concentration in a component of the high-temperature electrolysis process.

Figures 25 and 26 show the effect of varying permeability on the tritium activity concentration in gaseous process chemicals in the electrolyzer and in liquid process chemicals in the $\mathrm{H}_{2} / \mathrm{H}_{2} \mathrm{O}$ knockout tank, respectively. The curve profiles in both figures are almost the same as those of the tritium concentration in hydrogen product. The gaseous tritium concentration in the electrolyzer falls below the gaseous effluent limit below about $6 \times 10^{-3}$ times the base case IHX permeability, or below about 0.3 times of SHX base case permeability, or 0.2 times of PHX base case permeability. The tritium concentration in liquid process chemicals of the $\mathrm{H}_{2} / \mathrm{H}_{2} \mathrm{O}$ knockout tank is less than the liquid effluent limit, even for the base case. The tritium concentration exceeds the liquid effluent limit in the case at about 10 times the SHX base case permeability or about 8 times the PHX base case permeability. However, the tritium concentration in liquid process chemicals in the $\mathrm{H}_{2} / \mathrm{H}_{2} \mathrm{O}$ knockout tank is less than the limit regardless of the value of the IHX permeability if the SHX and PHX permeabilities are not varied from the base case.

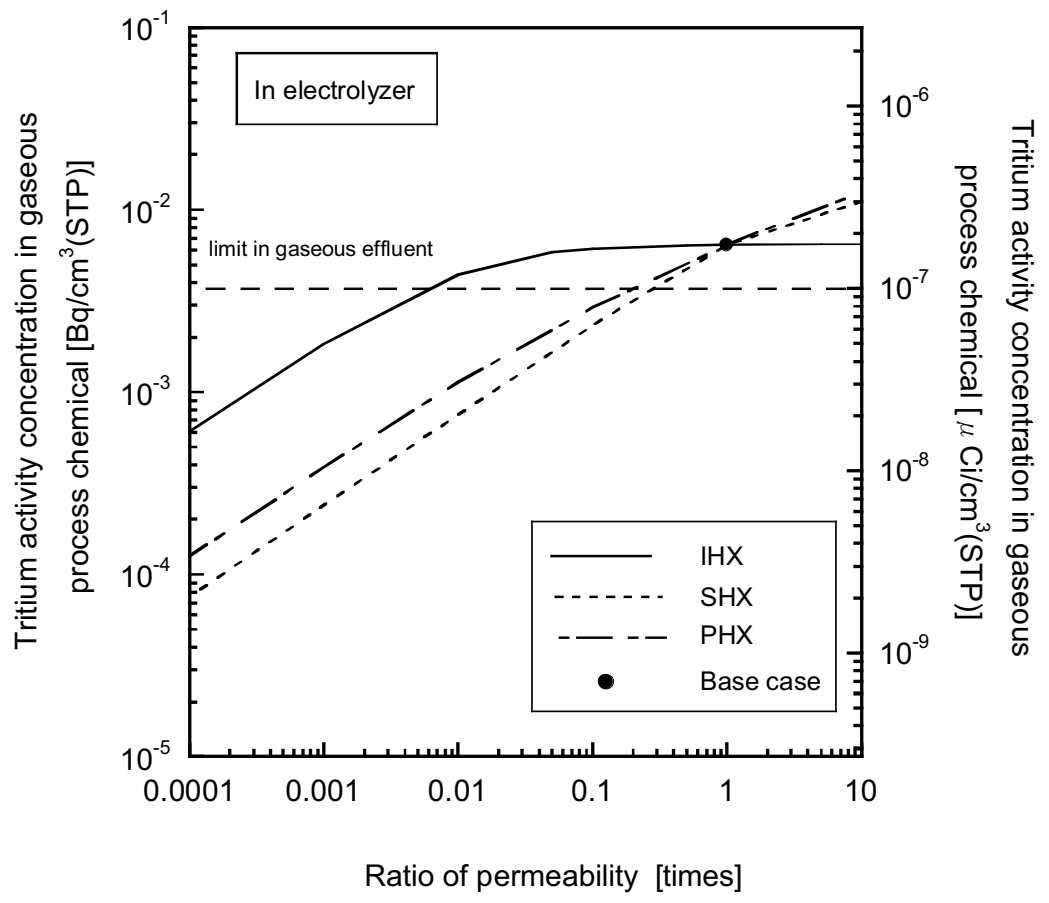

Figure 25. Effect of varying permeability on the tritium concentration in gaseous process chemicals in the electrolyzer for the Next Generation Nuclear Plant using the high-temperature electrolysis process. 


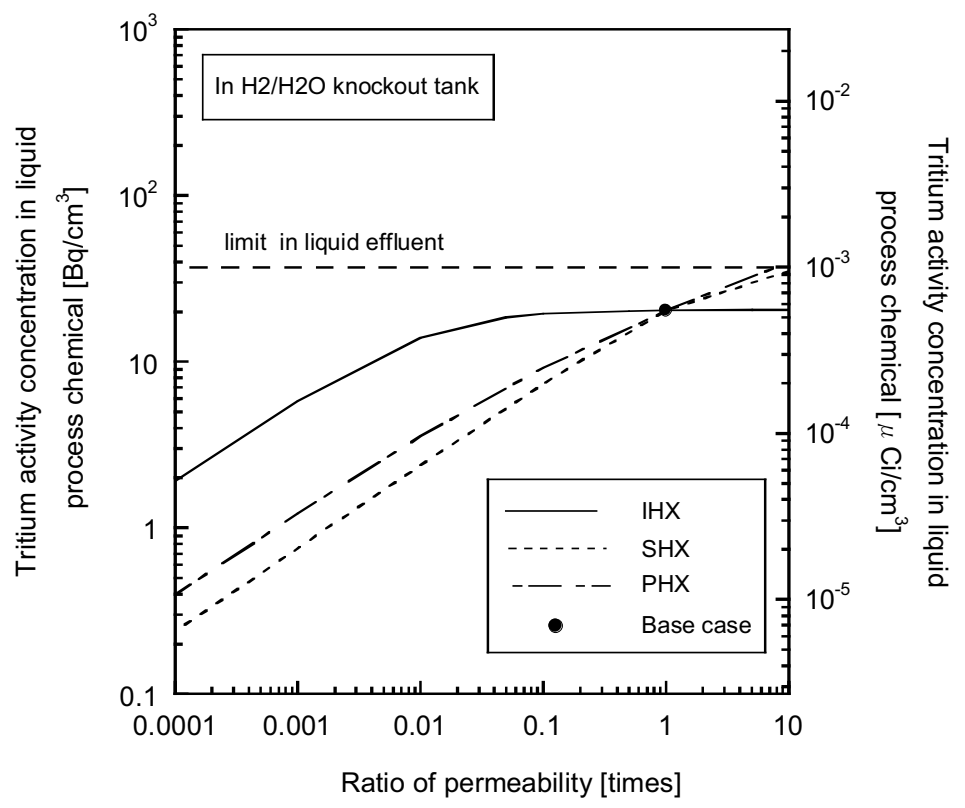

Figure 26. Effect of varying permeability on the tritium concentration in liquid process chemicals in the $\mathrm{H}_{2} / \mathrm{H}_{2} \mathrm{O}$ knockout tank for the Next Generation Nuclear Plant using the high-temperature electrolysis process.

Tritium concentration in helium coolant. Figure 27 shows the effect of varying IHX permeability on the tritium concentration in helium coolants. The tritium concentration in the primary helium reasonably increases with the decrease of IHX permeability. In response, tritium concentrations in the secondary and tertiary helium decrease with the decrease of IHX permeability. In addition, the difference between tritium concentrations in the secondary and tertiary helium decreases with the decrease of IHX permeability. The tritium concentration in the tertiary helium becomes less than the gaseous effluent limit below about $2 \times 10^{-8}$ times of IHX base case permeability.

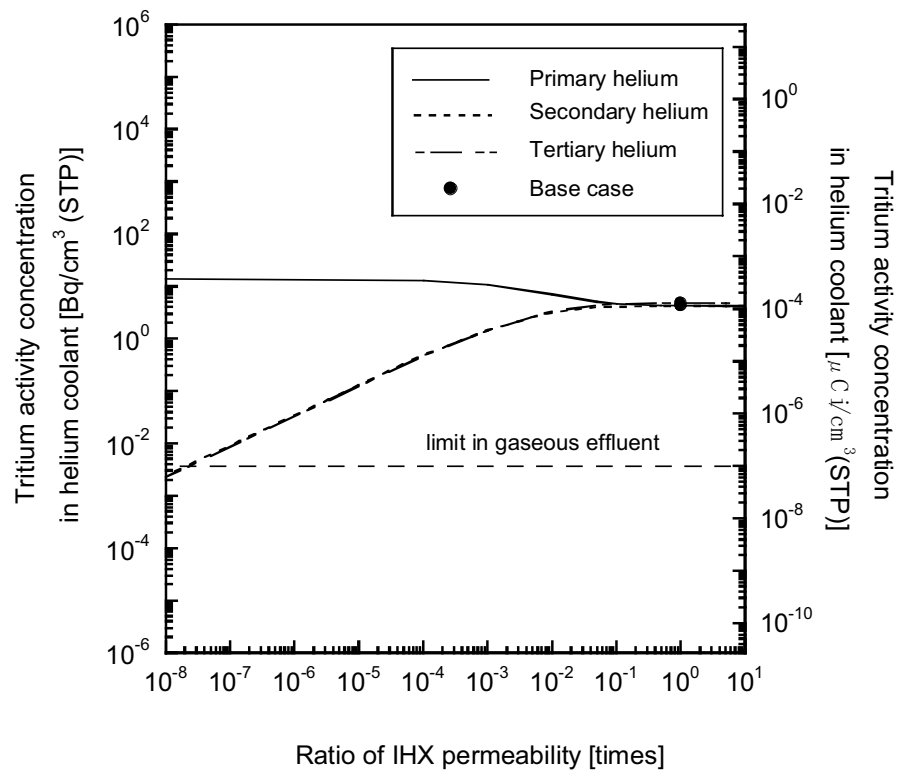

Figure 27. Effect of varying intermediate heat exchanger permeability on the tritium concentration in the helium coolant for the Next Generation Nuclear Plant using the high-temperature electrolysis process. 
Figure 28 shows the effect of varying SHX permeability on the tritium concentration in the helium coolants. In the cases studied, the tritium concentration in the primary helium is slightly higher than that in secondary helium. Tritium concentrations upstream of the SHX (i.e., concentrations in primary and secondary helium) increase slightly with the decrease of SHX permeability. However, the tritium concentration downstream of SHX (i.e., concentration in tertiary helium) decreases linearly with the decrease of SHX permeability. The tritium concentration in tertiary helium becomes less than the gaseous effluent limit below about $3 \times 10^{-6}$ times of SHX base case permeability. Therefore, the effect of varying the SHX permeability on the tritium concentration in tertiary helium is more significant than the effect of varying the IHX permeability.

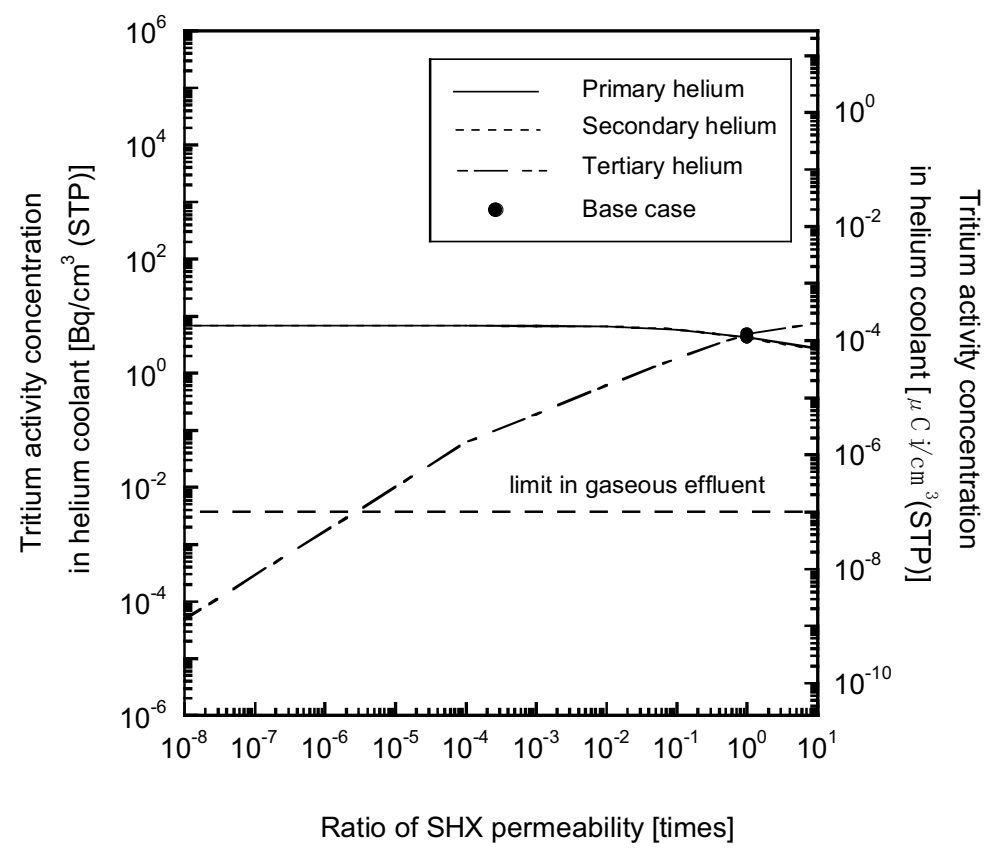

Figure 28. Effect of varying secondary heat exchanger permeability on the tritium concentration in the helium coolant for the Next Generation Nuclear Plant using the high-temperature electrolysis process.

Figure 29 shows the effect of varying PHX permeability on the tritium concentration in helium coolants. Tritium concentrations in the primary and secondary helium decrease slightly with the decrease of PHX permeability. However, the tritium concentration in tertiary helium increases slightly with the decrease of PHX permeability. Therefore, it is impossible to decrease the tritium concentration in tertiary helium less than the gaseous effluent limit by controlling the tritium permeability of the PHX. 


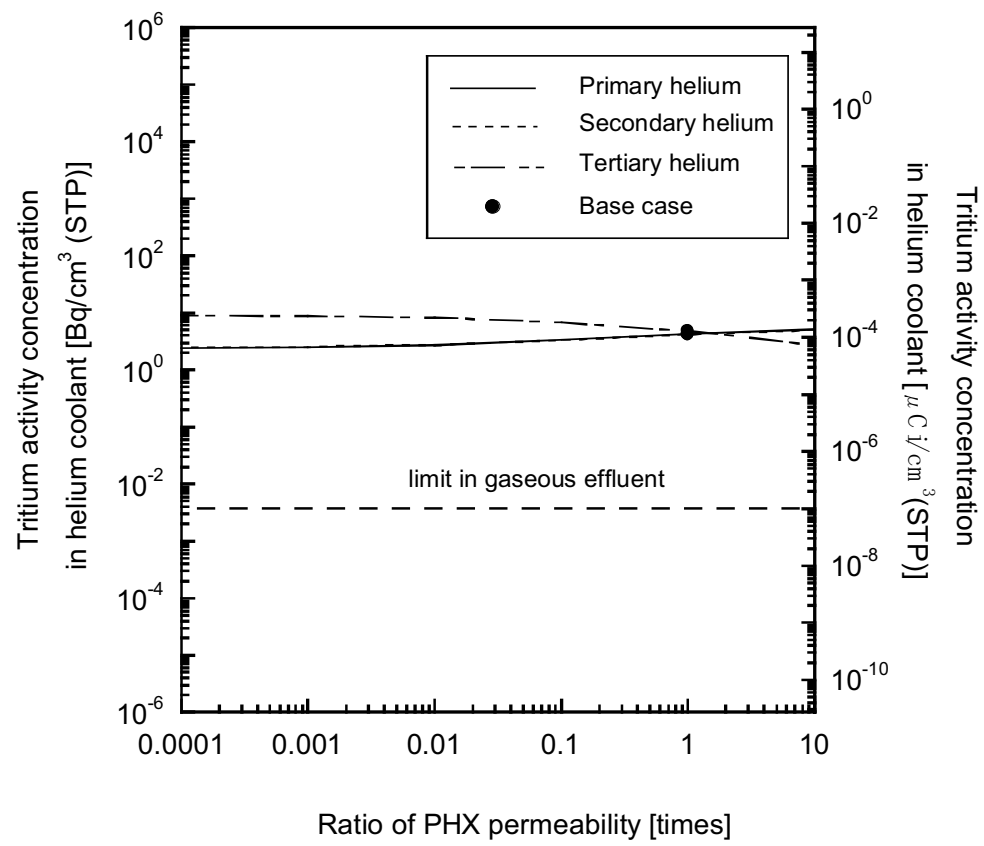

Figure 29. Effect of varying process heat exchanger permeability on the tritium concentration in the helium coolant for the Next Generation Nuclear Plant using the high-temperature electrolysis process.

\subsubsection{Effect of Helium Flow Rate at Purification System}

Tritium concentration in product hydrogen. Figure 30 shows the effect of varying helium flow rate at the purification system on the tritium concentration in the hydrogen product. The lower horizontal axis indicates the ratio of helium flow rate at the purification system to the helium inventory in each loop. The upper horizontal axis indicates the ratio of helium flow rate at the purification system to the helium circulation rate in each loop. This value physically must be less than or equal to 1.0. Note that the value of the upper axis in tertiary helium is different from that for the primary and secondary helium because the helium circulation rate in the tertiary loop is about 0.1 times that in the primary and secondary loops. As expected, the tritium concentration decreases with an increase of the helium flow rate at the purification system installed in each loop. There is no significant difference in tritium concentrations between the different purification systems. In order to decrease the tritium concentration in the hydrogen product below the drinking water limit, the ratio of helium flow rate at the purification system to the helium inventory in the primary, secondary, and , tertiary loops should be increased more than about $3 \mathrm{~h}^{-1}$, $3 \mathrm{~h}^{-1}$, and $4 \mathrm{~h}^{-1}$, respectively. The increase of the helium flow rate at all purification systems reasonably decreases the tritium concentration at each purification system. The tritium concentration in the hydrogen product falls below the drinking water limit in above about $0.6 \mathrm{~h}^{-1}$. However, the effect of helium flow rate at the purification system does not seem to be significant. For example, the tritium concentration in hydrogen product decreases by a factor of only about 0.19 with the increase of the helium flow rate at all purification systems by a factor of 10 (i.e., increasing from the base case of $0.12 \mathrm{~h}^{-1}$ to $1.2 \mathrm{~h}^{-1}$ ). 


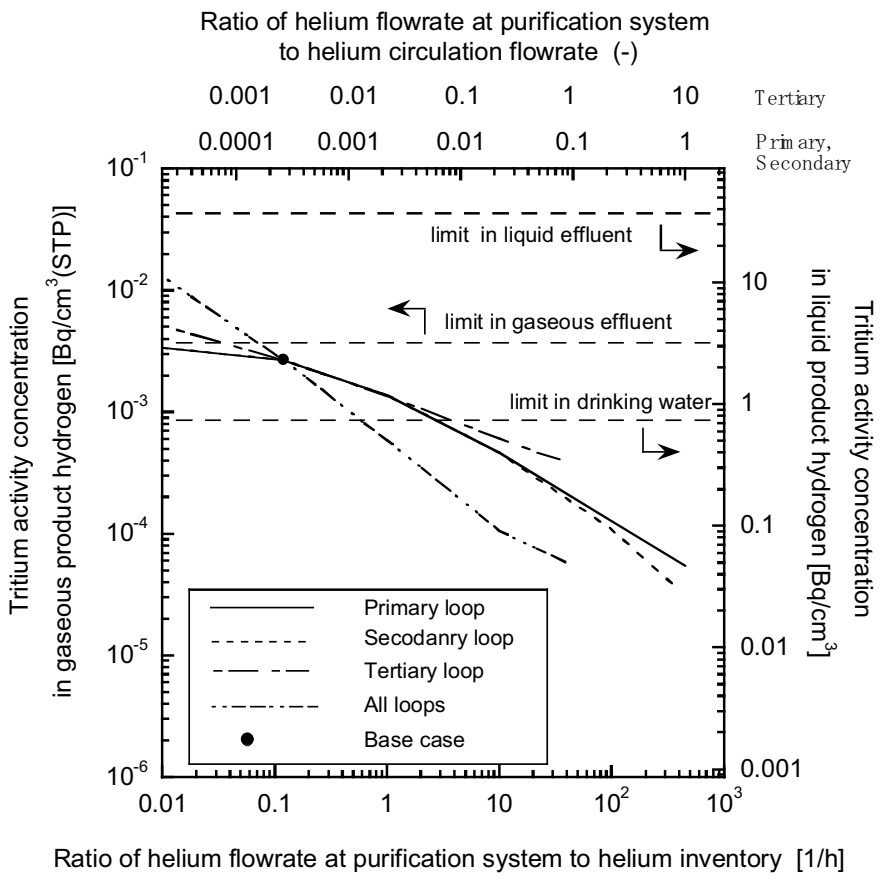

Figure 30. Effect of varying helium flow rate at the purification system on the tritium concentration in the hydrogen product for the Next Generation Nuclear Plant using the high-temperature electrolysis process.

Tritium concentration in a component of the high-temperature electrolysis process.

Figure 31 shows the effect of varying helium flow rate at the purification system in each loop on the tritium concentration in gaseous process chemicals in the electrolyzer. The dependency of the tritium concentration in the electrolyzer's gaseous process chemicals on the helium flow rate is almost the same as that in the hydrogen product. The tritium concentration becomes less than the gaseous effluent limit in the case that the helium flow rate at each purification system is more than about $0.7 \mathrm{~h}^{-1}$ or the helium flow rates at all purification systems are more than about $0.3 \mathrm{~h}^{-1}$, respectively.

Figure 32 shows the effect of varying helium flow rate at the purification system in each loop on the tritium concentration in liquid process chemicals in the $\mathrm{H}_{2} / \mathrm{H}_{2} \mathrm{O}$ knockout tank. The profile is almost the same as the tritium concentration in gaseous process chemicals in the electrolyzer. In the base case, the tritium concentration in the $\mathrm{H}_{2} / \mathrm{H}_{2} \mathrm{O}$ knockout tank is below the liquid effluent limit. The concentration of tritium is exceeded only if the helium flow rates at all purification systems falls below $0.04 \mathrm{~h}^{-1}$. 


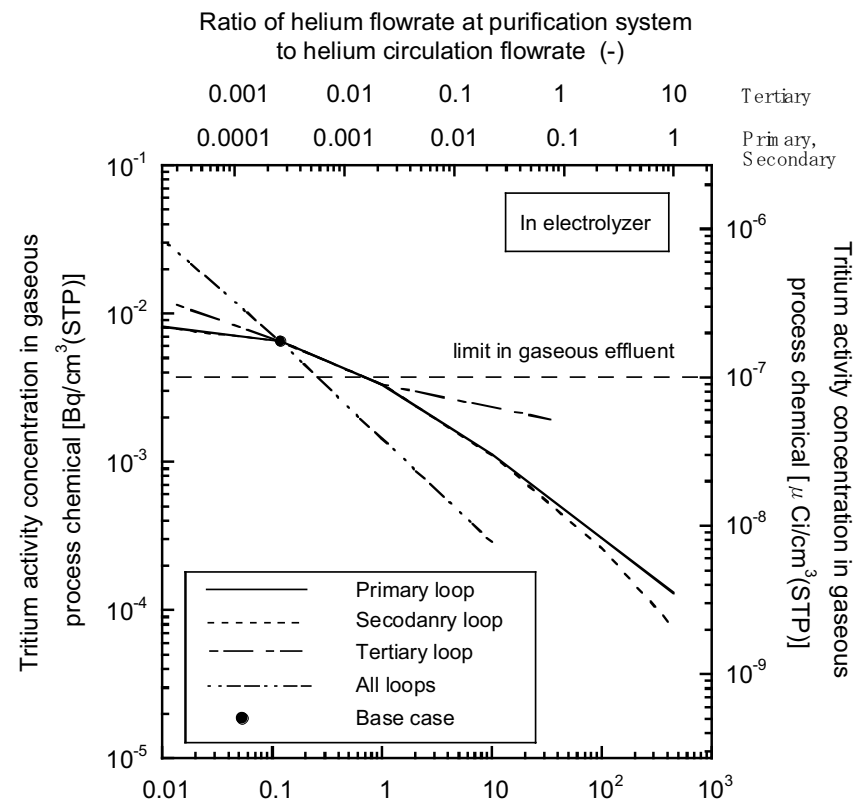

Ratio of helium flowrate at purification system to helium inventory $[1 / \mathrm{h}]$

Figure 31. Effect of varying helium flow rate at the purification system on the tritium concentration in the electrolyzer's gaseous process chemicals for the Next Generation Nuclear Plant using the hightemperature electrolysis process.

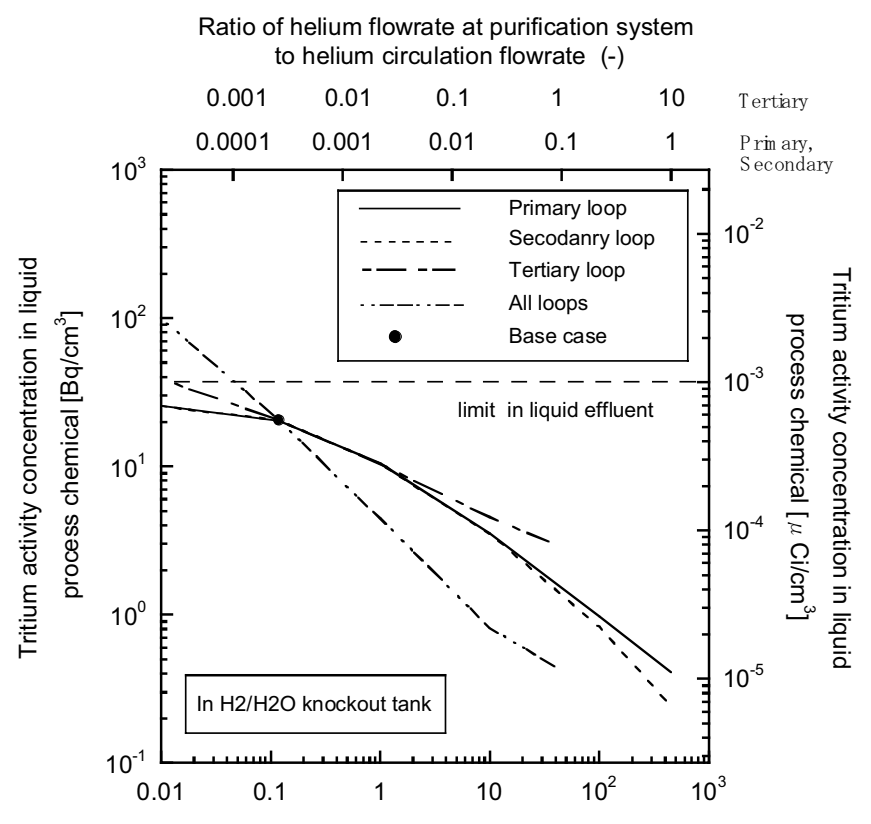

Ratio of helium flowrate at purification system to helium inventory [1/h]

Figure 32. Effect of varying helium flow rate at the purification system on the tritium concentration in liquid process chemicals in the $\mathrm{H}_{2} / \mathrm{H}_{2} \mathrm{O}$ knockout tank for the Next Generation Nuclear Plant using the high-temperature electrolysis process.

Tritium concentration in helium coolant. Figures 33, 34, and 35 show the tritium concentration in the helium loops at different helium flow rates in the loop purification system of the primary, secondary 
and tertiary loops. The ratio of helium flow rate at the purification system to helium circulation flow rate (the upper horizontal axis) should be less than 1.0. However, even if this value is 1.0, the tritium concentration in tertiary helium is larger than the gaseous effluent limit in all cases. Figure 36 shows the effect of varying helium flow rate at all purification systems.

From the figures, it is clear that the flow rates through the purification systems must be greatly increased over the base case in order to achieve the gaseous effluent limits in the primary, secondary, and tertiary helium loops. For the primary helium coolant, this is less of an issue since leaks from the primary coolant will be considered radioactively contaminated by virtue of its contact with the nuclear core materials, but for the secondary and tertiary helium coolants, the purification system flow rates would need to be greatly increased to limit the tritium concentration in these gases to below the gaseous effluent limit. Practically speaking, greatly increasing the purification system flow rates in the primary, secondary, and tertiary systems have some effect, but will not be able to achieve reduction by themselves of the tritium concentrations in the primary, secondary, and tertiary helium coolants.

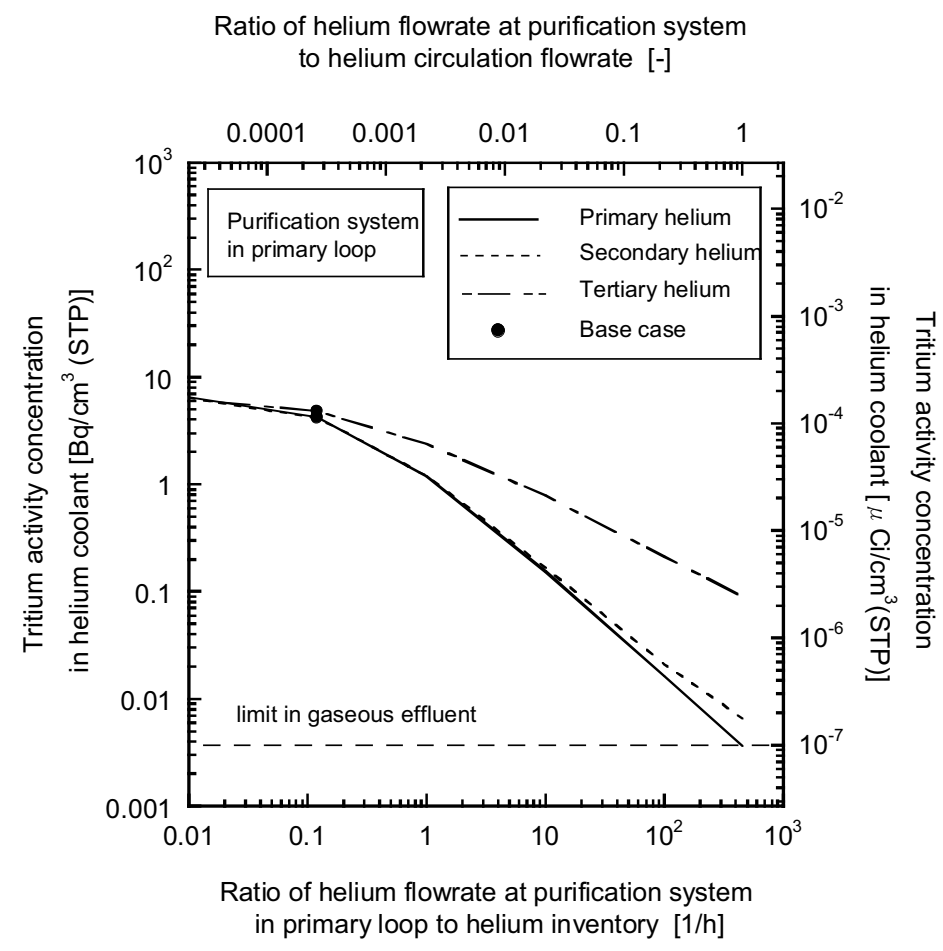

Figure 33. Effect of varying helium flow rate at the purification system in the primary loop on the tritium concentration in the helium coolant for the Next Generation Nuclear Plant using the high-temperature electrolysis process. 


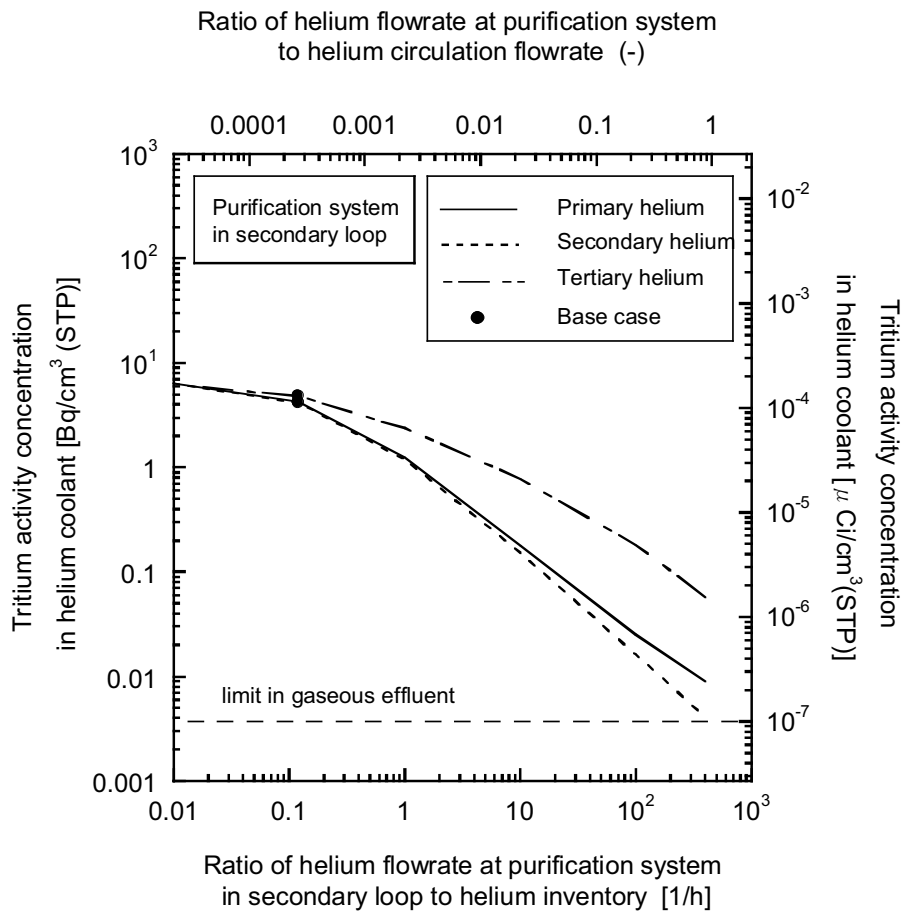

Figure 34. Effect of varying helium flow rate at the purification system in the secondary loop on the tritium concentration in the helium coolant for the Next Generation Nuclear Plant using the hightemperature electrolysis process.

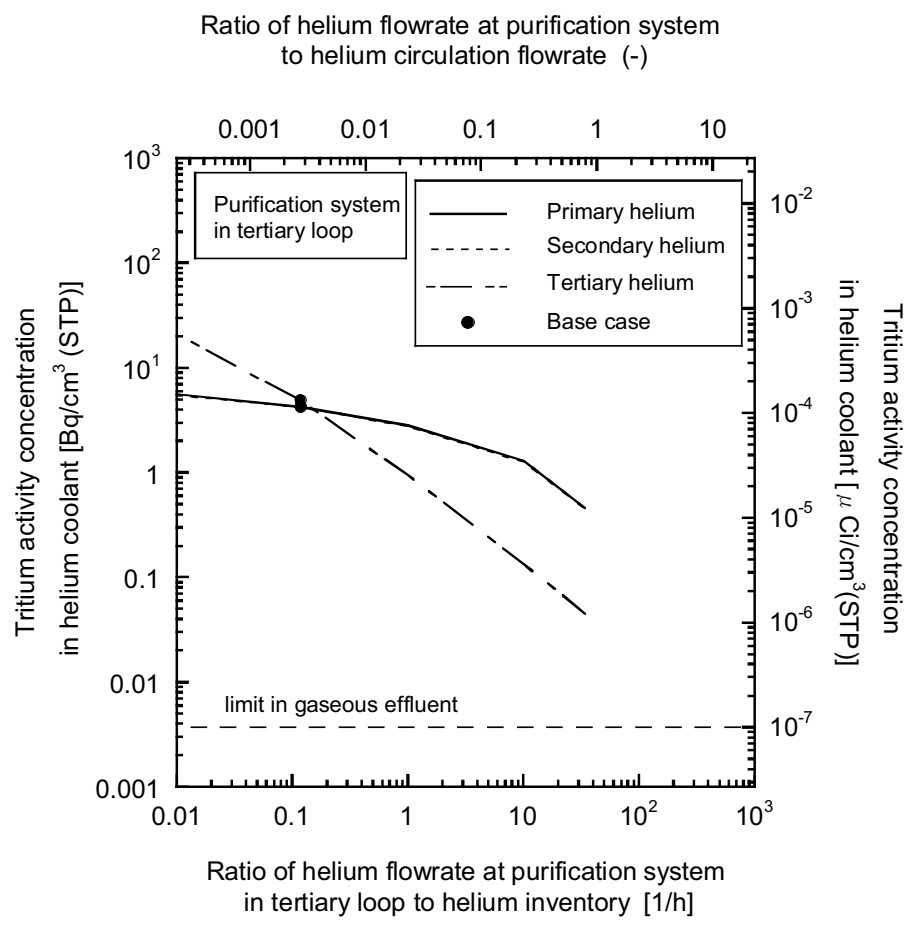

Figure 35. Effect of varying helium flow rate at the purification system in the tertiary loop on the tritium concentration in the helium coolant for the Next Generation Nuclear Plant using the high-temperature electrolysis process. 


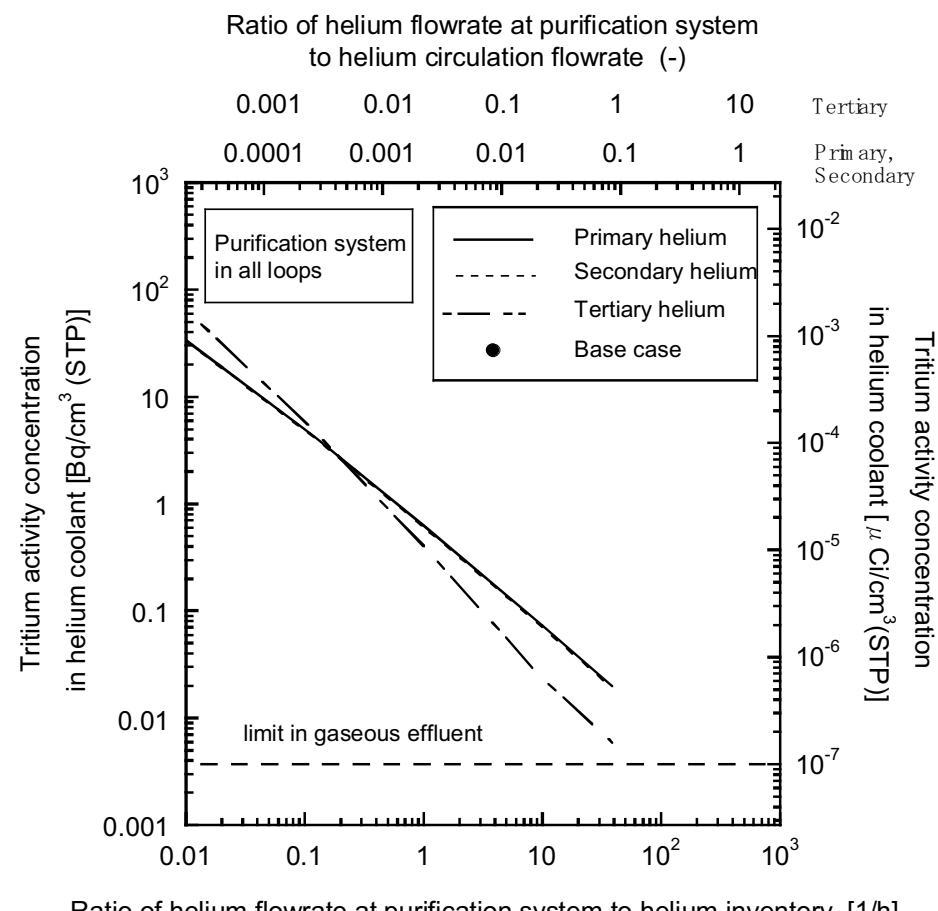

Figure 36. Effect of varying helium flow rate at the purification system in all loops on the tritium concentration in the helium coolant for the Next Generation Nuclear Plant using the high-temperature electrolysis process.

\subsubsection{Effect of Pressure in Tertiary Loop}

Tritium concentration in the hydrogen product. The base line pressure in the tertiary loop is assumed to be about $2 \mathrm{MPa}$, whereas pressure in the primary, secondary, and the HTE process are about $7 \mathrm{MPa}, 7 \mathrm{MPa}$, and $5 \mathrm{MPa}$, respectively. Since the tertiary loop is not used for any purpose other than long distance hea transfer, the tertiary loop pressure can be varied more widely than in the other loops without affecting the functionality of the loop. Therefore, the effect of pressure in the tertiary loop on the tritium concentration in the hydrogen product was calculated over the range 0.1 to $10 \mathrm{MPa}$ in the tertiary loop. The tritium concentration in the hydrogen product decreases with the decrease of pressure in the tertiary loop (see Figure 37) because the tritium permeation rate from the tertiary loop to the main line of the HTE process (i.e., permeation rate through PHX-1 and PHX-2) decreases with the decrease of pressure (see Figure 38). However, the effect of pressure is not significant. Tritium concentrations in the product hydrogen are $1.1 \times 10^{-3} \mathrm{~Bq} / \mathrm{cm}^{3}(\mathrm{STP})$ and $4.4 \times 10^{-3} \mathrm{~Bq} / \mathrm{cm}^{3}(\mathrm{STP})$ at $0.1 \mathrm{MPa}$ and $10 \mathrm{MPa}$, respectively. Even if pressure in the tertiary loop is reduced to $0.1 \mathrm{MPa}$, the tritium concentration in product hydrogen is larger than the drinking water limit. 


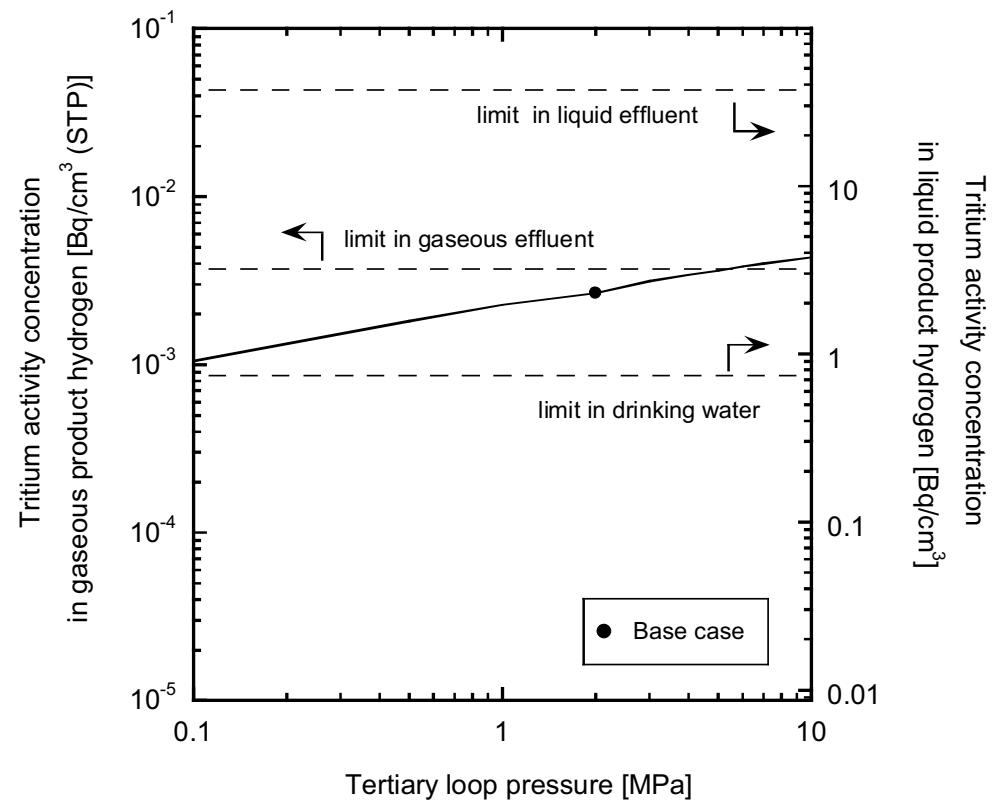

Figure 37. Effect of varying pressure in tertiary loop on the tritium concentration in the hydrogen product for the Next Generation Nuclear Plant using the high-temperature electrolysis process.

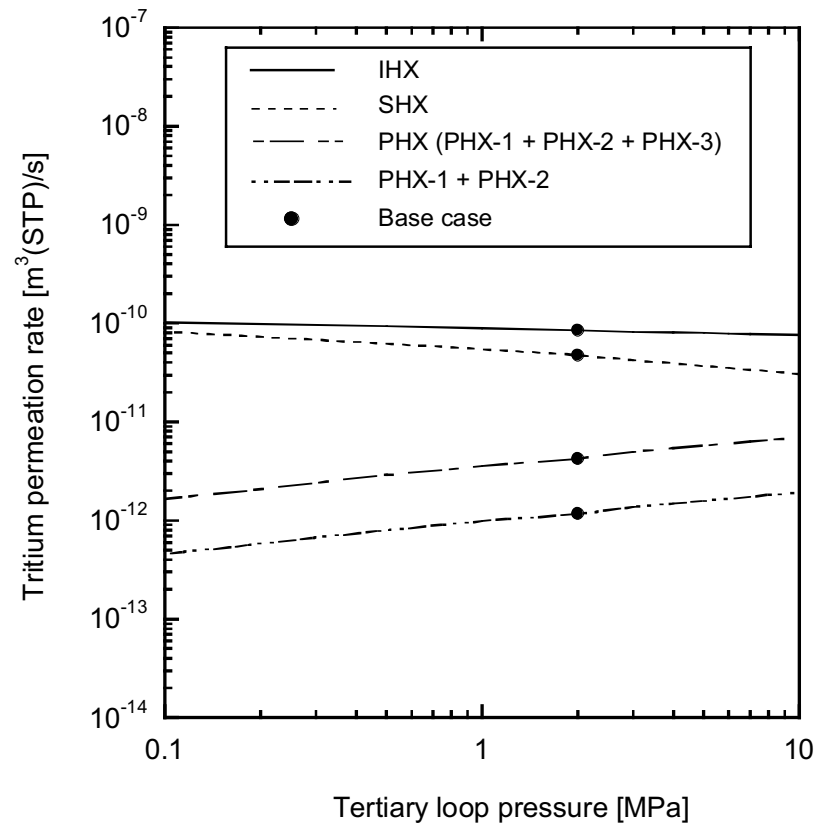

Figure 38. Effect of varying pressure in the tertiary loop on tritium permeation rate for the Next Generation Nuclear Plant using the high-temperature electrolysis process.

Tritium concentration in a component of the high-temperature electrolysis process.

Figures 39 and 40 show tritium concentrations in the electrolyzer's gaseous process chemicals and in the $\mathrm{H}_{2} / \mathrm{H}_{2} \mathrm{O}$ knockout tank's liquid process chemicals, respectively, in response to varying pressure. The concentration of tritium in the electrolyzer's gaseous components and in the $\mathrm{H}_{2} / \mathrm{H}_{2} \mathrm{O}$ knockout tank's liquid process chemicals increases with increasing tertiary loop pressure. The gaseous effluent limit is 
achieved by operating below about $0.3 \mathrm{MPa}$ in the tertiary loop, while the liquid effluent limit in the knockout tank is achieved over all of the pressure ranges studied.

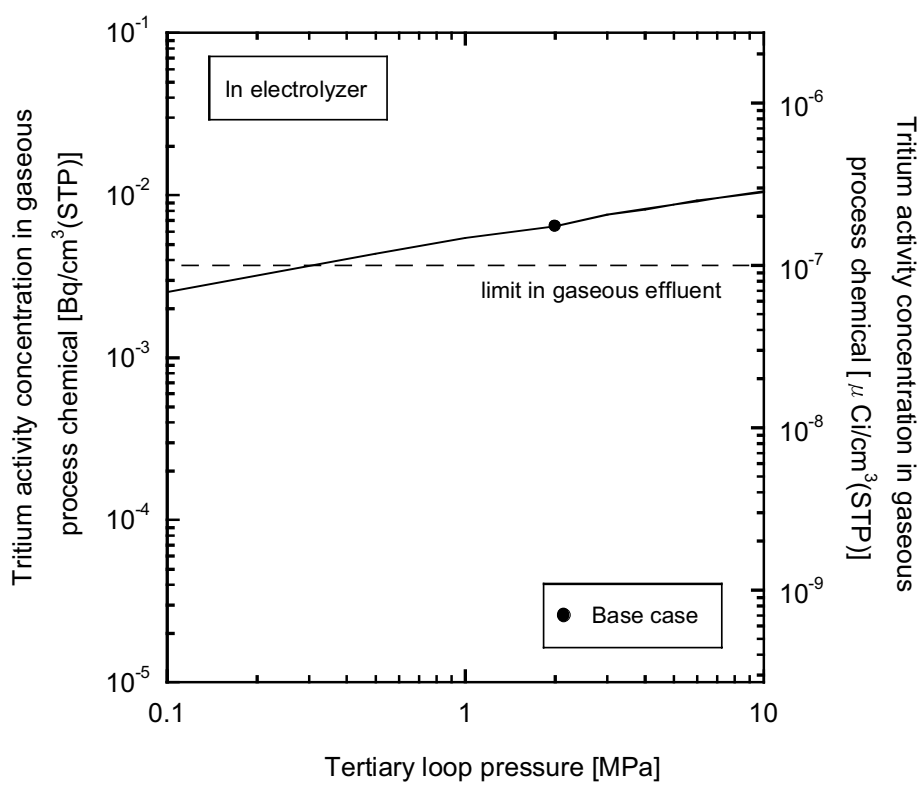

Figure 39. Effect of varying pressure in the tertiary loop on the tritium concentration in the electrolyzer's gaseous process chemicals for the Next Generation Nuclear Plant using the high-temperature electrolysis process.

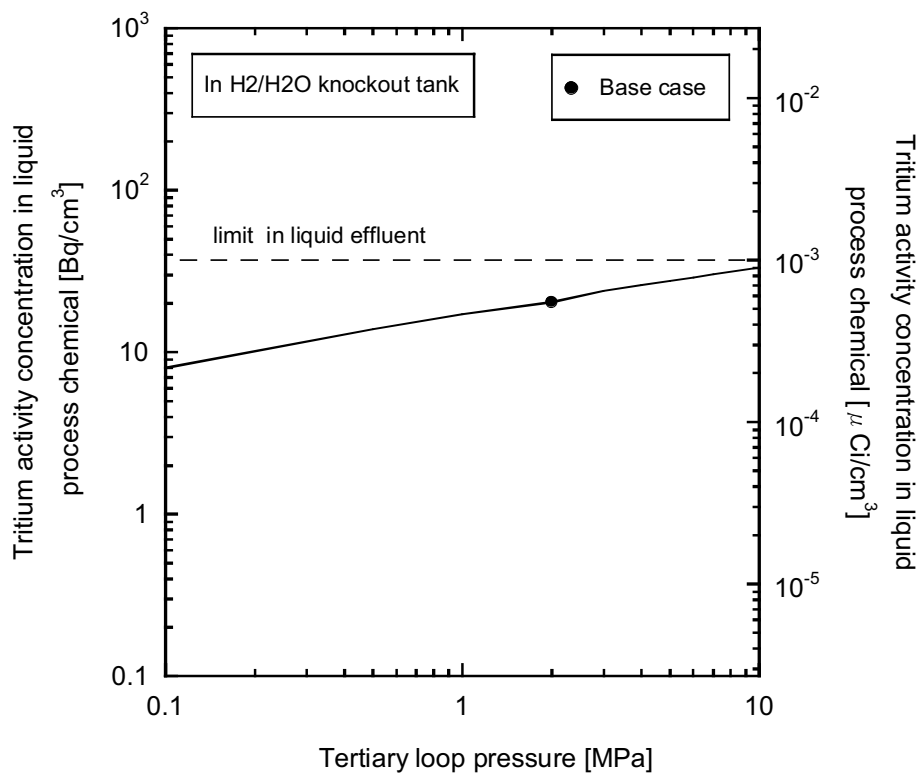

Figure 40. Effect of varying pressure in the tertiary loop on the tritium concentration in the $\mathrm{H}_{2} / \mathrm{H}_{2} \mathrm{O}$ knockout tank's liquid process chemicals for the Next Generation Nuclear Plant using the hightemperature electrolysis process.

Tritium concentration in helium coolant. Figure 41 shows the tritium concentration in helium coolants in response to varying loop pressure. With the decrease of pressure in the tertiary loop, the 
tritium concentration in the primary and secondary loops also decrease while the tritium concentration in the tertiary loop increases. This occurs because the tritium permeation rate through the SHX increases as the pressure decreases in the tertiary loop (see Figure 38). As seen in Figure 41, the tritium concentration in the tertiary helium is much larger than the gaseous effluent limit, even if the pressure is $10 \mathrm{MPa}$.

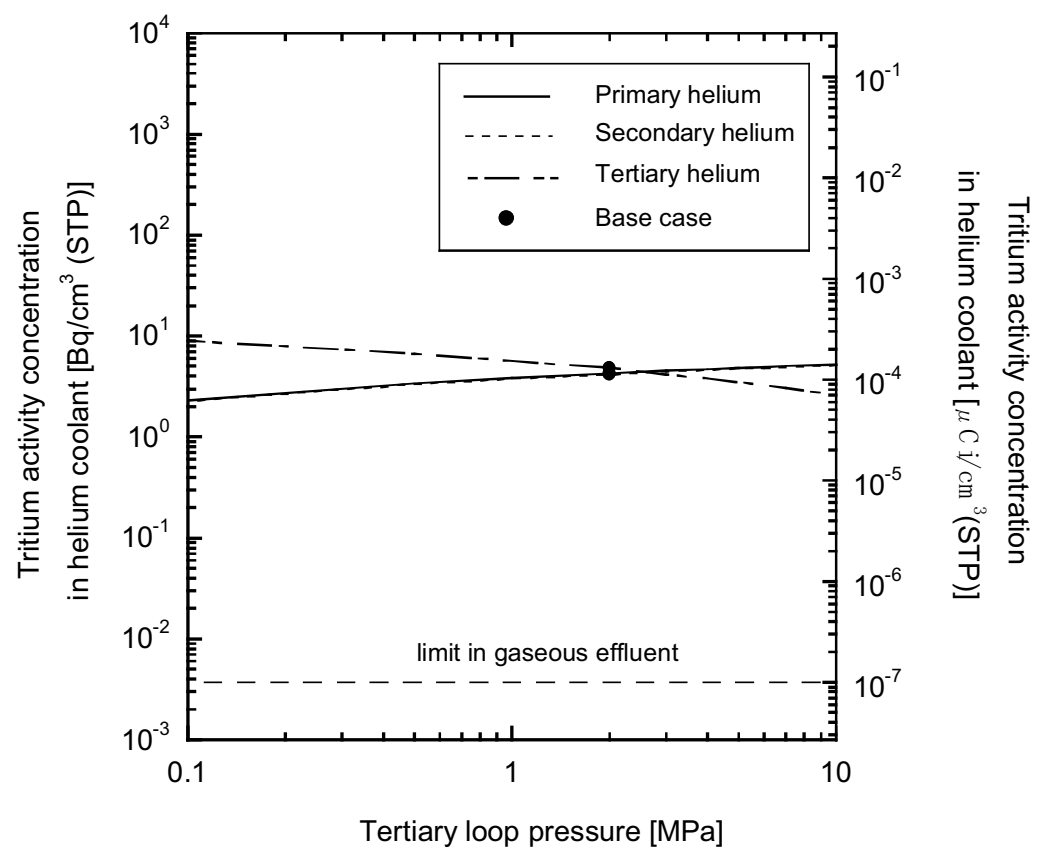

Figure 41. Effect of varying pressure in the tertiary loop on tritium concentration in the helium coolant for the Next Generation Nuclear Plant using the high-temperature electrolysis process.

\subsubsection{Effect of Reactor Outlet Temperature}

Tritium concentration in product hydrogen. The HTE process can be operated with the same hydrogen production efficiency at a lower reactor outlet temperature by installing a recuperator at the inlet of the electrolyzer. The effect of reactor outlet temperature on the tritium concentrations was investigated over the temperature range 823 to $1,173 \mathrm{~K}$. In this calculation, the temperature of the heat transfer tube was changed linearly with the reactor outlet temperature. Other parameters (e.g., tritium release rate) were maintained the same as those of the base case. Figure 42 shows the effect of varying temperature on the tritium concentration in product hydrogen. The tritium concentration in the hydrogen product decreases with the decrease of temperature due to the decrease of the tritium permeation rate from the tertiary loop to the main line of the HTE process (i.e., permeation rate through PHX-1 and PHX-2; see Figure 43). The tritium concentration becomes less than the drinking water limit at a temperature less than approximately $990 \mathrm{~K}$. With the decrease of the reactor outlet temperature from the base case of $1,173 \mathrm{~K}$ to $823 \mathrm{~K}$, the tritium concentration in product hydrogen decreases by factor of about 0.08 . 


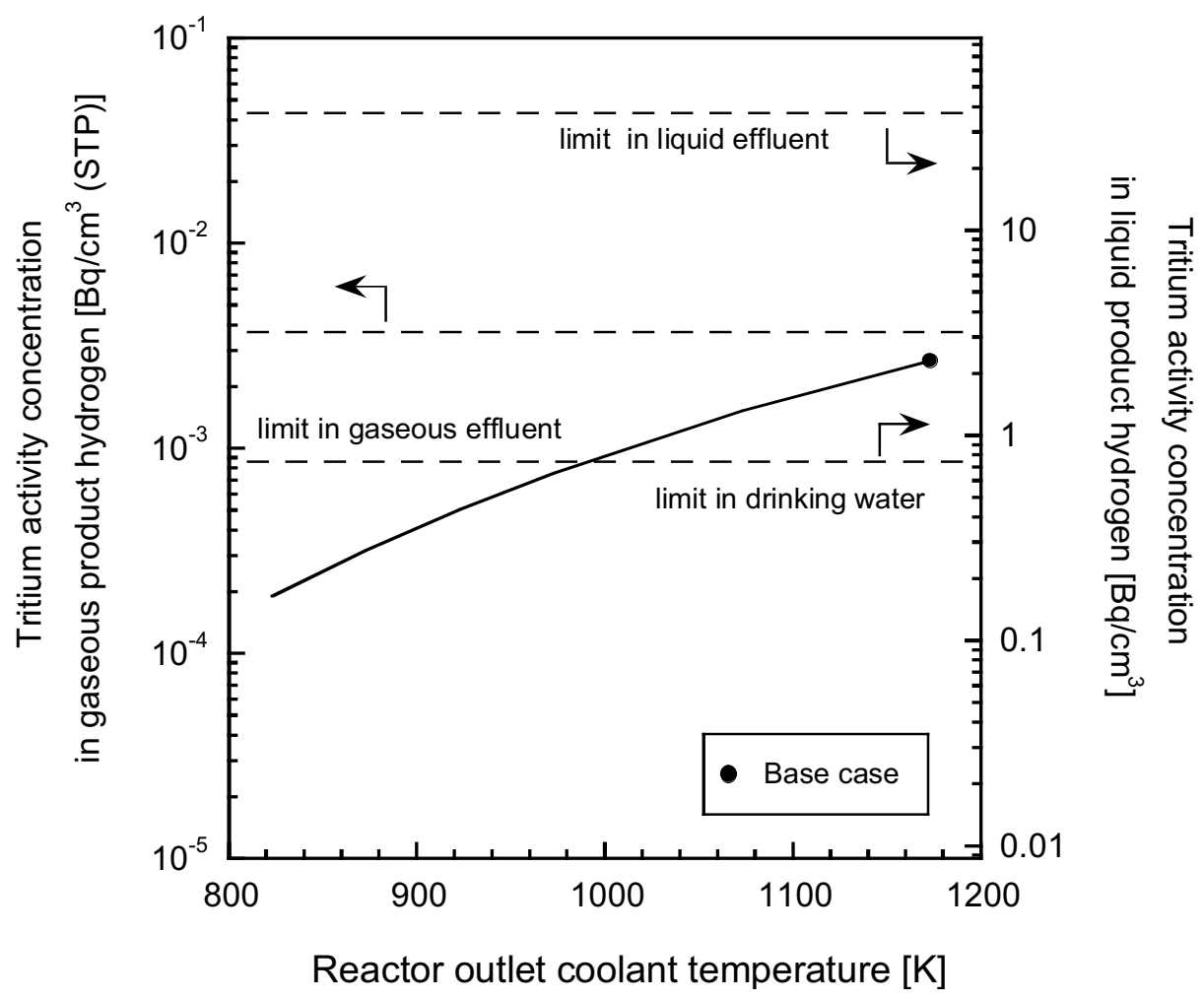

Figure 42. Effect of varying reactor outlet temperature on the tritium concentration in product hydrogen for the Next Generation Nuclear Plant using the high-temperature electrolysis process. 


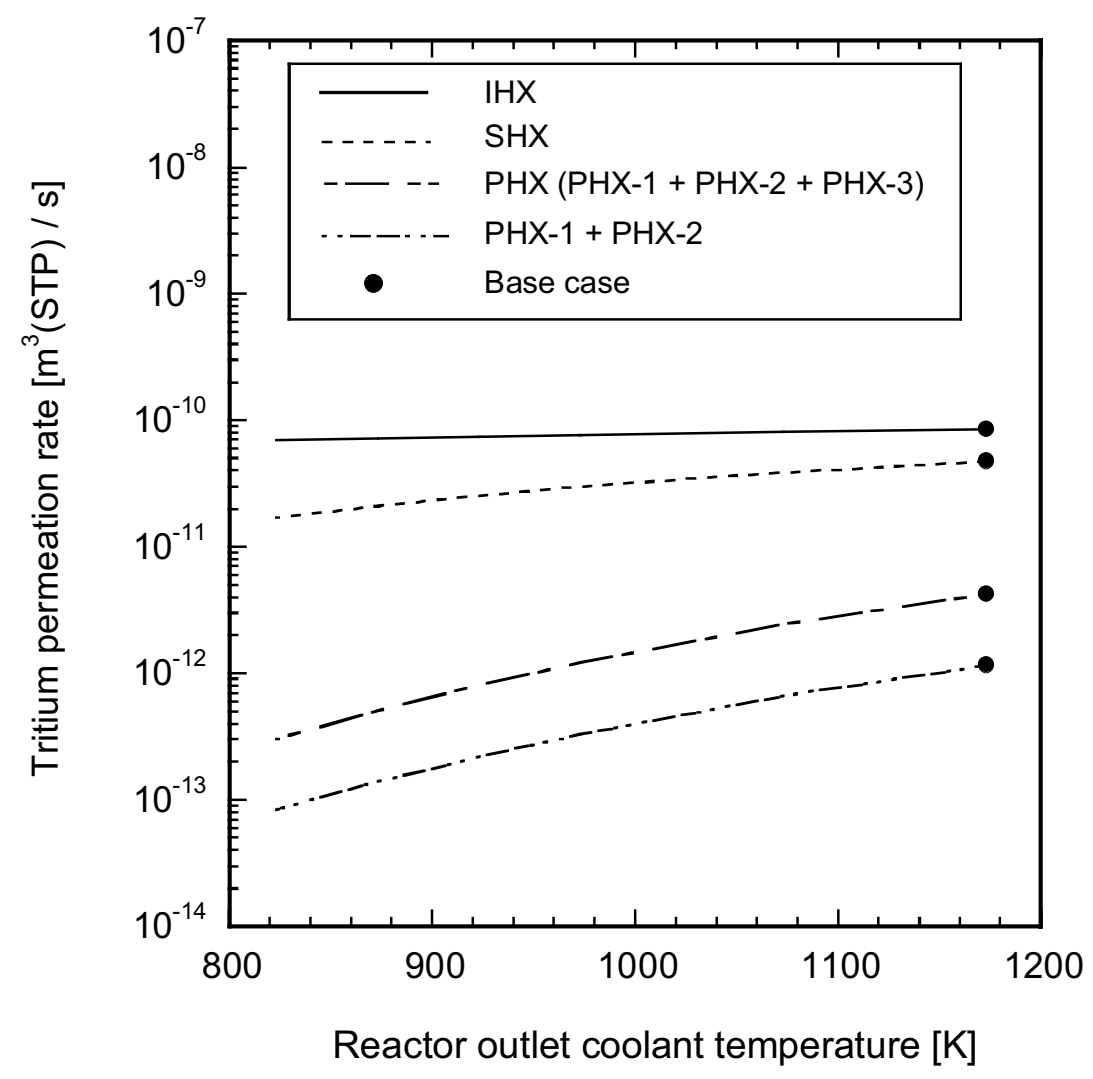

Figure 43. Effect of varying reactor outlet temperature on the tritium permeation rate for the Next Generation Nuclear Plant using the high-temperature electrolysis process.

Tritium concentration in a component of the high-temperature electrolysis process. Figure 44 shows the tritium concentration in the electolyzer's gaseous process chemicals in response to varying temperature. Tritium concentration decreases with temperature due to a decrease of the tritium permeation rate. The tritium concentration becomes less than the gaseous effluent limit at below about $1,070 \mathrm{~K}$. With the decrease of the reactor outlet temperature from the base case of $1,173 \mathrm{~K}$ to $823 \mathrm{~K}$, the tritium concentration in the electrolyzer's gaseous process chemicals decreases by a factor of about 0.07 .

Figure 45 shows the tritium concentration in the $\mathrm{H}_{2} / \mathrm{H}_{2} \mathrm{O}$ knockout tank's liquid process chemicals in response to varying reactor outlet temperature. The tritium concentration in the knockout tank also decreases with reactor outlet temperature, and it decreases by factor about 0.07 with the decrease of temperature from $1,173 \mathrm{~K}$ to $823 \mathrm{~K}$. At all points over the temperature range studied, the tritium concentration does not exceed the liquid effluent limit in the knockout tank. 


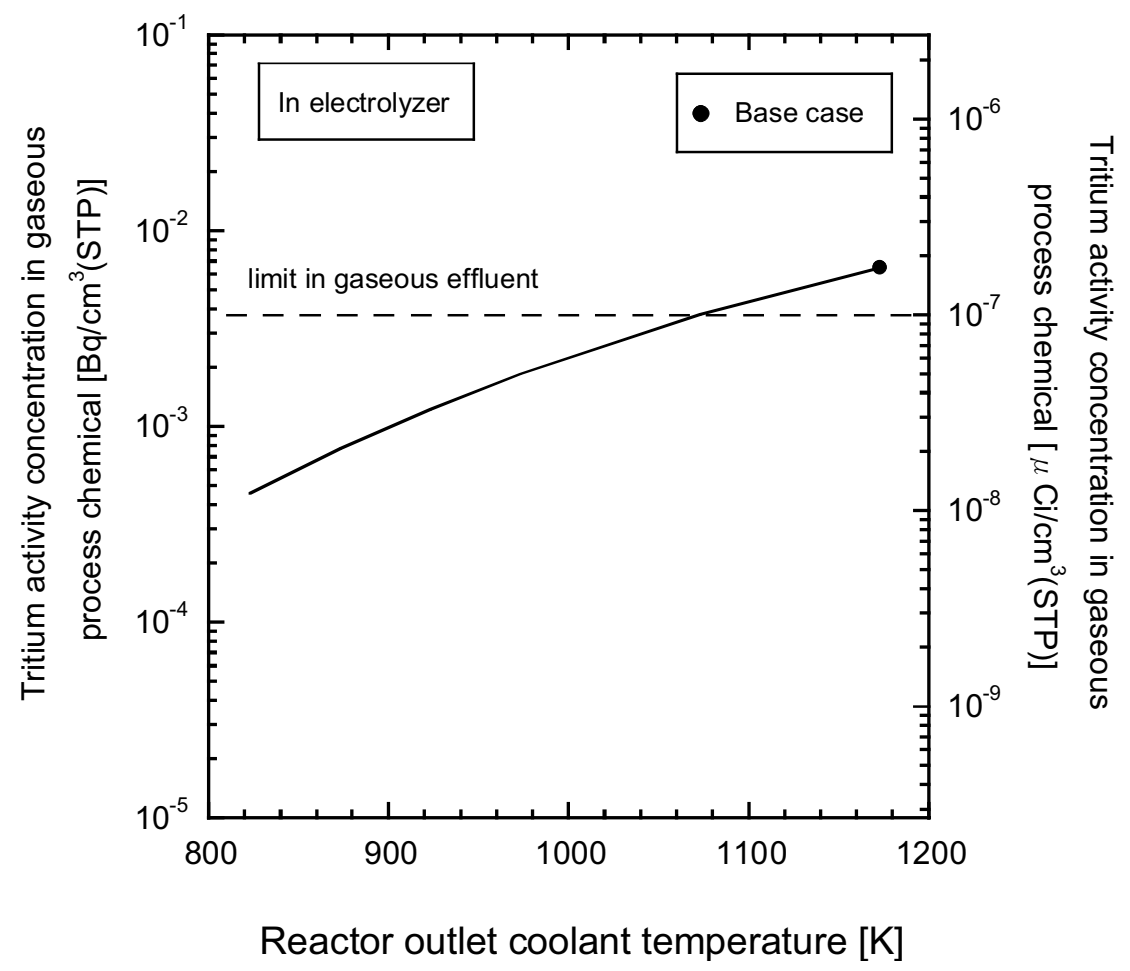

Figure 44. Effect of reactor outlet temperature on the the tritium concentration in the electrolyzer's gaseous process chemicals for the Next Generation Nuclear Plant using the high-temperature electrolysis process. 


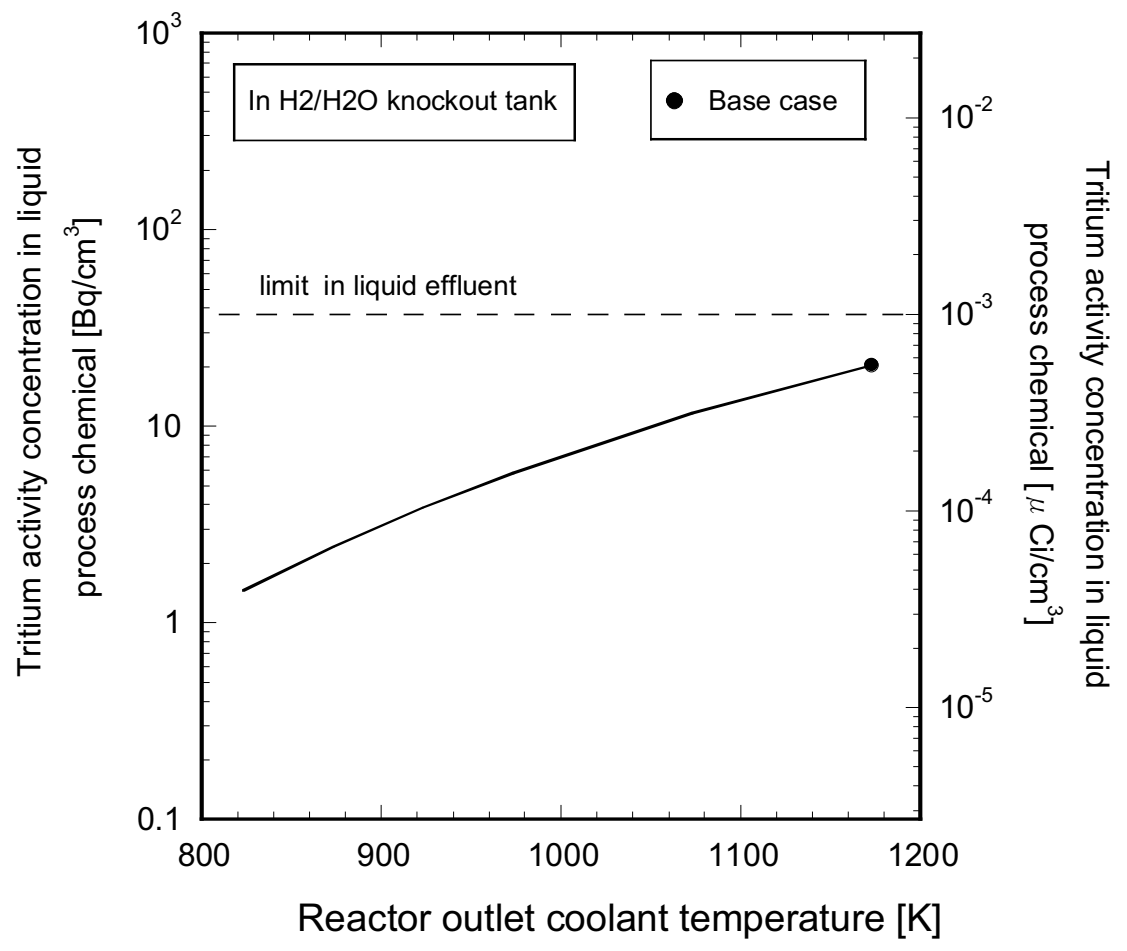

Figure 45. Effect of varying reactor outlet temperature on the tritium concentration in the $\mathrm{H}_{2} / \mathrm{H}_{2} \mathrm{O}$ knockout tank's liquid process chemicals for the Next Generation Nuclear Plant using the hightemperature electrolysis process.

Tritium concentration in helium coolant. Figure 46 shows the tritium concentration in helium coolants in response to varying reactor outlet temperature. The tritium concentrations in the primary and secondary helium increase, and the concentration in the tertiary helium decreases with decreasing reactor outlet temperature. These results indicate that the resistance to tritium permeation through the SHX increases more rapidly with decreasing temperature than the increase in resistance through the IHX and PHX. As shown in Figure 43, the tritium permeation rate through IHX, SHX and PHX decreases by 0.82 times, 0.36 times, and 0.07 times, the base case with the decrease of temperature from 1,173 to $823 \mathrm{~K}$. Though the tritium permeation rate changes more rapidly on a fractional basis in the PHX compared to the IHX and SHX as the temperature changes, the permeability rate through the PHX is smaller than that through the IHX and SHX, and so the permeation rate through the SHX dominates the tritium mass balance calculation. Over the tempertaure range, the tritium concentration in tertiary helium is much larger than the gaseous effluent limit. 


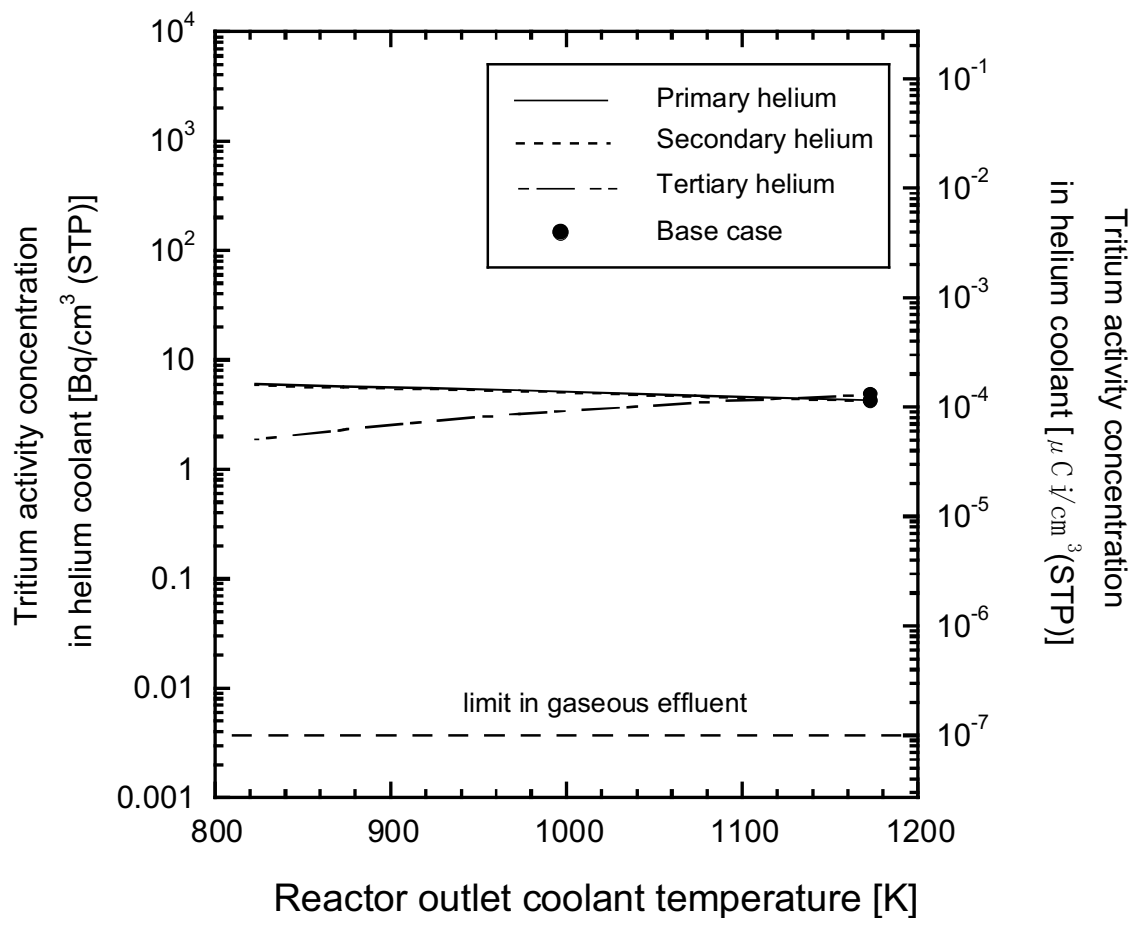

Figure 46. Effect of varying reactor outlet temperature on the tritium concentration in the helium coolant for the Next Generation Nuclear Plant using the high-temperature electrolysis process.

\subsubsection{Effect of Hydrogen Injection in Helium Coolant}

Tritium concentration in product hydrogen. One of the possible countermeasures for decreasing the tritium concentration in product hydrogen is a hydrogen injection in the helium coolant to decrease the tritium permeation rate (see Equations 71 and 72). Figure 47 shows the effect of varying the hydrogen injection rate in the primary, secondary, and tertiary helium on the tritium concentration in product hydrogen. The horizontal axis indicates the ratio of the hydrogen injection rate to the hydrogen production rate by the HTE process of $20.9 \mathrm{~m}^{3}$ (STP)/s. The tritium concentration in the hydrogen product with the increase of hydrogen injection rates. Hydrogen injection in primary and secondary helium is more effective than in tertiary helium. However, no significant difference exists between hydrogen injection in primary helium and secondary helium. For example, the tritium concentration becomes less than the drinking water limit above the injection rate of $0.002 \%$ in primary helium, $0.002 \%$ in secondary helium, and $0.004 \%$ in tertiary helium, respectively. 


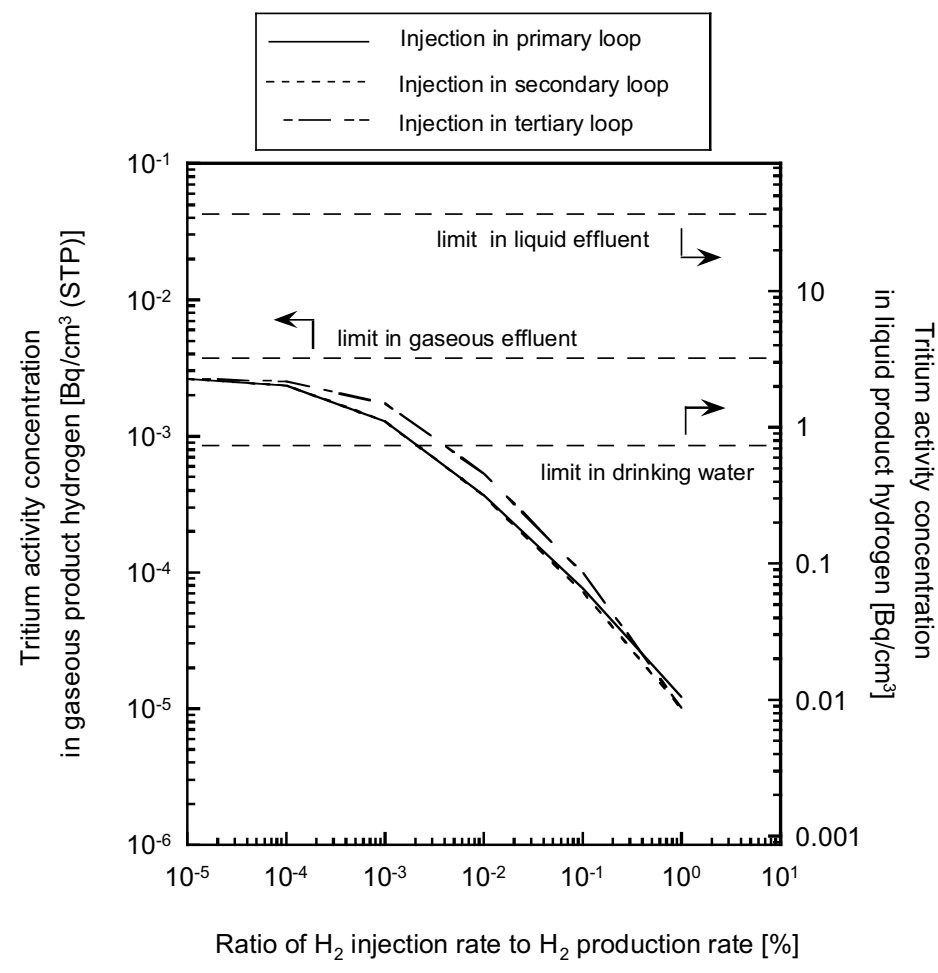

Figure 47. Effect of varying hydrogen injection in the helium coolant on the tritium concentration for the hydrogen product for the Next Generation Nuclear Plant using the high-temperature electrolysis process.

Figures 48,49 , and 50 show changes to the tritium permeation rates due to changes in the hydrogen injection rate in primary helium, secondary helium, and tertiary helium, respectively. Figures 51, 52, and 53 also show changes to hydrogen concentrations in each helium loop due to changes in the hydrogen injection rate in the primary helium, secondary helium, and tertiary helium, respectively. Hydrogen injection in the primary helium results in an increase of the hydrogen concentration not only in the primary helium but in the secondary and tertiary helium because of hydrogen permeation through IHX and SHX. Hydrogen injection in the secondary helium also results in an increased hydrogen concentration in all helium loops. The dependency of the hydrogen concentration and permeation rate on the hydrogen injection rate in the secondary helium is almost the same as in the case of hydrogen injection in the primary helium due to the relatively high permeation rate and large heat transfer area of IHX. However, the increased hydrogen concentration in the primary and secondary helium because of hydrogen injection in the tertiary helium is not significant when compared with the case of the injections in the primary and secondary helium. This is due to the relatively small heat transfer area of SHX when compared with that of IHX. Therefore, the decrease in tritium permeation rates with an increase of the injection rate is slightly smaller when compared with the case of injection in the primary and secondary helium. However, the tritium permeation rate through SHX becomes almost the same as that in the case of injection in the primary and secondary helium at around $1 \%$ of the hydrogen injection rate due to an increase of hydrogen concentration in tertiary helium. 


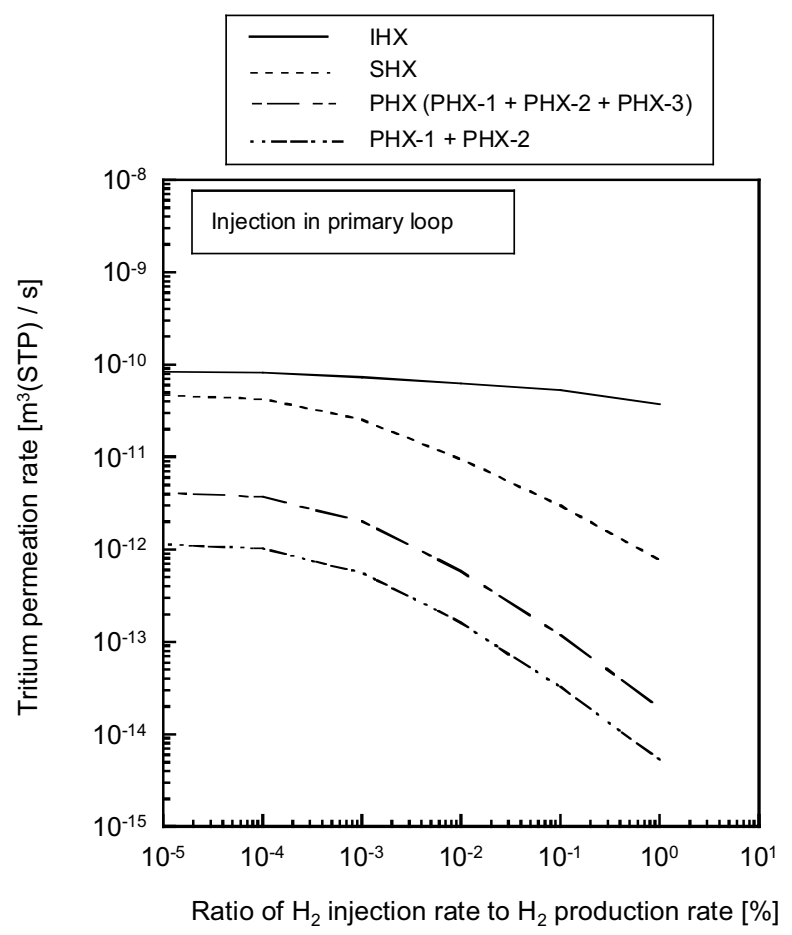

Figure 48. Effect of varying hydrogen injection in the primary helium coolant on tritium permeation rate for the Next Generation Nuclear Plant using the high-temperature electrolysis process.

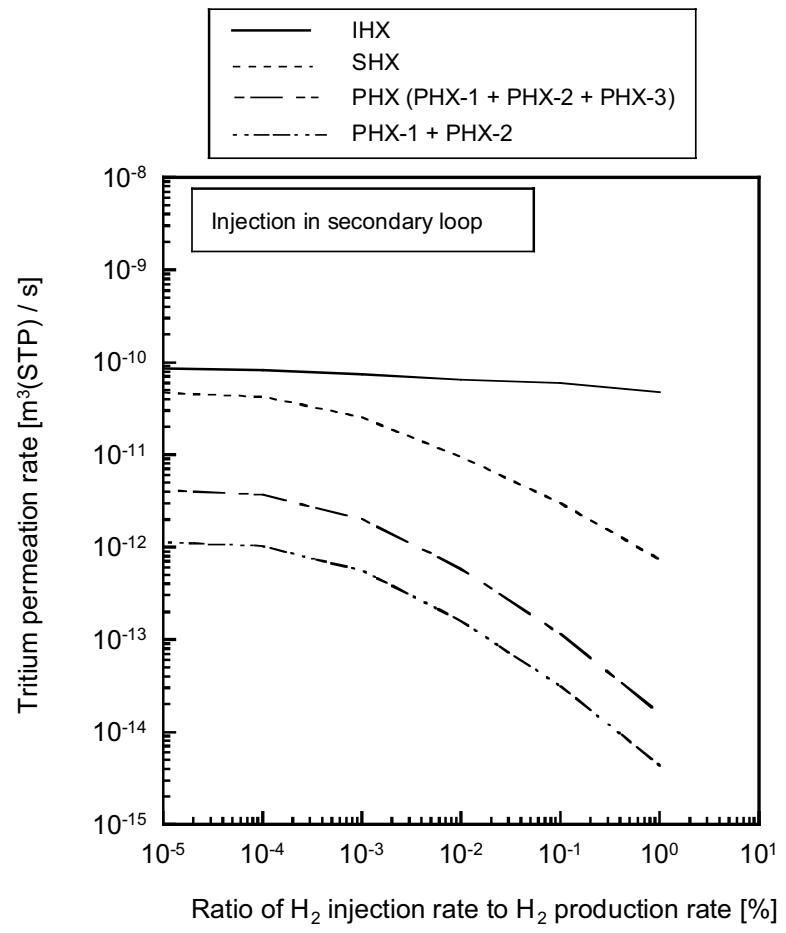

Figure 49. Effect of varying hydrogen injection in the secondary helium coolant on tritium permeation rate for the Next Generation Nuclear Plant using the high-temperature electrolysis process. 


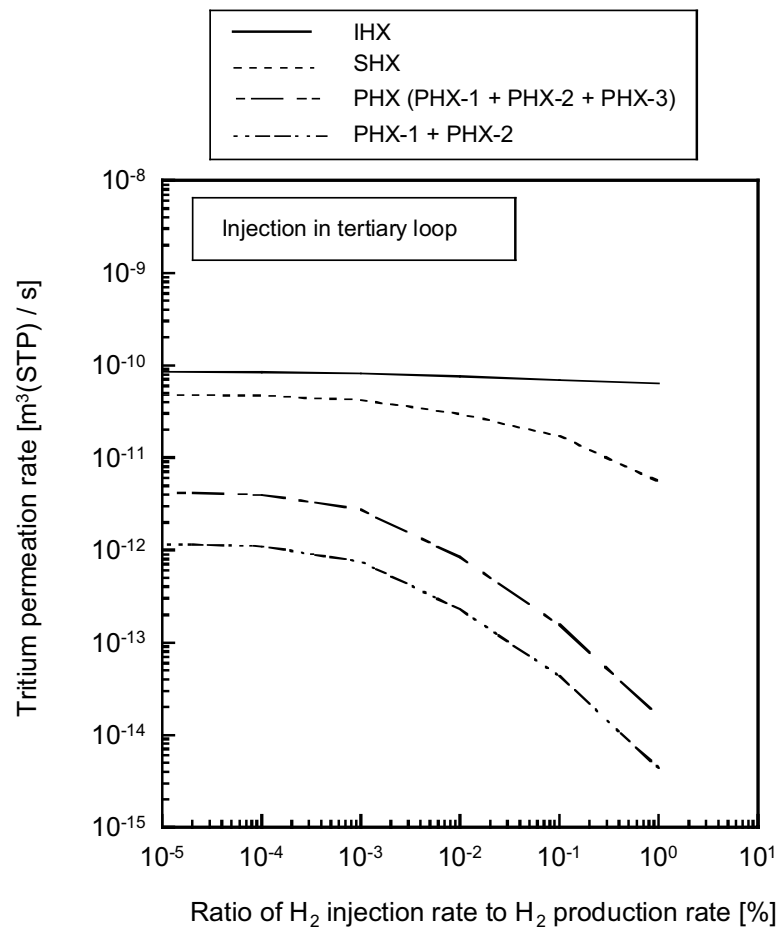

Figure 50. Effect of varying hydrogen injection in the tertiary helium coolant on tritium permeation rate for the Next Generation Nuclear Plant using the high-temperature electrolysis process.

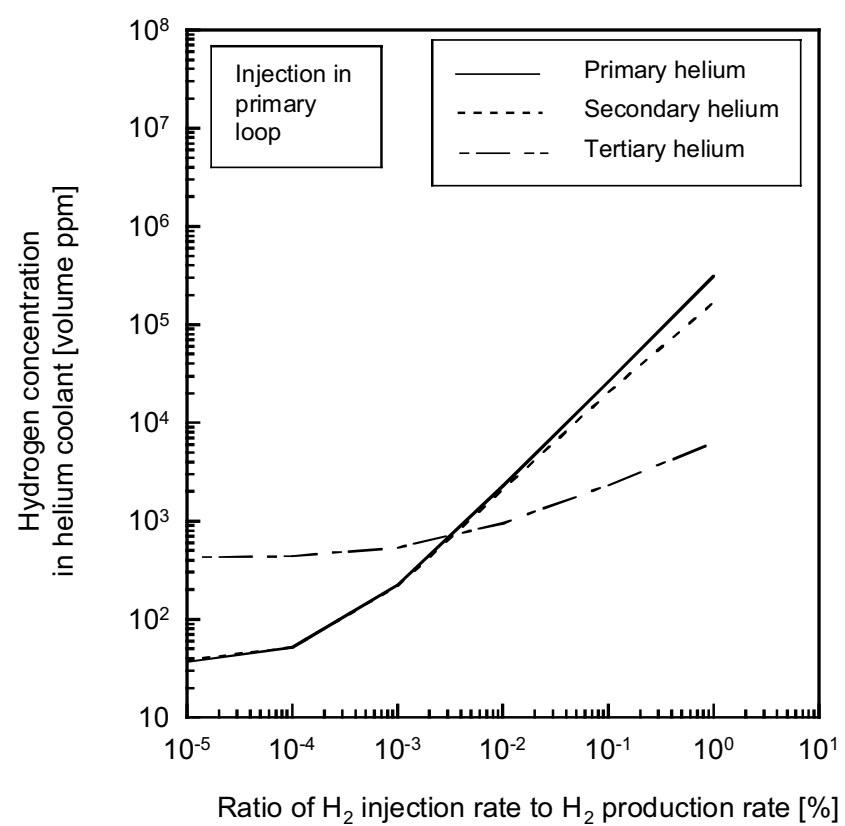

Figure 51. Effect of varying hydrogen injection in the primary helium coolant on hydrogen concentration in the helium coolant for the Next Generation Nuclear Plant using the high-temperature electrolysis process. 


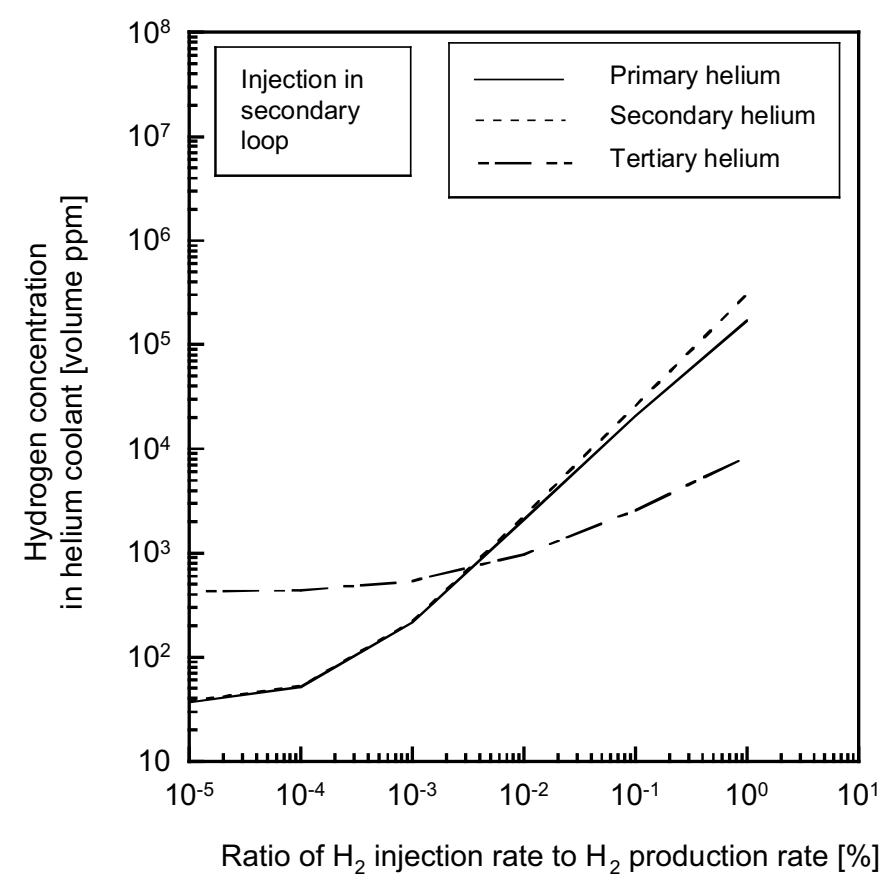

Figure 52. Effect of varying hydrogen injection in the secondary helium coolant on hydrogen concentration in the helium coolant for the Next Generation Nuclear Plant using the high-temperature electrolysis process.

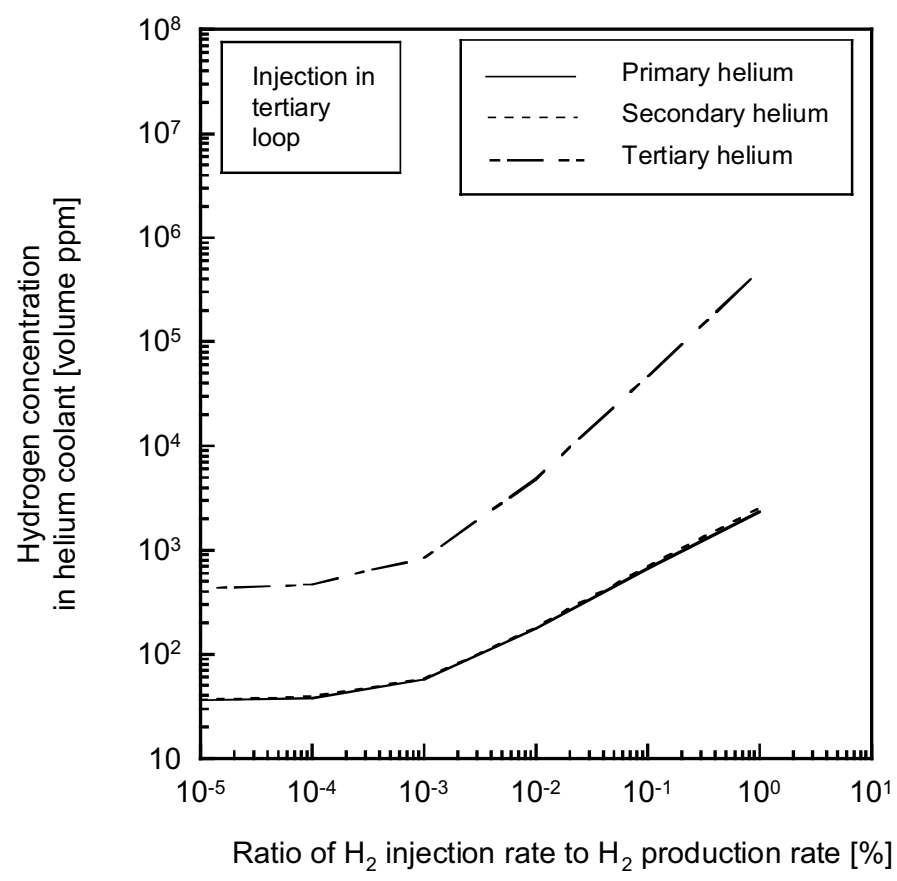

Figure 53. Effect of varying hydrogen injection in the tertiary helium coolant on hydrogen concentration in the helium coolant for the Next Generation Nuclear Plant using the high-temperature electrolysis process. 
The increased hydrogen concentration in the primary helium may cause a decrease in the amount of chemisorbed tritium in the core graphite. This would result in an increase in the tritium release rate to the primary coolant and the tritium concentration in the hydrogen product. This phenomenon is not currenly modeled in THYTAN. In future analyses, the possible effect of hydrogen injection on the core graphite retention of tritium should be examined and included in THYTAN.

The increased hydrogen concentration in the helium coolants results in a decrease of oxygen partial pressure. Therefore, injection of oxygen or water should be carried out to maintain the oxygen partial pressure at a certain value in order to maintain the material surface chemistries of high-temperature components (i.e., heat exchangers). However, injection of excess oxygen or water into primary helium may increase the risk of causing an accident due to graphite oxidation. To avoid this problem, injection of hydrogen and any balancing oxygen and water should be peformed on the tertiary loop, furthest away from the primary loop and the core graphite materials.

\section{Tritium concentration in a component of the high-temperature electrolysis process.}

Figure 54 shows the tritium concentration in the electrolyzer's gaseous process chemicals in response to changes in the hydrogen injection rates. Tritium concentration decreases with an increase of the hydrogen injection rates. No difference exists between injection in the primary and secondary helium. However, the effect of hydrogen injection in the primary and the secondary helium on the tritium concentration in gaseous process chemicals is slightly significant when compared with that in tertiary helium (as in the case of the tritium concentration in product hydrogen). The tritium concentration in gaseous process chemicals becomes less than the gaseous effluent limit above the injection rate of about $5 \times 10^{-4} \%$ in the primary and secondary helium, and $1 \times 10^{-3} \%$ in the tertiary helium.

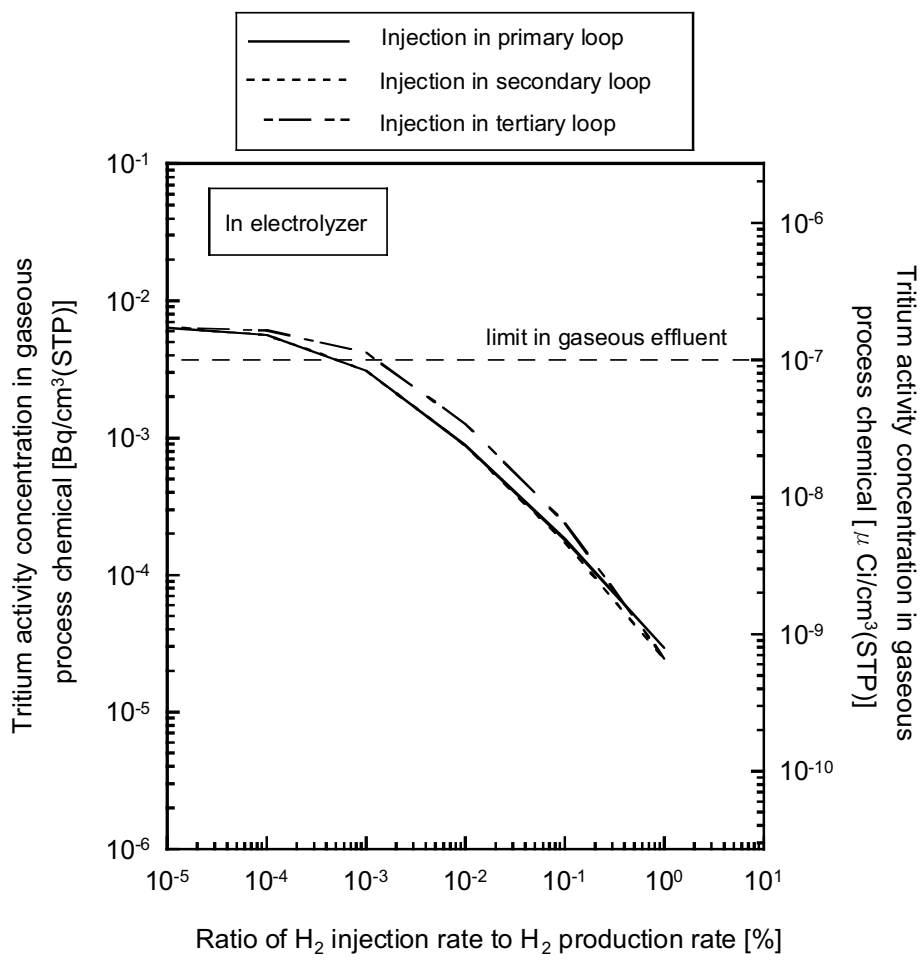

Figure 54. Effect of varying hydrogen injection in the helium coolant on the tritium concentration in the electrolyzer's gaseous process chemicals for the Next Generation Nuclear Plant using the hightemperature electrolysis process. 
Figure 55 shows the tritium concentration in the $\mathrm{H}_{2} / \mathrm{H}_{2} \mathrm{O}$ knockout tank's liquid process chemicals in response to varying the hydrogen injection rates. Tritium concentration in the knockout tank also decreases with an increase of hydrogen injection rates. The curve profile for the knockout tank is nearly the same as for the gaseous effluents in response to changes in the hydrogen injection rate, and at all points, the tritium concentration in the liquid process chemicals is below the liquid effluent limit.

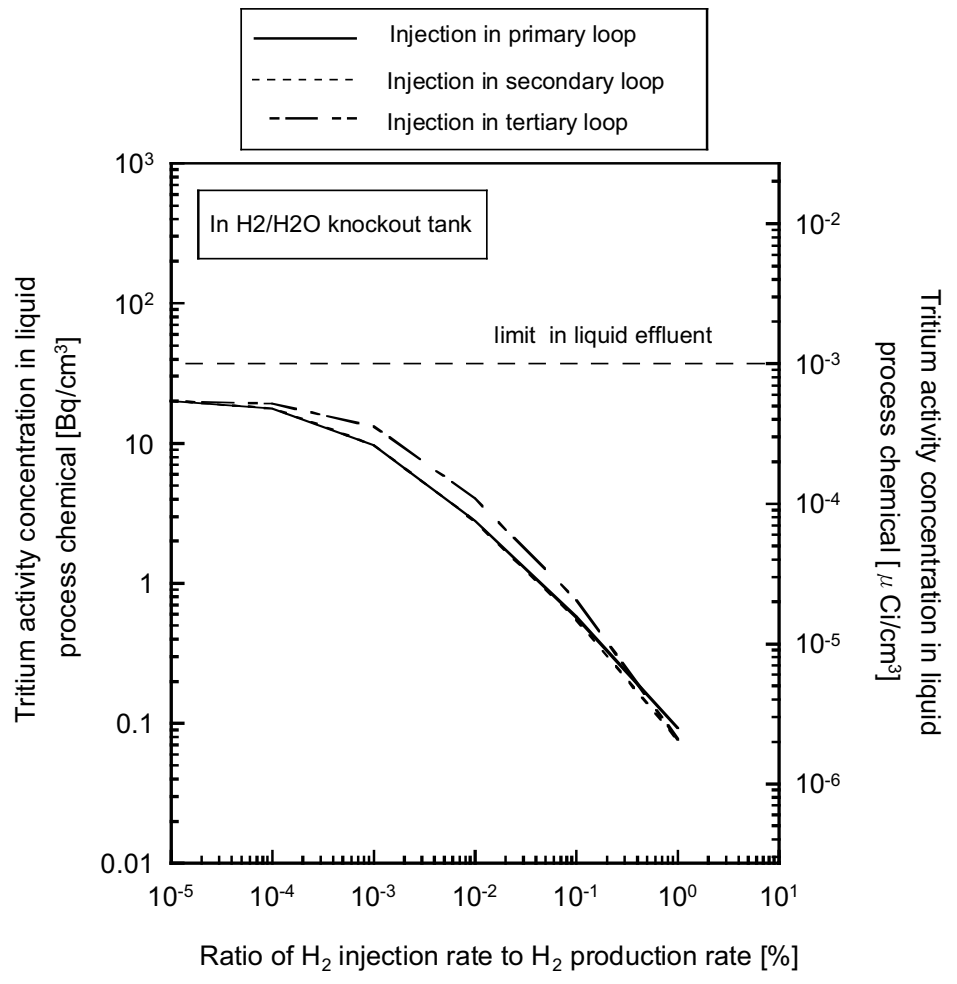

Figure 55. Effect of varying hydrogen injection in the helium coolant on the tritium concentration in the $\mathrm{H}_{2} / \mathrm{H}_{2} \mathrm{O}$ knockout tank's liquid process chemicals for the Next Generation Nuclear Plant using the high-temperature electrolysis process.

Tritium concentration in helium coolant. Figures 56,57 , and 58 show tritium concentration changes in the helium loops in response to changes in the hydrogen injection rate in the primary, secondary, and tertiary helium, respectively. In all cases, tritium concentrations in the primary and secondary helium slightly increase with an increase of the hydrogen injection rate. However, in all cases, tritium concentrations in tertiary helium decrease with an increase of the hydrogen injection rate. This is because the tritium permeation rates through PHX decrease more than those through IHX and SHX. However, the tritium concentration in tertiary helium is much larger than the gaseous effluent limit. 


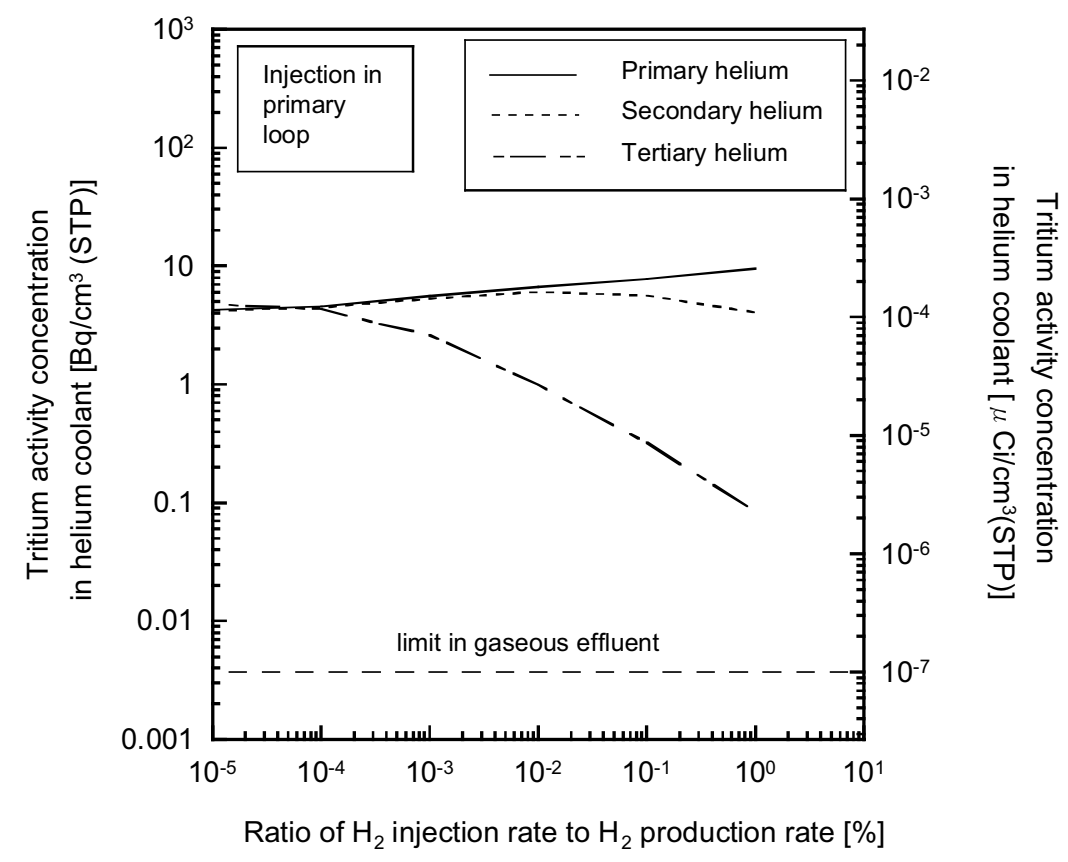

Figure 56. Effect of varying hydrogen injection in the primary helium coolant on the tritium concentration of the helium coolant for the Next Generation Nuclear Plant using the high-temperature electrolysis process.

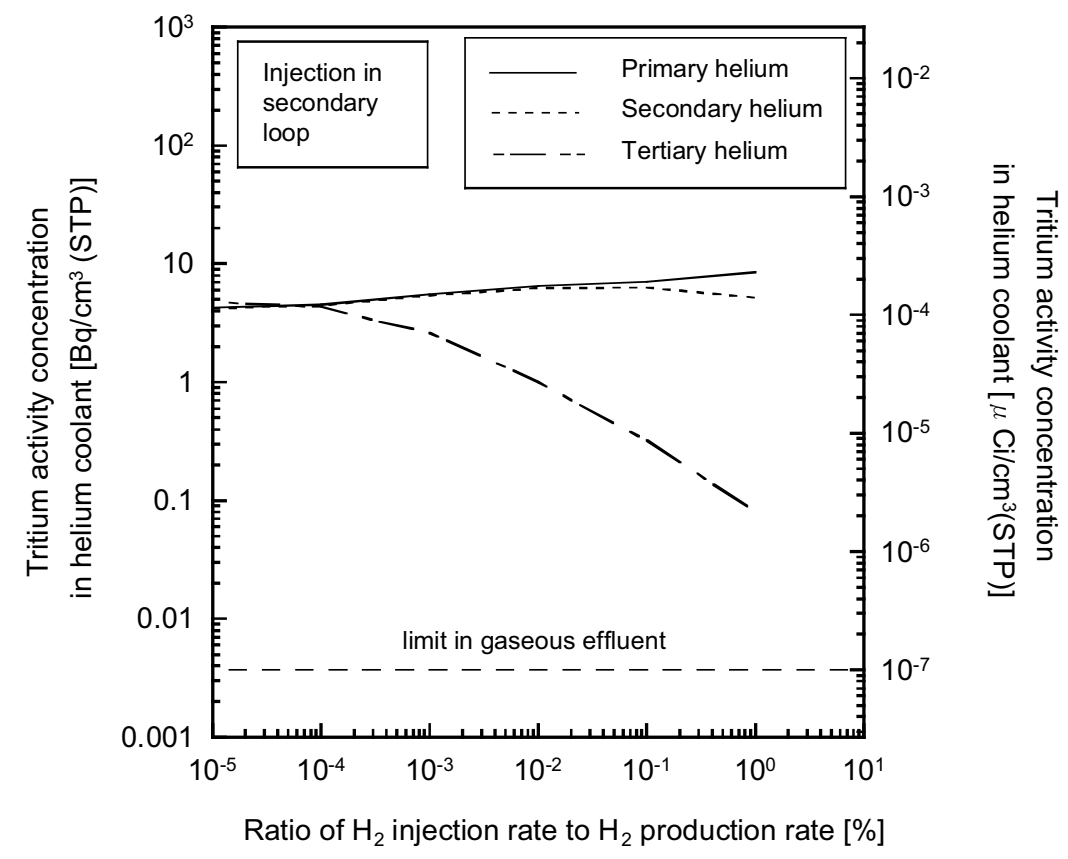

Figure 57. Effect of varying hydrogen injection in the secondary helium coolant on the tritium concentration of the helium coolant for the Next Generation Nuclear Plant using the high-temperature electrolysis process. 


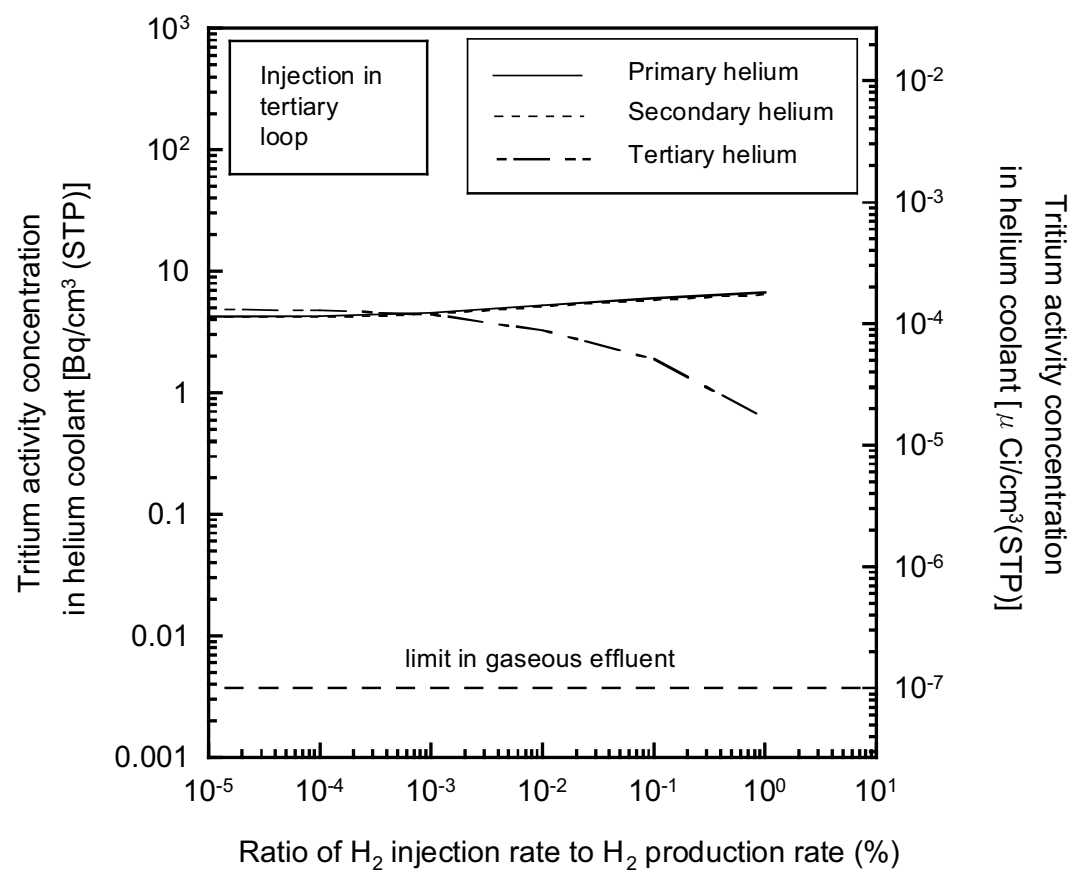

Figure 58. Effect of varying hydrogen injection in the tertiary helium coolant on the tritium concentration of the helium coolant for the Next Generation Nuclear Plant using the high-temperature electrolysis process.

\subsubsection{Effect of Tertiary Loop}

Model. In the current NGNP design, the tertiary loop will be employed to increase the isolation between the VHTR and the hydrogen production plant for safety reasons. In order to estimate the effect the tertiary loop has on the tritium concentration in product hydrogen, the calculation is carried out using an alternative model without a tertiary loop (see Figure 59). The SHX is eliminated and the secondary helium loop is connected to PHX-1, PHX-2, and PHX-3. The secondary helium flow rate at SHX in the base case (i.e., $31.9 \mathrm{~kg} / \mathrm{s}$ ) is slightly larger than the tertiary helium flow rate of $27.5 \mathrm{~kg} / \mathrm{s}$. Therefore, the total helium flow rate to PHX-1 and PHX-3 is set as the secondary helium flow rate at SHX for the base case; also, it is divided at the same ratio of PHX-1 and PHX-3 for the base case. The temperature of the heat transfer tube is kept at the temperature of the base case. The purification system in the tertiary loop also is eliminated.

Results. Calculation results are summarized in Table 28. Tritium concentrations in the primary and secondary helium decreased to about $35 \%$ and $33 \%$, respectively, by eliminating the tertiary loop. However, tritium concentrations in the HTE process (i.e., in product hydrogen, in product oxygen, in the electrolyzer's gaseous process chemicals, and in the $\mathrm{H} 2 / \mathrm{H} 2 \mathrm{O}$ knockout tank's liquid process chemicals) increased by about 1.56 times by eliminating the tertiary loop. In other words, tritium concentrations in the HTE process can be reduced by factor of 0.64 when employing the tertiary loop with SHX and purification system. Therefore, the effect of the tertiary loop on the tritium concentration is not significant. 


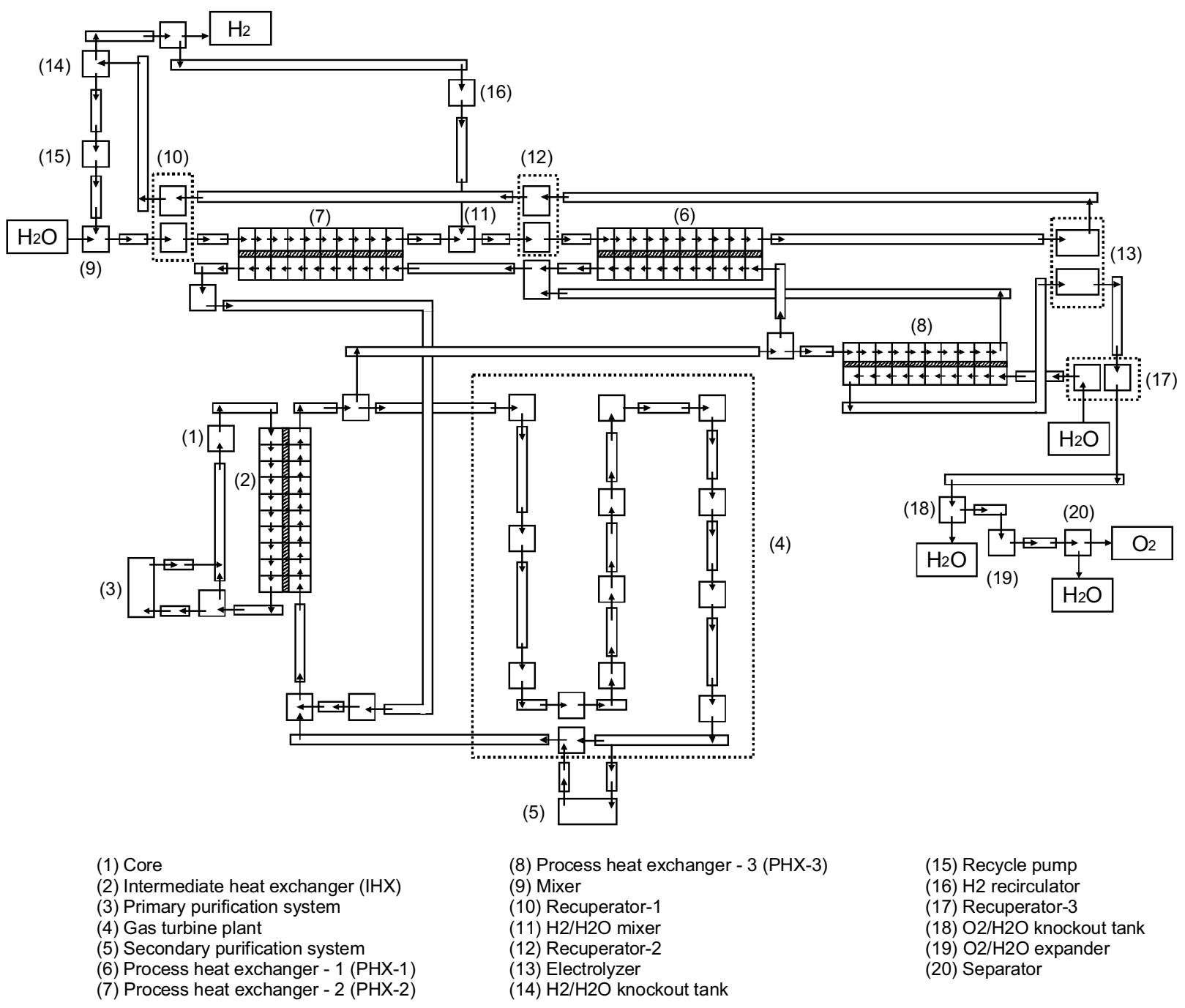

Figure 59. Nodalization scheme for the Next Generation Nuclear Plant using the high-temperature electrolysis process without a tertiary loop.

Table 28. Comparison of tritium concentrations for the Next Generation Nuclear Plant using the high-temperature electrolysis process with and without the tertiary loop.

\begin{tabular}{|l|c|c|}
\hline & $\begin{array}{c}\text { With } \\
\text { Tertiary Loop }\end{array}$ & $\begin{array}{c}\text { Without } \\
\text { Tertiary Loop }\end{array}$ \\
\hline In product hydrogen $\left(\mathrm{Bq} / \mathrm{cm}^{3}[\mathrm{STP}]\right)$ & $2.67 \times 10^{-3}$ & $4.16 \times 10^{-3}$ \\
\hline In product oxygen $\left(\mathrm{Bq} / \mathrm{cm}^{3}[\mathrm{STP}]\right)$ & $2.97 \times 10^{-4}$ & $4.66 \times 10^{-4}$ \\
\hline In gaseous process chemicals (in the electrolyzer) $\left(\mathrm{Bq} / \mathrm{cm}^{3}[\mathrm{STP}]\right)$ & $6.44 \times 10^{-3}$ & $1.01 \times 10^{-2}$ \\
\hline $\begin{array}{l}\text { In liquid process chemicals (in the } \mathrm{H}_{2} / \mathrm{H}_{2} \mathrm{O} \text { knockout tank) } \\
\left(\mathrm{Bq} / \mathrm{cm}^{3}\right)\end{array}$ & 20.3 & 31.7 \\
\hline In primary helium $\left(\mathrm{Bq} / \mathrm{cm}^{3}[\mathrm{STP}]\right)$ & 4.24 & 1.50 \\
\hline In secondary helium $\left(\mathrm{Bq} / \mathrm{cm}^{3}[\mathrm{STP}]\right)$ & 4.18 & 1.38 \\
\hline
\end{tabular}




\subsection{Summary}

For the base case of the NGNP using the HTE process, the tritium concentration in the gaseous product hydrogen (i.e., $2.67 \times 10^{-3} \mathrm{~Bq} / \mathrm{cm}^{3}[\mathrm{STP}]$ ) is slightly less than the gaseous effluent limit of $3.7 \times 10^{-3} \mathrm{~Bq} / \mathrm{cm}^{3}(\mathrm{STP})$. However, the tritium concentration in the liquid hydrogen product (i.e., $2.30 \mathrm{~Bq} / \mathrm{ml}$ ) is larger than the drinking water limit of $0.74 \mathrm{~Bq} / \mathrm{ml}$. The tritium concentration in gaseous process chemicals in the electrolyzer shows the maximum concentration among whole components in the HTE process at $6.44 \times 10^{-3} \mathrm{~Bq} / \mathrm{cm}^{3}(\mathrm{STP})$. This is slightly higher than the gaseous effluent limit of $3.7 \times 10^{-3} \mathrm{~Bq} / \mathrm{cm}^{3}$ (STP). The tritium concentration in liquid process chemicals in the $\mathrm{H}_{2} / \mathrm{H}_{2} \mathrm{O}$ knockout tank is the highest among all components in the HTE process at $20.3 \mathrm{~Bq} / \mathrm{cm}^{3}$. This is less than the liquid effluent limit. The tritium concentration in the tertiary helium (i.e., $4.85 \mathrm{~Bq} / \mathrm{cm}^{3}$ [STP]) is larger than the gaseous effluent limit in of $3.7 \times 10^{-3} \mathrm{~Bq} / \mathrm{cm}^{3}$ (STP) by a factor of more than 1,000. The effect of some parameters was evaluated. Values of each parameter used to decrease the tritium concentrations less than the limit are summarized in Table 29. Note that the tritium concentration in liquid process chemicals is less than the liquid effluent limit, even for the base case. The concentration is less than the liquid effluent limit regardless of the values of some parameters (e.g., IHX permeability and hydrogen injection rate).

Table 29. Conditions for decreasing tritium concentrations to below gaseous and liquid limits.

\begin{tabular}{|c|c|c|c|c|}
\hline Item & $\begin{array}{l}\text { In Product } \\
\text { Hydrogen }\end{array}$ & $\begin{array}{c}\text { In Gaseous } \\
\text { Process Chemicals }\end{array}$ & $\begin{array}{c}\text { In Liquid Process } \\
\text { Chemicals }\end{array}$ & $\begin{array}{l}\text { In Tertiary } \\
\text { Helium }\end{array}$ \\
\hline Limit & In drinking water & In gaseous effluent & In liquid effluent & $\begin{array}{c}\text { In gaseous } \\
\text { effluent }\end{array}$ \\
\hline Release rate & $\leq 0.3$ times $^{\mathrm{a}}$ & $\leq 0.6$ times $^{\mathrm{a}}$ & $\leq 2$ times $^{\mathrm{a}}$ & $\leq 8 \times 10^{-4}$ times $^{\mathrm{a}}$ \\
\hline $\begin{array}{l}\text { Intermediate heat exchanger } \\
\text { permeability }\end{array}$ & $\leq 0.001$ times $^{\mathrm{a}}$ & $\leq 0.006$ times $^{\mathrm{a}}$ & Less than limit & $\leq 2 \times 10^{-8}$ times $^{\mathrm{a}}$ \\
\hline $\begin{array}{l}\text { Secondary heat exchanger } \\
\text { permeability }\end{array}$ & $\leq 0.08$ times $^{\mathrm{a}}$ & $\leq 0.3$ times $^{\mathrm{a}}$ & $\leq 10$ times $^{\mathrm{a}}$ & $\leq 3 \times 10^{-6}$ times $^{\mathrm{a}}$ \\
\hline Process heat exchanger permeability & $\leq 0.04$ times $^{\mathrm{a}}$ & $\leq 0.2$ times $^{\mathrm{a}}$ & $\leq 8$ times $^{\mathrm{a}}$ & None \\
\hline $\begin{array}{l}\text { Helium flow rate at purification } \\
\text { system in primary loop }\end{array}$ & $\geq 3 \mathrm{~h}^{-1 \mathrm{~b}}$ & $\geq 0.7 \mathrm{~h}^{-1 \mathrm{~b}}$ & $>0.01 \mathrm{~h}^{-1 \mathrm{~b}}$ & None \\
\hline $\begin{array}{l}\text { Helium flow rate at purification } \\
\text { system in secondary loop }\end{array}$ & $\geq 3 \mathrm{~h}^{-1 b}$ & $\geq 0.7 \mathrm{~h}^{-1 \mathrm{~b}}$ & $>0.01 \mathrm{~h}^{-1 \mathrm{~b}}$ & None \\
\hline $\begin{array}{l}\text { Helium flow rate at purification } \\
\text { system in tertiary loop }\end{array}$ & $\geq 4 \mathrm{~h}^{-1 \mathrm{~b}}$ & $\geq 0.7 \mathrm{~h}^{-1 \mathrm{~b}}$ & $\geq 0.01 \mathrm{~h}^{-1 \mathrm{~b}}$ & None \\
\hline $\begin{array}{l}\text { Helium flow rate at purification } \\
\text { system in all loops }\end{array}$ & $\geq 0.6 \mathrm{~h}^{-1 \mathrm{~b}}$ & $\geq 0.3 \mathrm{~h}^{-1 \mathrm{~b}}$ & $\geq 0.05 \mathrm{~h}^{-1 \mathrm{~b}}$ & $\geq 60 \mathrm{~h}^{-1 b}$ \\
\hline Pressure in tertiary loop & $<0.1 \mathrm{MPa}$ & $\leq 0.3 \mathrm{MPa}$ & $<10 \mathrm{MPa}$ & None \\
\hline Reactor outlet temperature & $\geq 990 \mathrm{~K}$ & $\leq 1070 \mathrm{~K}$ & $<1173 \mathrm{~K}$ & None \\
\hline Hydrogen injection in primary loop & $\geq 0.002 \%{ }^{\mathrm{c}}$ & $\geq 5 \times 10^{-4} \%^{\mathrm{c}}$ & Less than limit & None \\
\hline Hydrogen injection in secondary loop & $\geq 0.002 \%^{\mathrm{c}}$ & $\geq 5 \times 10^{-4} \%{ }^{\mathrm{c}}$ & Less than limit & None \\
\hline Hydrogen injection in tertiary loop & $\geq 0.004 \%{ }^{\mathrm{c}}$ & $\geq 0.001 \%^{\mathrm{c}}$ & Less than limit & None \\
\hline
\end{tabular}


The tritium concentration decreases proportionally with a decrease in the tritium release rate to the primary coolant. Therefore, the effect of the tritium release rate is significant. Tritium concentrations in the hydrogen product and in gaseous process chemicals becomes less than the drinking water limit and the gaseous effluent limit under the conditions that the tritium release rate is less than 0.3 times and 0.6 times against the base case, respectively. However, the tritium release rate should be decreased less than $8 \times 10^{-4}$ times in order to decrease the tritium concentration in the tertiary helium less than the gaseous effluent limit.

A decrease in permeability of SHX is more effective than that of IHX and PHX. Tritium concentrations in product hydrogen and in gaseous process chemicals can be decreased less than the drinking water limit and in the gaseous effluent by decreasing SHX permeability below about 0.08 times and 0.3 times against the base case, respectively. However, SHX permeability should be decreased more drastically (i.e., less than $3 \times 10^{-6}$ times) to reduce the tritium concentration in the tertiary helium less than the gaseous effluent limit.

For the helium flow rate at the purification system, no significant difference exists among the purification systems in each loop. Increasing helium flow rates at all purification systems is reasonably more effective than at each purification system. Tritium concentrations in the hydrogen product and in gaseous process chemicals can be decreased to less than the drinking water limit and the gaseous effluent limit under the condition that all helium flow rates at purification systems are above $0.6 \mathrm{~h}^{-1}$ and $0.3 \mathrm{~h}^{-1}$ of the ratio of helium flow rate to the helium inventory, respectively. The value at the base case is $0.12 \mathrm{~h}^{-1}$. Hence, there are many ways to achieve lower tritium concentrations by altering helium purification flow rates. However, all helium flow rates at purification systems should be increased more than $60 \mathrm{~h}^{-1}$ to decrease the tritium concentration in tertiary helium less than the gaseous effluent limit.

The effect of pressure in the tertiary loop is not significant. The tritium concentration in the gaseous process chemicals becomes less than the gaseous effluent limit below $0.3 \mathrm{MPa}$. Tritium concentrations in product hydrogen and in tertiary helium are larger than the drinking water limit and the gaseous effluent limit at the evaluated condition from 0.1 to $10 \mathrm{MPa}$, respectively.

The tritium concentration in product hydrogen and in gaseous process chemicals becomes less than the drinking water limit and the gaseous effluent below $990 \mathrm{~K}$ and $1,070 \mathrm{~K}$ of reactor outlet temperature, respectively. However, it is difficult to decrease tritium concentration in the tertiary helium less than the gaseous effluent limit by changing the reactor outlet temperature by itself.

The tritium concentration in the hydrogen product and in gaseous process chemicals can be decreased efficiently by hydrogen injection in the helium coolant, especially in the primary or secondary systems. Hydrogen injection rates required to decrease the tritium concentration in product hydrogen and in gaseous process chemicals less than the drinking water limit and the gaseous effluent limit are $0.002 \%$ and $5 \times 10^{-4} \%$ of the hydrogen production rate, respectively. However, it is impossible to decrease the tritium concentration in tertiary helium less than the gaseous effluent limit under the reasonable hydrogen injection rate (e.g., less than $1 \%$ of the hydrogen production rate).

The effect of having or not having a tertiary loop is not significant in regard to tritium concentrations in the hydrogen products. Tritium concentrations in the HTE process can be reduced by a factor of only 0.64 by employing the tertiary loop.

Tritium concentrations in the hydrogen product and gaseous process chemicals can be decreased less than the drinking water limit and gaseous effluent limit by the simultaneous application of some controls under reasonable conditions (i.e., increase purification system capacity, decrease temperature, 
and hydrogen injection). However, possible countermeasures to decrease the tritium concentration in tertiary helium less than the gaseous effluent limit seems more difficult to achieve. These measure include the following: decreasing the tritium release rate less than $8 \times 10^{-4}$ times against the base case, decreasing IHX permeability less than $2 \times 10^{-8}$ times, decreasing SHX permeability less

than $3 \times 10^{-6}$ times, and increasing helium flow rate at all purification systems more than $60 \mathrm{~h}^{-1}$.

Decreasing the tritium release rate and permeabilities are technical challenges. However, increasing the capacity of purification systems is an economical issue. Decreasing SHX permeability can be considered the most reasonable countermeasure to decrease the tritium concentration in tertiary helium. 


\section{NUMERICAL ANALYSIS OF THE NEXT GENERATION NUCLEAR PLANT USING THE SULFUR IODINE PROCESS}

\subsection{System Description}

The SI process is a thermochemical water-splitting hydrogen production method that is composed of the following three main chemical reactions:

$\mathrm{I}_{2}+\mathrm{SO}_{2}+2 \mathrm{H}_{2} \mathrm{O}=2 \mathrm{HI}+\mathrm{H}_{2} \mathrm{SO}_{4}$

$\mathrm{H}_{2} \mathrm{SO}_{4}=\mathrm{H}_{2} \mathrm{O}+\mathrm{SO}_{2}+0.5 \mathrm{O}_{2}$

$2 \mathrm{HI}=\mathrm{H}_{2}+\mathrm{I}_{2}$.

The thermal decomposition of $\mathrm{H}_{2} \mathrm{SO}_{4}$ that is expressed by Equation (79) can be distinguished into the following consecutive reactions:

$\mathrm{H}_{2} \mathrm{SO}_{4}=\mathrm{H}_{2} \mathrm{O}+\mathrm{SO}_{3}$.

$\mathrm{SO}_{3}=\mathrm{SO}_{2}+0.5 \mathrm{O}_{2}$.

The reaction expressed by Equation (78), known as the Bunsen reaction, produces $\mathrm{HI}$ and $\mathrm{H}_{2} \mathrm{SO}_{4}$ through the reaction among raw materials water, iodine $\left(\mathrm{I}_{2}\right)$, and sulfur dioxide $\left(\mathrm{SO}_{2}\right)$. The $\mathrm{H}_{2} \mathrm{SO}_{4}$ and $\mathrm{HI}$ produced are decomposed at temperatures around $850^{\circ} \mathrm{C}$ and $450^{\circ} \mathrm{C}$, respectively, to produce oxygen and hydrogen according to the reactions shown in Equations (79) and (80).

A current NGNP flowsheet using the SI process is not available. However, an SI process flowsheet employing reactive distillation instead of the current extractive distillation is available (Richards et al., 2006) and is the one employed in this study. Figures 60, 61, and 62 show the SI process flowsheet: Section 1 for Bunsen reaction, Section 2 for sulfuric acid decomposition, and Section 3 for hydrogen iodine decomposition, respectively. In Section $1, \mathrm{H}_{2} \mathrm{SO}_{4}$ and $\mathrm{HI}$ are generated by the Bunsen reaction in a Bunsen reactor (R101). The $\mathrm{H}_{2} \mathrm{SO}_{4}$ and $\mathrm{HI}$ produced in this section are supplied to Section 2 and Section 3, respectively. In Section 2, helium flows into Decomposer 2 (H210B), Decomposer 1 (H210A), Recuperator 2 (H209), Vaporizer 3 (H208B), and Vaporizer 2 (H208A) in a series to vaporize and decompose $\mathrm{H}_{2} \mathrm{SO}_{4}$. The products (i.e., $\mathrm{H}_{2} \mathrm{O}, \mathrm{SO}_{2}$, and $\mathrm{O}_{2}$ ) and unreacted raw material (i.e., $\mathrm{H}_{2} \mathrm{SO}_{4}$ ) are recycled to Section 1. Oxygen is obtained from \#1 $\mathrm{O}_{2}$ scrubber (C104) and \#2 $\mathrm{O}_{2}$ scrubber (C101) in Section 1. In Section 3, HI is decomposed to $\mathrm{H}_{2}$ and $\mathrm{I}_{2}$ in a reactive still (C301). Hydrogen is obtained from a $\mathrm{H}_{2}$ product scrubber (C302) in Section 3. The products of Section 3 except $\mathrm{H}_{2}$ (i.e., $\mathrm{I}_{2}$ ) and unreacted raw materials (i.e., $\mathrm{HI}$ and $\mathrm{H}_{2} \mathrm{O}$ ) are recycled to Section 1. The thermal energy required to power Section 3 not supplied from helium coolant but from Section 2.

Figure 63 shows a schematic flowsheet of the NGNP using the SI process, which is tentatively modeled in this study. The major specifications are listed in Table 30. As for primary and secondary loops, the same system configuration and operating condition for the NGNP as was used in the HTE process modeling are applied (i.e., thermal energy of $50 \mathrm{MW}$ from the reactor is supplied to the SI process). The tertiary helium loop is connected to PHXs in Section 2 of the SI process in a series (i.e., H210B, H210A, H209, H208B, and H208A). Flow rate and pressure of the tertiary coolant is assumed to be the same as for the NGNP using the HTE process. Flow rates of process chemicals are reported by General Atomics, which correspond to thermal energy of $600 \mathrm{MW}$. In the model discussed here, flow rates of process chemicals in the SI process are assumed to be based on the ratio of thermal energy supplied from reactor coolant to the SI process. Therefore, the hydrogen production rate is 
approximately $1.1 \times 10^{4} \mathrm{~m}^{3}(\mathrm{STP}) / \mathrm{h}$, which is less than that of the HTE process by approximately 0.15 times. 


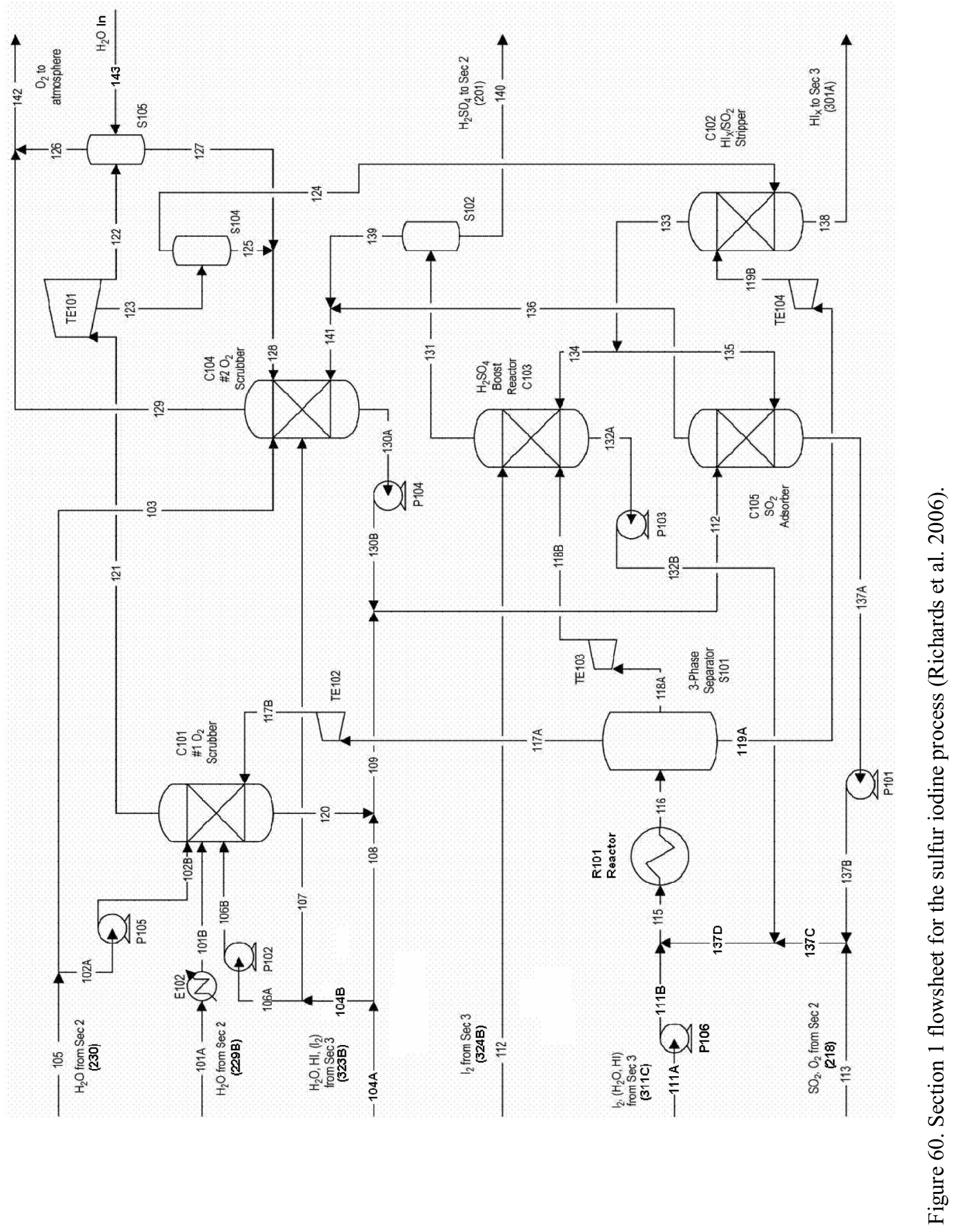




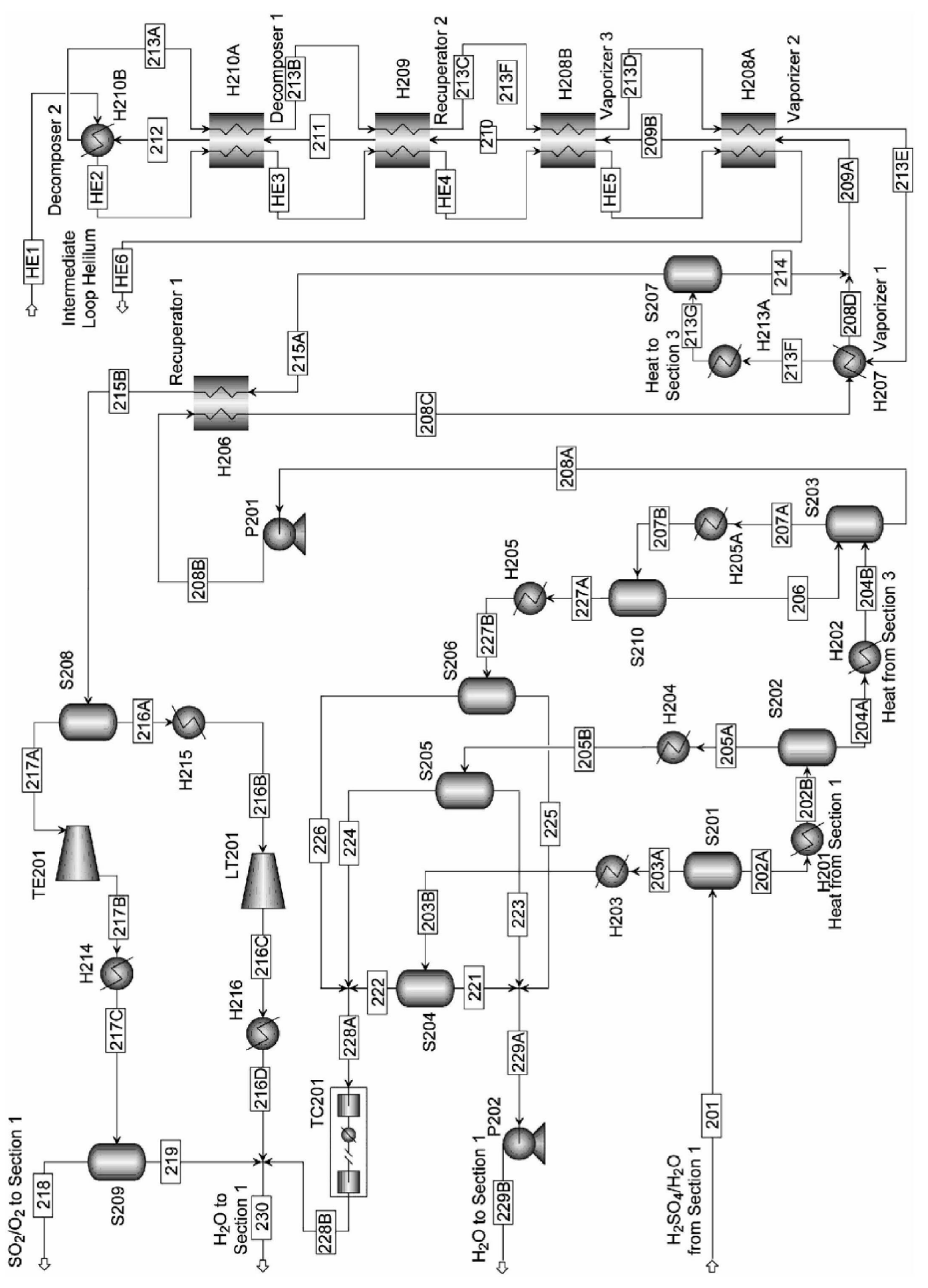

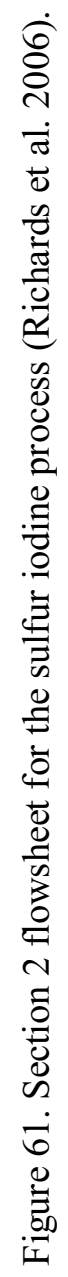




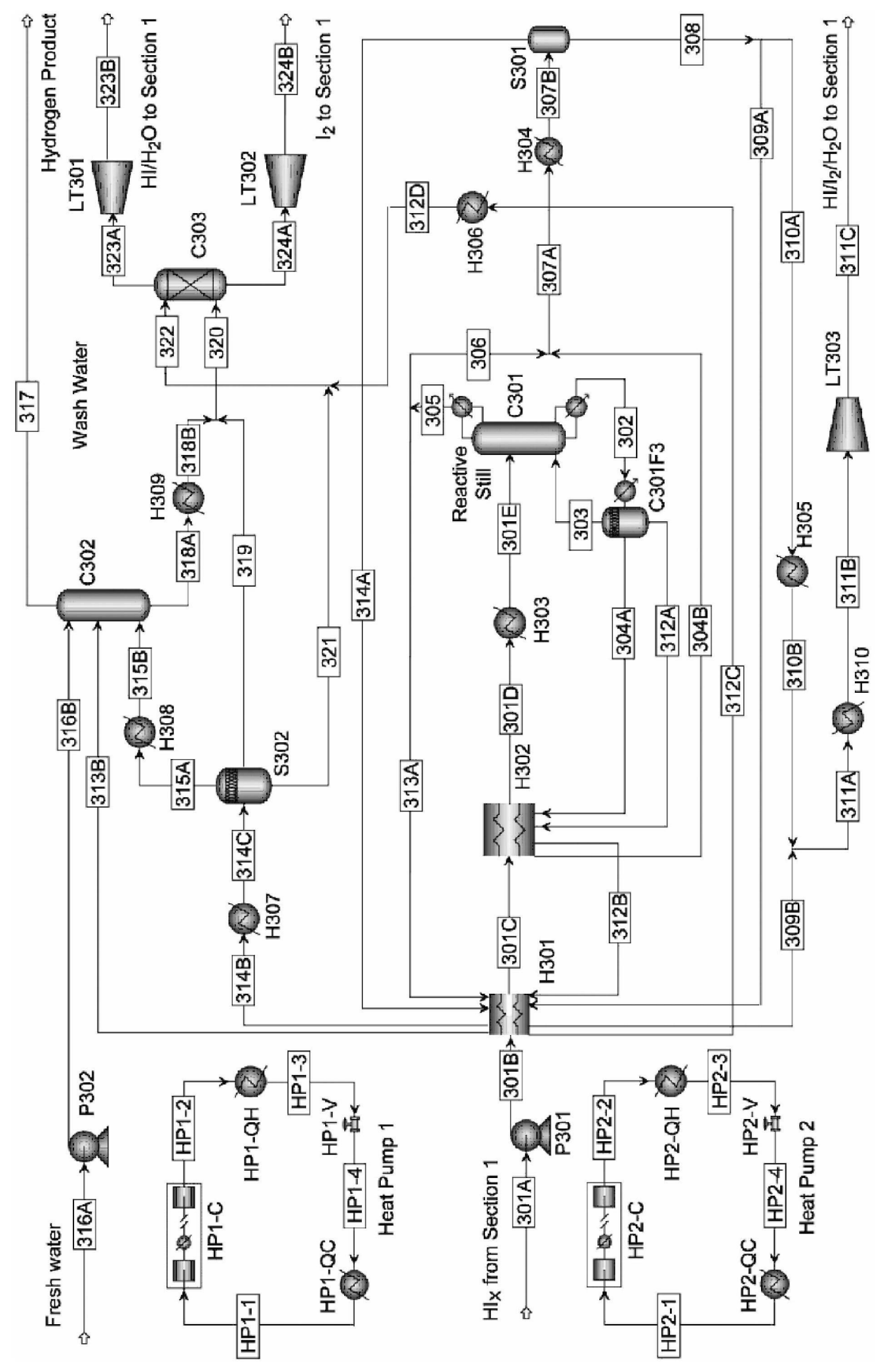

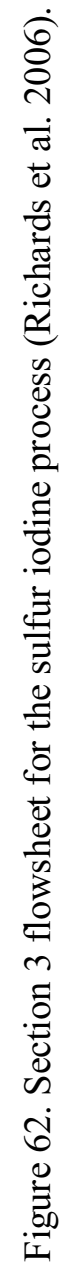




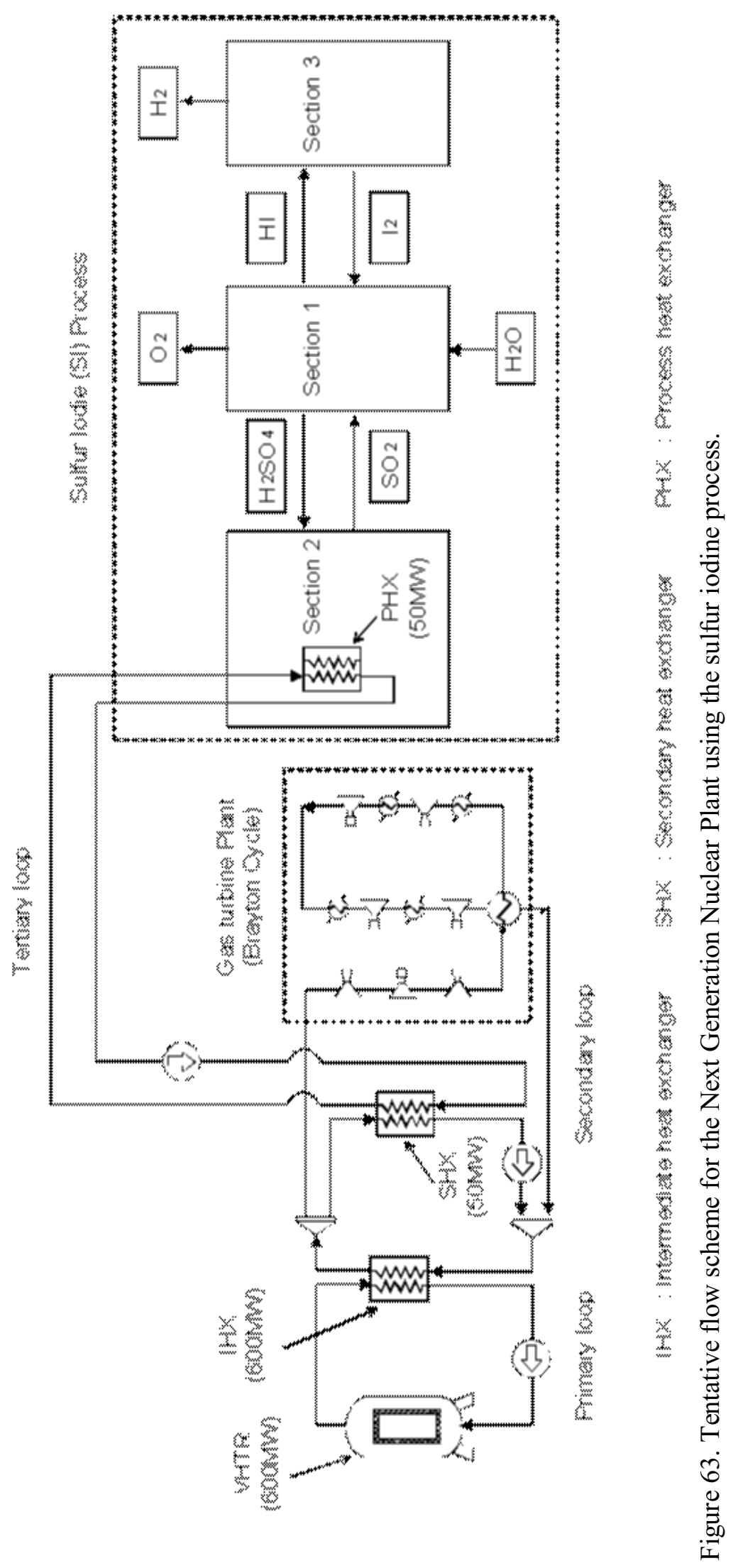


Table 30. Major specifications for the Next Generation Nuclear Plant using the sulfur iodine process.

\begin{tabular}{|c|c|}
\hline Item & Value \\
\hline Reactor power & $600 \mathrm{MWt}$ \\
\hline Heat transfer rate of IHX & $600 \mathrm{MWt}$ \\
\hline Heat transfer rate of SHX & $50 \mathrm{MWt}$ \\
\hline \multicolumn{2}{|l|}{ Primary coolant } \\
\hline Reactor outlet temperature & $900^{\circ} \mathrm{C}$ \\
\hline Reactor inlet temperature & $495^{\circ} \mathrm{C}$ \\
\hline Flow rate & $289 \mathrm{~kg} / \mathrm{s}$ \\
\hline Pressure & $7.0 \mathrm{MPa}$ \\
\hline \multicolumn{2}{|l|}{ Secondary coolant } \\
\hline \multicolumn{2}{|l|}{ Total } \\
\hline IHX outlet temperature & $885^{\circ} \mathrm{C}$ \\
\hline IHX inlet temperature & $480^{\circ} \mathrm{C}$ \\
\hline Flow rate & $289 \mathrm{~kg} / \mathrm{s}$ \\
\hline Pressure & $7.0 \mathrm{MPa}$ \\
\hline \multicolumn{2}{|l|}{ Gas turbine plant line } \\
\hline Gas turbine plant inlet temperature & $885^{\circ} \mathrm{C}$ \\
\hline Gas turbine plant outlet temperature & $467^{\circ} \mathrm{C}$ \\
\hline Flow rate & $257 \mathrm{~kg} / \mathrm{s}$ \\
\hline \multicolumn{2}{|l|}{ SHX line } \\
\hline SHX inlet temperature & $885^{\circ} \mathrm{C}$ \\
\hline SHX outlet temperature & $580^{\circ} \mathrm{C}$ \\
\hline Flow rate & $32 \mathrm{~kg} / \mathrm{s}$ \\
\hline \multicolumn{2}{|l|}{ Tertiary coolant } \\
\hline SHX outlet temperature & $875^{\circ} \mathrm{C}$ \\
\hline SHX inlet temperature & $522^{\circ} \mathrm{C}$ \\
\hline Flow rate & $27.5 \mathrm{~kg} / \mathrm{s}$ \\
\hline Pressure & $2.0 \mathrm{MPa}$ \\
\hline \multicolumn{2}{|l|}{ Sulfur iodine process } \\
\hline Hydrogen production rate & $1.1 \times 10^{4} \mathrm{~m}^{3}(\mathrm{STP}) / \mathrm{h}$ \\
\hline
\end{tabular}




\subsection{Model}

Figures $64,65,66$, and 67 show the helium loop nodalization scheme for the overall layout and the layout of Section 1, Section 2, and Section 3 of the SI process, respectively. The primary and secondary helium model is the same as that for the NGNP using HTE process. A part of the tertiary helium loop model is shown in the Section 2 model of the SI process. Only the heat exchangers between tertiary helium and the SI process (i.e., Decomposer 2 [H210B], Decomposer 1 [H210A], Recuperator 2 [H209], Vaporizer 3 [H208B], and Vaporizer 2 [H208A]) are modeled (among several heat exchangers and recuperators) due to the lack of design data. Each heat exchanger is modeled using five nodes in each flow channel. Pumps, compressors, and expanders are not included in the model.

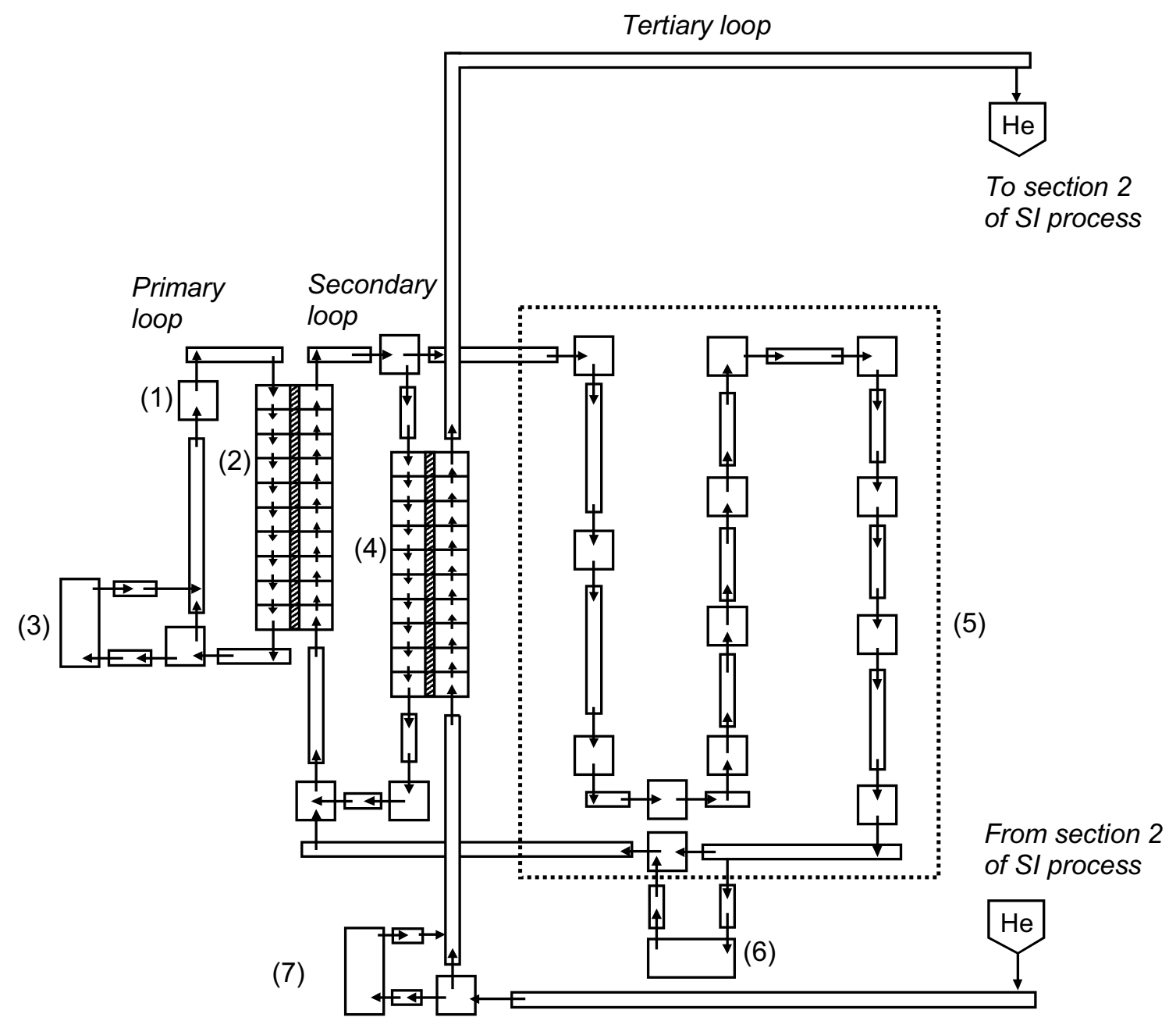

(1) Core

(2) Intermediate heat exchanger $(\mathrm{IHX})$

(3) Primary purification system

(4) Secondary heat exchanger (SHX)

(5) Gas turbine plant

(6) Secondary purification system

(7) Tertiary purification sysytem

Figure 64. Helium loop nodalization scheme for the Next Generation Nuclear Plant using the sulfur iodine process. 


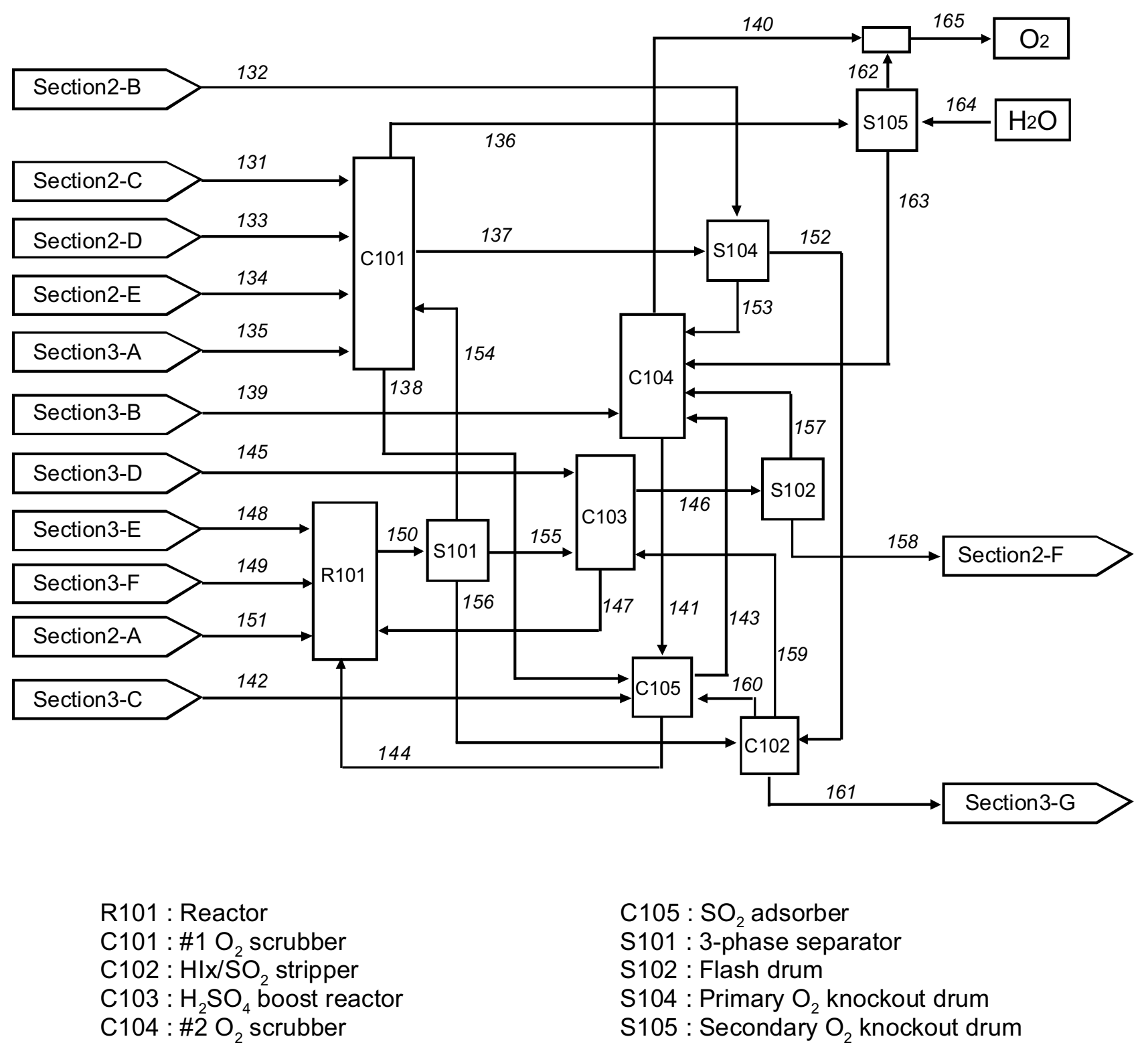

Figure 65. Section 1 nodalization scheme in the sulfur iodine process for Next Generation Nuclear Plant. 
Tertiary loop

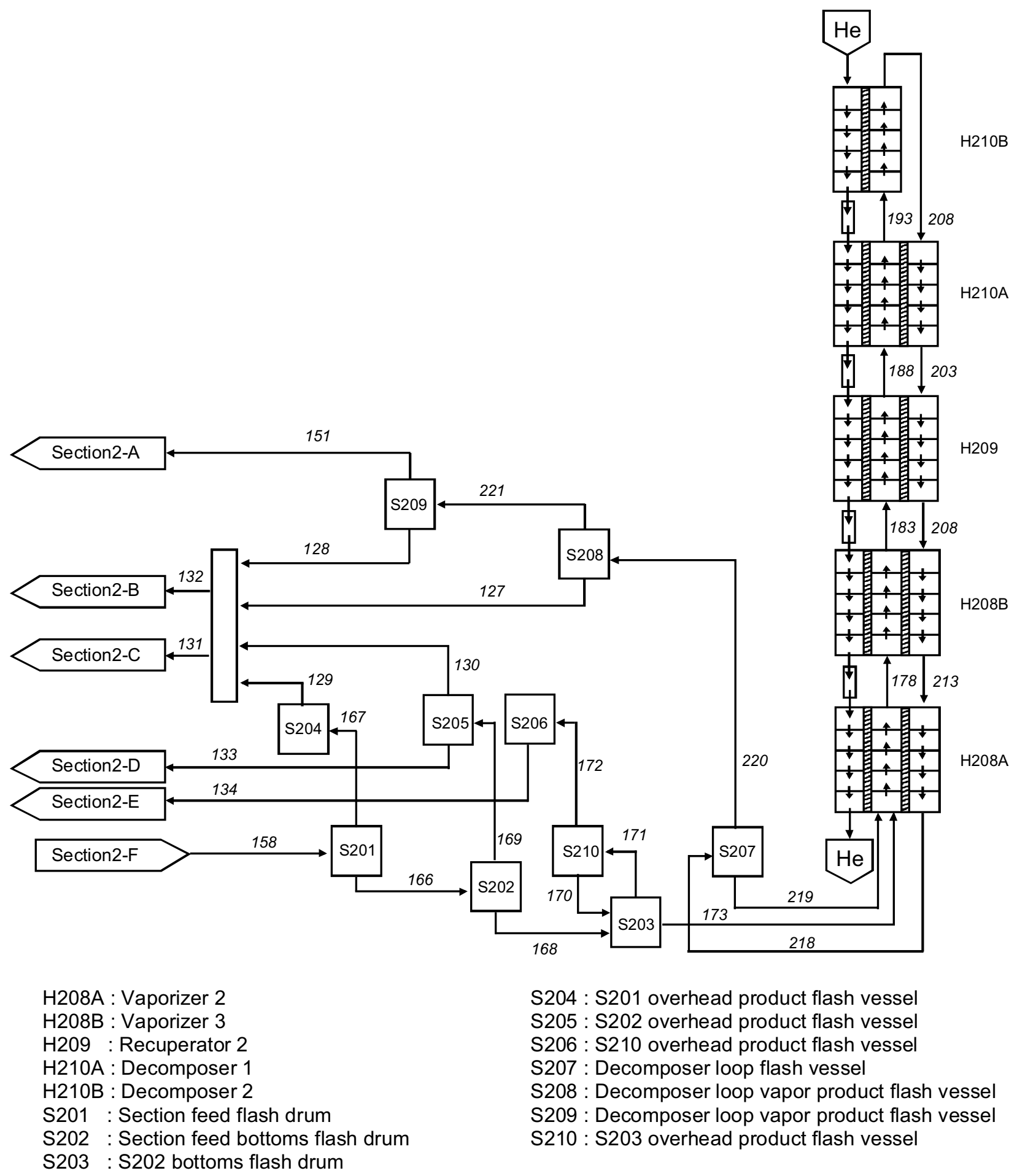

Figure 66. Section 2 nodalization scheme in the sulfur iodine process for the Next Generation Nuclear Plant. 


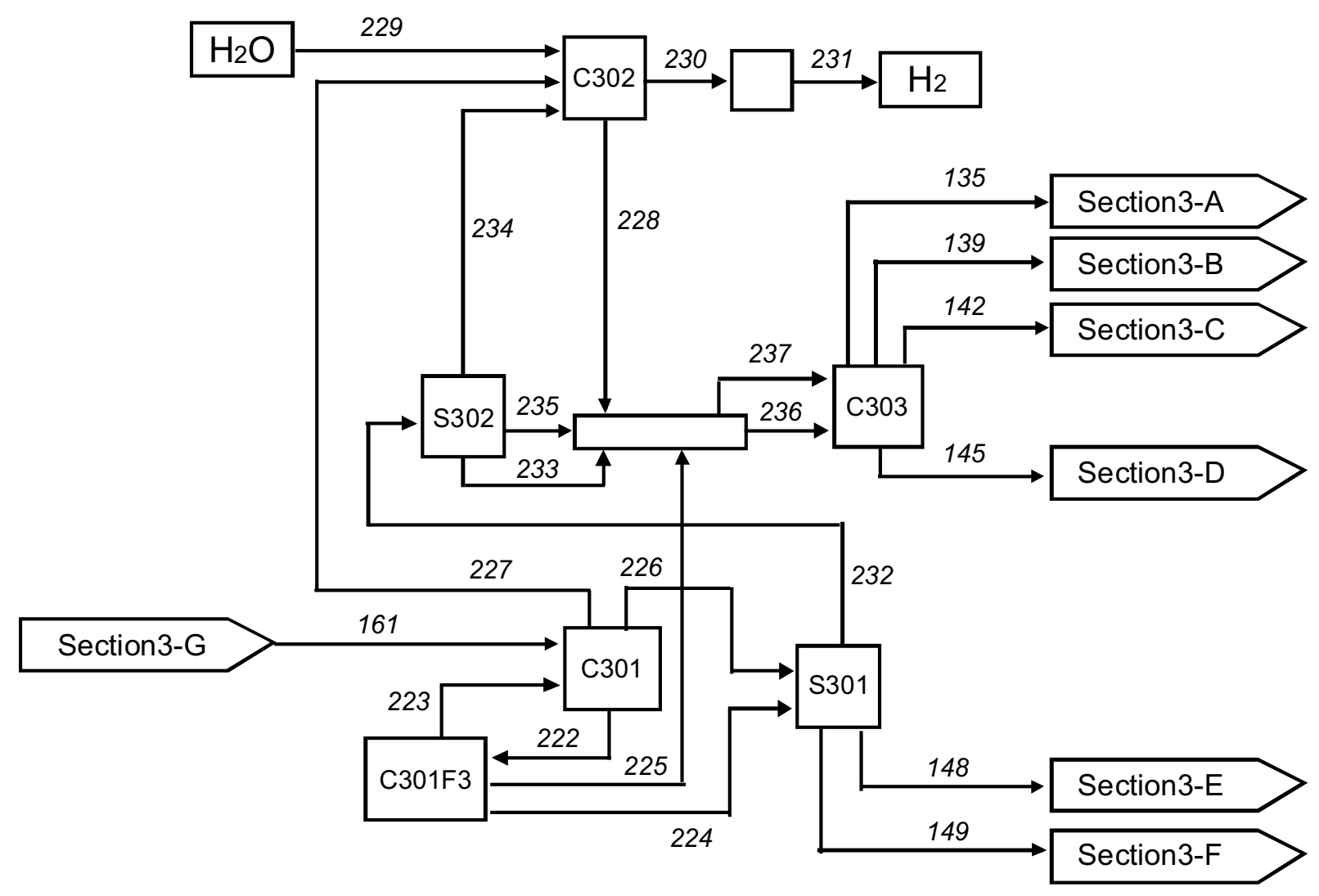

C301: Reactive still

C301F3 : Auxiliary reboiler

C302: $\mathrm{H}_{2}$ product scrubber
C303: $I_{2}$ scrubber

S301: Flash drum

S302 : Flash drum

Figure 67. Section 3 nodalization scheme in the sulfur iodine process for the Next Generation Nuclear Plant.

\subsection{Boundary Conditions}

\subsubsection{Tritium Release Rate}

The tritium release rate to the primary coolant is independent of the type of hydrogen production plant. The tritium release rate to the primary coolant evaluated as the boundary condition for the NGNP using the HTE process (i.e., $1.86 \times 10^{14} \mathrm{~Bq} / \mathrm{y}$ ) is also employed for the base case for the NGNP using the SI process.

\subsubsection{Heat Exchanger}

Permeability of heat transfer tube. Permeabilities of IHX and SHX evaluated in the boundary conditions for the NGNP using the HTE process also are employed for NGNP using the SI process. However, in practice the PHX heat transfer tube will be made of ceramics (e.g., $\mathrm{SiC}, \mathrm{Si}_{3} \mathrm{~N}_{4}$, others) due to the highly corrosive environment associated with the $\mathrm{H}_{2} \mathrm{SO}_{4}$ decomposer and perhaps the HIx decomposition section. The tritium permeability of the material that will be applied to the PHX is not 
available. Therefore, the permeability of the superheater of the Peach Bottom HTGR, Incoloy 800, is also employed to that of PHX for the base case; this is the same as for the NGNP using the HTE process.

Heat transfer tube heat transfer area, thickness, and temperature. The heat exchangers' boundary conditions of heat transfer area, thickness, and temperature are summarized in Table 31. Boundary conditions for the IHX and the SHX are the same as those for the NGNP using the HTE process. The heat transfer area and thickness of the PHX for the NGNP using the SI process will likely be different from those parameters used for the NGNP using the HTE process. However, no design data is yet available. Therefore, the total heat transfer area between tertiary helium and the process chemicals of PHXs (i.e., H210B, H210A, H209, H208B, and H208A) is assumed to be the same value as those of PHXs in the HTE process (i.e., PHX-1, PHX-2, PHX-3). The total heat transfer area is evenly divided into five PHXs for the SI process. The heat transfer area between process and product chemicals in H210B, H210A, H209, H208B, and H208A are assumed to be the same value as that between tertiary helium and the process chemical. The thickness of the PHX is assumed to be the same value as that for the PHX used for an NGNP using the HTE process. Metal temperature is calculated as the average value of gas temperature between a high-temperature and a low-temperature side.

Table 31. Boundary conditions of the heat transfer tube for the Next Generation Nuclear Plant using the sulfur iodine process.

\begin{tabular}{|c|c|c|c|c|c|}
\hline \multirow[b]{2}{*}{ Type } & \multirow{2}{*}{$\begin{array}{l}\text { Flowsheet } \\
\text { ID }\end{array}$} & \multirow{2}{*}{$\begin{array}{c}\text { Heat Transfer } \\
\text { Area } \\
\left(\mathrm{m}^{2}\right)\end{array}$} & \multirow{2}{*}{$\begin{array}{c}\text { Thickness } \\
(\mathrm{mm})\end{array}$} & \multicolumn{2}{|c|}{$\begin{array}{l}\text { Metal Temperature } \\
(\mathrm{K})\end{array}$} \\
\hline & & & & Inlet $^{\mathrm{a}}$ & Outlet $^{\mathrm{a}}$ \\
\hline Intermediate heat exchanger & - & 50,390 & 0.96 & 1,166 & 761 \\
\hline Secondary heat exchanger & - & 1,924 & 2.82 & 1,148 & 826 \\
\hline Decomposer 2 (He-process) & $\mathrm{H} 210 \mathrm{~B}$ & 696 & 0.90 & 1,161 & 1,083 \\
\hline Decomposer 1 (He-process) & $\mathrm{H} 210 \mathrm{~A}$ & 696 & 0.90 & 1,083 & 1,006 \\
\hline Recuperator 2 (He-process) & H209 & 696 & 0.90 & 1,006 & 929 \\
\hline Vaporizer 3 (He-process) & H208B & 696 & 0.90 & 929 & 851 \\
\hline Vaporizer 2 (He-process) & H208A & 696 & 0.90 & 851 & 736 \\
\hline Decomposer 1 (process-product) & $\mathrm{H} 210 \mathrm{~A}$ & 696 & 0.90 & 1,131 & 1,034 \\
\hline Recuperator 2 (process-product) & H209 & 696 & 0.90 & 1,034 & 936 \\
\hline Vaporizer 3 (process-product) & H208B & 696 & 0.90 & 936 & 839 \\
\hline Vaporizer 2 (process-product) & H208A & 696 & 0.90 & 839 & 703 \\
\hline
\end{tabular}

\subsubsection{Purification System}

The base case for the flow rate at the purification system that is installed in each helium loop is defined the same as the value for the NGNP using the HTE process (i.e., $275 \mathrm{~kg} / \mathrm{h}$ ). The purification system's removal efficiency for tritium also is assumed to be 1.0. 


\subsubsection{Helium Leak Rate and Inventory}

The helium leak rate from each helium loop to the outside and the helium inventory are the same as the boundary conditions for NGNP using the HTE process (i.e., leak rate of $9.95 \times 10^{-3} / \mathrm{d}$ and helium inventory of 2,293 Kg).

\subsubsection{Helium Loop}

Boundary conditions of temperature, flow rate, and pressure are based on the values in Table 30 .

\subsubsection{Sulfur lodine Process}

The flow rate boundary condition for each link in the SI process is listed in Table 32, and is defined based on stream flow rates reported by General Atomics. Table 33 lists the temperature and pressure of each node in the SI process.

Table 32. Flow rate boundary condition for each link in the sulfur iodine process.

\begin{tabular}{|c|c|c|c|c|c|c|c|c|}
\hline \multirow{2}{*}{ Link } & \multicolumn{7}{c|}{$\begin{array}{c}\text { Flow Rate } \\
(\mathrm{mol} / \mathrm{s})\end{array}$} \\
\cline { 2 - 10 } & $\mathrm{H}_{2} \mathrm{O}$ & $\mathrm{H}_{2} \mathrm{SO}_{4}$ & $\mathrm{SO}_{3}$ & $\mathrm{SO}_{2}$ & $\mathrm{O}_{2}$ & $\mathrm{HI}$ & $\mathrm{I}_{2}$ & $\mathrm{H}_{2}$ \\
\hline 127 & 67.666 & 9.590 & 0 & 7.159 & 0.135 & 0 & 0 & 0 \\
\hline 128 & 141.951 & 0 & 0 & 9.319 & 0 & 0 & 0 & 0 \\
\hline 129 & 0.810 & 0 & 0 & 0.405 & 0 & 0 & 0 & 0 \\
\hline 130 & 0.135 & 0 & 0 & 0 & 0 & 0 & 0 & 0 \\
\hline 131 & 37.102 & 9.485 & 0 & 16.872 & 0.135 & 0 & 0 & 0 \\
\hline 132 & 173.760 & 0.135 & 0 & 0 & 0 & 0 & 0 & 0 \\
\hline 133 & 304.567 & 0 & 0 & 0.135 & 0 & 0 & 0 & 0 \\
\hline 134 & 199.758 & 0.676 & 0 & 0 & 0 & 0 & 0 & 0 \\
\hline 135 & 16.117 & 0 & 0 & 0 & 0 & 0.166 & 0.352 & 0 \\
\hline 136 & 1.284 & 0 & 0 & 0 & 42.894 & 0 & 0 & 0 \\
\hline 137 & 0.743 & 0 & 0 & 0 & 24.679 & 0 & 0 & 0 \\
\hline 138 & 93.176 & 18.887 & 0 & 53.051 & 0.270 & 0.166 & 1.368 & 0 \\
\hline 139 & 70.847 & 0 & 0 & 0 & 0 & 10.912 & 6.438 & 0 \\
\hline 140 & 1.914 & 0 & 0 & 0 & 24.679 & 0 & 0 & 0 \\
\hline 141 & 242.592 & 6.035 & 0 & 0 & 0 & 22.664 & 3.064 & 0 \\
\hline 142 & 449.089 & 0 & 0 & 0 & 0 & 0 & 4.919 & 0 \\
\hline 143 & 4.860 & 0 & 0 & 0.014 & 22.580 & 0 & 0.041 & 0 \\
\hline 144 & $9,149.673$ & 29.380 & 0 & 169.563 & 0 & $1,351.465$ & 748.762 & 0 \\
\hline 145 & 5.630 & 0 & 0 & 0 & 0 & 0.033 & 279.326 & 0.154 \\
\hline 146 & 559.053 & 138.504 & 0 & 6.413 & 2.090 & 0 & 2.485 & 0 \\
\hline 147 & 125.074 & 0 & 0 & 2.090 & 0 & 18.719 & 107.446 & 0 \\
\hline
\end{tabular}


Table 31. (continued).

\begin{tabular}{|c|c|c|c|c|c|c|c|c|}
\hline \multirow[b]{2}{*}{ Link } & \multicolumn{8}{|c|}{$\begin{array}{c}\text { Flow Rate } \\
(\mathrm{mol} / \mathrm{s})\end{array}$} \\
\hline & $\mathrm{H}_{2} \mathrm{O}$ & $\mathrm{H}_{2} \mathrm{SO}_{4}$ & $\mathrm{SO}_{3}$ & $\mathrm{SO}_{2}$ & $\mathrm{O}_{2}$ & $\mathrm{HI}$ & $\mathrm{I}_{2}$ & $\mathrm{H}_{2}$ \\
\hline 148 & $1,822.716$ & 0 & 0 & 0 & 0 & 206.109 & $1,459.244$ & 0.720 \\
\hline 149 & 693.329 & 0 & 0 & 0 & 0 & 78.400 & 555.070 & 0.274 \\
\hline 150 & $9,653.325$ & 129.271 & 0 & 206.497 & 67.573 & $1,678.839$ & $6,488.713$ & 0 \\
\hline 151 & 2.031 & 0 & 0 & 118.358 & 67.489 & 0 & 0 & 0 \\
\hline 152 & 0.364 & 0 & 0 & 0 & 24.679 & 0 & 0 & 0 \\
\hline 153 & 0.379 & 0 & 0 & 0 & 0 & 0 & 0 & 0 \\
\hline 154 & 4.566 & 0 & 0 & 19.223 & 67.573 & 0 & 1.016 & 0 \\
\hline 155 & 695.879 & 129.271 & 0 & 2.082 & 0 & 0 & 0 & 0 \\
\hline 156 & $8,897.847$ & 0 & 0 & 185.512 & 0 & $1,678.839$ & $6,488.713$ & 0 \\
\hline 157 & 5.884 & 0 & 0 & 5.888 & 2.099 & 0 & 2.486 & 0 \\
\hline 158 & 553.177 & 138.504 & 0 & 0.527 & 0 & 0 & 0 & 0 \\
\hline 159 & 4.281 & 0 & 0 & 15.697 & 2.090 & 0 & 0.311 & 0 \\
\hline 160 & 46.084 & 0 & 0 & 169.563 & 22.580 & 0 & 3.349 & 0 \\
\hline 161 & $2,968.171$ & 0 & 0 & 0 & 0 & 562.890 & $2,168.943$ & 0 \\
\hline 162 & 0.689 & 0 & 0 & 0 & 42.894 & 0 & 0 & 0 \\
\hline 163 & 0.594 & 0 & 0 & 0 & 0 & 0 & 0 & 0 \\
\hline 164 & 49.358 & 0 & 0 & 0 & 0 & 0 & 0 & 0 \\
\hline 165 & 2.611 & 0 & 0 & 0 & 67.573 & 0 & 0 & 0 \\
\hline 166 & 581.039 & 145.462 & 0 & 0.135 & 0 & 0 & 0 & 0 \\
\hline 167 & 0.810 & 0 & 0 & 0.405 & 0 & 0 & 0 & 0 \\
\hline 168 & 276.338 & 145.462 & 0 & 0 & 0 & 0 & 0 & 0 \\
\hline 169 & 304.701 & 0 & 0 & 0.135 & 0 & 0 & 0 & 0 \\
\hline 170 & 29.443 & 26.877 & 0 & 0 & 0 & 0 & 0 & 0 \\
\hline 171 & 229.201 & 27.688 & 0 & 0 & 0 & 0 & 0 & 0 \\
\hline 172 & 199.758 & 0.676 & 0 & 0 & 0 & 0 & 0 & 0 \\
\hline 173 & 76.580 & 144.652 & 0 & 0 & 0 & 0 & 0 & 0 \\
\hline 174 & 202.053 & 244.193 & 10.805 & 0 & 0 & 0 & 0 & 0 \\
\hline 175 & 212.858 & 233.388 & 21.610 & 0 & 0 & 0 & 0 & 0 \\
\hline 176 & 223.663 & 222.583 & 32.415 & 0 & 0 & 0 & 0 & 0 \\
\hline 177 & 234.468 & 211.778 & 43.220 & 0 & 0 & 0 & 0 & 0 \\
\hline 178 & 245.273 & 200.973 & 54.025 & 0 & 0 & 0 & 0 & 0 \\
\hline 179 & 265.749 & 180.498 & 74.500 & 0 & 0 & 0 & 0 & 0 \\
\hline 180 & 286.225 & 160.022 & 94.976 & 0 & 0 & 0 & 0 & 0 \\
\hline
\end{tabular}


Table 31. (continued).

\begin{tabular}{|c|c|c|c|c|c|c|c|c|}
\hline \multirow[b]{2}{*}{ Link } & \multicolumn{8}{|c|}{$\begin{array}{c}\text { Flow Rate } \\
(\mathrm{mol} / \mathrm{s})\end{array}$} \\
\hline & $\mathrm{H}_{2} \mathrm{O}$ & $\mathrm{H}_{2} \mathrm{SO}_{4}$ & $\mathrm{SO}_{3}$ & $\mathrm{SO}_{2}$ & $\mathrm{O}_{2}$ & $\mathrm{HI}$ & $\mathrm{I}_{2}$ & $\mathrm{H}_{2}$ \\
\hline 181 & 306.700 & 139.547 & 115.451 & 0 & 0 & 0 & 0 & 0 \\
\hline 182 & 327.176 & 119.071 & 135.927 & 0 & 0 & 0 & 0 & 0 \\
\hline 183 & 347.651 & 98.596 & 156.402 & 0 & 0 & 0 & 0 & 0 \\
\hline 184 & 347.651 & 98.596 & 156.402 & 0 & 0 & 0 & 0 & 0 \\
\hline 185 & 347.651 & 98.596 & 156.402 & 0 & 0 & 0 & 0 & 0 \\
\hline 186 & 347.651 & 98.596 & 156.402 & 0 & 0 & 0 & 0 & 0 \\
\hline 187 & 347.651 & 98.596 & 156.402 & 0 & 0 & 0 & 0 & 0 \\
\hline 188 & 347.651 & 98.596 & 156.402 & 0 & 0 & 0 & 0 & 0 \\
\hline 189 & 357.011 & 89.249 & 152.256 & 13.506 & 6.753 & 0 & 0 & 0 \\
\hline 190 & 366.371 & 79.903 & 148.110 & 27.013 & 13.506 & 0 & 0 & 0 \\
\hline 191 & 375.731 & 70.557 & 143.963 & 40.519 & 20.259 & 0 & 0 & 0 \\
\hline 192 & 385.091 & 61.210 & 139.817 & 54.025 & 27.013 & 0 & 0 & 0 \\
\hline 193 & 394.450 & 51.864 & 135.670 & 67.531 & 33.766 & 0 & 0 & 0 \\
\hline 194 & 403.810 & 42.518 & 131.524 & 81.038 & 40.519 & 0 & 0 & 0 \\
\hline 195 & 413.170 & 33.171 & 127.378 & 94.544 & 47.272 & 0 & 0 & 0 \\
\hline 196 & 422.530 & 23.825 & 123.231 & 108.050 & 54.025 & 0 & 0 & 0 \\
\hline 197 & 431.889 & 14.479 & 119.085 & 121.556 & 60.778 & 0 & 0 & 0 \\
\hline 198 & 441.249 & 5.132 & 114.938 & 135.063 & 67.531 & 0 & 0 & 0 \\
\hline 199 & 418.316 & 28.066 & 92.005 & 135.063 & 67.531 & 0 & 0 & 0 \\
\hline 200 & 395.382 & 50.999 & 69.071 & 135.063 & 67.531 & 0 & 0 & 0 \\
\hline 201 & 372.448 & 73.933 & 46.138 & 135.063 & 67.531 & 0 & 0 & 0 \\
\hline 202 & 349.515 & 96.867 & 23.204 & 135.063 & 67.531 & 0 & 0 & 0 \\
\hline 203 & 326.581 & 119.800 & 0.270 & 135.063 & 67.531 & 0 & 0 & 0 \\
\hline 204 & 326.581 & 119.800 & 0.270 & 135.063 & 67.531 & 0 & 0 & 0 \\
\hline 205 & 326.581 & 119.800 & 0.270 & 135.063 & 67.531 & 0 & 0 & 0 \\
\hline 206 & 326.581 & 119.800 & 0.270 & 135.063 & 67.531 & 0 & 0 & 0 \\
\hline 207 & 326.581 & 119.800 & 0.270 & 135.063 & 67.531 & 0 & 0 & 0 \\
\hline 208 & 326.581 & 119.800 & 0.270 & 135.063 & 67.531 & 0 & 0 & 0 \\
\hline 209 & 326.581 & 119.800 & 0.270 & 135.063 & 67.531 & 0 & 0 & 0 \\
\hline 210 & 326.581 & 119.800 & 0.270 & 135.063 & 67.531 & 0 & 0 & 0 \\
\hline 211 & 326.581 & 119.800 & 0.270 & 135.063 & 67.531 & 0 & 0 & 0 \\
\hline 212 & 326.581 & 119.800 & 0.270 & 135.063 & 67.531 & 0 & 0 & 0 \\
\hline 213 & 326.581 & 119.800 & 0.270 & 135.063 & 67.531 & 0 & 0 & 0 \\
\hline
\end{tabular}


Table 31. (continued).

\begin{tabular}{|c|c|c|c|c|c|c|c|c|}
\hline \multirow[b]{2}{*}{ Link } & \multicolumn{8}{|c|}{$\begin{array}{c}\text { Flow Rate } \\
(\mathrm{mol} / \mathrm{s})\end{array}$} \\
\hline & $\mathrm{H}_{2} \mathrm{O}$ & $\mathrm{H}_{2} \mathrm{SO}_{4}$ & $\mathrm{SO}_{3}$ & $\mathrm{SO}_{2}$ & $\mathrm{O}_{2}$ & $\mathrm{HI}$ & $\mathrm{I}_{2}$ & $\mathrm{H}_{2}$ \\
\hline 214 & 326.581 & 119.800 & 0.270 & 135.063 & 67.531 & 0 & 0 & 0 \\
\hline 215 & 326.581 & 119.800 & 0.270 & 135.063 & 67.531 & 0 & 0 & 0 \\
\hline 216 & 326.581 & 119.800 & 0.270 & 135.063 & 67.531 & 0 & 0 & 0 \\
\hline 217 & 326.581 & 119.800 & 0.270 & 135.063 & 67.531 & 0 & 0 & 0 \\
\hline 218 & 326.581 & 119.800 & 0.270 & 135.063 & 67.531 & 0 & 0 & 0 \\
\hline 219 & 114.668 & 110.346 & 0 & 0 & 0 & 0 & 0 & 0 \\
\hline 220 & 211.913 & 9.319 & 0.270 & 135.063 & 67.531 & 0 & 0 & 0 \\
\hline 221 & 143.976 & 0 & 0 & 127.904 & 67.396 & 0 & 0 & 0 \\
\hline 222 & $2,380.938$ & 0 & 0 & 0 & 0 & 385.983 & $2,631.733$ & 0.003 \\
\hline 223 & 949.031 & 0 & 0 & 0 & 0 & 154.979 & 326.632 & 0.003 \\
\hline 224 & $1,409.377$ & 0 & 0 & 0 & 0 & 227.949 & $2,102.093$ & 0 \\
\hline 225 & 22.533 & 0 & 0 & 0 & 0 & 3.055 & 203.009 & 0 \\
\hline 226 & $1,513.222$ & 0 & 0 & 0 & 0 & 58.178 & 0.248 & 134.365 \\
\hline 227 & 23.044 & 0 & 0 & 0 & 0 & 0.886 & 0.004 & 2.047 \\
\hline 228 & 120.355 & 0 & 0 & 0 & 0 & 0.886 & 0.648 & 0.071 \\
\hline 229 & 90.046 & 0 & 0 & 0 & 0 & 0 & 0 & 0 \\
\hline 230 & 0.148 & 0 & 0 & 0 & 0 & 0 & 0 & 135.063 \\
\hline 231 & 0.148 & 0 & 0 & 0 & 0 & 0 & 0 & 135.063 \\
\hline 232 & 406.544 & 0 & 0 & 0 & 0 & 1.618 & 88.027 & 133.370 \\
\hline 233 & 1.801 & 0 & 0 & 0 & 0 & 0.012 & 85.260 & 0.054 \\
\hline 234 & 7.413 & 0 & 0 & 0 & 0 & 0 & 0.644 & 133.087 \\
\hline 235 & 397.332 & 0 & 0 & 0 & 0 & 1.606 & 2.124 & 0.230 \\
\hline 236 & 517.687 & 0 & 0 & 0 & 0 & 2.492 & 2.772 & 0.301 \\
\hline 237 & 24.332 & 0 & 0 & 0 & 0 & 3.067 & 288.268 & 0.054 \\
\hline
\end{tabular}

Table 33. Boundary conditions of temperature and pressure in components of the sulfur iodine process.

\begin{tabular}{|c|l|c|c|c|}
\hline \multicolumn{1}{|c|}{ Component } & Flowsheet ID & $\begin{array}{c}\text { Temperature } \\
(\mathrm{K})\end{array}$ & $\begin{array}{c}\text { Pressure } \\
(\mathrm{MPa})\end{array}$ \\
\hline 1 & Bunsen reactor & $\mathrm{R} 101$ & 393.1 & 0.70 \\
\hline 1 & $\# 2 \mathrm{O}_{2}$ scrubber & $\mathrm{C} 101$ & 393.1 & 0.10 \\
\hline 1 & $\mathrm{HIx} / \mathrm{SO}_{2}$ stripper & $\mathrm{C} 102$ & 393.1 & 0.19 \\
\hline 1 & $\mathrm{H}_{2} \mathrm{SO}_{4}$ boost reactor & $\mathrm{C} 103$ & 384.6 & 0.19 \\
\hline 1 & $\# 1 \mathrm{O}_{2}$ scrubber & $\mathrm{C} 104$ & 384.5 & 0.42 \\
\hline
\end{tabular}


Table 32. (continued).

\begin{tabular}{|c|c|c|c|c|}
\hline Section & Component & Flowsheet ID & $\begin{array}{c}\text { Temperature } \\
(\mathrm{K})\end{array}$ & $\begin{array}{c}\text { Pressure } \\
(\mathrm{MPa})\end{array}$ \\
\hline 1 & $\mathrm{SO}_{2}$ adsorber & $\mathrm{C} 105$ & 369.7 & 0.19 \\
\hline 1 & 3-phase separator & S101 & 393.1 & 0.70 \\
\hline 1 & Flash drum & S102 & 384.6 & 0.19 \\
\hline 1 & Primary $\mathrm{O}_{2}$ knockout drum & S104 & 289.1 & 0.19 \\
\hline 1 & Secondary $\mathrm{O}_{2}$ knockout drum & $\mathrm{S} 105$ & 289.1 & 0.10 \\
\hline \multirow{5}{*}{2} & \multirow{5}{*}{$\mathrm{H}_{2} \mathrm{SO}_{4}$ vaporizer 2 (process) $^{\mathrm{a}}$} & \multirow{5}{*}{ H208A } & 676.2 & 7.05 \\
\hline & & & 716.4 & 7.05 \\
\hline & & & 756.6 & 7.05 \\
\hline & & & 796.8 & 7.05 \\
\hline & & & 837.1 & 7.05 \\
\hline \multirow[t]{5}{*}{2} & \multirow{5}{*}{$\mathrm{H}_{2} \mathrm{SO}_{4}$ vaporizer 3 (process) ${ }^{\mathrm{a}}$} & \multirow{5}{*}{ H208B } & 837.1 & 7.05 \\
\hline & & & 858.1 & 7.05 \\
\hline & & & 879.1 & 7.05 \\
\hline & & & 900.1 & 7.05 \\
\hline & & & 921.1 & 7.05 \\
\hline \multirow[t]{5}{*}{2} & \multirow{5}{*}{ Recuperator 2 (process) ${ }^{\mathrm{a}}$} & \multirow{5}{*}{$\mathrm{H} 209 \mathrm{H}$} & 921.1 & 7.05 \\
\hline & & & 942.1 & 7.05 \\
\hline & & & 963.1 & 7.05 \\
\hline & & & 984.1 & 7.05 \\
\hline & & & $1,005.1$ & 7.05 \\
\hline \multirow[t]{5}{*}{2} & \multirow{5}{*}{ Decomposer 1 (process) $^{\mathrm{a}}$} & \multirow{5}{*}{$\mathrm{H} 210 \mathrm{~A}$} & $1,005.1$ & 7.05 \\
\hline & & & $1,026.1$ & 7.05 \\
\hline & & & $1,047.1$ & 7.05 \\
\hline & & & $1,068.1$ & 7.05 \\
\hline & & & $1,089.1$ & 7.05 \\
\hline \multirow{5}{*}{2} & \multirow{5}{*}{ Decomposer 2 (process) $^{\mathrm{a}}$} & \multirow{5}{*}{ H210B } & $1,089.1$ & 7.05 \\
\hline & & & $1,110.1$ & 7.05 \\
\hline & & & $1,131.1$ & 7.05 \\
\hline & & & $1,152.1$ & 7.05 \\
\hline & & & $1,173.2$ & 7.05 \\
\hline \multirow[t]{2}{*}{2} & \multirow[t]{2}{*}{ Decomposer 1 (product) $^{\mathrm{a}}$} & \multirow[t]{2}{*}{$\mathrm{H} 210 \mathrm{~A}$} & $1,173.2$ & 7.05 \\
\hline & & & $1,145.5$ & 7.05 \\
\hline
\end{tabular}


Table 32. (continued).

\begin{tabular}{|c|c|c|c|c|}
\hline Section & Component & Flowsheet ID & $\begin{array}{c}\text { Temperature } \\
(\mathrm{K})\end{array}$ & $\begin{array}{c}\text { Pressure } \\
(\mathrm{MPa})\end{array}$ \\
\hline & & & $1,117.8$ & 7.05 \\
\hline & & & $1,090.1$ & 7.05 \\
\hline & & & $1,062.5$ & 7.05 \\
\hline \multirow{5}{*}{2} & \multirow{5}{*}{ Recuperator 2 (product) $^{\mathrm{a}}$} & \multirow{5}{*}{ H209 } & $1,062.5$ & 7.05 \\
\hline & & & $1,034.8$ & 7.05 \\
\hline & & & $1,007.1$ & 7.05 \\
\hline & & & 979.4 & 7.05 \\
\hline & & & 951.8 & 7.05 \\
\hline \multirow{5}{*}{2} & \multirow{5}{*}{$\mathrm{H}_{2} \mathrm{SO}_{4}$ vaporizer 3 (product) ${ }^{\mathrm{a}}$} & \multirow{5}{*}{ H208B } & 951.8 & 7.05 \\
\hline & & & 924.1 & 7.05 \\
\hline & & & 896.4 & 7.05 \\
\hline & & & 868.8 & 7.05 \\
\hline & & & 841.1 & 7.05 \\
\hline \multirow{5}{*}{2} & \multirow{5}{*}{$\mathrm{H}_{2} \mathrm{SO}_{4}$ vaporizer 2 (product) $^{\mathrm{a}}$} & \multirow{5}{*}{$208 \mathrm{~A}$} & 841.1 & 7.05 \\
\hline & & & 813.4 & 7.05 \\
\hline & & & 785.7 & 7.05 \\
\hline & & & 758.1 & 7.05 \\
\hline & & & 730.4 & 7.05 \\
\hline 2 & Section feed flash drum & $\mathrm{S} 201$ & 339.6 & 0.01 \\
\hline 2 & Section feed bottoms flash drum & S202 & 383.2 & 0.01 \\
\hline 2 & S202 bottoms flash drum & S203 & 463.1 & 0.01 \\
\hline 2 & S201 overhead product flash vessel & S204 & 313.2 & 0.01 \\
\hline 2 & S202 overhead product flash vessel & S205 & 312.8 & 0.01 \\
\hline 2 & S210 overhead product flash vessel & S206 & 313.2 & 0.01 \\
\hline 2 & Decomposer loop flash vessel & S207 & 675.1 & 7.05 \\
\hline 2 & Decomposer loop vapor product flash vessel & S208 & 525.8 & 7.05 \\
\hline 2 & Decomposer loop vapor product flash vessel & S209 & 313.2 & 0.70 \\
\hline 2 & S203 overhead product flash vessel & $\mathrm{S} 210$ & 433.2 & 0.01 \\
\hline 3 & Reactive still & $\mathrm{C} 301$ & 562.2 & 4.00 \\
\hline 3 & Flash drum & $\mathrm{C} 301 \mathrm{~F} 3$ & 562.2 & 4.00 \\
\hline 3 & $\mathrm{H}_{2}$ product scrubber & $\mathrm{C} 302$ & 309.0 & 4.00 \\
\hline 3 & $\mathrm{I}_{2}$ scrubber & $\mathrm{C} 303$ & 392.4 & 4.00 \\
\hline
\end{tabular}


Table 32. (continued).

\begin{tabular}{|c|l|c|c|c|}
\hline Section & \multicolumn{1}{|c|}{ Component } & Flowsheet ID & $\begin{array}{c}\text { Temperature } \\
(\mathrm{K})\end{array}$ & $\begin{array}{c}\text { Pressure } \\
(\mathrm{MPa})\end{array}$ \\
\hline 3 & Flash drum & $\mathrm{S} 301$ & 530.3 & 4.00 \\
\hline 3 & Flash drum & $\mathrm{S} 302$ & 393.2 & 4.00 \\
\hline
\end{tabular}

\subsubsection{Isotope Exchange Reaction}

The equilibrium constant data for the isotope exchange reaction between $\mathrm{HT}$ and $\mathrm{H}_{2} \mathrm{SO}_{4}$ are not available. The equilibrium constant is assumed to be equal to 1.0 until new data is available.

\subsection{Calculation Results and Discussion}

\subsubsection{Base Case}

Tritium Pathway. Figure 68 shows calculation results for the base case on tritium distribution in the NGNP using the SI process at steady state. Tritium flow rates are normalized to the primary coolant tritium release rate at $1.86 \times 10^{14} \mathrm{~Bq} / \mathrm{y}$. In the primary helium loop, only $3.607 \%$ of tritium released from the core is removed by the purification system. A small portion of tritium $(0.0125 \%)$ leaks to the outside from the primary loop with helium leakage. The remainder of tritium $(96.381 \%)$ permeates into the secondary helium loop through IHX. For the secondary helium loop, only $3.625 \%$ of tritium is removed by the purification system. A small portion of tritium $(0.012 \%)$ leaks outside with leakage of bulk helium. Consequently, $92.746 \%$ of tritium permeates from the secondary helium loop to the tertiary loop. In the tertiary loop, $12.583 \%$ of tritium is removed by the purification system. The amount of tritium removed by the purification system in the tertiary loop is the largest for all helium loops. The ratio of tritium from the tertiary loop to the SI process is $80.120 \%$. Concentrations of tritium-containing chemicals (i.e., HT, HTO, $\mathrm{HTSO}_{4}$, and TI) for the SI process are stable in the steady state. Therefore, it appears that the tritium permeation rate from the tertiary helium loop corresponds to the sum of the tritium flow rates in product oxygen and product hydrogen (i.e., a tritium effluent flow rate from the SI process). The forms of tritium in product oxygen and product hydrogen are HT and HTO, respectively. Note that no heat exchangers exist between Section 3 of the SI process and the tertiary helium. However, tritium permeated through PHX in Section 2 migrates into Section 3 with the circulating process chemicals by changing its form from HT to HTO, from HTO to TI, and from TI to HT due to the isotope exchange reactions. HTO is the principle contaminant in the oxygen product, but the flow rate of HTO in the system is smaller than the flow rate of HT, and most of the tritium contamination in the process goes out with the hydrogen product. Overall, the amount of tritium in the hydrogen product is $62.991 \%$ of the tritium released from the core to the primary helium loop.

Tritium Concentrations. Tritium concentrations in the hydrogen and oxygen products are summarized in Tables 34 and 35. Tritium concentrations in the hydrogen and oxygen products are $1.23 \mathrm{~Bq} / \mathrm{cm}^{3}$ (STP) and $6.67 \times 10^{-1} \mathrm{~Bq} / \mathrm{cm}^{3}$ (STP), which are much higher than the gaseous effluent limit. The tritium concentration in the hydrogen product for the NGNP using the SI process is larger than for the NGNP using the HTE process by about 460 times. One of the reasons for the difference involves the amount of thermal energy needed per unit of hydrogen produced. The demand for thermal to produce hydrogen is 6.9 times larger than for the HTE process. This means that the PHXs needed by the SI process are much larger than those required for the HTE process, and this results in a much larger heat exchanger surface area through which to transmit tritium to the hydrogen production process. In addition, the current HTE process uses a sweep gas, which decreases the concentration of tritium in the hydrogen 
product. As a result, if the conditions of tritium permeation are the same, the tritium concentrations for the SI process should be larger than the HTE process by about 26 times. 


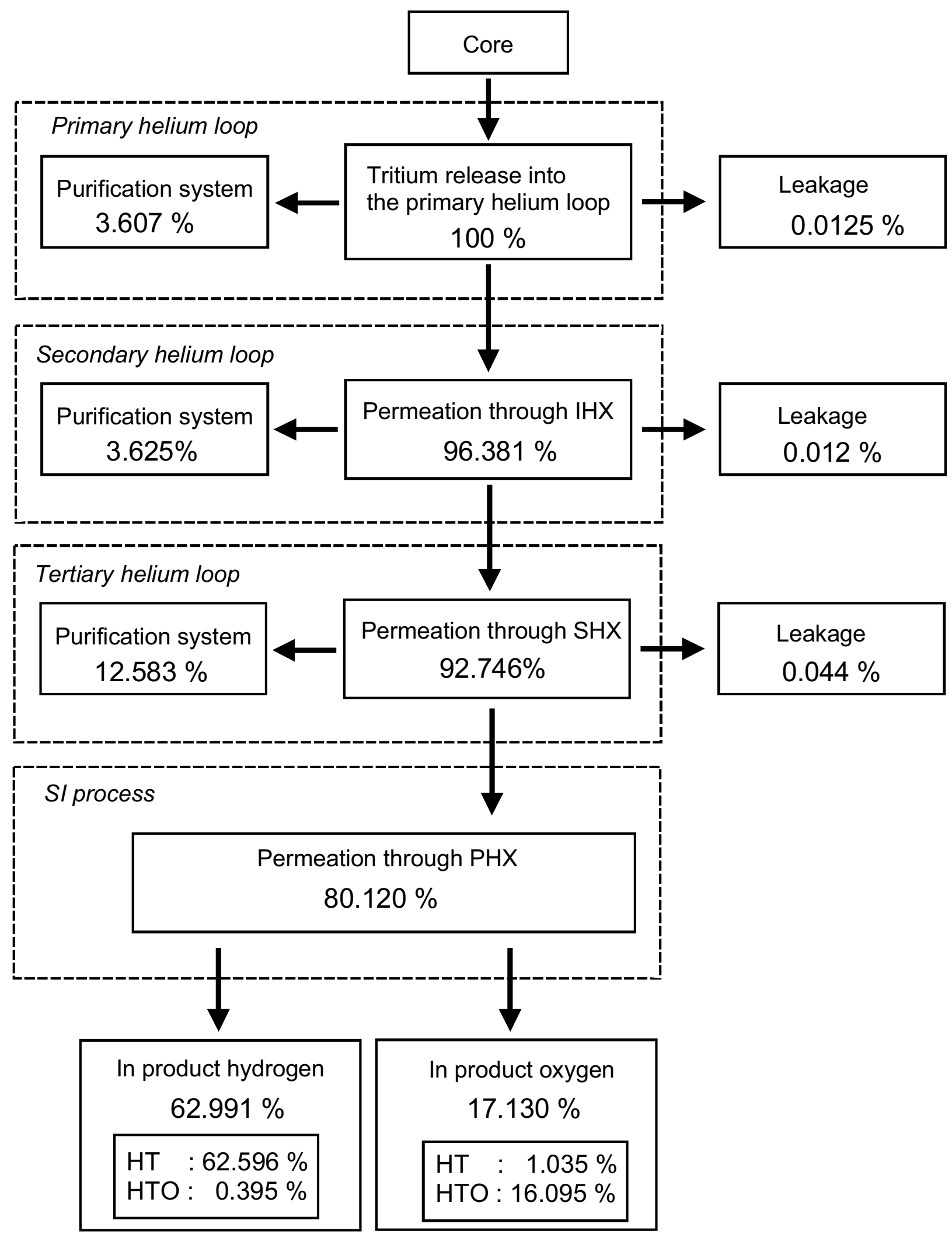

Figure 68. Tritium distributions for the Next Generation Nuclear Plant using the sulfur iodine process. 
Table 34. Tritium concentration in the hydrogen product in the base case for the Next Generation Nuclear Plant using the sulfur iodine process.

\begin{tabular}{|c|c|c|c|c|c|c|}
\hline \multicolumn{3}{|c|}{ In Gaseous Hydrogen } & \multicolumn{2}{c|}{ In Liquid Hydrogen } & \multicolumn{2}{c|}{ Weight Base } \\
$(\mathrm{ppb})$ & $\left(\mu \mathrm{Ci} / \mathrm{cm}^{3}[\mathrm{STP}]\right)$ & $\left(\mathrm{Bq} / \mathrm{cm}^{3}[\mathrm{STP}]\right)$ & $\left(\mu \mathrm{Ci} / \mathrm{cm}^{3}\right)$ & $\left(\mathrm{Bq} / \mathrm{cm}^{3}\right)$ & $\left(\mu \mathrm{Ci} / \mathrm{g}-\mathrm{H}_{2}\right)$ & $\left(\mathrm{Bq} / \mathrm{g}-\mathrm{H}_{2}\right)$ \\
\hline $2.55 \times 10^{-2}$ & $3.32 \times 10^{-5}$ & 1.23 & $2.86 \times 10^{-2}$ & $1.06 \times 10^{3}$ & $3.70 \times 10^{-1}$ & $1.36 \times 10^{4}$ \\
\hline
\end{tabular}

Table 35. Tritium concentration in the oxygen product in the base case for the Next Generation Nuclear Plant using the sulfur iodine process.

\begin{tabular}{|c|c|c|c|c|c|c|}
\hline \multicolumn{3}{|c|}{ In Gaseous Hydrogen } & \multicolumn{2}{c|}{ In Liquid Hydrogen } & \multicolumn{2}{c|}{ Weight Base } \\
$(\mathrm{ppb})$ & $\left(\mu \mathrm{Ci} / \mathrm{cm}^{3}[\mathrm{STP}]\right)$ & $\left(\mathrm{Bq} / \mathrm{cm}^{3}[\mathrm{STP}]\right)$ & $\left(\mu \mathrm{Ci} / \mathrm{cm}^{3}\right)$ & $\left(\mathrm{Bq} / \mathrm{cm}^{3}\right)$ & $\left(\mu \mathrm{Ci} / \mathrm{g}-\mathrm{O}_{2}\right)$ & $\left(\mathrm{Bq} / \mathrm{g}-\mathrm{O}_{2}\right)$ \\
\hline $1.34 \times 10^{-2}$ & $1.80 \times 10^{-5}$ & $6.67 \times 10^{-1}$ & $1.44 \times 10^{-2}$ & $5.30 \times 10^{-2}$ & $1.26 \times 10^{-2}$ & $4.67 \times 10^{2}$ \\
\hline
\end{tabular}

Another reason for the much higher tritium release rates from the SI process in comparison to the HTE process is due to the lower hydrogen concentration (assuming no hydrogen injection) in the helium heat transfer loops. For the NGNP using the HTE process, hydrogen in the HTE process permeates backward to the helium loops through PHX, SHX, and IHX. Hydrogen concentrations in the primary, secondary, and tertiary helium for the base case of the NGNP using the HTE process are about 36 ppm, $37 \mathrm{ppm}$, and $425 \mathrm{ppm}$, respectively. These relatively lower tritium concentrations lead to a decrease in tritium permeation. Tertiary helium for the NGNP using the SI process flows only in heat exchangers in Section 2, where there is no hydrogen, and therefore no hydrogen is available to dampen the permeation of tritium. Therefore, the tritium permeation rate for the NGNP using the SI process is larger than for the NGNP using the HTE process. However, hydrogen may be released to the helium coolants from the components in the loop (e.g., insulator) in the actual reactor. The hydrogen concentration in the primary coolant of the Peach Bottom HTGR was reported at about 10 ppm (Burnette and Baldwin 1980), resulting in a decrease of the tritium permeation rate from the estimated value for NGNP using the SI process. However, the hydrogen release rate to helium coolant is conservatively neglected in the base case of this study due to lack of design data.

Tritium concentrations in the SI process components are summarized in Table 36 . The form of the tritium in gaseous and liquid process chemicals is also listed in Table 36. The phase of the tritiumcontaining chemicals (liquid or gas) is determined by assuming that the condensation temperature of $\mathrm{HTO}, \mathrm{HTSO}_{4}$, and TI is same as that of $\mathrm{H}_{2} \mathrm{O}, \mathrm{H}_{2} \mathrm{SO}_{4}$, and $\mathrm{HI}$, respectively, and then examining the temperature of the process flow stream on the flow sheet. The tritium concentration in gaseous process chemicals in the flash drum (S301) shows the maximum concentration for the process at $18.95 \mathrm{~Bq} / \mathrm{cm}^{3}$ (STP). Tritium concentrations in all components are much higher than the gaseous effluent limit at $3.7 \times 10^{-3} \mathrm{~Bq} / \mathrm{cm}^{3}(\mathrm{STP})$. For the tritium concentration in liquid process chemicals, the tritium concentration in the secondary $\mathrm{O}_{2}$ knockout drum (S105) shows the maximum concentration for the whole process at $4.22 \times 10^{4} \mathrm{~Bq} / \mathrm{cm}^{3}$. The tritium concentration in the primary $\mathrm{O}_{2}$ knockout drum (S104) has a similar value as that in the secondary $\mathrm{O}_{2}$ knockout drum (S105). Tritium concentrations for all components are much higher than the liquid effluent limit at $3.7 \mathrm{~Bq} / \mathrm{cm}^{3}$. 


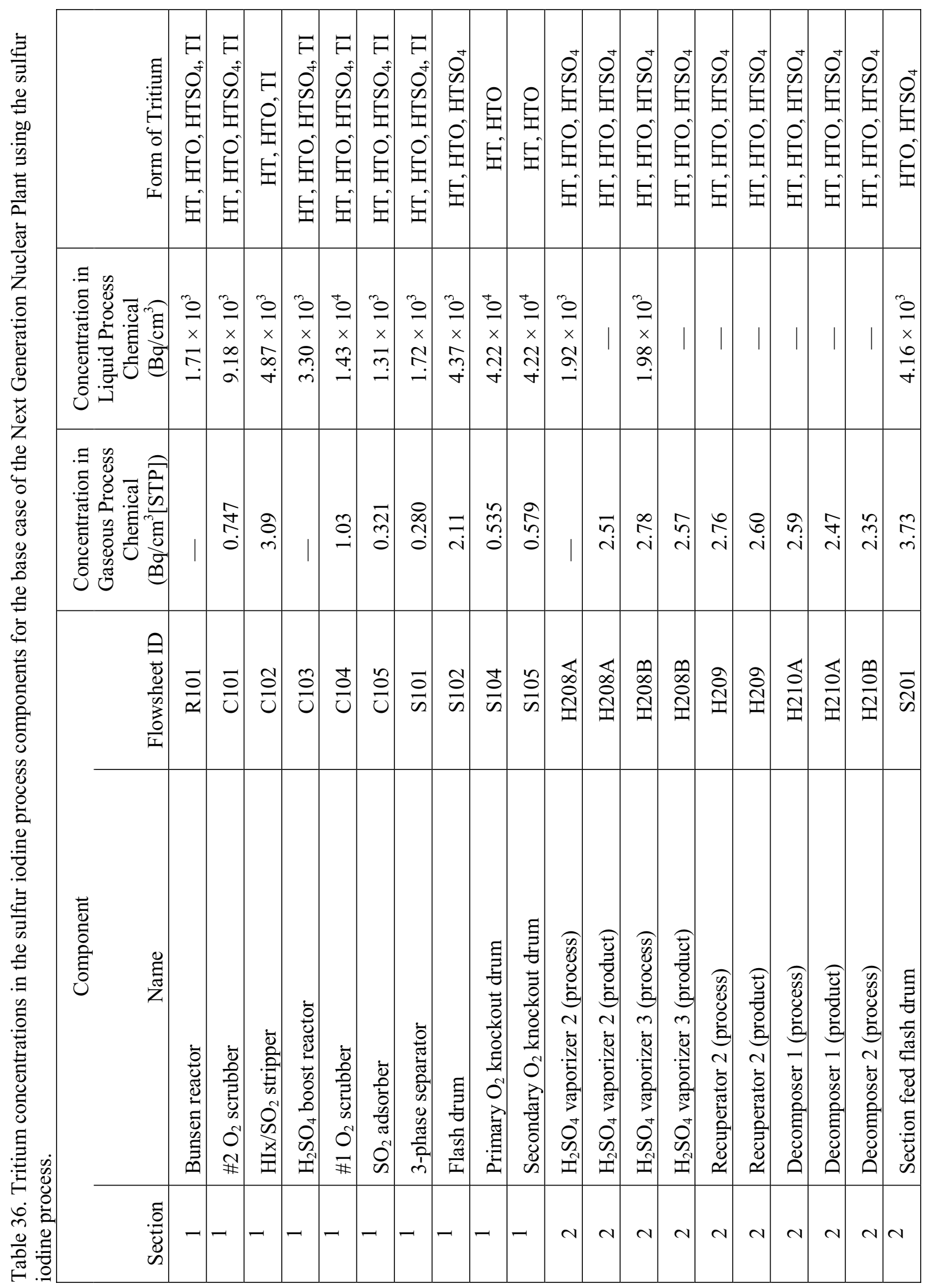




\begin{tabular}{|c|c|c|c|c|c|c|c|c|c|c|c|c|c|c|c|}
\hline 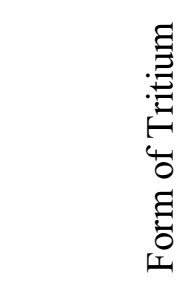 & 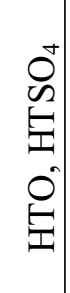 & 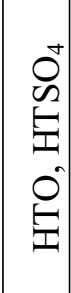 & 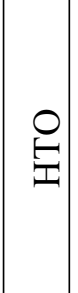 & 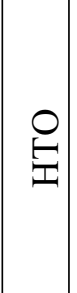 & $\begin{array}{l}0 \\
\vdots \\
\vdots \\
\Xi \\
0 \\
0 \\
\Xi\end{array}$ & $\begin{array}{l}0^{+} \\
\mathscr{I} \\
\Xi \\
\Xi^{+} \\
0 \\
\Xi \\
\Xi \\
\Xi \\
\Xi\end{array}$ & $\begin{array}{l}0^{+} \\
\mathscr{I} \\
\Xi \\
I \\
0 \\
0 \\
\Xi \\
\Xi \\
ت \\
\Xi\end{array}$ & 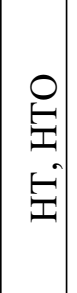 & 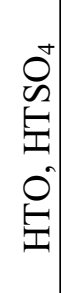 & 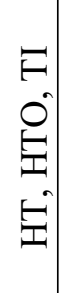 & 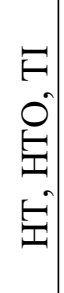 & 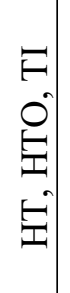 & 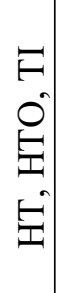 & 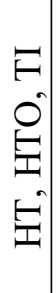 & 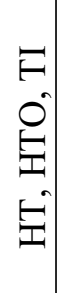 \\
\hline 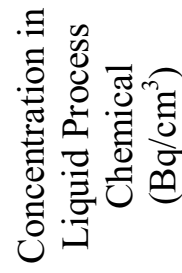 & $\begin{array}{c}30 \\
\times \\
\times \\
\vdots \\
\dot{n}\end{array}$ & $\begin{array}{l}\tilde{0} \\
\times \\
\times \\
\tilde{\sigma} \\
- \\
-\end{array}$ & 1 & $\begin{array}{c}0 \\
0 \\
x \\
0 \\
\infty \\
0 \\
0\end{array}$ & $\begin{array}{l}30 \\
x \\
x \\
+ \\
n \\
0\end{array}$ & $\begin{array}{l}0 \\
\times \\
x \\
\hat{a} \\
-\end{array}$ & $\begin{array}{c}3 \\
\stackrel{0}{x} \\
\times \\
\vec{\sim} \\
m\end{array}$ & $\begin{array}{l}3 \\
\stackrel{0}{x} \\
\times \\
\vec{\nabla} \\
\dot{\nabla}\end{array}$ & 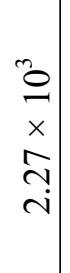 & $\begin{array}{l}3 \\
\times \\
\times \\
6 \\
\dot{0}\end{array}$ & $\begin{array}{l}3 \\
\stackrel{0}{x} \\
\times \\
\stackrel{+}{r} \\
\dot{i}\end{array}$ & $\begin{array}{l}30 \\
\times \\
+ \\
\dot{\infty}\end{array}$ & $\begin{array}{l}3 \\
0 \\
x \\
+ \\
m \\
a\end{array}$ & 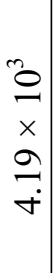 & $\begin{array}{l}+0 \\
\times \\
\times \\
\widetilde{a} \\
\sigma\end{array}$ \\
\hline 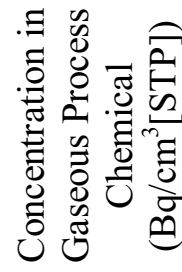 & $\begin{array}{l}n \\
n \\
n\end{array}$ & $\begin{array}{l}\hat{\sigma} \\
\dot{\nabla}\end{array}$ & $\begin{array}{c}\stackrel{m}{r} \\
\dot{m}\end{array}$ & 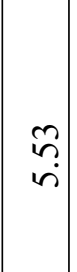 & $\mid$ & $\begin{array}{c}0 \\
\stackrel{0}{\sim} \\
\text {. }\end{array}$ & $\stackrel{n}{\beth}$ & $\begin{array}{l}\hat{1} \\
0 \\
x \\
0 \\
\dot{y} \\
\dot{\gamma}\end{array}$ & $\begin{array}{c}\bar{n} \\
i\end{array}$ & $\begin{array}{l}\infty \\
\dot{ \pm}\end{array}$ & $\stackrel{a}{0}$ & $\stackrel{\overbrace{}}{\sim}$ & $\mid$ & $\begin{array}{l}n \\
\infty \\
\infty\end{array}$ & $\stackrel{n}{\stackrel{n}{+}}$ \\
\hline $\begin{array}{l}\text { 目 } \\
0 \\
\frac{0}{0} \\
\frac{0}{0} \\
\frac{0}{1}\end{array}$ & 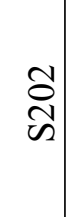 & $\begin{array}{l}\hat{\tilde{s}} \\
\text { nู }\end{array}$ & 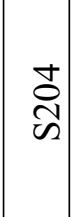 & $\begin{array}{l}\tilde{c} \\
\tilde{N} \\
\tilde{n}\end{array}$ & $\begin{array}{l}\text { ठे } \\
\text { N }\end{array}$ & $\begin{array}{l}\hat{0} \\
\text { ஸे }\end{array}$ & 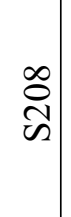 & 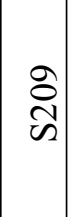 & $\begin{array}{l}\stackrel{0}{\sim} \\
\tilde{\sigma}\end{array}$ & $\begin{array}{c}\bar{\delta} \\
\text { Uె }\end{array}$ & 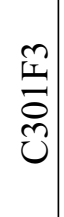 & $\begin{array}{l}\text { ¿ै } \\
\text { లె }\end{array}$ & 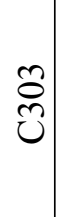 & $\begin{array}{l}\bar{D} \\
\text { in } \\
\text { no }\end{array}$ & 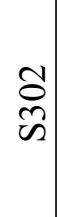 \\
\hline 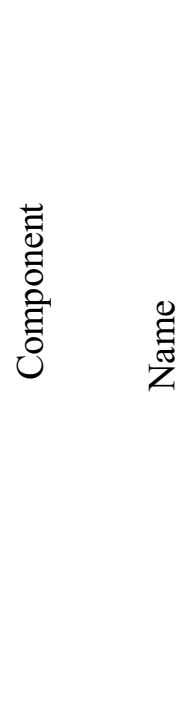 & 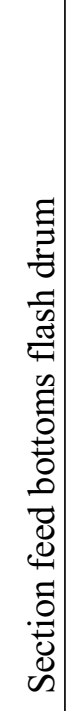 & 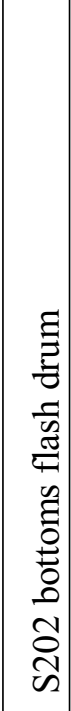 & 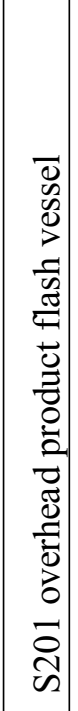 & 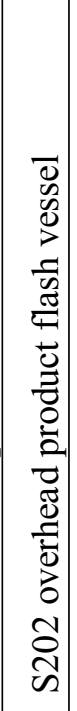 & 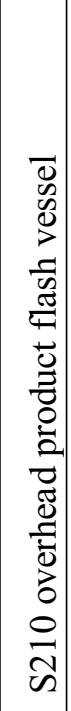 & 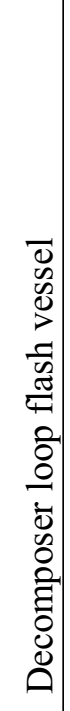 & 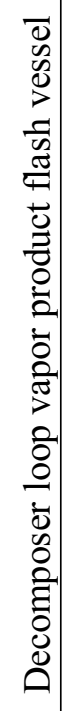 & 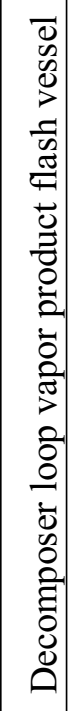 & 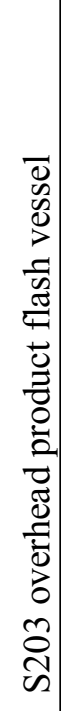 & 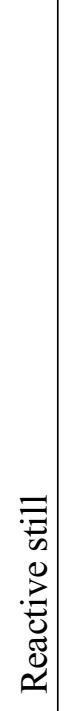 & 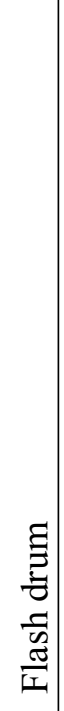 & 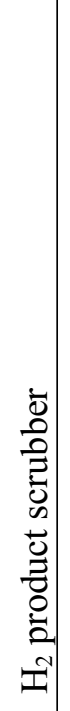 & 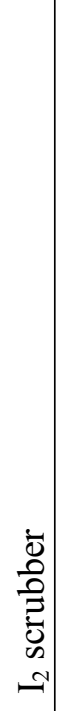 & 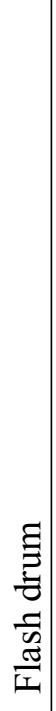 & 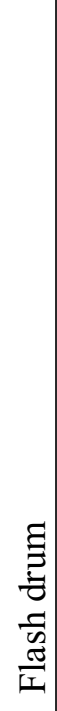 \\
\hline $\begin{array}{l}\stackrel{0}{0} \\
\mathscr{\infty}\end{array}$ & $N$ & $\sim$ & $\sim$ & $\sim$ & $N$ & $N$ & $N$ & $N$ & $N$ & $m$ & $m$ & $m$ & $m$ & $m$ & $m$ \\
\hline
\end{tabular}


Tritium concentrations in the helium loops are listed in Table 37. The tritium concentration in the primary helium is almost the same as in secondary helium, with the amount of tritium in the primary helium slightly exceeding that found in the secondary helium. The tritium concentration in tertiary helium is the largest of the three loops due to the lower total pressure of the tertiary loop. The tritium concentration in tertiary helium also is much higher than the gaseous effluent limit.

Table 37. Tritium concentrations in the helium coolant for the base case of the Next Generation Nuclear Plant using the sulfur iodine process.

\begin{tabular}{|l|c|c|c|}
\hline \multirow{2}{*}{ Coolant } & \multicolumn{3}{|c|}{ Tritium concentration } \\
& $(\mathrm{ppb})$ & $\left(\mu \mathrm{Ci} / \mathrm{cm}^{3}[\mathrm{STP}]\right)$ & $\left(\mathrm{Bq} / \mathrm{cm}^{3}[\mathrm{STP}]\right)$ \\
\hline Primary & $1.04 \times 10^{-2}$ & $1.35 \times 10^{-5}$ & $5.01 \times 10^{-1}$ \\
\hline Secondary & $1.04 \times 10^{-2}$ & $1.35 \times 10^{-4}$ & $5.00 \times 10^{-1}$ \\
\hline Tertiary & $3.68 \times 10^{-2}$ & $4.77 \times 10^{-5}$ & 1.77 \\
\hline
\end{tabular}

\subsubsection{Effect of Equilibrium Constant of the Isotope Exchange Reaction}

Tritium concentration in product hydrogen. One of the undetermined parameters is the equilibrium constant of the isotope exchange reaction between $\mathrm{HT}$ and $\mathrm{H}_{2} \mathrm{SO}_{4}$. To undertand better the effect of different equilibrium constants for this reaction, a range of equilibrium constants were evaluated for their efffect on tritium concentrations. Over this range, the tritium concentration in the hydrogen product stays constant (see Figure 69), as would be expected from an overall tritium mass balance on the hydrogen plant. At steady state, the amount of tritium in product hydrogen is equal to the tritium permeation rate from the tertiary helium coolant for the SI process. The effect of the equilibrium constant on the tritium permeation rate is relatively small. Tritium concentrations in the hydrogen product are independent of the equilibrium constant of the isotope exchange reaction between $\mathrm{HT}$ and $\mathrm{H}_{2} \mathrm{SO}_{4}$.

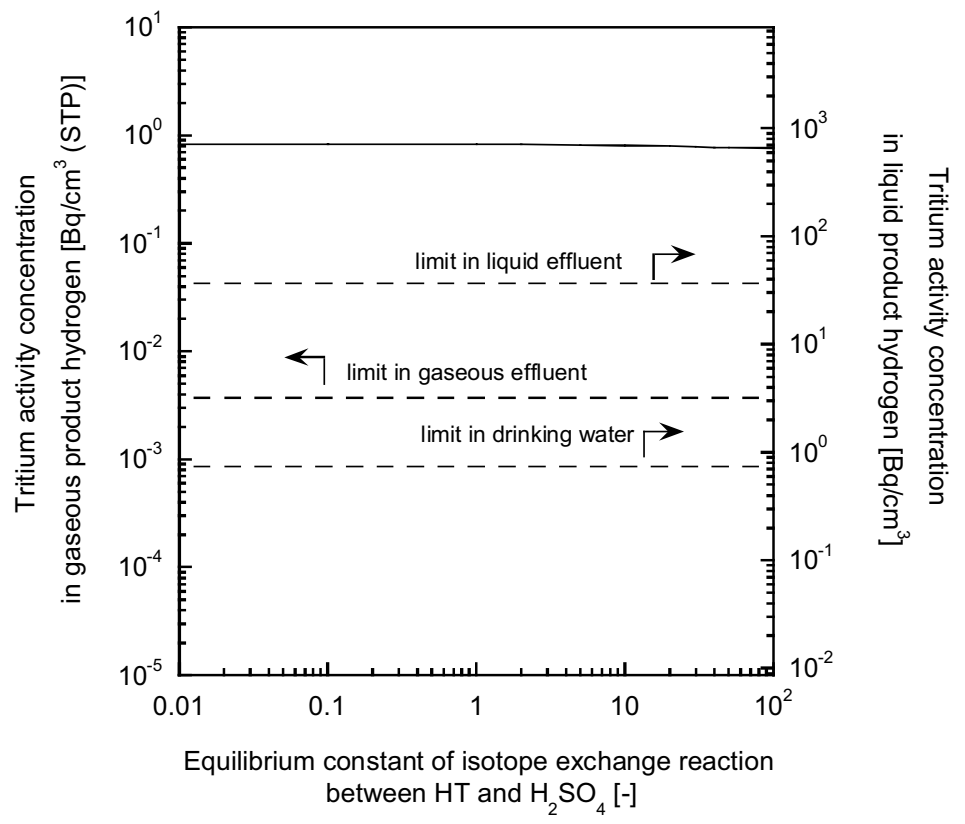

Figure 69. Effect of varying equilibrium constant of isotope exchange reaction between $\mathrm{HT}$ and $\mathrm{H}_{2} \mathrm{SO}_{4}$ on the hydrogen product tritium concentration for the Next Generation Nuclear Plant using the sulfur iodine process. 
Tritium concentration in a component of the sulfur iodine process. The tritium concentration in gaseous process chemicals found in the following components located in Section 2 increase with an increase of the isotope exchange reaction between $\mathrm{HT}$ and $\mathrm{H}_{2} \mathrm{SO}_{4}$ due to the increase of the $\mathrm{HTSO}_{4}$ concentration: S202 bottoms flash drum (S203), decomposer loop flash vessel (S207), decomposer loop vapor product flash vessel (S208), decomposer loop vapor product flash vessel (S209), H2SO4 Vaporizer 2 (H208A), H2SO4 Vaporizer 3 (H208B), Recuperator 2 (H209), Decomposer 1 (H210A), and Decomposer 2 (H210B). The tritium concentration in the $\mathrm{H}_{2} \mathrm{SO}_{4}$ Vaporizer 3 (H208B) shows the maximum concentration among these components at a high value of the equilibrium constant. However, tritium concentrations in other components are almost constant or slightly decrease with an increase of the equilibrium constant. The tritium concentration in the flash drum (S301) shows the maximum value among these components. Figure 70 shows the tritium concentration in gaseous process chemicals for the $\mathrm{H}_{2} \mathrm{SO}_{4}$ Vaporizer $3(\mathrm{H} 208 \mathrm{~B})$ and the flash drum (S301). The tritium concentration in gaseous process chemicals in the flash drum (S301) shows the maximum concentration for all process components below an equilibrium constant of about 10. However, the tritium concentration in the $\mathrm{H}_{2} \mathrm{SO}_{4}$ Vaporizer 3 (H208B) becomes larger than in the flash drum (S301) above an equilibrium constnat of 10.

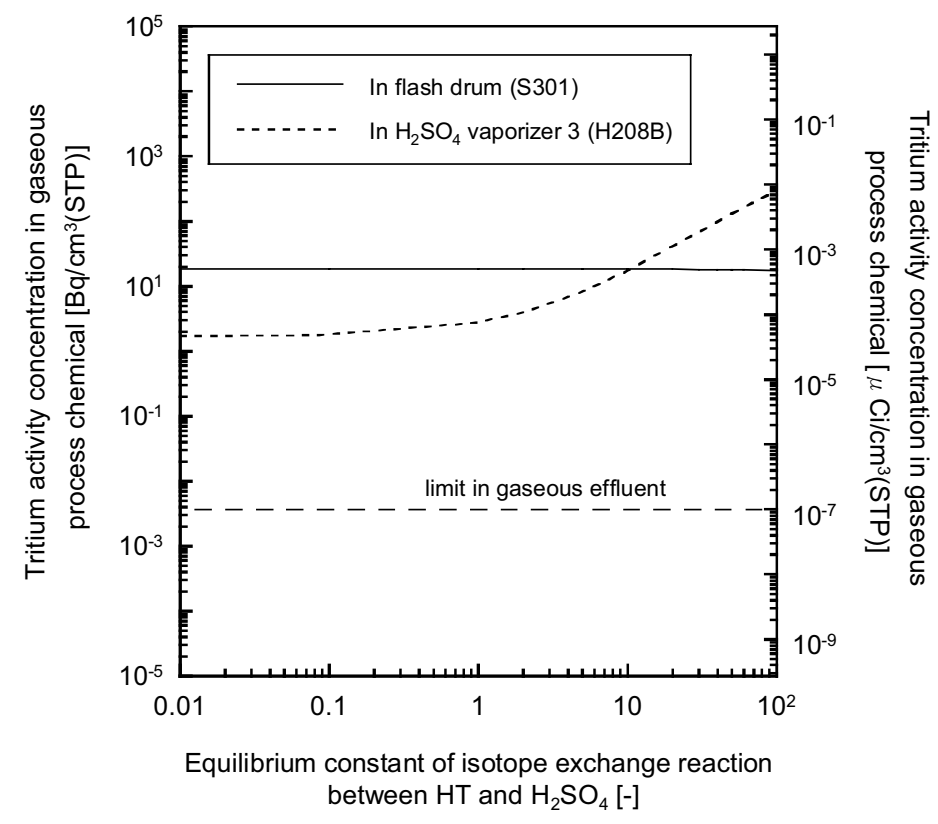

Figure 70. Effect of varying equilibrium constant of isotope exchange reaction between $\mathrm{HT}$ and $\mathrm{H}_{2} \mathrm{SO}_{4}$ on the tritium concentration in gaseous process chemicals for the Next Generation Nuclear Plant using the sulfur iodine process.

With an increase of the equilibrium constant, the tritium concentration in liquid process chemicals increases for some components. Figure 71 shows the tritium concentration in liquid process chemicals in the secondary $\mathrm{O}_{2}$ knockout drum (S105) and in the $\mathrm{H}_{2} \mathrm{SO}_{4}$ Vaporizer $2(\mathrm{H} 208 \mathrm{~A})$ in response to varying isotope exchange equilibrium constant. The tritium concentration in the secondary $\mathrm{O}_{2}$ knockout drum (S105), which stays almost constant, is the maximum for all process components below an equilibrium constant of approximately 20. However, the tritium concentration in the $\mathrm{H}_{2} \mathrm{SO}_{4}$ Vaporizer 2 (H208A) increases with an increase of the equilibrium constant and becomes the maximum for all process components above an equilibriium constant of approximately 20. 


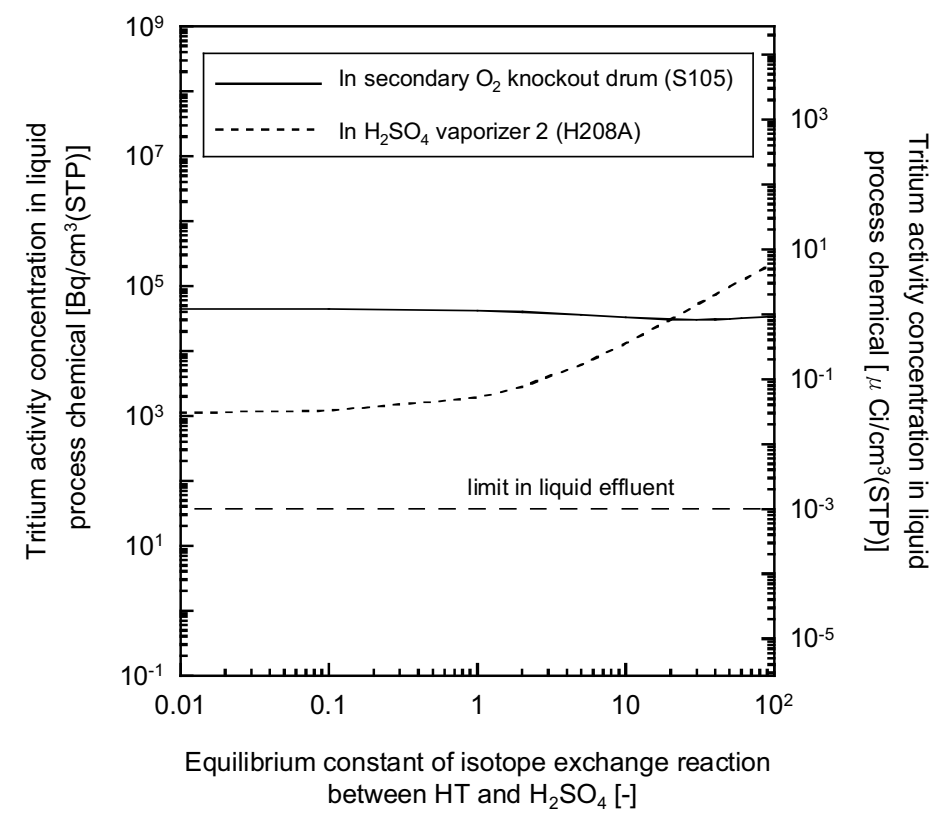

Figure 71. Effect of varying equilibrium constant of the isotope exchange reaction between HT and $\mathrm{H}_{2} \mathrm{SO}_{4}$ on the tritium concentration in liquid process chemicals for the Next Generation Nuclear Plant using the sulfur iodine process.

Tritium concentration in helium coolant. Figure 72 shows tritium concentrations for each helium loop in response to varying isotope exchange equilibrium constant. The concentration of tritium in the loops are independent of the equilibrium constant, since the equilibrium constants only affect the accumulation of tritium in the hydrogen production plant.

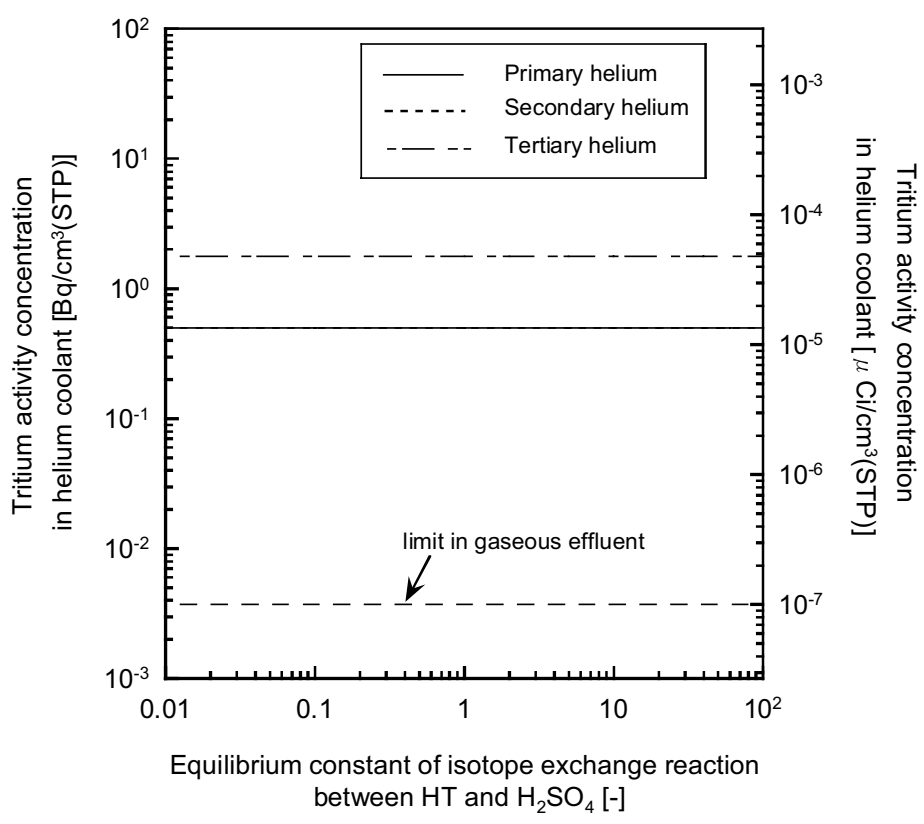

Figure 72. Effect of varying equilibrium constant of the isotope exchange reaction between HT and $\mathrm{H}_{2} \mathrm{SO}_{4}$ on the tritium concentration in the helium coolant for the Next Generation Nuclear Plant using the sulfur iodine process. 


\subsubsection{Effect of Process Heat Exchanger Permeability}

Tritium concentration in product hydrogen. Another significant undetermined parameter is PHX permeability because the PHX(s) of the SI process is expected to be made of ceramic materials, materials for which the tritium permeability is not well characterized. Figure 73 shows the effect of varying PHX permeability on the tritium concentration in the hydrogen product. The effect of PHX permeability is not significant above about $1 \times 10^{-2}$ times the ratio of PHX permeability for the base case, (i.e., permeability of Incoloy 800). However, tritium concentration in the product hydrogen decreases with a decrease of PHX permeability below $1 \times 10^{-2}$ times the ratio of PHX permeability. The tritium concentration becomes less than the gaseous effluent limit, the liquid effluent limit, and the drinking water limit below about $2 \times 10^{-4}$ times, $2 \times 10^{-5}$ times, $5 \times 10^{-6}$ times, respectively. Therefore, the effect of PHX permeability on the tritium concentration in product hydrogen is significant.

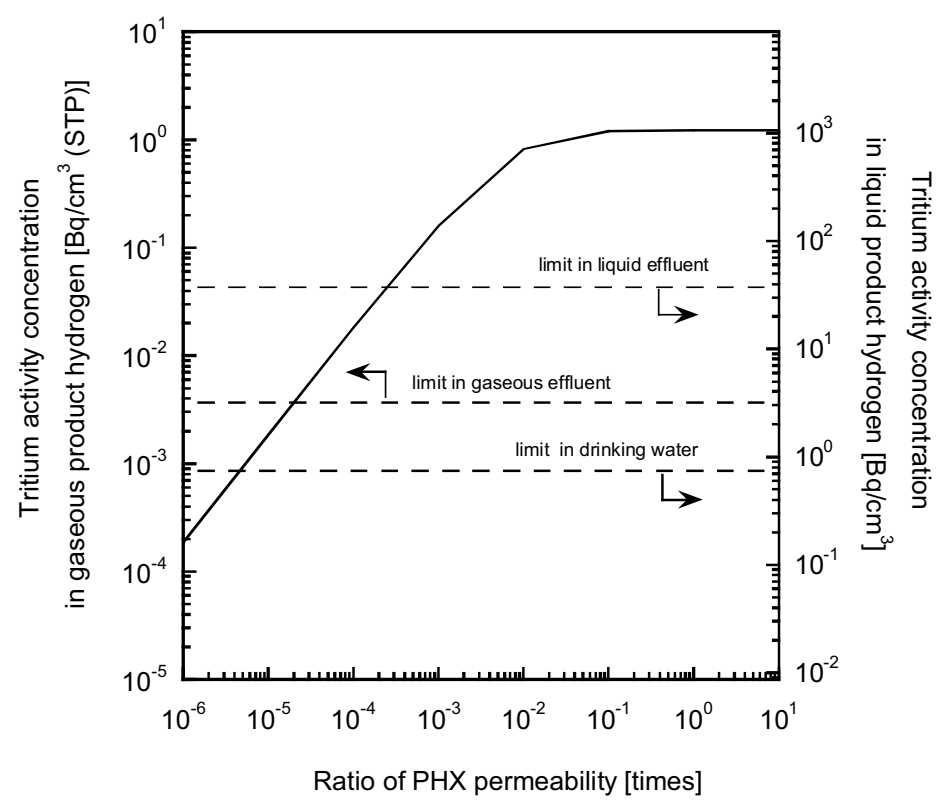

Figure 73. Effect of varying process heat exchanger permeability on the tritium concentration in the hydrogen product for the Next Generation Nuclear Plant using the sulfur iodine process.

Tritium concentration in a component of the sulfur iodine process. The tritium concentration in gaseous process chemicals of the flash drum (S301) shows maximum concentration for all process units. The relationship between PHX permeability and the tritium concentration in gaseous process chemicals of the flash drum (S301) is shown in Figure 74. Tritium concentration the flash drum decreases with a decrease of PHX permeability. The tritium concentration in the hydrogen product also decreases and becomes less than the gaseous effluent limit below about $1 \times 10^{-6}$ times the ratio of PHX permeability for the base case. 


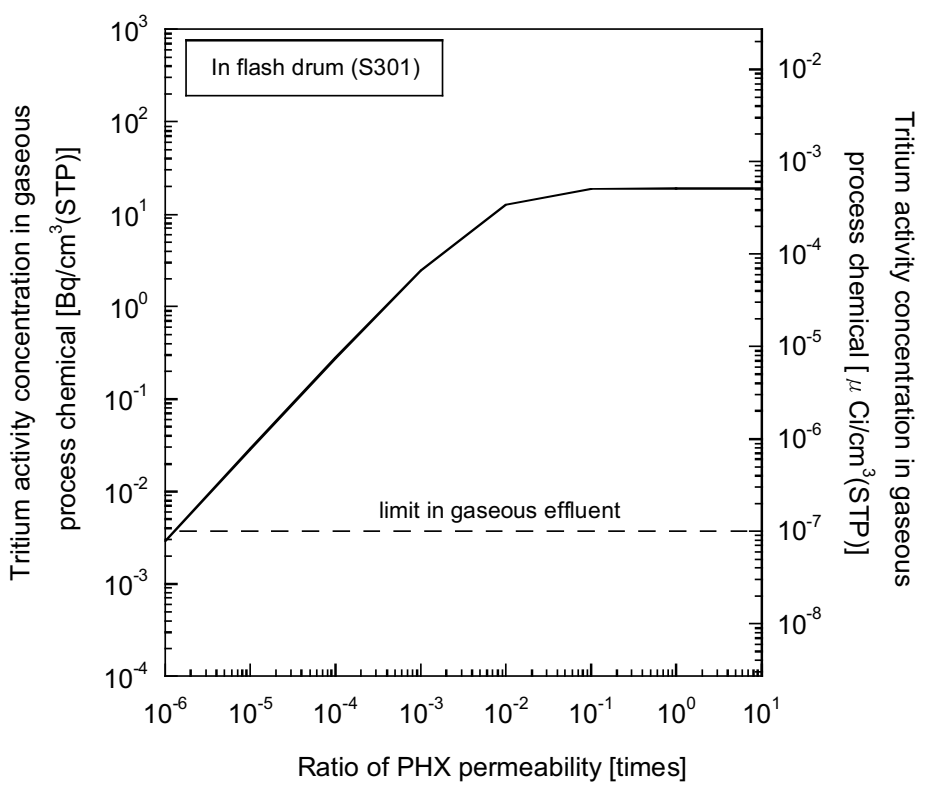

Figure 74. Effect of varying process heat exchanger permeability on the tritium concentration in gaseous process chemicals of the flash drum (S301) for the Next Generation Nuclear Plant using the sulfur iodine process.

The tritium concentration in the liquid process chemicals of the secondary $\mathrm{O}_{2}$ knockout drum (S105) shows maximum concentration for all process components regardless of the PHX permeability value. Dependency of the concentration in liquid process chemicals of the secondary $\mathrm{O}_{2}$ knockout drum (S105) on PHX permeability is almost the same as for gaseous process chemicals of the flash drum (S301) (see Figure 75). The tritium concentration becomes less than the drinking water limit below about $6 \times 10^{-6}$ times the baseline PHX permeability. 


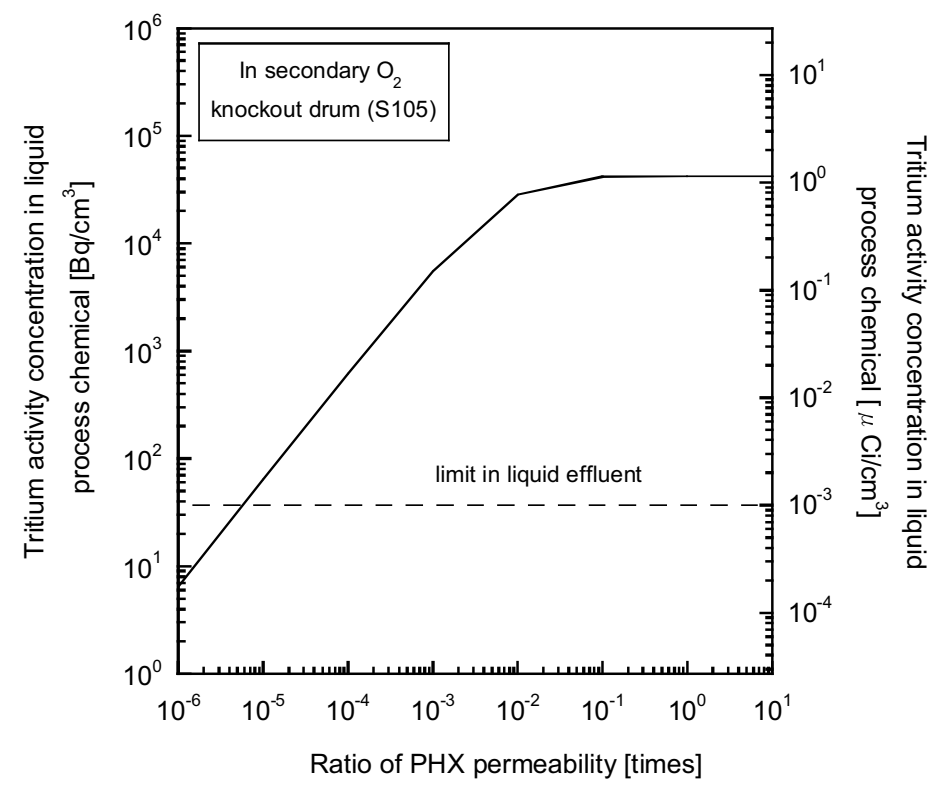

Figure 75. Effect of varying process heat exchanger permeability on the tritium concentration in liquid process chemicals of the secondary $\mathrm{O}_{2}$ knockout drum (S105) for the Next Generation Nuclear Plant using the sulfur iodine process.

Tritium concentration in helium coolant. Figure 76 shows the relationship between PHX permeability and the tritium concentration in the primary, secondary and tertiary helium coolants. Regardless of the PHX permeability value, the tritium concentration in the primary helium is almost the same value as the tritium concentration in the secondary helium. They increase with a decrease of PHX permeability, especially in the range from about $1 \times 10^{-1}$ to about $1 \times 10^{-3}$ times the baseline permeability. The tritium concentration in tertiary helium is larger than primary and the secondary helium and shows the same dependency on PHX permeability. In all cases, the tritium concentrations in all three coolants are above the gaseous effluent limit. . 


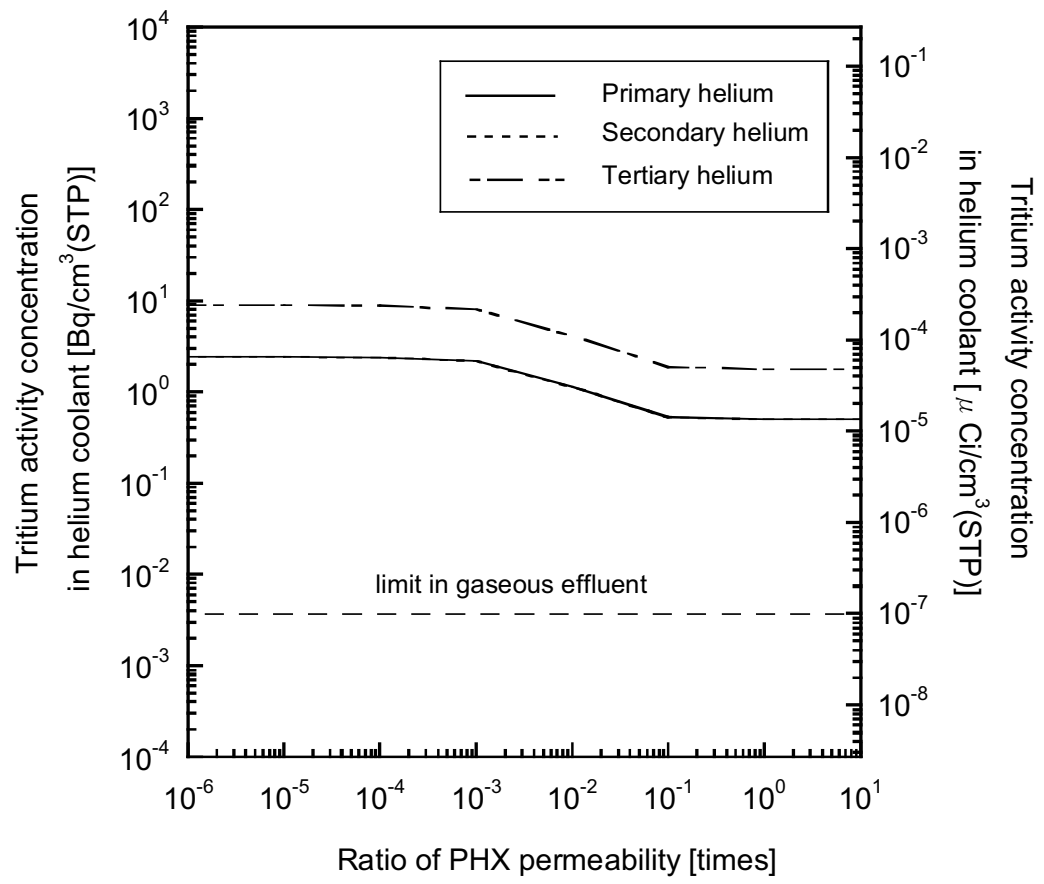

Figure 76. Effect of varying process heat exchanger permeability on the tritium concentration in helium coolant for the Next Generation Nuclear Plant using the sulfur iodine process.

\subsubsection{Effect of Hydrogen Concentration in Helium Coolant}

Tritium concentration in product hydrogen. The hydrogen concentration in the helium coolant affects the tritium permeation rate. For an NGNP using the HTE process, hydrogen permeates from the hydrogen plant. Estimated hydrogen concentrations in primary, secondary, and tertiary helium for the base case are about $36 \mathrm{ppm}, 37 \mathrm{ppm}$, and $425 \mathrm{ppm}$, respectively. These are larger than for primary coolant in the Peach Bottom HTGR at $10 \mathrm{ppm}$. Therefore, the effect of uncertainty of hydrogen release rates from components to the coolant based on the calculation result for the base case may not be significant for NGNP using the HTE process. However, hydrogen does not permeate from the hydrogen plant to helium coolants for an NGNP using the SI process because there is no heat exchange between helium coolant and Section 3 of the SI process.

The effect of hydrogen concentration in helium coolant was evaluated by considering hydrogen release to primary helium. Figure 77 shows the relationship between the hydrogen concentration in primary coolant and the tritium concentration in the hydrogen product under the condition that the ratio of PHX permeability is from 1.0 to $1 \times 10^{-6}$ times the base case. Tritium concentrations decrease with an increase of the hydrogen concentration in primary helium. For example, at a hydrogen concentration of $10 \mathrm{ppm}$, the tritium concentration in product hydrogen is about $3 \times 10^{-1} \mathrm{~Bq} / \mathrm{cm}^{3}$ (STP) for the base case PHX permeability, which is about 0.25 times the tritium concentration for the base case. Tritium concentrations in product hydrogen at $1 \times 10^{-3}$ times and $1 \times 10^{-6}$ times the PHX permeability ratio are about $2 \times 10^{-3}$ times and $2 \times 10^{-3}$ times less than those without hydrogen in helium coolants, respectively. Therefore, even if the ratio of PHX permeability is $1 \times 10^{-3}$ times, the tritium concentration in product hydrogen is less than the drinking water limit at $10 \mathrm{ppm}$ of the hydrogen concentration. The effect of hydrogen concentration in helium coolant is significant, especially for the low PHX permeability condition. 


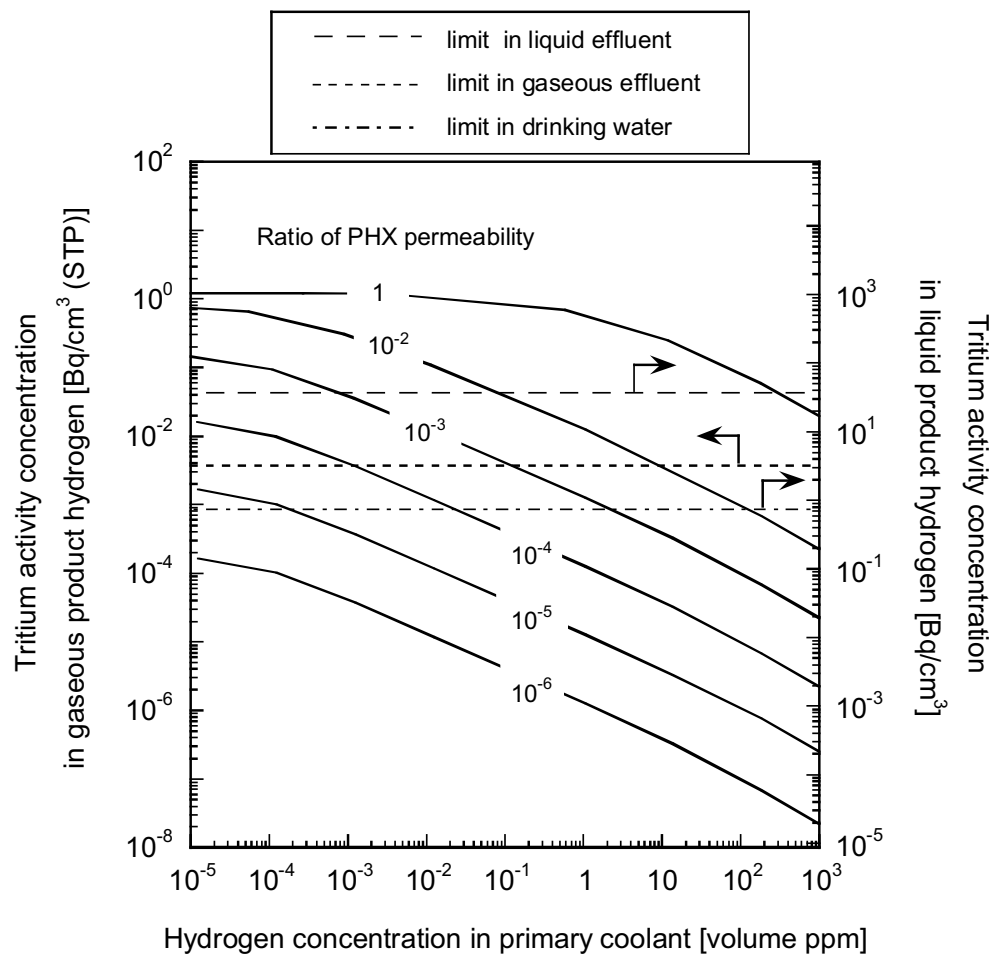

Figure 77. Effect of varying hydrogen concentration in the helium coolant on the tritium concentration in the hydrogen product for the Next Generation Nuclear Plant using the sulfur iodine process.

Tritium concentration in a component of the sulfur iodine process. Figure 78 shows the tritium concentration in gaseous process chemicals of the flash drum (S301) in response to varying hydrogen concentration in the primary helium loop. The gaseous tritium concentration in the flash drum is the maximum for all process components. The tritium concentration in gaseous process chemicals of the flash drum (S301) becomes less than the gaseous effluent limit above $3 \times 10^{-3} \mathrm{ppm}, 0.3 \mathrm{ppm}, 30 \mathrm{ppm}$, and $1,000 \mathrm{ppm}$ of the hydrogen concentration in primary helium at a permeability ratio of $1 \times 10^{-5}$ times, $1 \times 10^{-4}$ times, $1 \times 10^{-3}$ times, and $1 \times 10^{-2}$ times, respectively. Figure 79 shows the tritium concentration in liquid process chemicals of the secondary $\mathrm{O}_{2}$ knockout drum (S105) in response to varying hydrogen concentration in the primary helium loop. The tritium concentration in the knockout drum becomes less than the liquid effluent limit above $1 \times 10^{-4} \mathrm{ppm}, 0.01 \mathrm{ppm}, 1 \mathrm{ppm}$, and $100 \mathrm{ppm}$ of the hydrogen concentration in primary helium at a permeability ratio of $1 \times 10^{-5}$ times, $1 \times 10^{-4}$ times, $1 \times 10^{-3}$ times and $1 \times 10^{-2}$ times, respectively. 


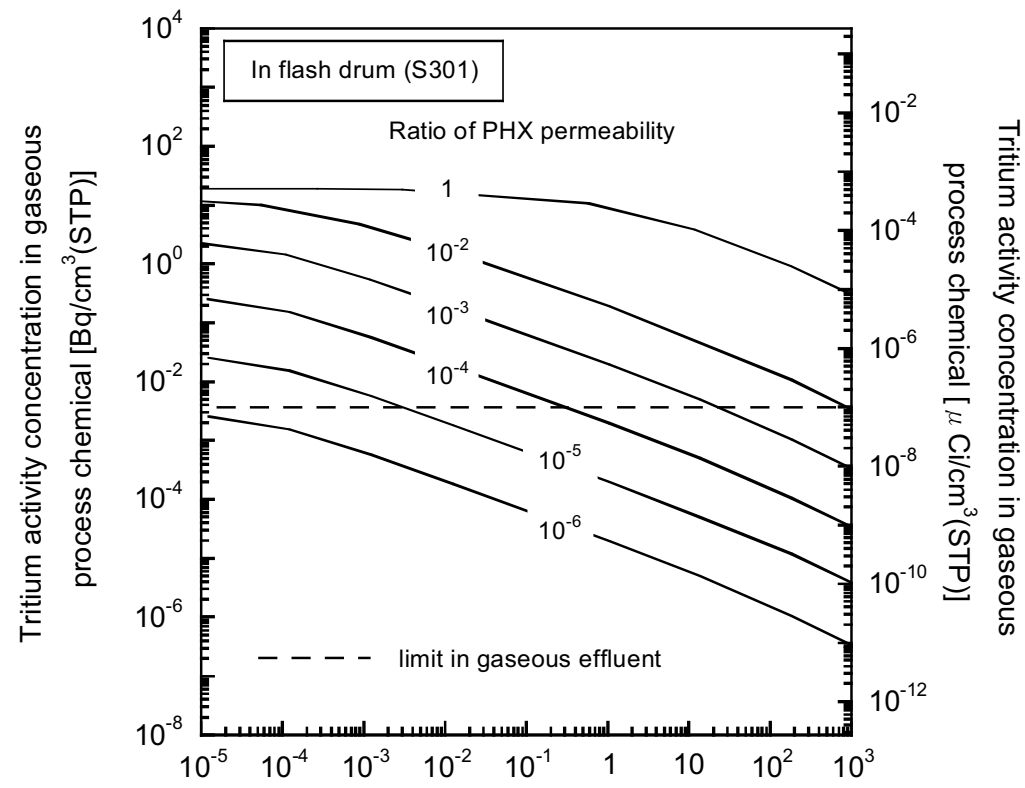

Hydrogen concentration in primary coolant [volume ppm]

Figure 78. Effect of varying hydrogen concentration in helium coolant on the tritium concentration in gaseous process chemicals of the flash drum (S301) for the Next Generation Nuclear Plant using the sulfur iodine process.

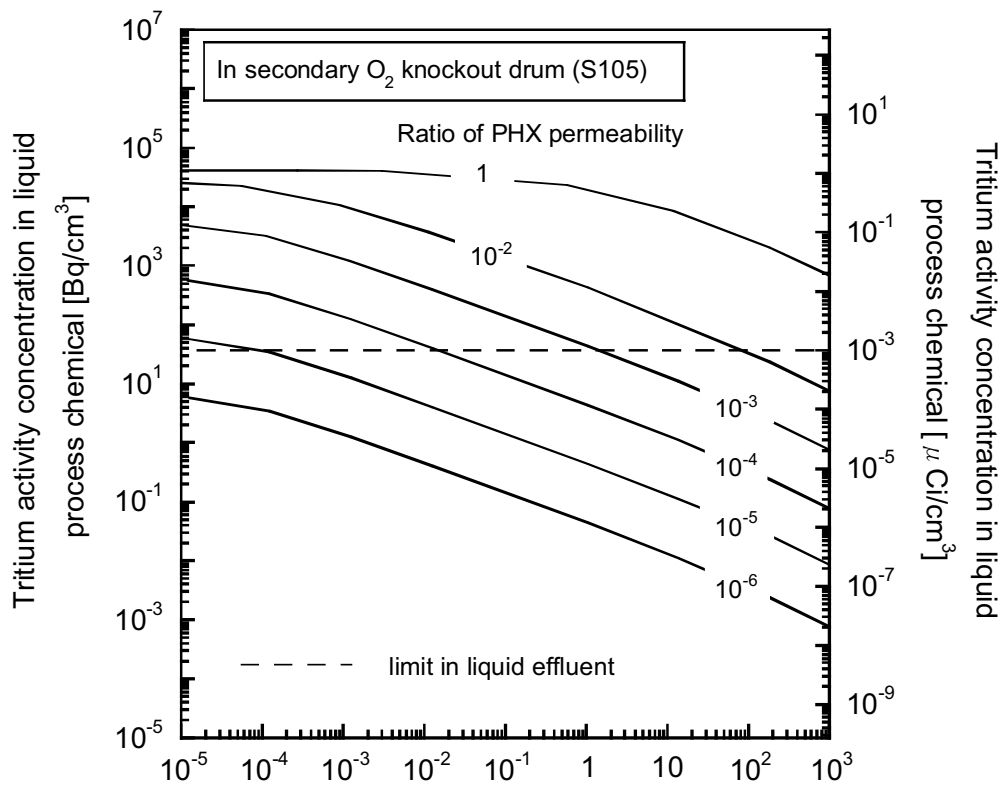

Hydrogen concentration in primary coolant [volume ppm]

Figure 79. Effect of varying hydrogen concentration in helium coolant on the tritium concentration in liquid process chemicals of the secondary $\mathrm{O}_{2}$ knockout drum (S105) for the Next Generation Nuclear Plant using the sulfur iodine process. 
Tritium concentration in helium coolant. Figures 80,81 , and 82 show tritium concentrations in primary, secondary, and tertiary helium coolants, respectively, in response to varying hydrogen concentration in the primary helium coolant. Tritium concentrations in primary and secondary helium coolants show the same dependency on the hydrogen concentration in the primary helium coolant - they increase slightly with an increase of hydrogen concentration in the primary helium coolant. The tritium concentration in tertiary helium decreases with an increase of hydrogen concentration in the primary helium coolant. In all cases, the tritium concentrations are larger than the gaseous effluent limit.

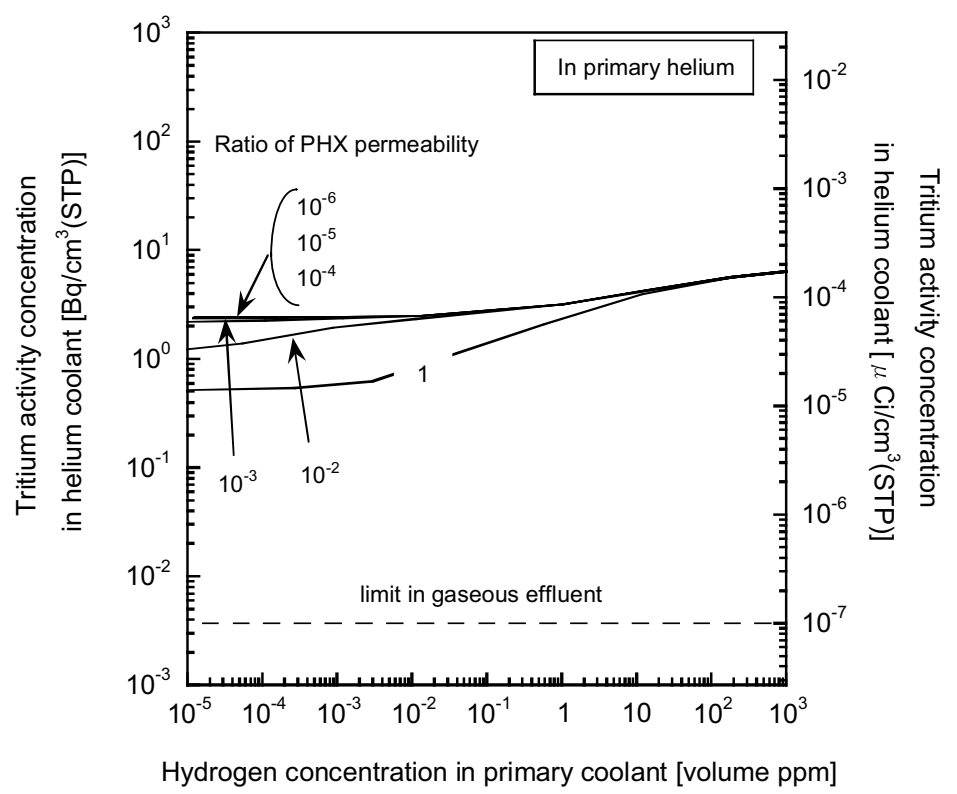

Figure 80. Effect of varying hydrogen concentration in helium coolant on the tritium concentration in the primary helium coolant for the Next Generation Nuclear Plant using the sulfur iodine process.

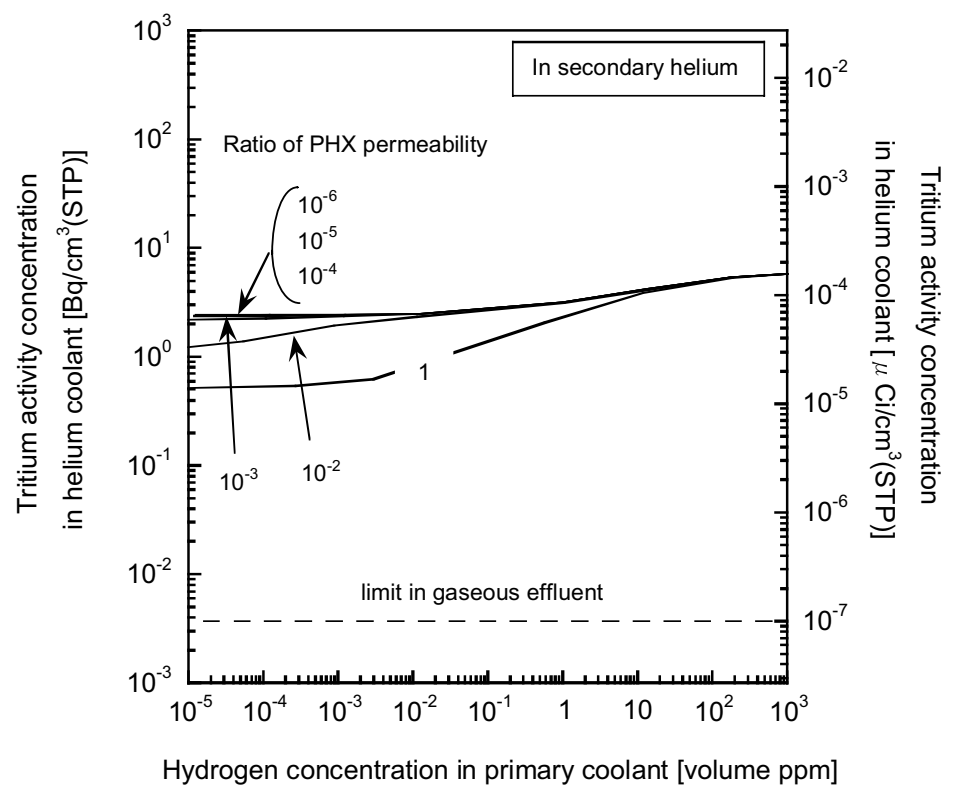

Figure 81. Effect of varying hydrogen concentration in helium coolant on the tritium concentration in the secondary helium coolant for the Next Generation Nuclear Plant using the sulfur iodine process. 


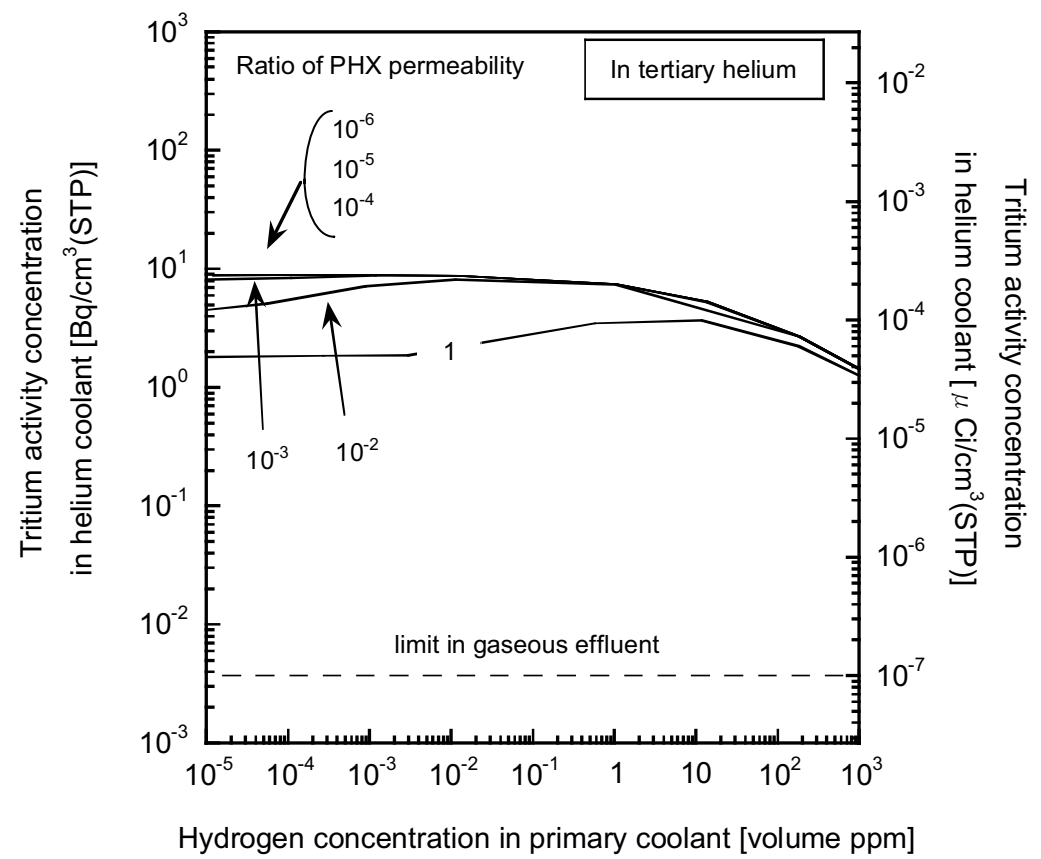

Figure 82. Effect of varying hydrogen concentration in helium coolant on the tritium concentration in the tertiary helium coolant for the Next Generation Nuclear Plant using the sulfur iodine process.

\subsubsection{Effect of Primary Coolant Tritium Release Rate}

Tritium concentration in product hydrogen. Figure 83 shows the relationship between the tritium release rate to the primary coolant and the tritium concentration in the hydrogen product at the condition PHX permeability ranging from $1.0 \times 10^{-6}$ to 1.0 times the base case PHX permeability. The tritium concentration in product hydrogen decreases with a decrease of the tritium release rate. At $1 \times 10^{-6}$ times the ratio of PHX permeability, the tritium concentration in the hydrogen product is less than the drinking water limit, even if the tritium release rate from the nuclear reactor core is 10 times the base case. Tritium concentrations in product hydrogen at $1 \times 10^{-5}$ times and $1 \times 10^{-4}$ times the ratio of PHX permeability becomes less than the drinking water limit below about 0.2 times and $3 \times 10^{-3}$ times the ratio of the tritium release rate, respectively. For tritium concentrations in the hydrogen product at the condition above $1 \times 10^{-3}$ times the ratio of PHX permeability, the tritium release ratio must be less than $1 \times 10^{-3}$ times the base case to reduce the tritium concentration in the hydrogen product lower than the drinking water limit.

Tritium concentration in a component of the sulfur iodine process. Figures 84 and 85 show the tritium concentration in gaseous process chemicals of the flash drum (S301) and in liquid process chemicals of the secondary $\mathrm{O}_{2}$ knockout drum (S105), respectively, in response to varying the ratio of the tritium release rate from the nuclear core. The concentrations shown in these components are the maximum concentrations for the entire process. Both concentrations show the same dependency on the tritium release rate and PHX permeability, with a decrease in tritium release rate or a decrease in PHX permeability causing a decrease in the tritium concentrations in both components. However, it is more difficult to lower the tritium concentration in the gaseous process chemicals to below the gaseous effluent limit than it is to lower the tritium concentration in the liquid process chemicals below the liquid effluent limit by adjusting these two paramaters (i.e., tritium release rate and PHX permeability). 


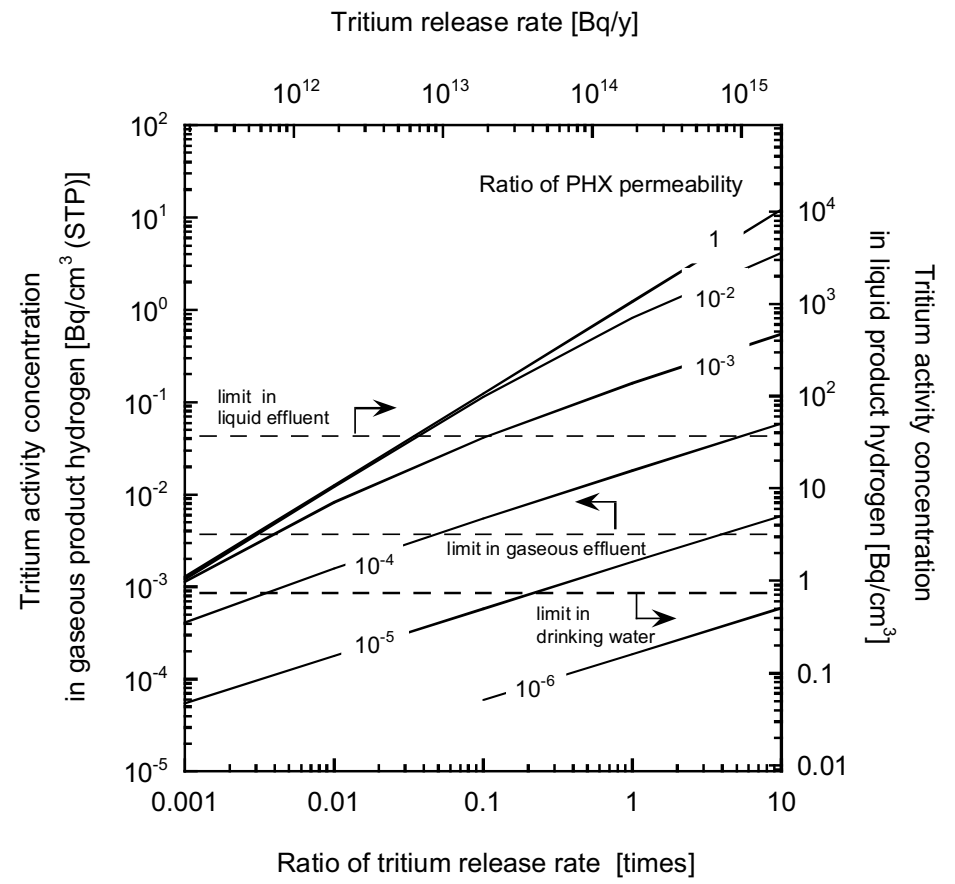

Figure 83. Effect of varying tritium release rate on the tritium concentration in the hydrogen product for the Next Generation Nuclear Plant using the sulfur iodine process.

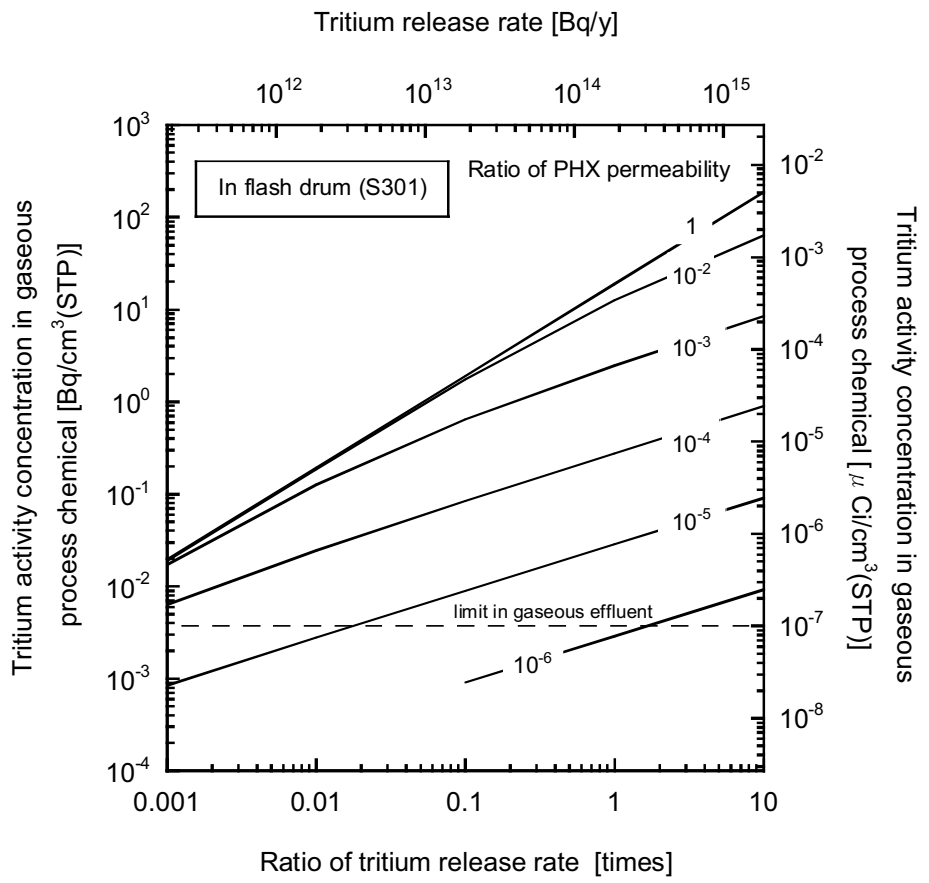

Figure 84. Effect of varying tritium release rate on the tritium concentration in gaseous process chemicals of the flash drum (S301) for the Next Generation Nuclear Plant using the sulfur iodine process. 


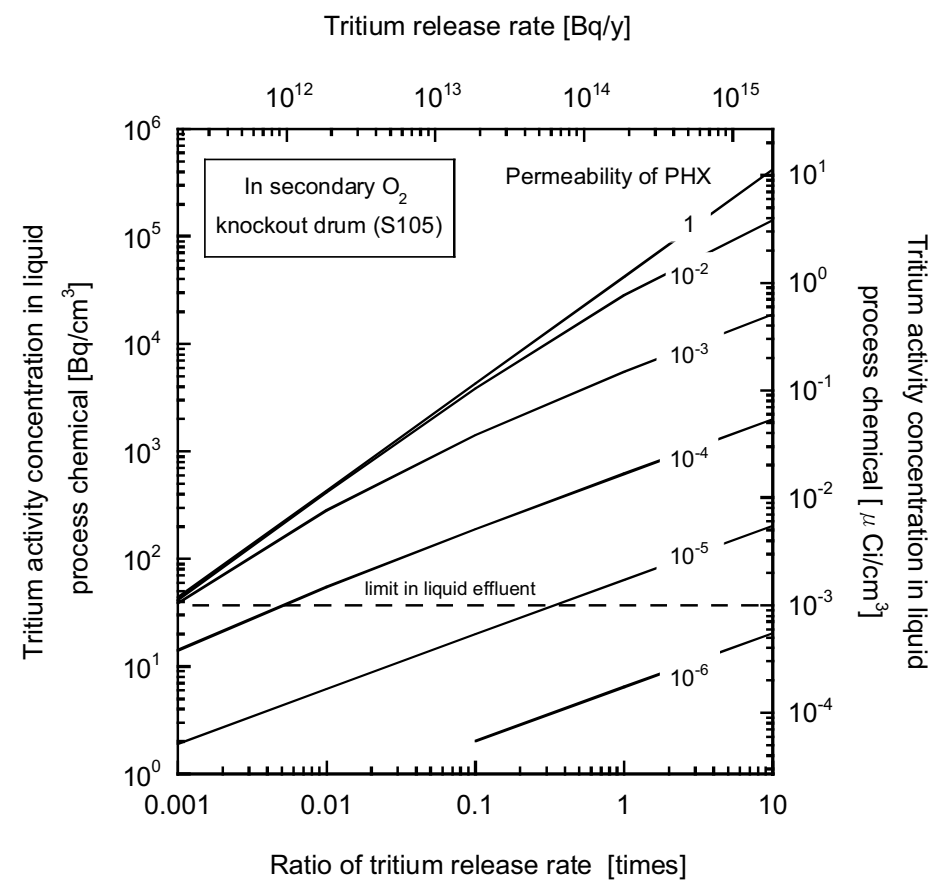

Figure 85. Effect of varying tritium release rate on the tritium concentration in liquid process chemicals of the secondary $\mathrm{O}_{2}$ knockout drum (S105) for the Next Generation Nuclear Plant using the sulfur iodine process.

Tritium concentration in helium coolant. Figures 86,87 , and 88 show tritium concentrations in the primary, secondary, and tertiary helium, respectively, in response to varying the ratio of the tritium release rate from the core. Tritium concentrations in the primary and secondary helium take almost the same values. The tritium concentration in the tertiary helium is larger than in the primary and secondary helium. The concentrations for the primary and secondary helium decrease with a decrease of the tritium release rate and increase of PHX permeability. The tritium concentration in tertiary helium becomes less than the gaseous effluent limit below about $3 \times 10^{-3}$ times the release rate, even if PHX permeability is the base case. 


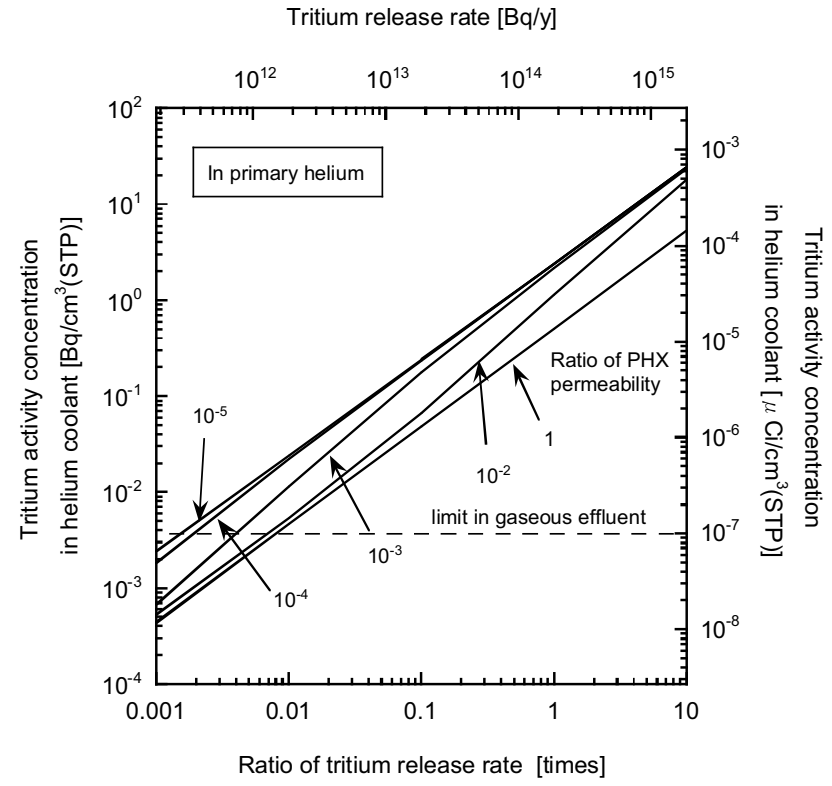

Figure 86. Effect of varying tritium release rate on the tritium concentration in the primary helium coolant for the Next Generation Nuclear Plant using the sulfur iodine process.

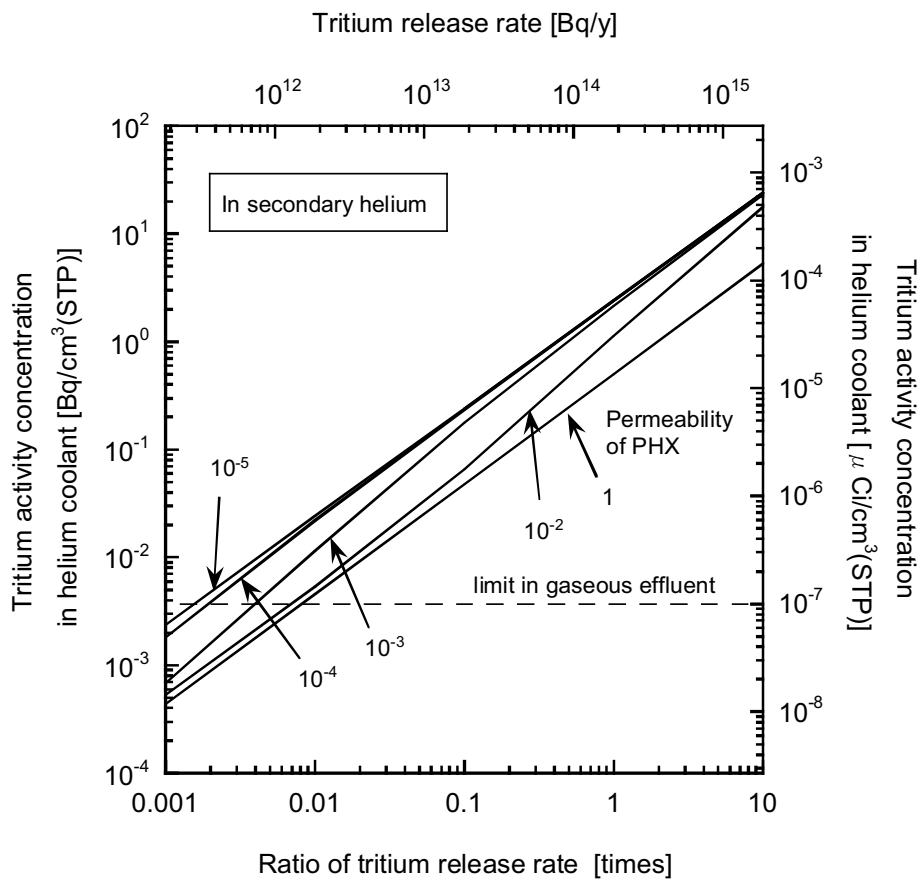

Figure 87. Effect of varying tritium release rate on the tritium concentration in the secondary helium coolant for the Next Generation Nuclear Plant using the sulfur iodine process. 


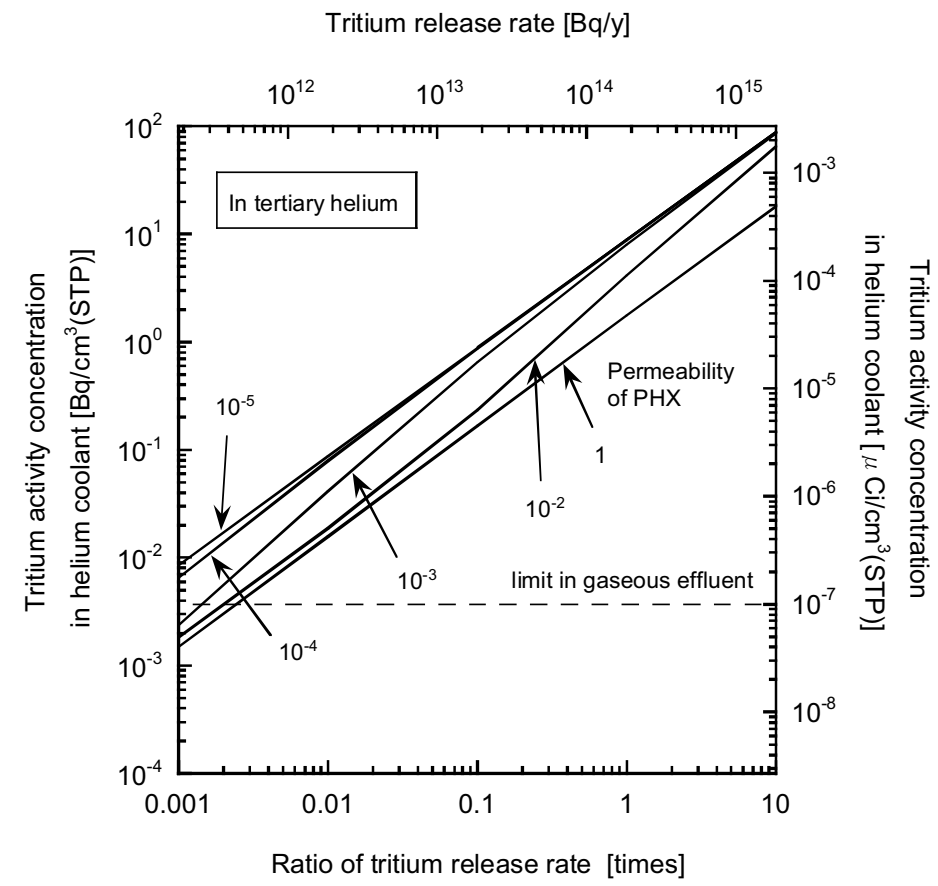

Figure 88. Effect of varying tritium release rate on the tritium concentration in the tertiary helium coolant for the Next Generation Nuclear Plant using the sulfur iodine process.

\subsubsection{Effect of Intermediate Heat Exchanger and Secondary Heat Exchanger Permeability}

Tritium concentration in product hydrogen. Figures 89 and 90 show the effect of varying the IHX permeability and PHX permeability, respectively, on the tritium concentration in product hydrogen.

Tritium concentrations start to decrease below about $1 \times 10^{-2}$ times the ratio of SHX permeability, which is similar to the case of PHX permeability shown in Figure 73. However, the ratio of IHX permeability should be reduced less than about $1 \times 10^{-4}$ times to effect a decrease the tritium concentration in the hydrogen product. This is caused by a high heat transfer area per unit heat transfer rate and the thin heat transfer tube of IHX. If the ratio of PHX permeability is $1 \times 10^{-6}$ times, the tritium concentration in the hydrogen product is less than the drinking water limit. However, if the ratio of PHX permeability is $1 \times 10^{-5}$ times, the ratio of IHX permeability should also be less than about $7 \times 10^{-6}$ times or the ratio of SHX permeability should also be less than about $6 \times 10^{-4}$ times to decrease the tritium concentration in the hydrogen product to less than the drinking water limit.

The permeabilities' effect on the tritium concentration in the hydrogen product for an NGNP using the SI process is not significant when compared with an NGNP using the HTE process. This is because of the absence of hydrogen in the helium loops. Figure 91 shows the relationship between IHX permeability and $P_{H T} / \sqrt{P_{H 2}+P_{H T}}$ in the IHX primary and the secondary coolants, and the tritium permeation rate through IHX. Figure 91 shows the relationship between SHX permeability and $P_{H T} / \sqrt{P_{H 2}+P_{H T}}$ in the SHX secondary and the tertiary coolants, and the tritium permeation rate through SHX. The differences of $P_{H T} / \sqrt{P_{H 2}+P_{H T}}$ at IHX and SHX are smaller than those for an NGNP using the HTE process (see Figures 22 and 23). This is due to the absence of hydrogen. In the case of a low value for the difference of $P_{H T} / \sqrt{P_{H 2}+P_{H T}}$, the driving force (i.e., the difference of 
$P_{H T} / \sqrt{P_{H 2}+P_{H T}}$ ) increases lineally with a decrease of permeability. This results in a constant permeation rate in spite of a decrease in permeability.

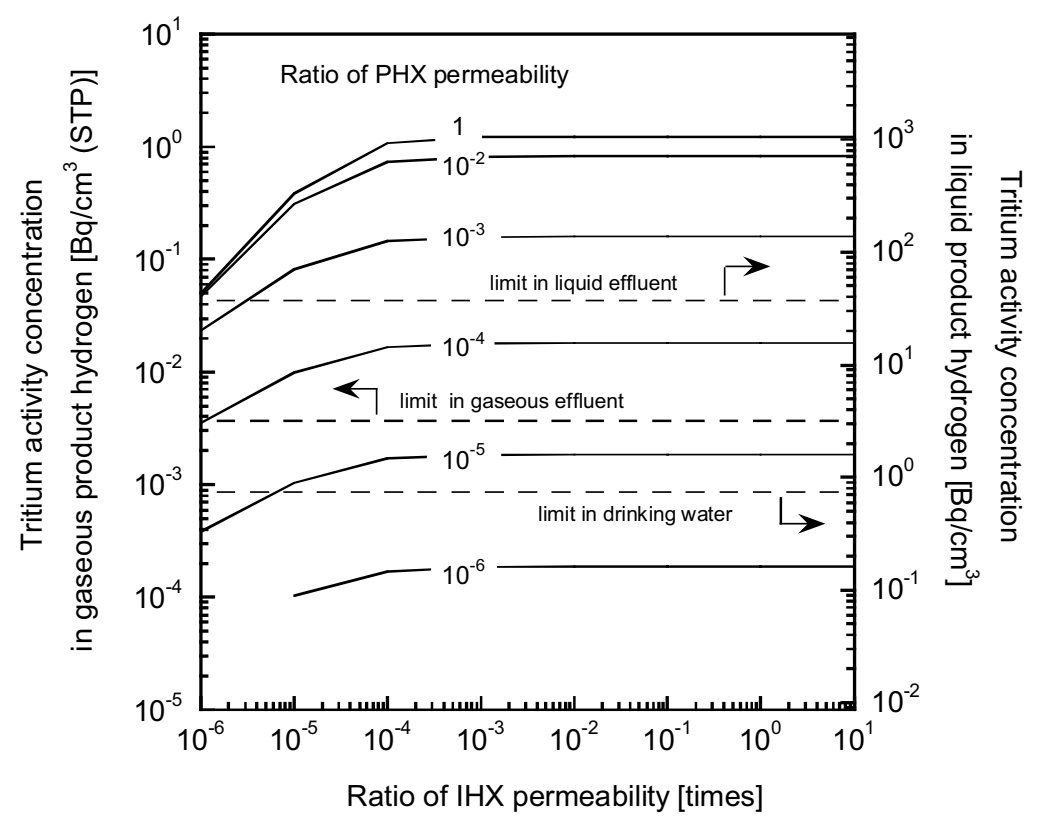

Figure 89. Effect of varying intermediate heat exchanger permeability on the tritium concentration in the hydrogen product for the Next Generation Nuclear Plant using the sulfur iodine process.

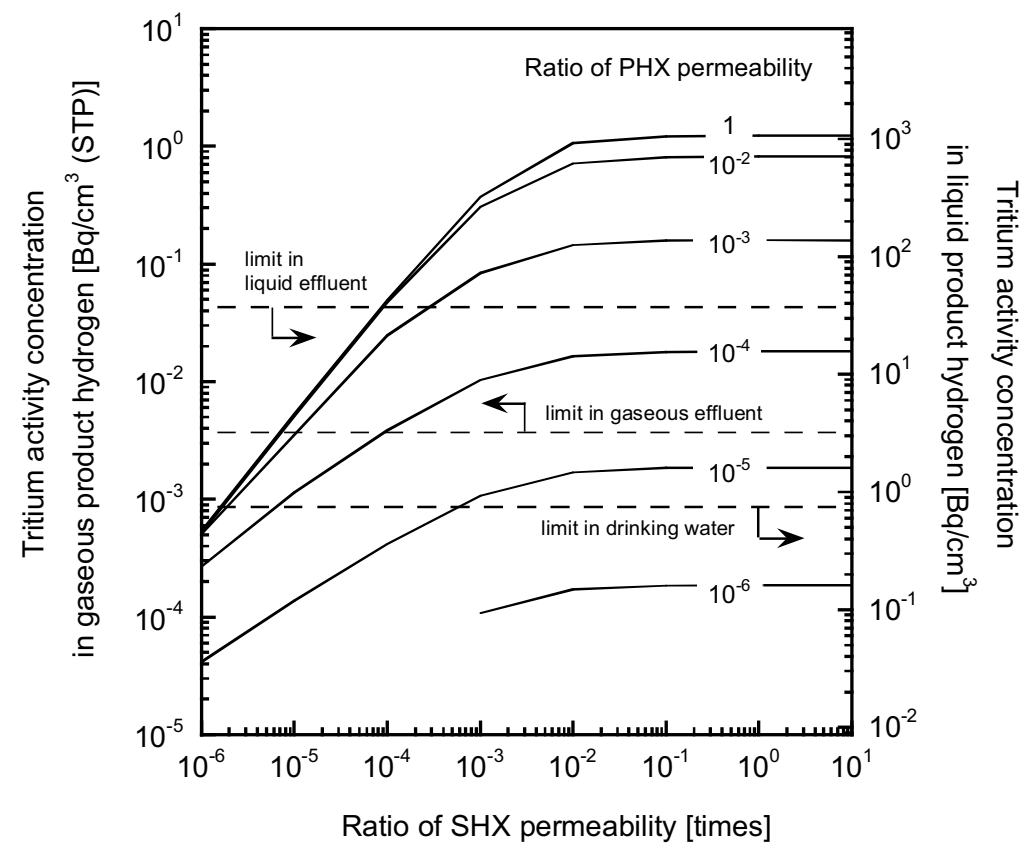

Figure 90. Effect of varying secondary heat exchanger permeability on the tritium concentration in the hydrogen product for the Next Generation Nuclear Plant using the sulfur iodine process. 


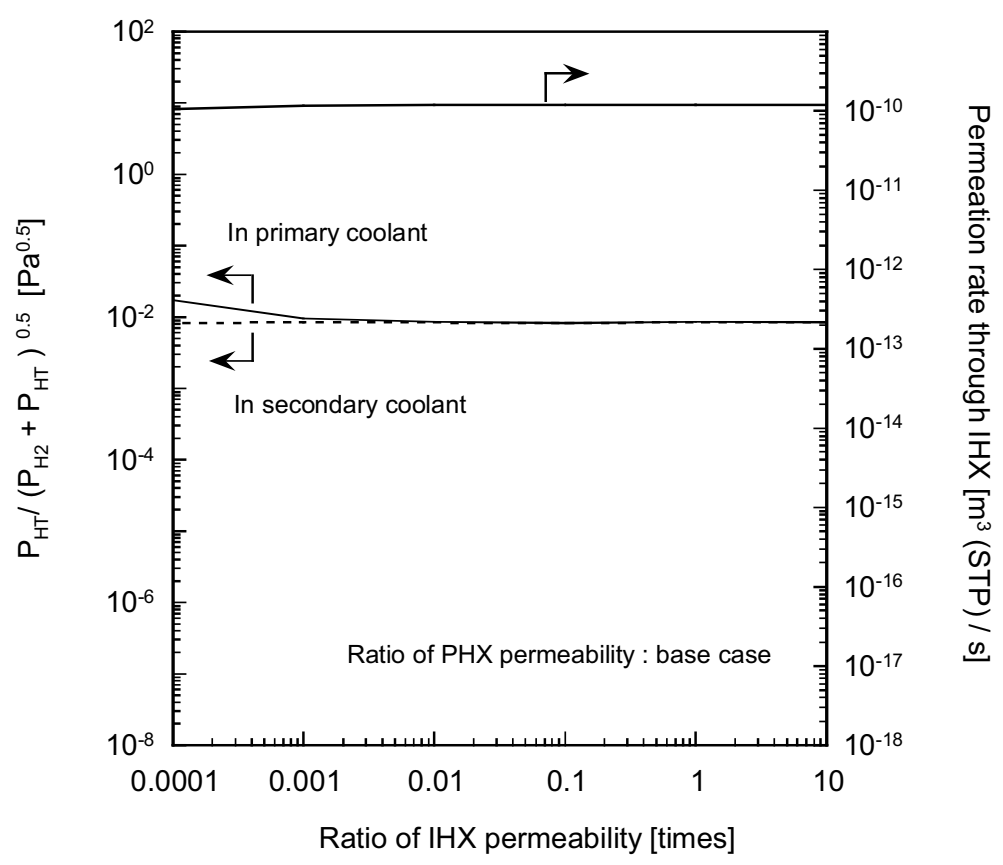

Figure 91. Effect of varying intermediate heat exchanger permeability on the tritium permeation driving force and tritium permeation rate through the intermediate heat exchanger for the Next Generation Nuclear Plant using the sulfur iodine process.

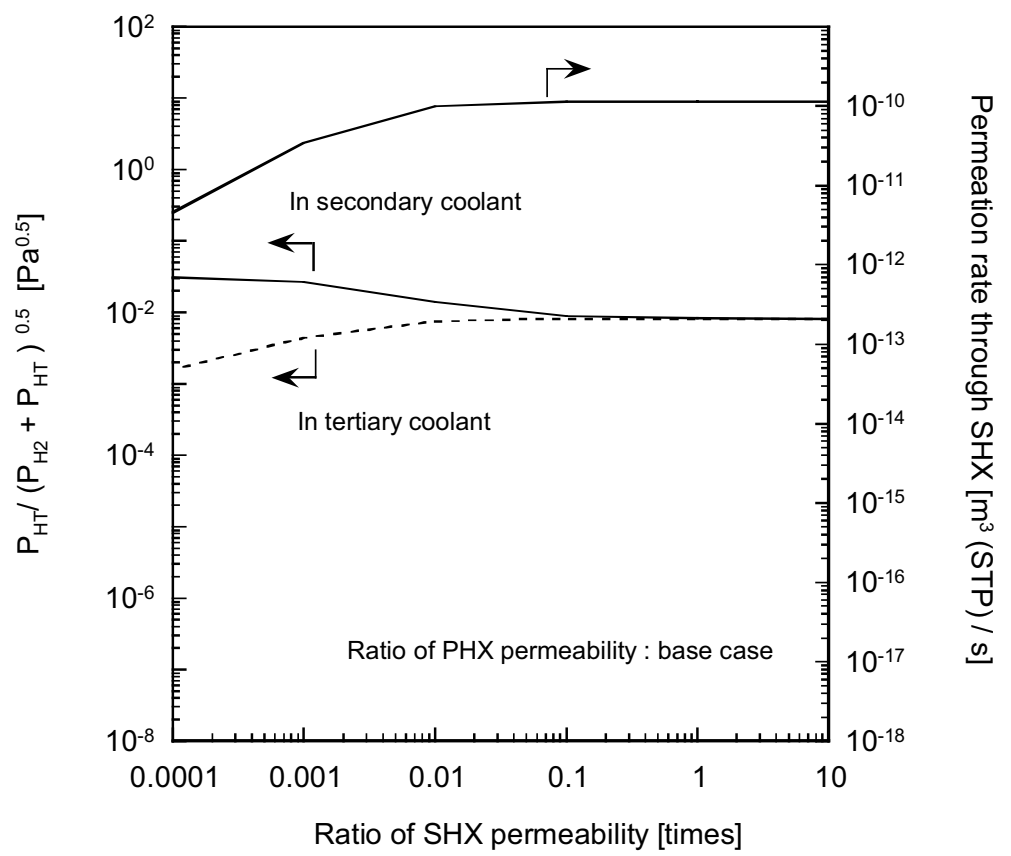

Figure 92. Effect of varying secondary heat exchanger permeability on the tritium permeation driving force and tritium permeation rate through the secondary heat exchanger for the Next Generation Nuclear Plant using the sulfur iodine process. 
Tritium concentration in a component of the sulfur iodine process. Figure 93 shows the relationship between IHX permeability and the tritium concentration in the gaseous process chemicals of the flash drum (S301), where the concentration of gaseous tritium compounds is the maximum concentration for the entire process. The effect of IHX permeability is not significant, which is unlike the case of tritium concentration in the hydrogen product. According to the figure, it is difficult to decrease the concentration in gaseous process chemicals by decreasing IHX permeability. Figure 94 shows the relationship between SHX permeability and the tritium concentration in the gaseous process chemicals of the flash drum (S301). The effect of changing SHX permeability is larger than the effect of changing IHX permeability on the tritium concentration in the gaseous process chemicals. However, a relatively small SHX permeability is required to decrease the concentration to less than the gaseous effluent limit. For example, the ratio of SHX permeability should be less than about $3 \times 10^{-5}$ times and about $1 \times 10^{-6}$ times when the PHX permeability has a value of $1 \times 10^{-5}$ and $1 \times 10^{-4}$ times the base case value, respectively.

Figures 95 and 96 show the effect of varying the IHX permeability and SHX permeability on the tritium concentration in liquid process chemical of the secondary $\mathrm{O}_{2}$ knockout drum (S105), respectively, where the tritium concentration in the liquid process chemicals is the highest of the entire process. The profiles in each figure are almost the same as the profiles for Figures 93 and 94 . However, it is slightly easier to decrease the tritium concentration in liquid process chemicals to less than the liquid effluent limit than to decrease the tritium concentration in gaseous process chemicals to less than the gaseous effluent limit by adjusting the IHX and SHX permeability. Still large changes in the permeability of both heat exchangers are needed to reduce the tritium concentration to below the liquid effluent limit.

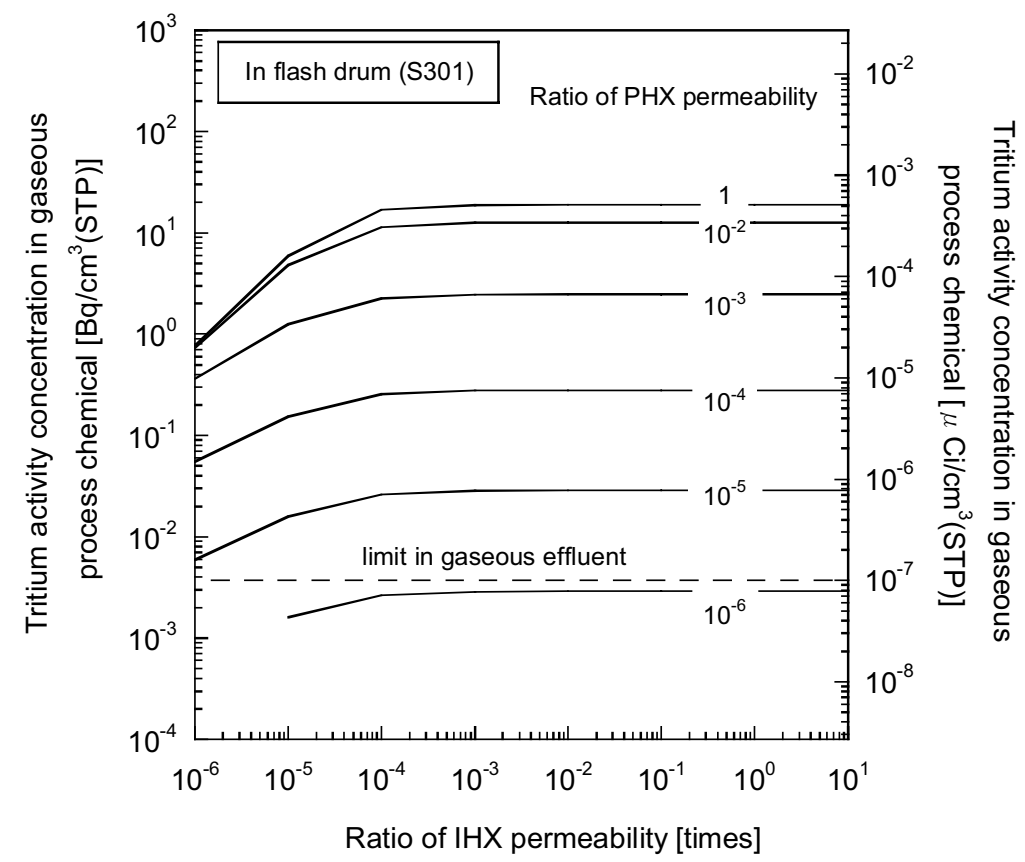

Figure 93. Effect of varying intermediate heat exchanger permeability on the tritium concentration in gaseous process chemicals of the flash drum (S301) for the Next Generation Nuclear Plant using the sulfur iodine process. 


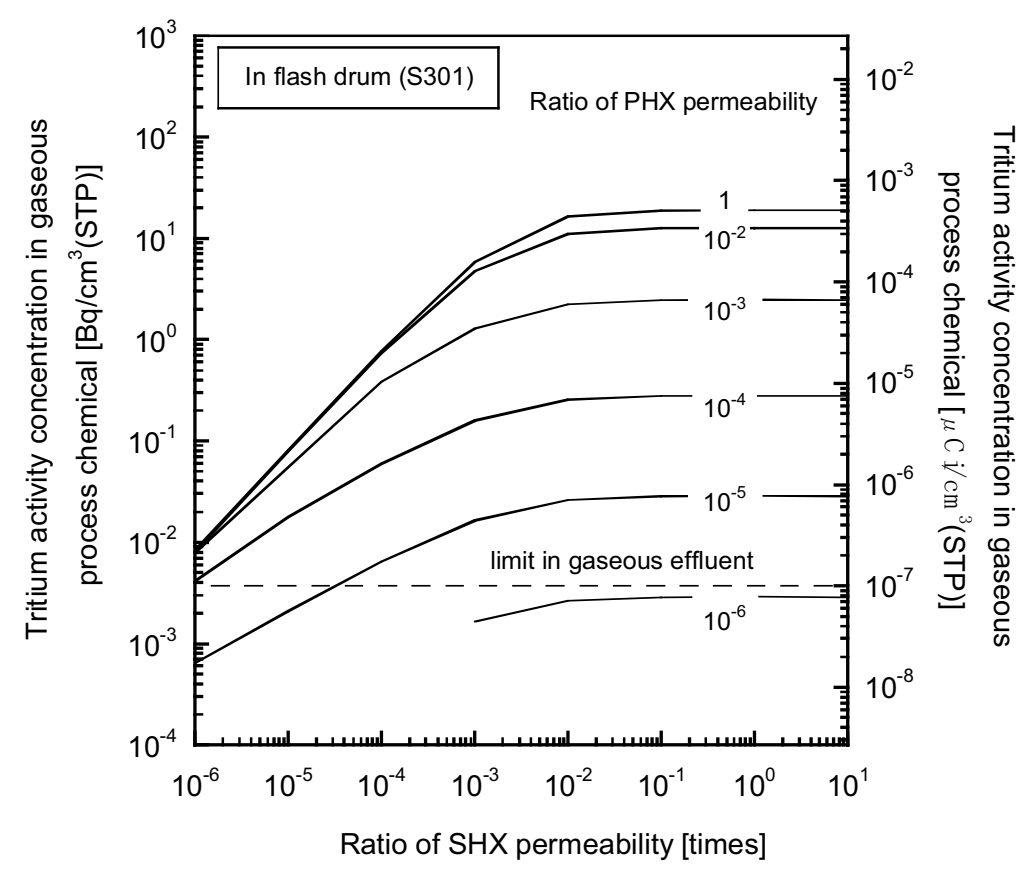

Figure 94. Effect of varying secondary heat exchanger permeability on the tritium concentration in gaseous process chemicals of the flash drum (S301) for the Next Generation Nuclear Plant using the sulfur iodine process.

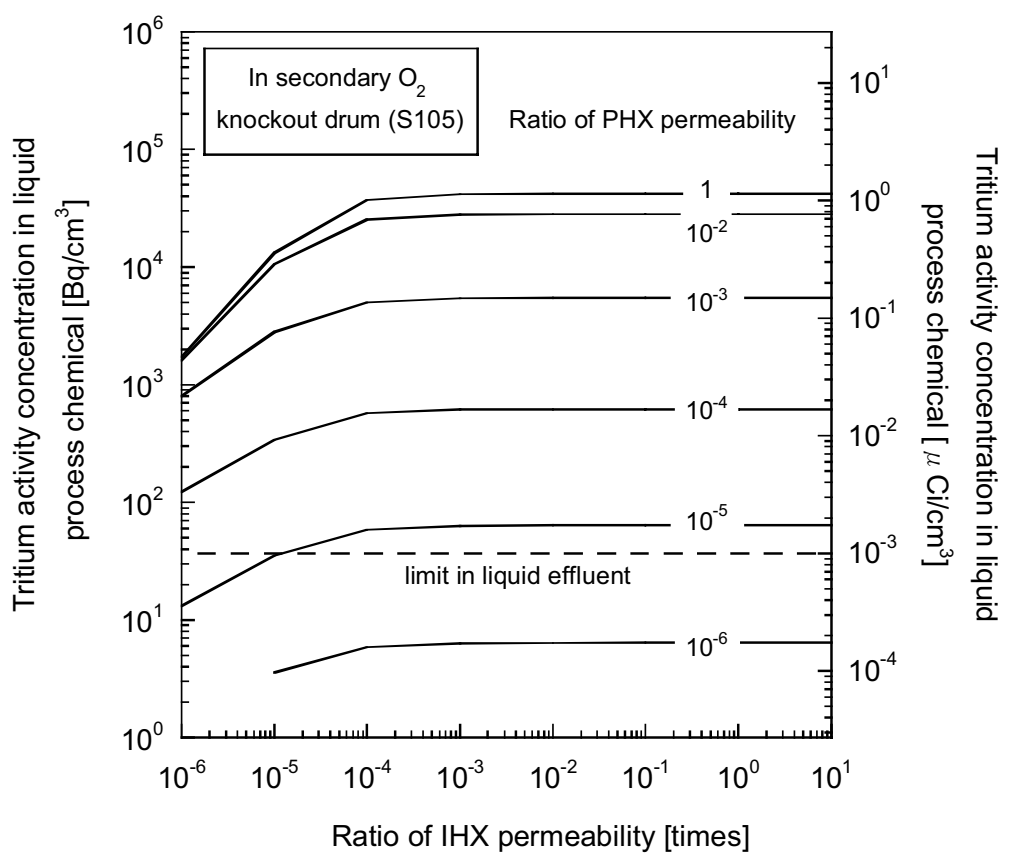

Figure 95. Effect of varying intermediate heat exchanger permeability on the tritium concentration in liquid process chemicals of the secondary $\mathrm{O}_{2}$ knockout drum $(\mathrm{S} 105)$ for the Next Generation Nuclear Plant using the sulfur iodine process. 


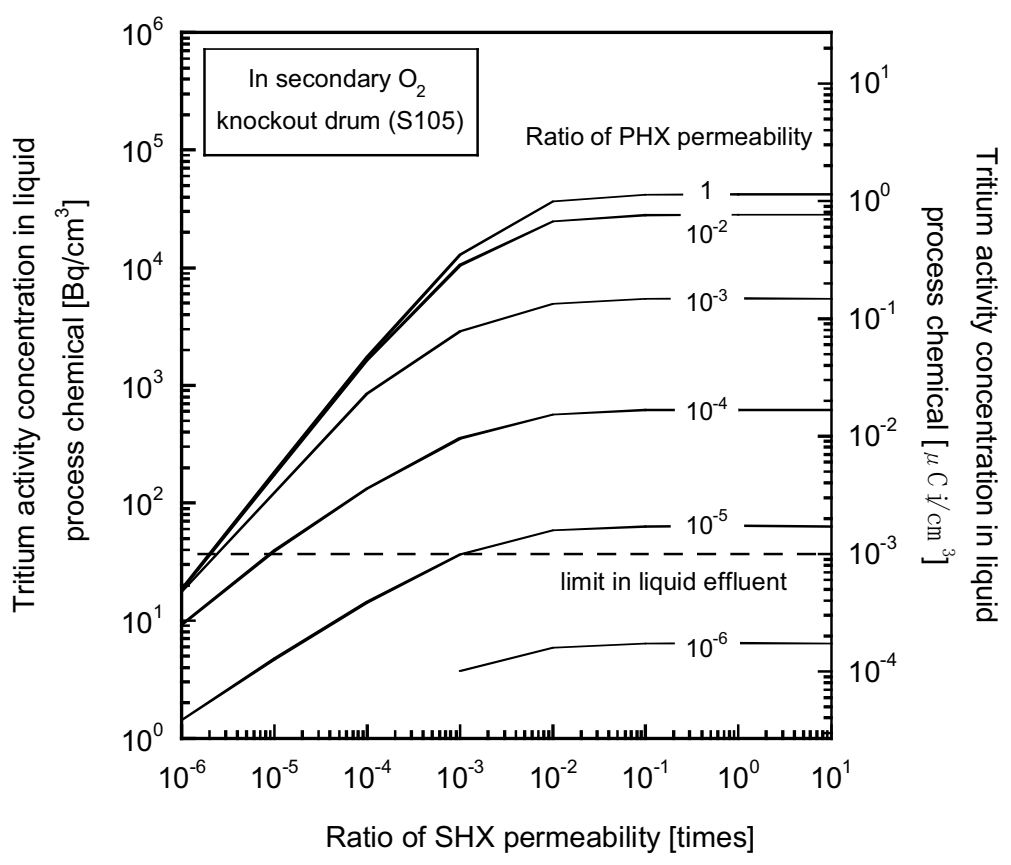

Figure 96. Effect of varying secondary heat exchanger permeability on the tritium concentration in liquid process chemicals of the secondary $\mathrm{O}_{2}$ knockout drum (S105) for the Next Generation Nuclear Plant using the sulfur iodine process.

Tritium concentration in helium coolant. Figures 97, 98, and 99 show the relationship between IHX permeability and the tritium concentration in primary, secondary, and tertiary helium, respectively. The tritium concentration in primary helium increases with a decrease of IHX permeability below about $1 \times 10^{-3}$ times due to a decrease of the tritium permeation rate. Tritium concentrations in secondary and tertiary helium also reasonably decrease with a decrease of IHX permeability. However, the tritium concentration in tertiary helium is larger than the gaseous effluent limit, even if the ratio of IHX permeability is $1 \times 10^{-6}$ times. Figures 100,101 , and 102 show the relationship between SHX permeability and the tritium concentration in primary, secondary and tertiary helium, respectively. The tritium concentration in tertiary helium becomes less than the gaseous effluent limit below $6 \times 10^{-6}$ times the ratio of SHX permeability at $1 \times 10^{-6}$ times of ratio of PHX permeability. 


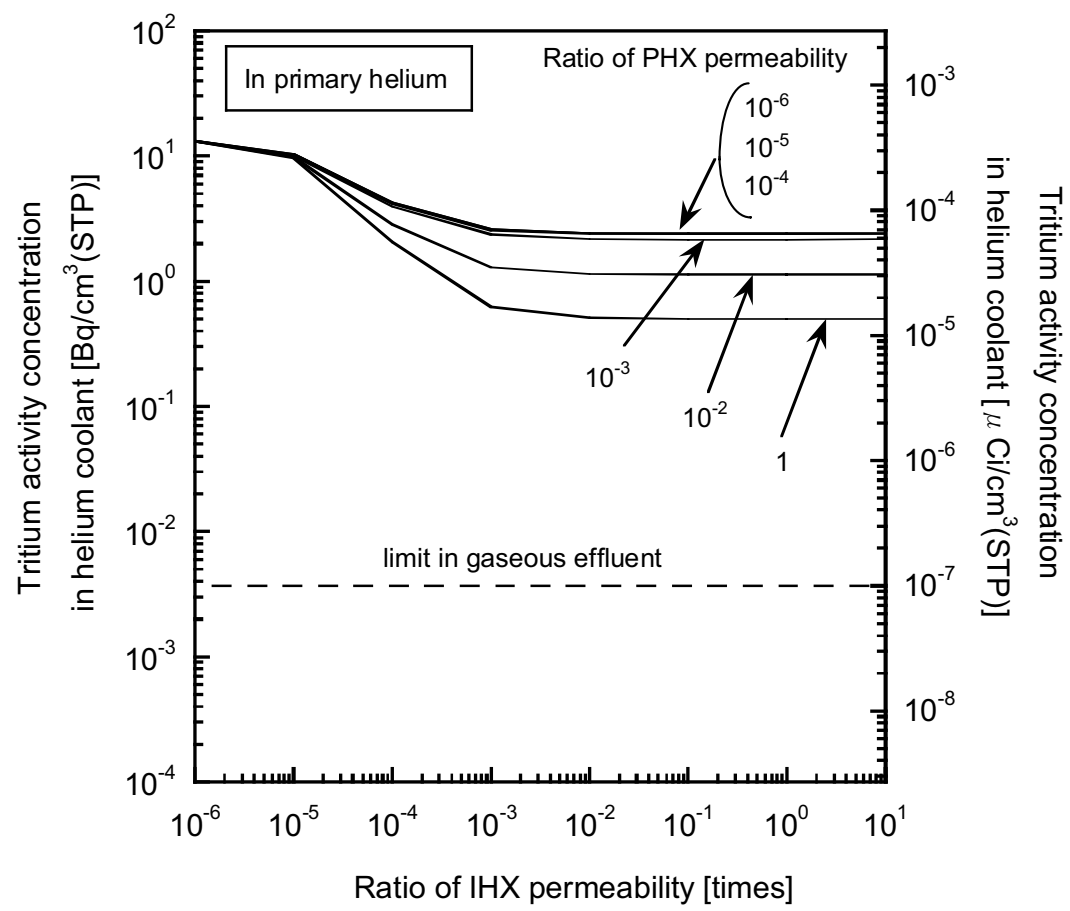

Figure 97. Effect of varying intermediate heat exchanger permeability on the tritium concentration in the primary helium coolant for the Next Generation Nuclear Plant using the sulfur iodine process.

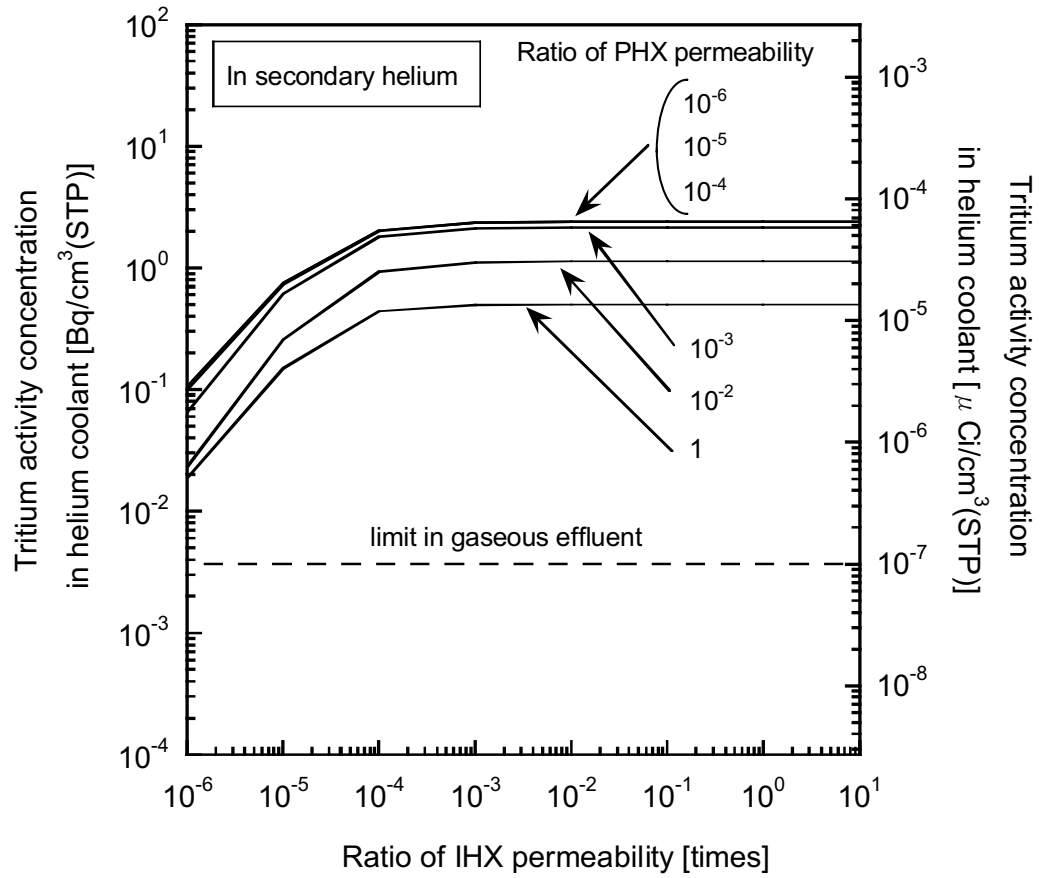

Figure 98. Effect of varying intermediate heat exchanger permeability on the tritium concentration in the secondary helium coolant for the Next Generation Nuclear Plant using the sulfur iodine process. 


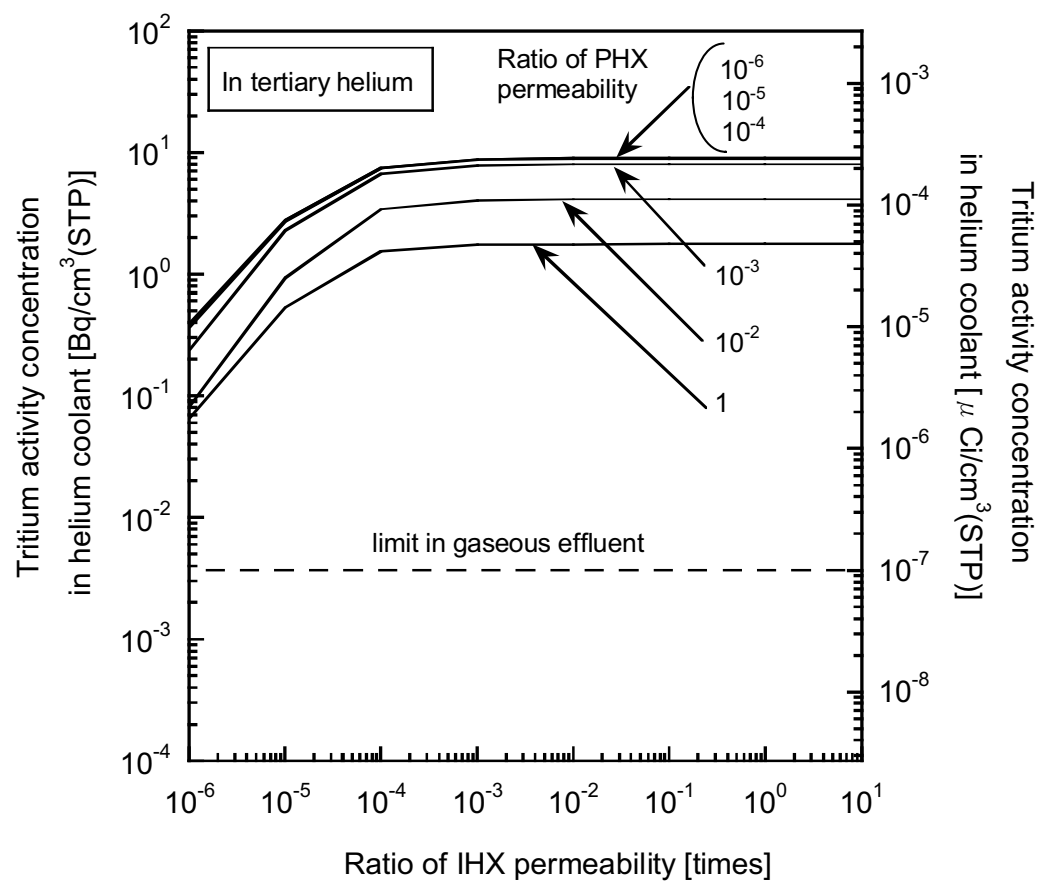

Figure 99. Effect of varying intermediate heat exchanger permeability on the tritium concentration in the tertiary helium coolant for the Next Generation Nuclear Plant using the sulfur iodine process.

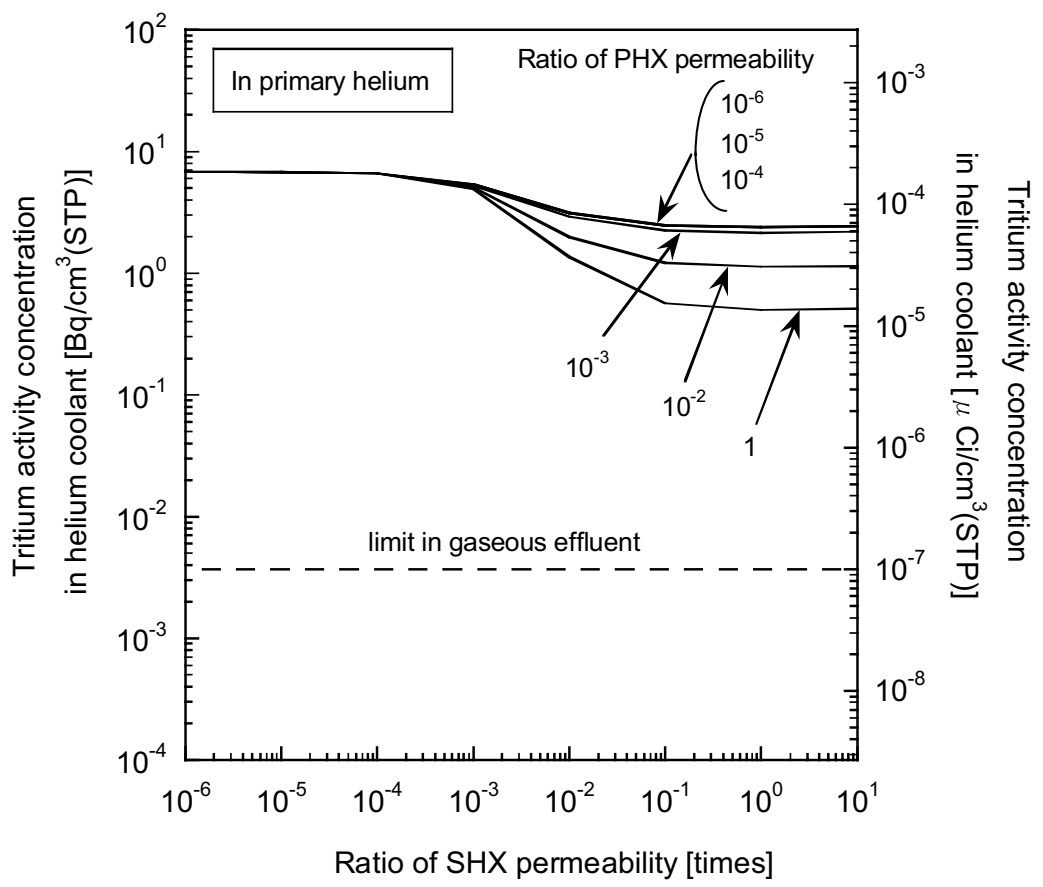

Figure 100. Effect of varying secondary heat exchanger permeability on the tritium concentration in the primary helium coolant for the Next Generation Nuclear Plant using the sulfur iodine process. 


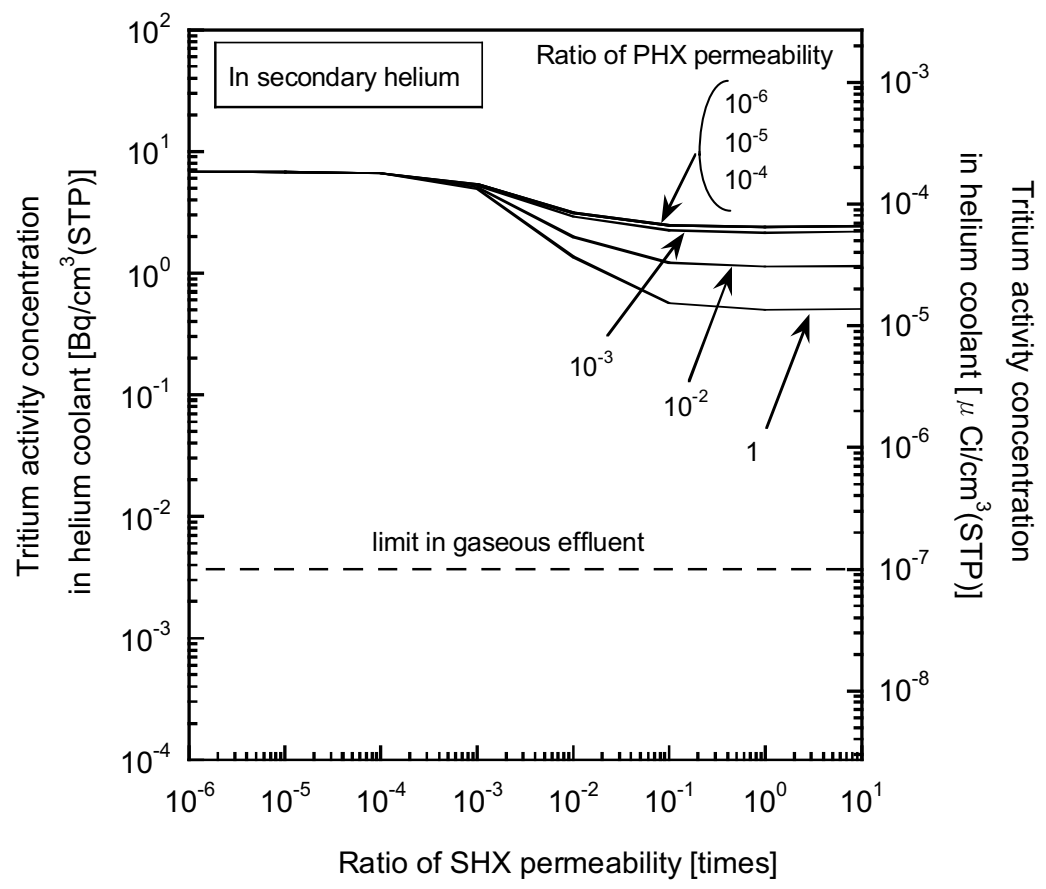

Figure 101. Effect of varying secondary heat exchanger permeability on the tritium concentration in the secondary helium coolant for the Next Generation Nuclear Plant using the sulfur iodine process.

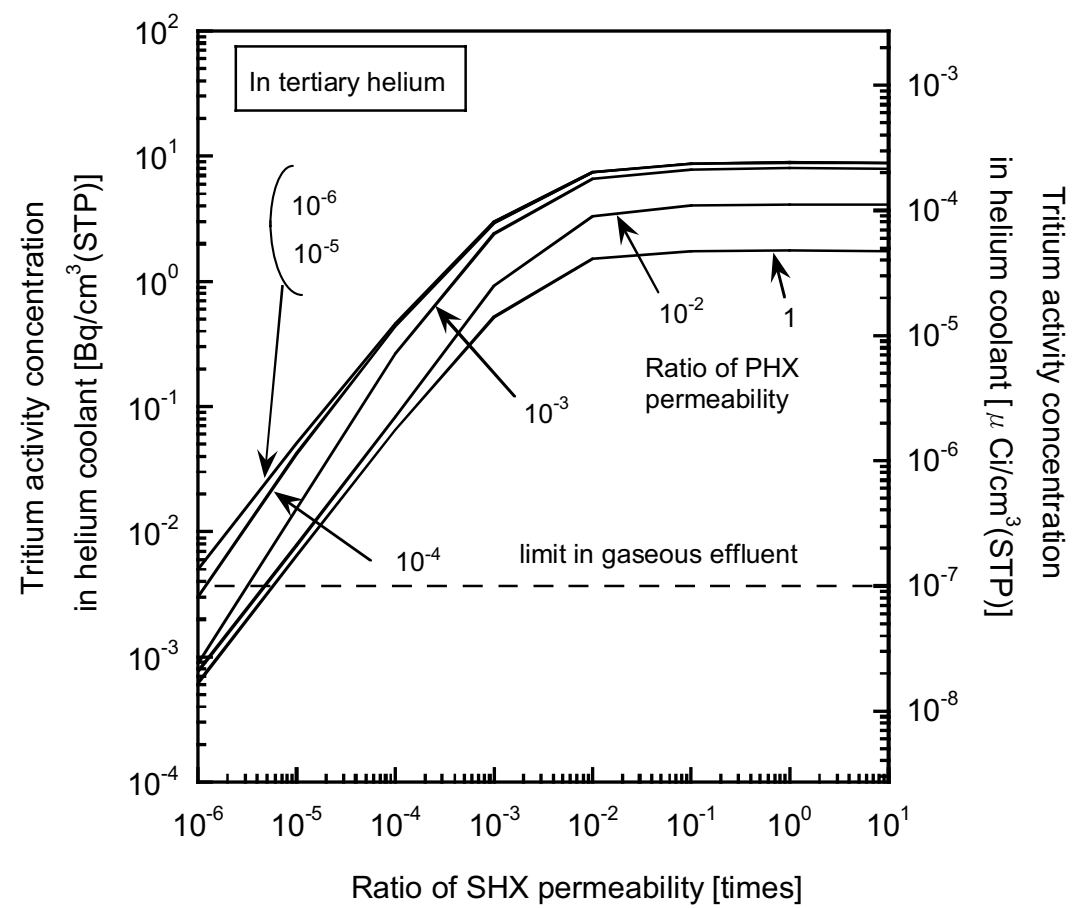

Figure 102. Effect of varying secondary heat exchanger permeability on the tritium concentration in the tertiary helium coolant for the Next Generation Nuclear Plant using the sulfur iodine process. 


\subsubsection{Effect of Helium Flow Rate at the Purification System}

Tritium concentration in product hydrogen. Figures 103, 104, and 105 show the effect of varying the helium flow rate in the purification system in the primary, secondary, and tertiary loops on the tritium concentration in product hydrogen, respectively. Tritium concentrations in the hydrogen product decrease with an increase in helium flow rate at each purification system. Whereas the tritium concentration in the hydrogen product can be decreased to a greater extent by increasing the flow rate of the hydrogen purification system in the primary coolant loop versus increasing the flow rate in the secondary cooling loop by the same extent, there is no significant difference between the two actions on the calculated tritium concentration in the hydrogen product. Increasing the helium flow rate at the purification system in the tertiary loop is slightly more effective at reducing the tritium concentration in the hydrogen product, but negligibly so, than can be caused by increasing the flow rate in the primary or secondary loops. For example, the helium flow rate at the purification system in the tertiary loop should be increased about 700 times to decrease concentration by a factor of 0.1 . The effect of helium flow rate at the purification system in all helium loops is also evaluated as shown in Figure 106. Increasing the flow rates of the purification systems in all loops is slightly more effective than just increasing the flow rate in the tertiary loop alone. In the case the ratio of PHX permeability is less than $1 \times 10^{-3}$ times the base case, the tritium concentration in product hydrogen decreases linearly with an increase of helium flow rate. The helium flow rate at the purification system in all loops should be increased about 100 times to decrease the tritium concentration by a factor of 0.1 . It can be concluded from these results that it is difficult to decrease the tritium concentration in the hydrogen product drastically by increasing helium flow rate at the purification system.

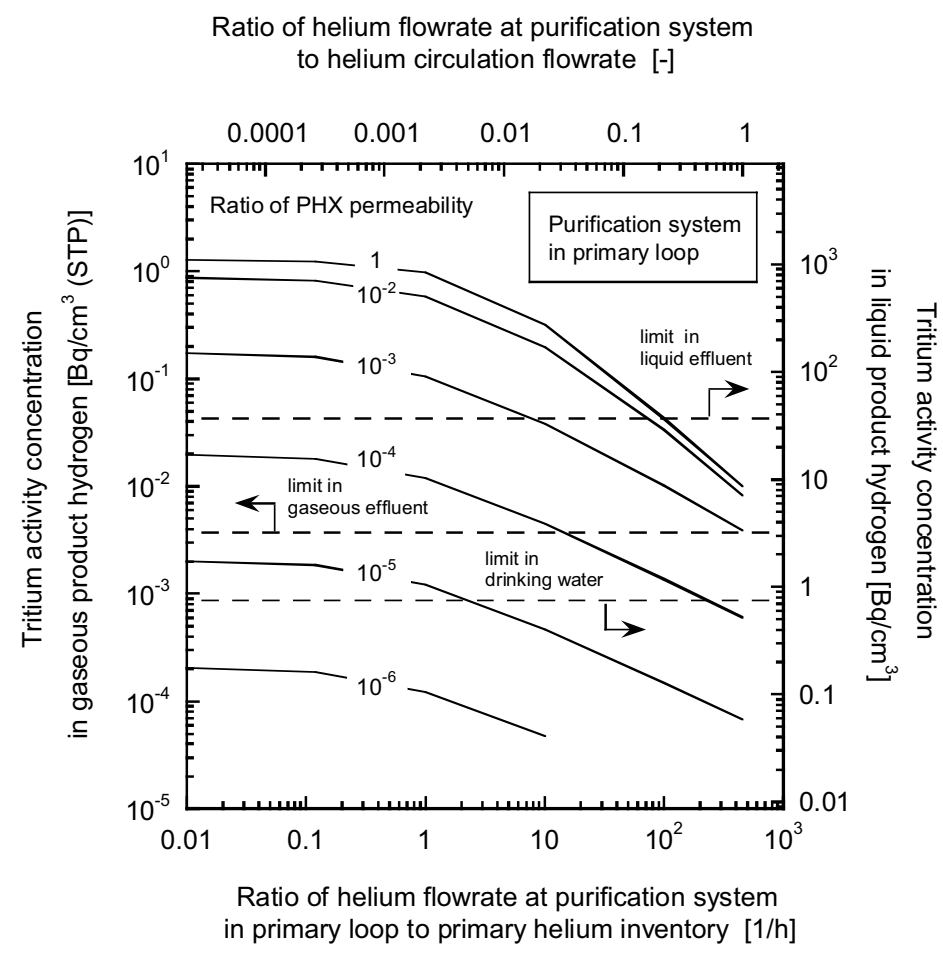

Figure 103. Effect of varying helium flow rate at the purification system in the primary loop on the tritium concentration in the hydrogen product for the Next Generation Nuclear Plant using the sulfur iodine process. 


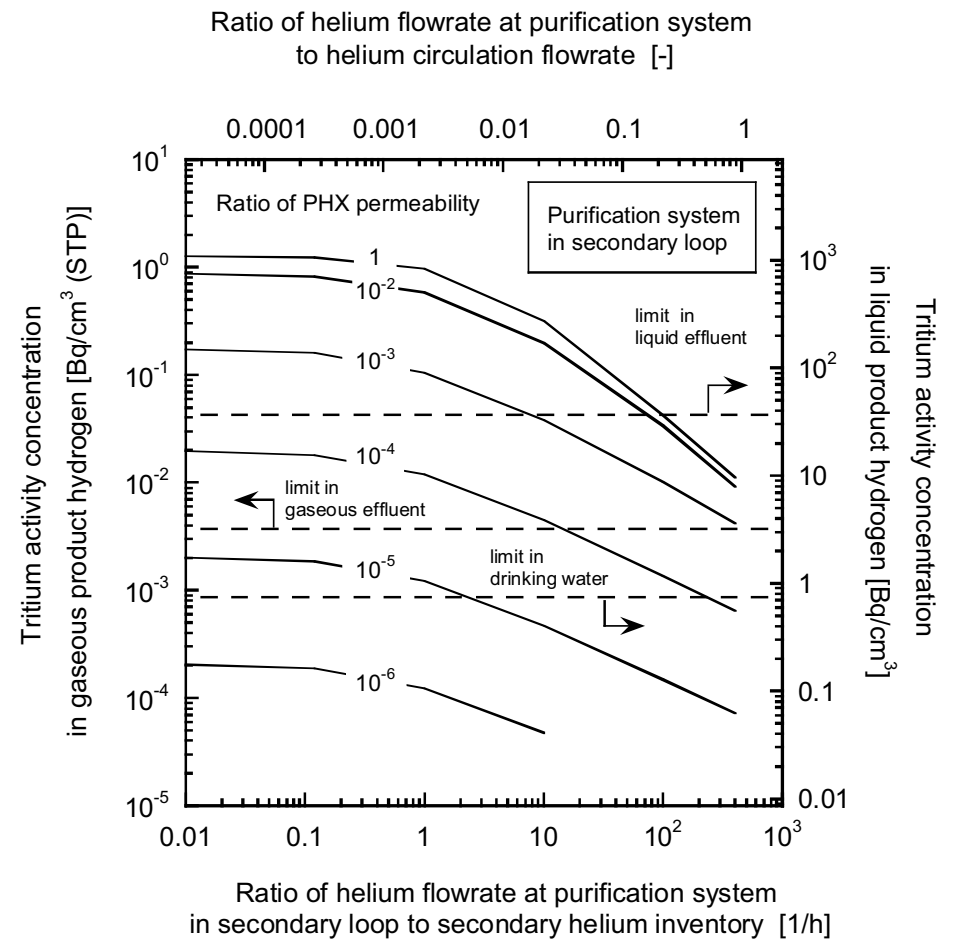

Figure 104. Effect of varying helium flow rate at the purification system in the secondary loop on the tritium concentration in the hydrogen product for the Next Generation Nuclear Plant using the sulfur iodine process. 


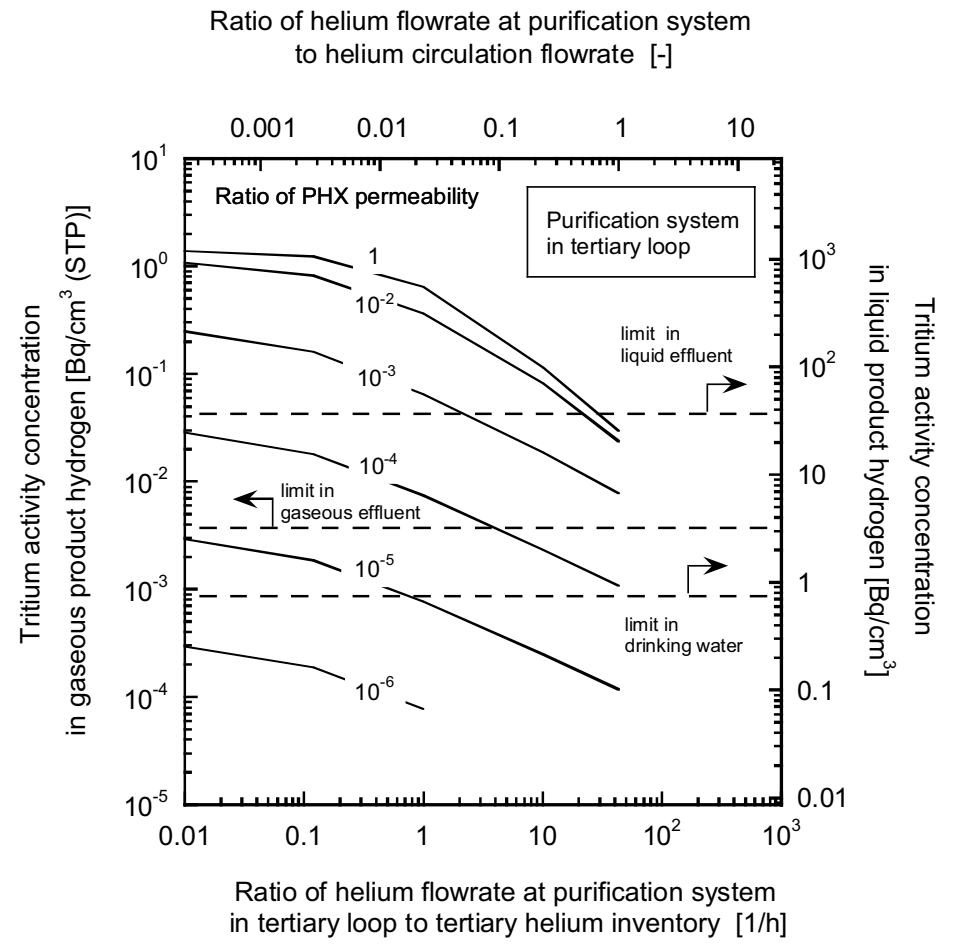

Figure 105. Effect of varying helium flow rate at the purification system in the tertiary loop on the tritium concentration in the hydrogen product for the Next Generation Nuclear Plant using the sulfur iodine process. 


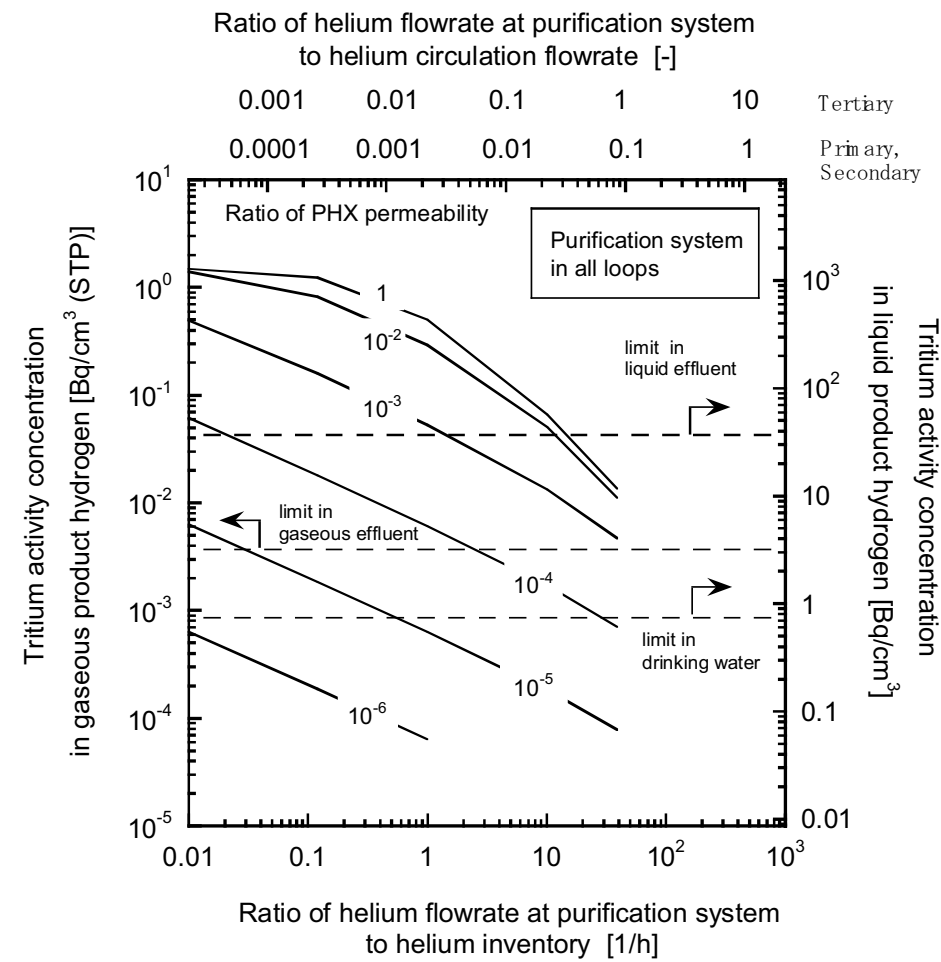

Figure 106. Effect of varying helium flow rate at the purification system in all loops on the tritium concentration in the hydrogen product for the Next Generation Nuclear Plant using the sulfur iodine process.

Tritium concentration in a component of the sulfur iodine process. Figures 107, 108, 109, and 110 show tritium concentrations in gaseous process chemicals of the flash drum (S301) in response to changing the helium flow rate at the purification system in the primary, secondary, tertiary, and in all loops, respectively. The tritium concentration decreases with an increase of the helium flow rate. However, the effect of the helium flow rate is not significant. Figures 111, 112, 113, and 114 show tritium concentrations in liquid process chemicals of the secondary $\mathrm{O}_{2}$ knockout drum (S105) by changing the helium flow rate at the purification system in the primary, secondary, tertiary, and in all loops, respectively. The effect of helium flow rate on the tritium concentration in liquid process chemicals of the secondary $\mathrm{O}_{2}$ knockout drum (S105) is the same as for the tritium concentration in gaseous process chemicals of the flash drum (S301). Therefore, it appears difficult to drastically decrease the tritium concentration in gaseous and liquid process chemicals for SI process components by increasing the helium flow rate at the purification system. 


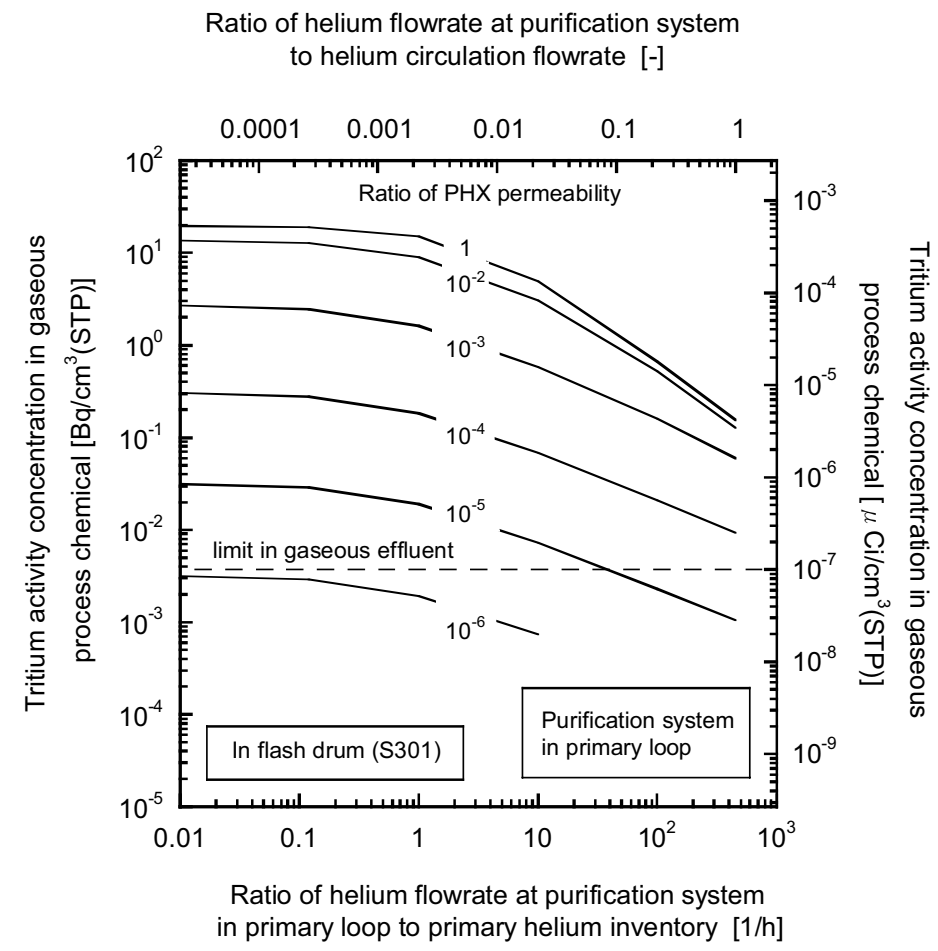

Figure 107. Effect of varying helium flow rate at the purification system in the primary loop on the tritium concentration in gaseous process chemicals of the flash drum (S301) for the Next Generation Nuclear Plant using the sulfur iodine process.

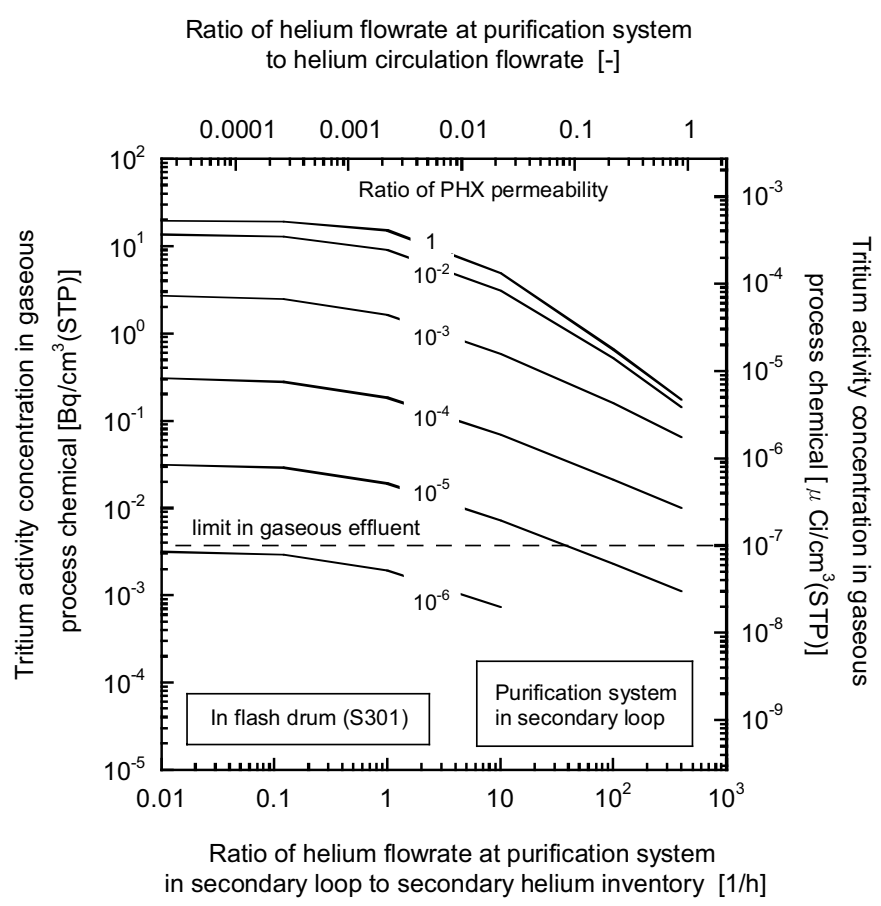

Figure 108. Effect of varying helium flow rate at the purification system in the secondary loop on the tritium concentration in gaseous process chemicals of the flash drum (S301) for the Next Generation Nuclear Plant using the sulfur iodine process. 


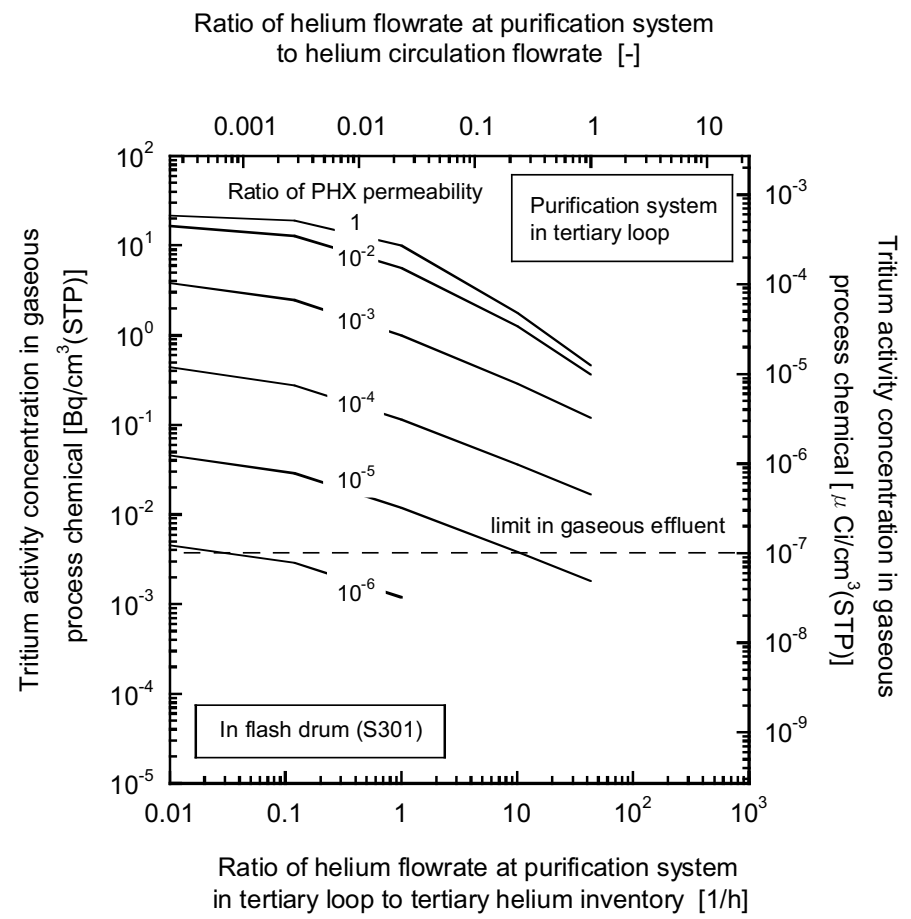

Figure 109. Effect of varying helium flow rate at the purification system in the tertiary loop on the tritium concentration in gaseous process chemicals of the flash drum (S301) for the Next Generation Nuclear Plant using the sulfur iodine process.

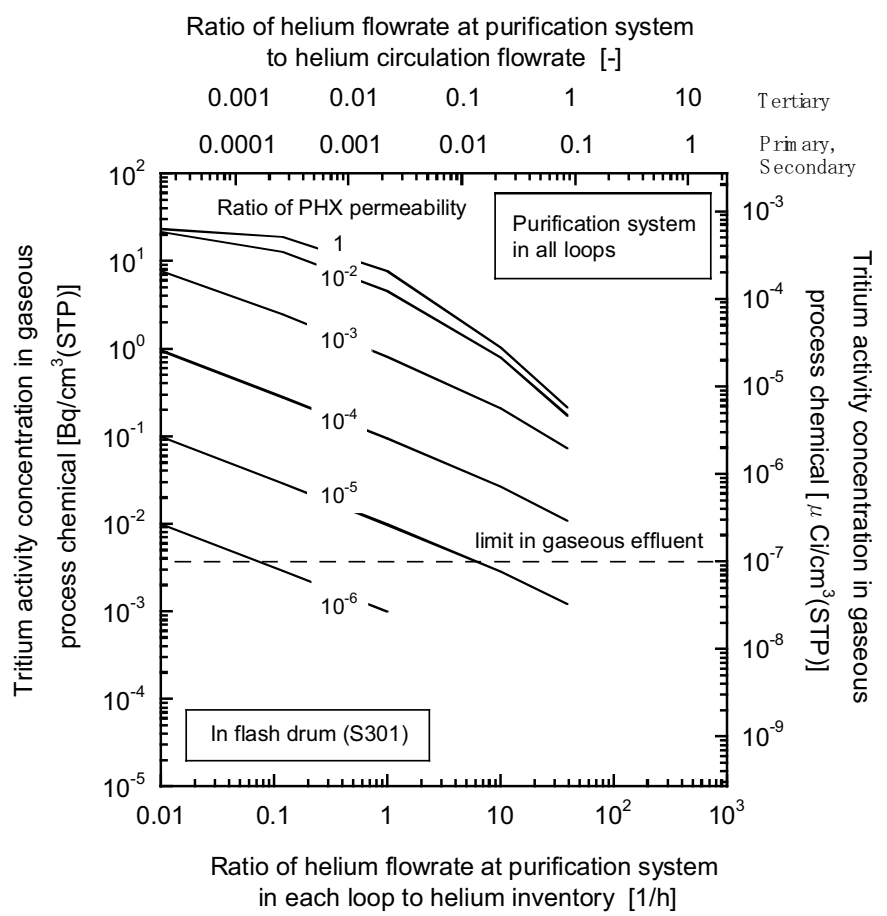

Figure 110. Effect of varying helium flow rate at the purification system in all loops on the tritium concentration in gaseous process chemicals of the flash drum (S301) for the Next Generation Nuclear Plant using the sulfur iodine process. 


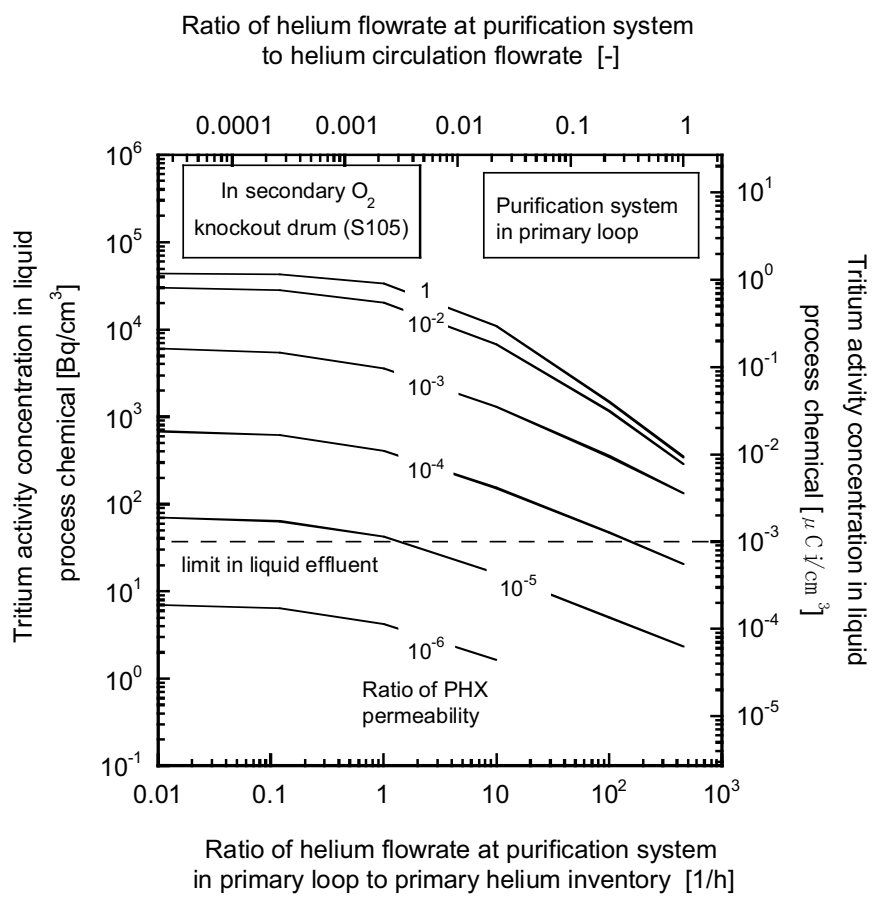

Figure 111. Effect of varying helium flow rate at the purification system in the primary loop on the tritium concentration in liquid process chemicals of the secondary $\mathrm{O}_{2}$ knockout drum (S105) for the Next Generation Nuclear Plant using the sulfur iodine process.

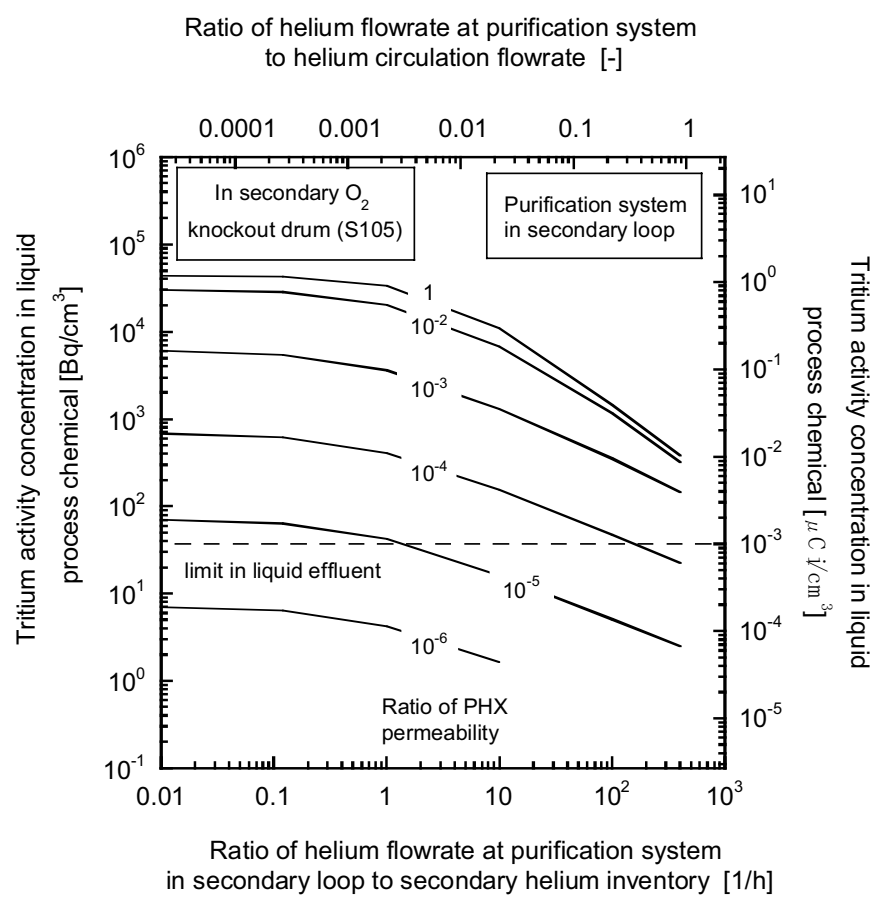

Figure 112. Effect of varying helium flow rate at the purification system in the secondary loop on the tritium concentration in liquid process chemicals of the secondary $\mathrm{O}_{2}$ knockout drum (S105) for the Next Generation Nuclear Plant using the sulfur iodine process. 


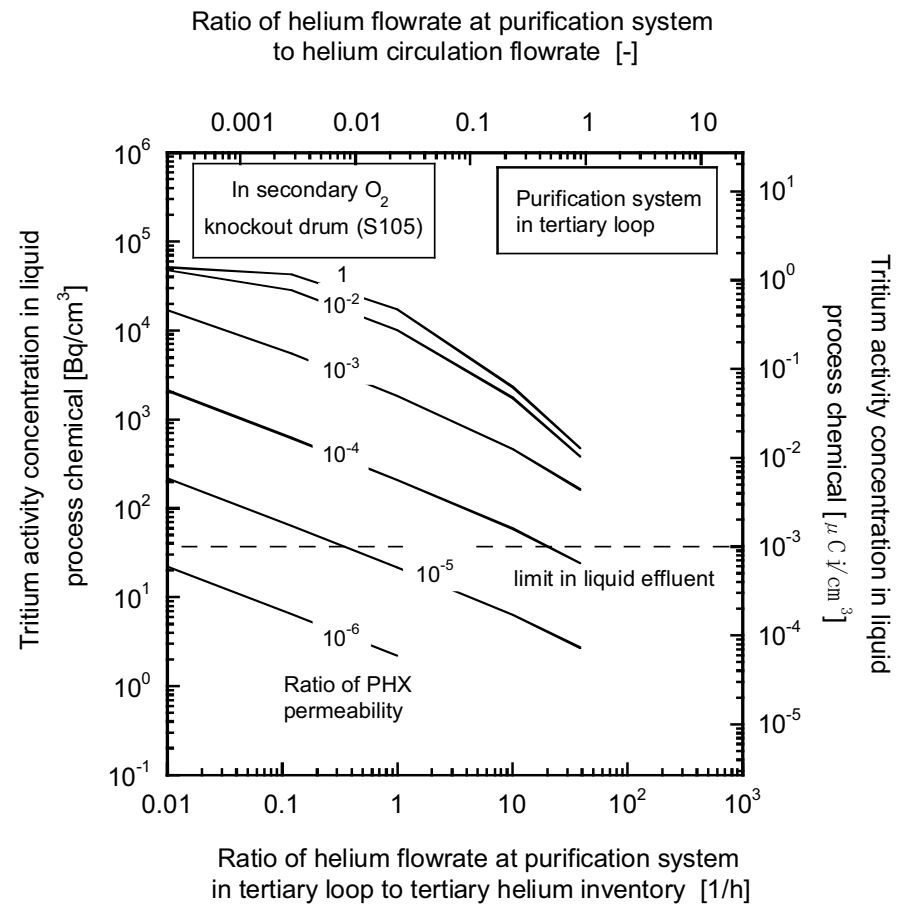

Figure 113. Effect of varying helium flow rate at the purification system in the tertiary loop on the tritium concentration in liquid process chemicals of the secondary $\mathrm{O}_{2}$ knockout drum (S105) for the Next Generation Nuclear Plant using the sulfur iodine process.

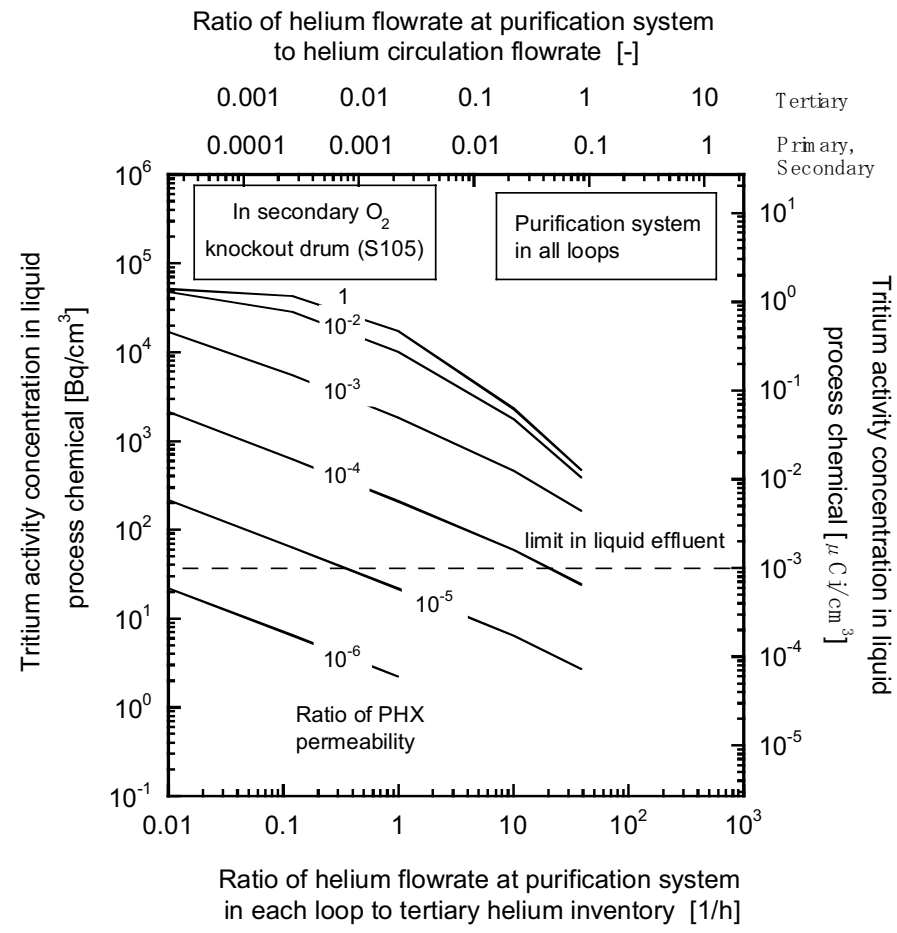

Figure 114. Effect of varying helium flow rate at the purification system in all loops on the tritium concentration in liquid process chemicals of the secondary $\mathrm{O}_{2}$ knockout drum (S105) for the Next Generation Nuclear Plant using the sulfur iodine process. 
Tritium concentration in helium coolant. Figures 115, 116, and 117 show the effect of varying the helium flow rate at the purification system in the primary loop on the tritium concentration in the primary, secondary, and tertiary helium, respectively. Tritium concentrations decrease with an increase of helium flow rate. Under the conditions examined, the tritium concentration in the secondary helium is slightly higher than found in the primary helium. The tritium concentration in tertiary helium is the largest for all helium loops; it is larger than the gaseous effluent limit, even if helium flow rate at the purification system is the same as circulation flow rate.

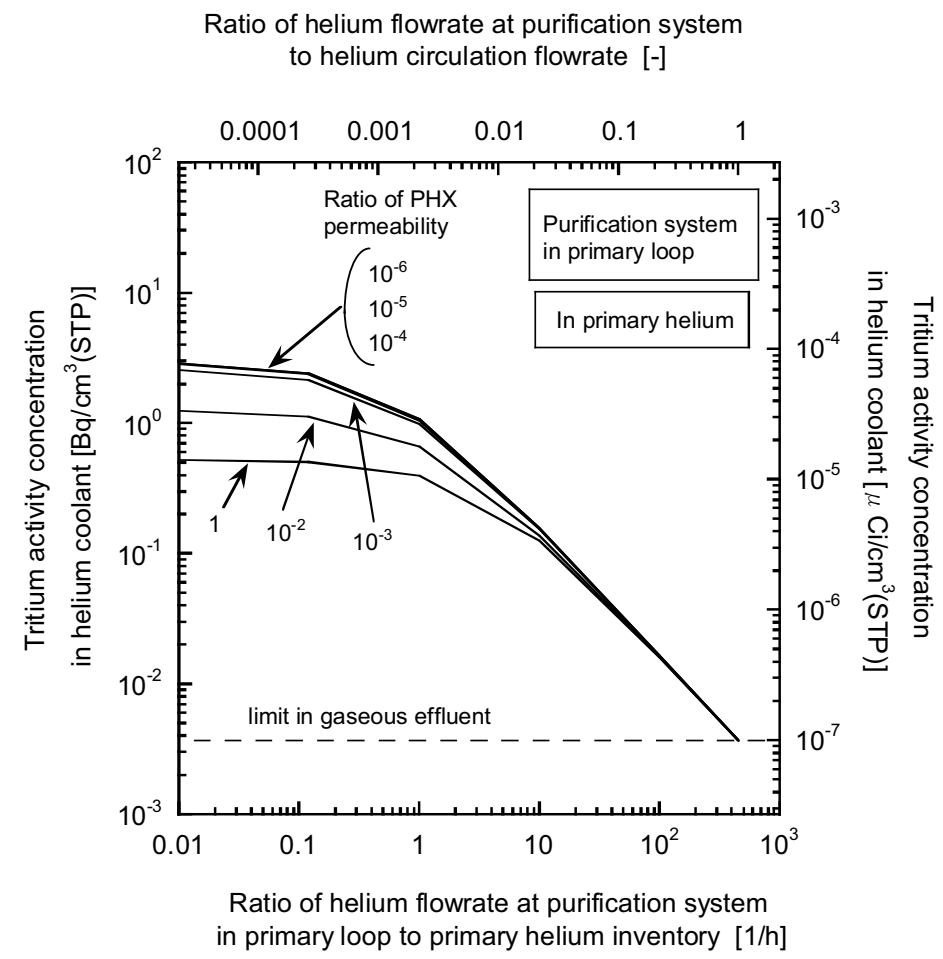

Figure 115. Effect of varying helium flow rate at the purification system in the primary loop on the tritium concentration in the primary helium coolant for Next Generation Nuclear Plant using sulfur iodine process. 


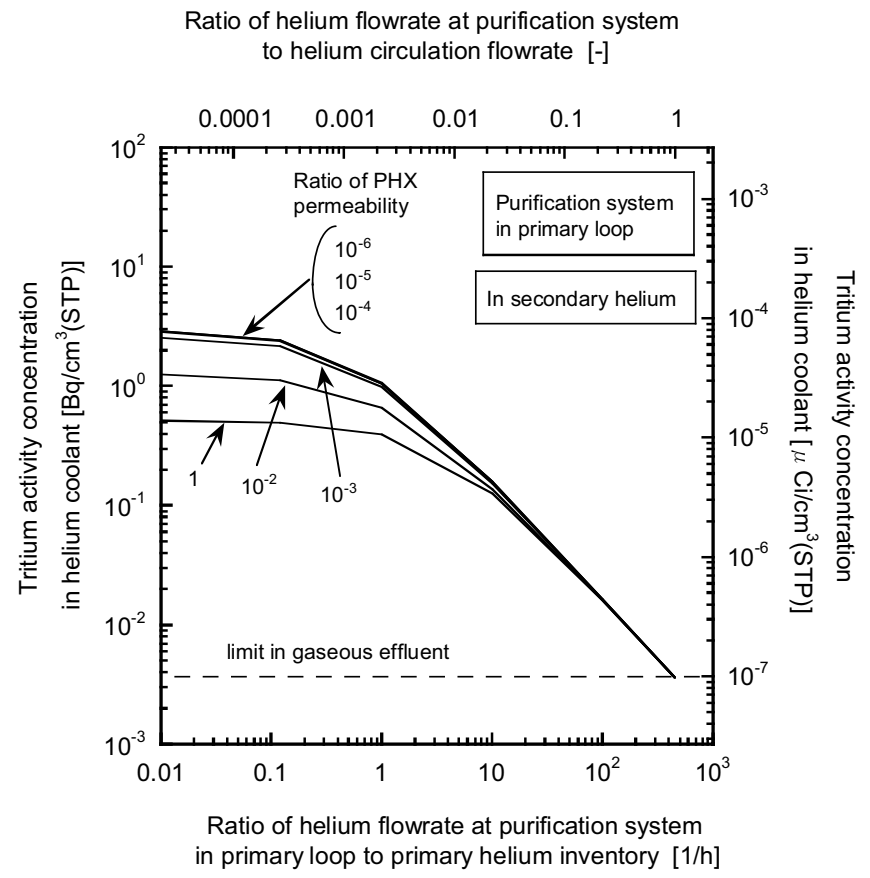

Figure 116. Effect of varying helium flow rate at the purification system in the primary loop on the tritium concentration in the secondary helium coolant for the Next Generation Nuclear Plant using the sulfur iodine process.

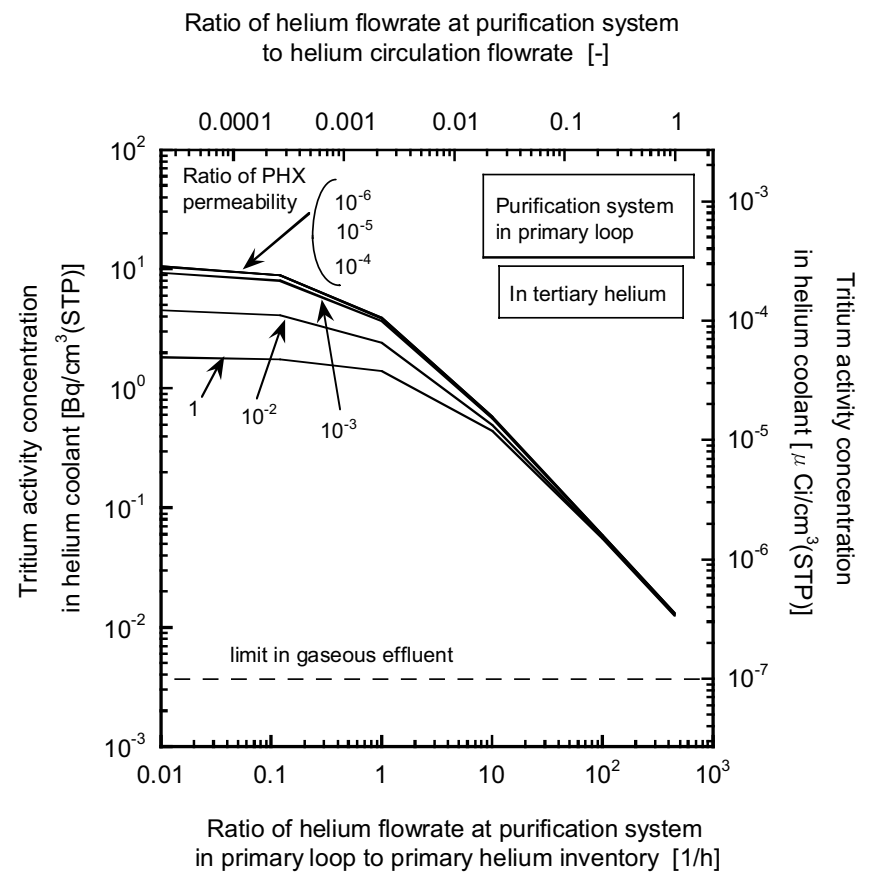

Figure 117. Effect of varying helium flow rate at the purification system in the primary loop on the tritium concentration in the tertiary helium coolant for the Next Generation Nuclear Plant using the sulfur iodine process. 
Figures 118,119 , and 120 show the effect of varying the helium flow rate at the purification system in the secondary loop on the tritium concentration in the primary, secondary, and tertiary helium, respectively. The figures show almost the same dependency of the helium flow rate as for the flow rate in the purification system of the primary helium loop. However, the difference in tritium concentrations between the primary and secondary helium is slightly larger in response to changes the flow rate in the purification system of the secondary helium loop, which is due to tritium removal in the secondary helium. The tritium concentration in tertiary helium is larger than the gaseous effluent limit, even if helium flow rate at the purification system is the same as circulation flow rate.

Figures 121, 122, and 123 show the effect of varying the helium flow rate at the purification system in the tertiary loop on the tritium concentration in the primary, secondary, and tertiary helium, respectively. All tritium concentrations decrease with an increase of the helium flow rate. The tritium concentration in the secondary helium coolant is slightly higher than that in the primary helium coolant. The difference in the tritium concentrations of the secondary and tertiary helium coolants decreases with an increase of the helium flow rate at the purification system in the tertiary loop. However, the tritium concentration in tertiary helium is the largest of all helium loops, and it is larger than the gaseous effluent limit.

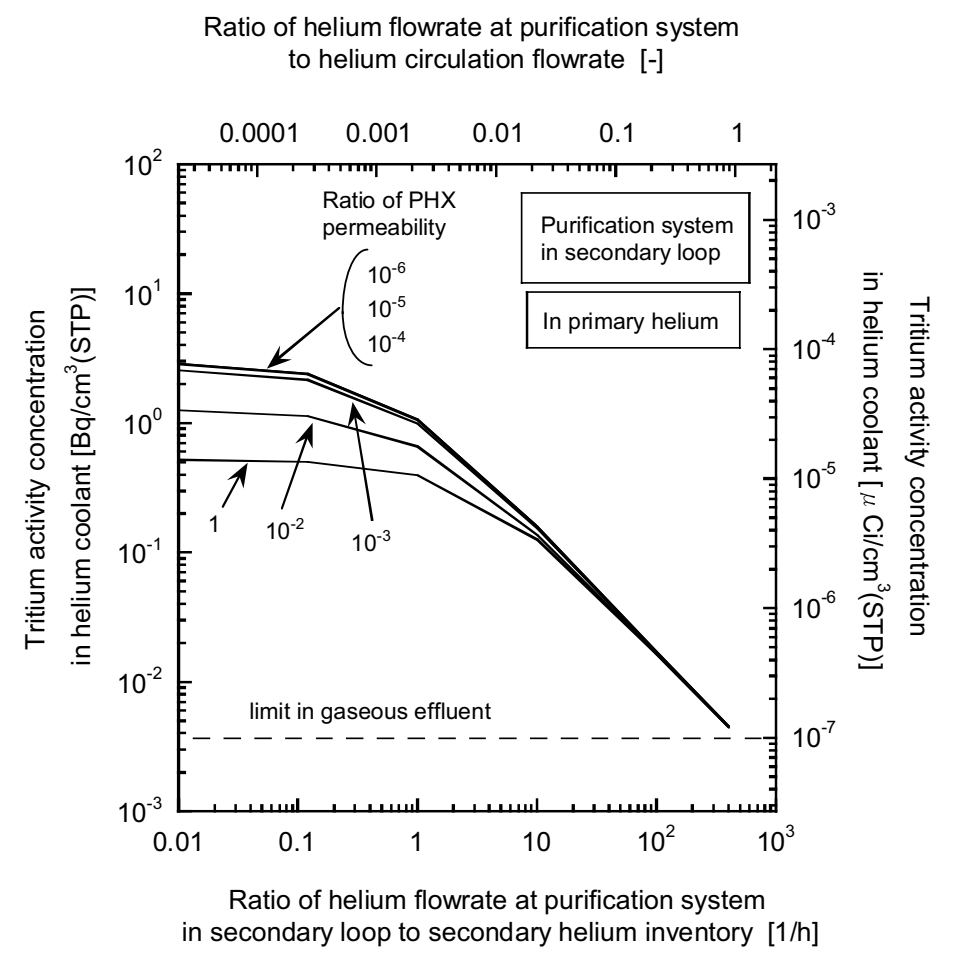

Figure 118. Effect of varying helium flow rate at the purification system in the secondary loop on the tritium concentration in the primary helium coolant for the Next Generation Nuclear Plant using the sulfur iodine process. 


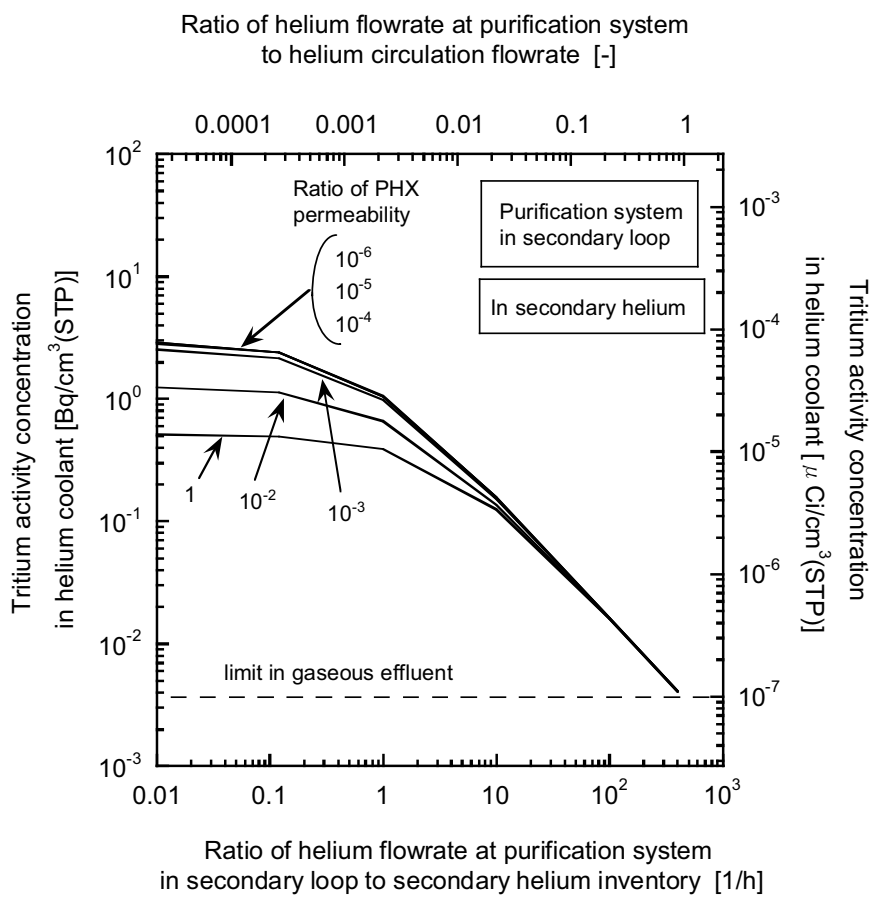

Figure 119. Effect of varying helium flow rate at the purification system in the secondary loop on the tritium concentration in the secondary helium coolant for the Next Generation Nuclear Plant using the sulfur iodine process.

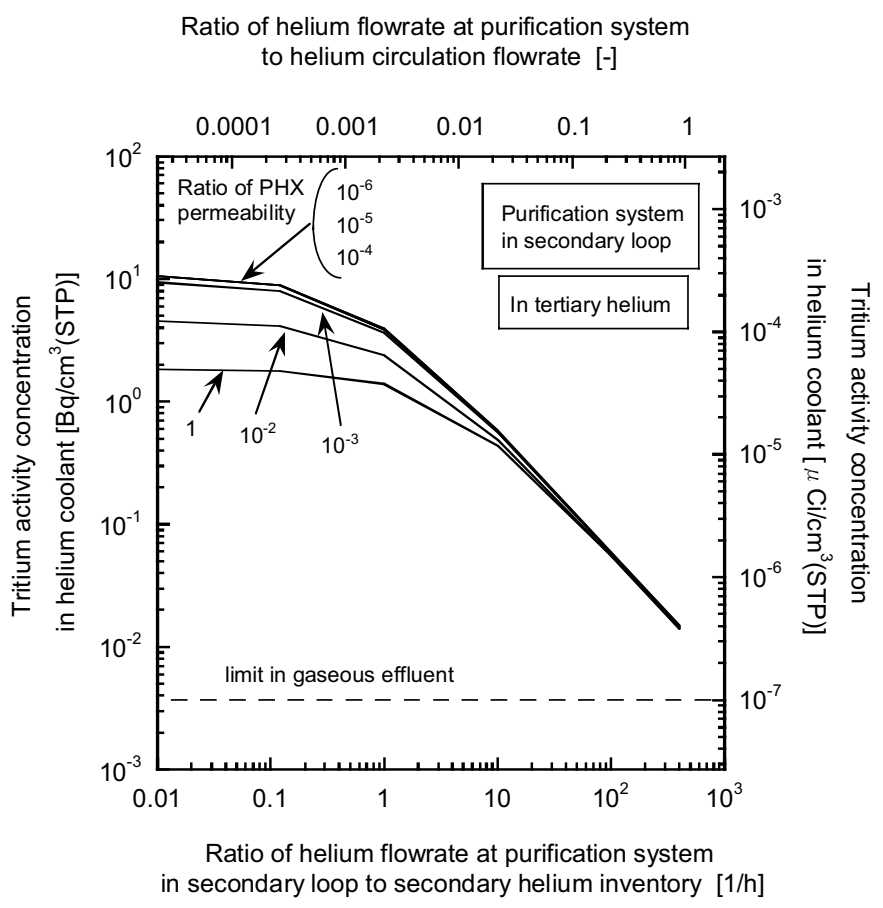

Figure 120. Effect of varying helium flow rate at the purification system in the secondary loop on the tritium concentration in the tertiary helium coolant for the Next Generation Nuclear Plant using the sulfur iodine process. 


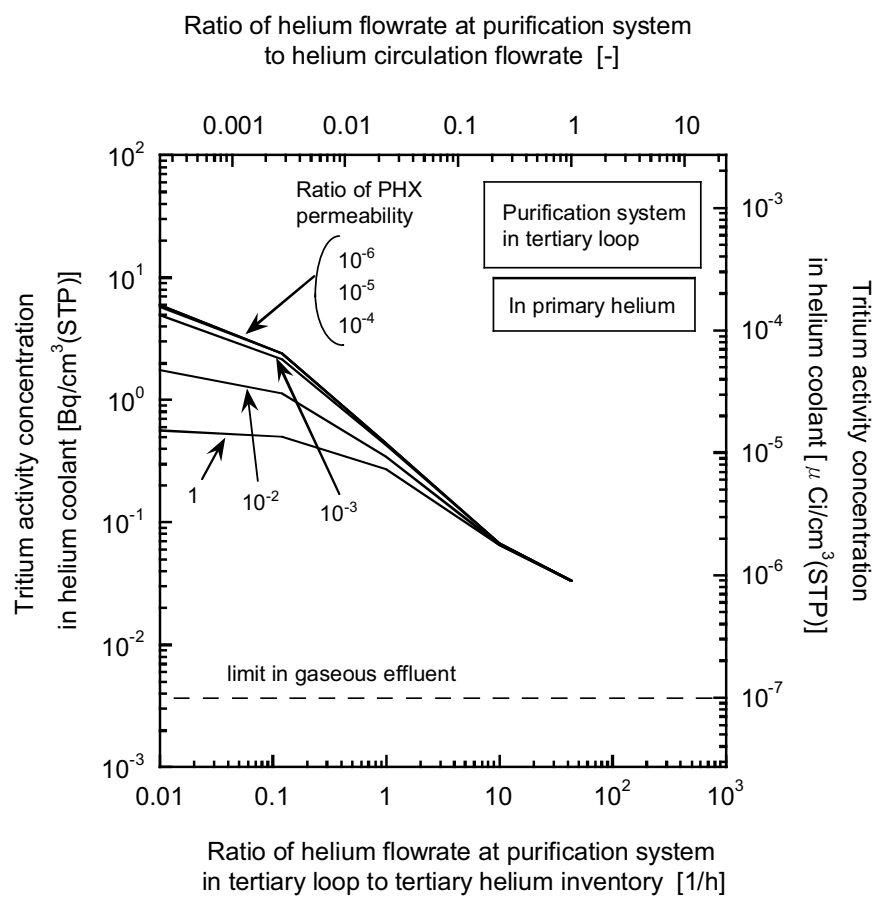

Figure 121. Effect of varying helium flow rate at the purification system in the tertiary loop on the tritium concentration in the primary helium coolant for the Next Generation Nuclear Plant using the sulfur iodine process.

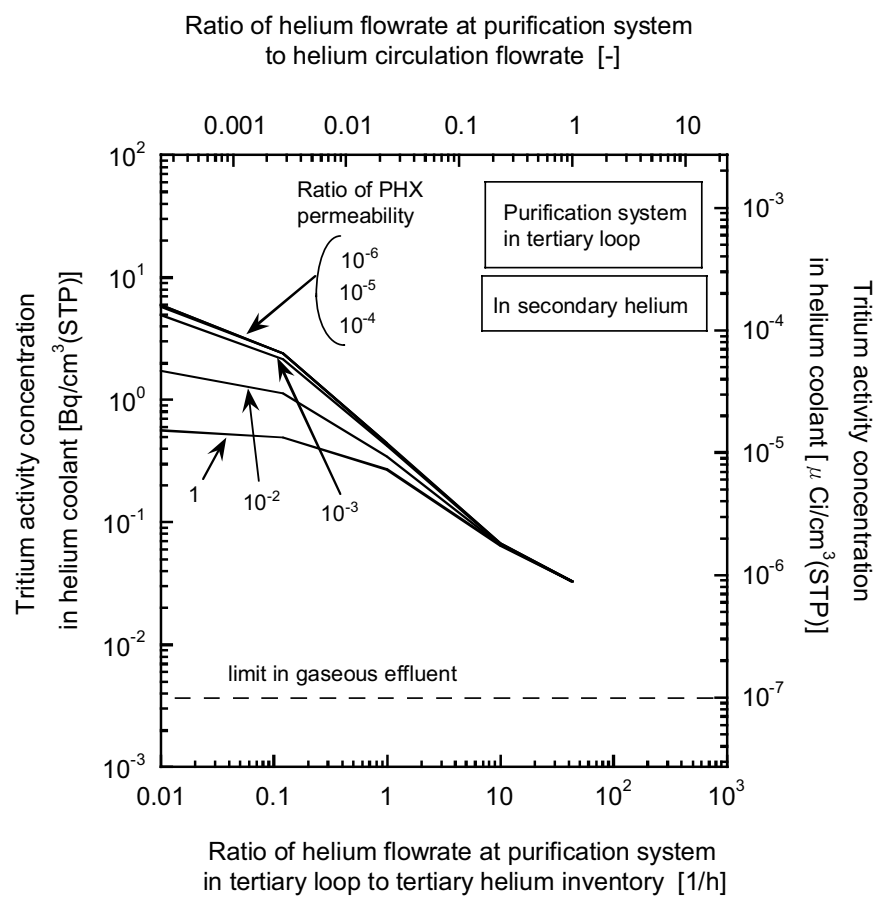

Figure 122. Effect of varying helium flow rate at the purification system in the tertiary loop on the tritium concentration in the secondary helium coolant for the Next Generation Nuclear Plant using the sulfur iodine process. 


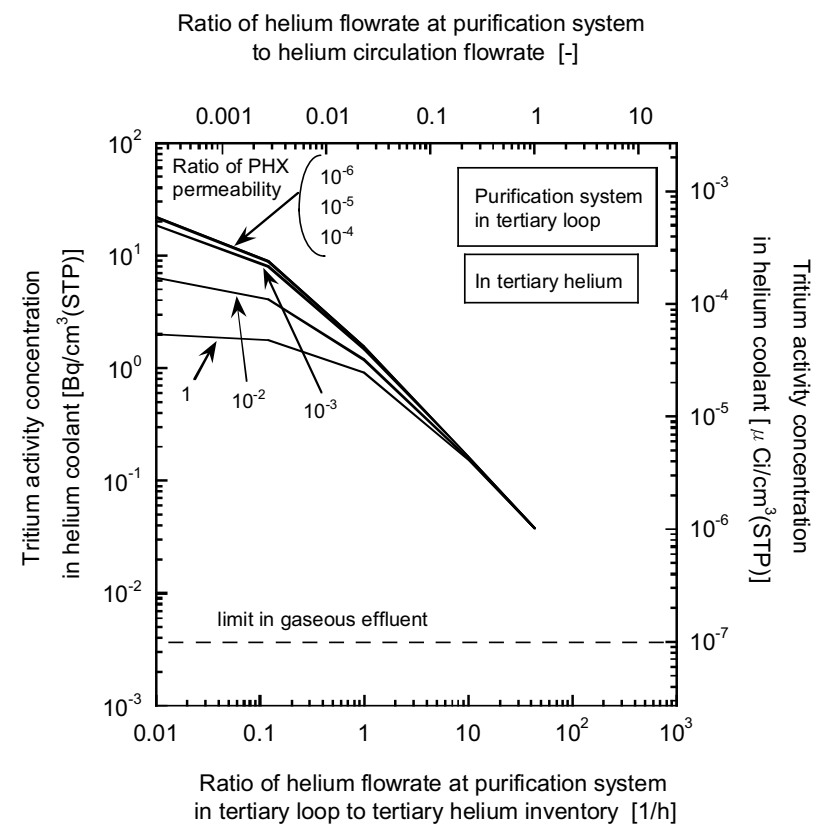

Figure 123. Effect of varying helium flow rate at the purification system in the tertiary loop on the tritium concentration in the tertiary helium coolant for the Next Generation Nuclear Plant using the sulfur iodine process.

Figures 124, 125, and 126 show the effect of varying the helium flow rate at the purification system in all loops on the tritium concentration in the primary, secondary, and tertiary helium, respectively. The tritium concentrations decrease drastically with an increase of helium flow rate. The largest tritium concentrations are found in the tertiary loop, followed by the primary loop and the secondary loop, in decreasing order. In all cases, the tritium concentration in the loops exceed the gaseous effluent limit. 


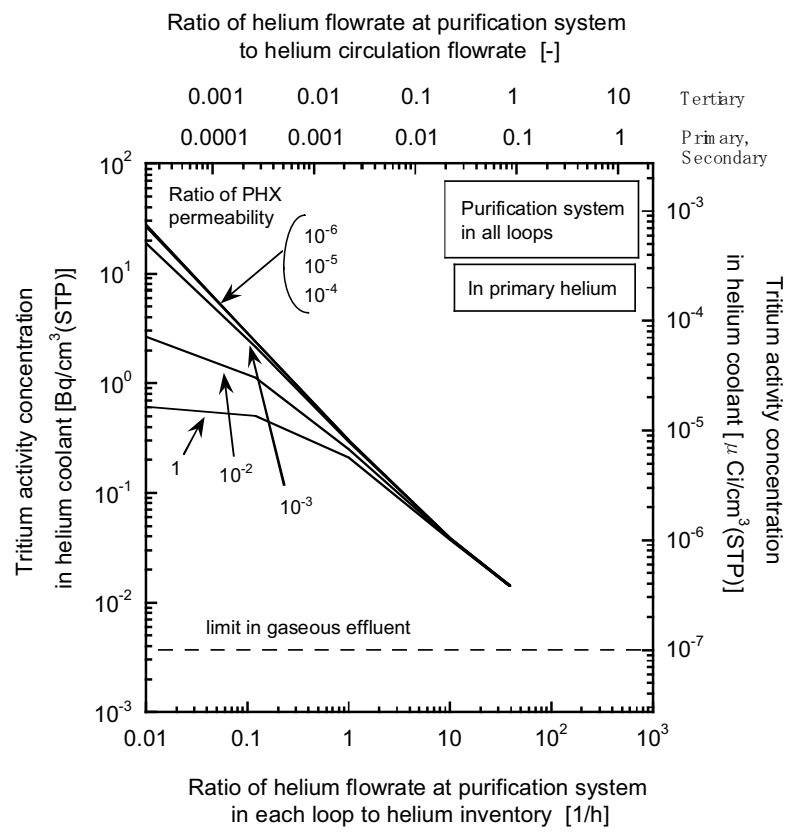

Figure 124. Effect of varying helium flow rate at the purification system in all loops on the tritium concentration in the primary helium coolant for the Next Generation Nuclear Plant using the sulfur iodine process.

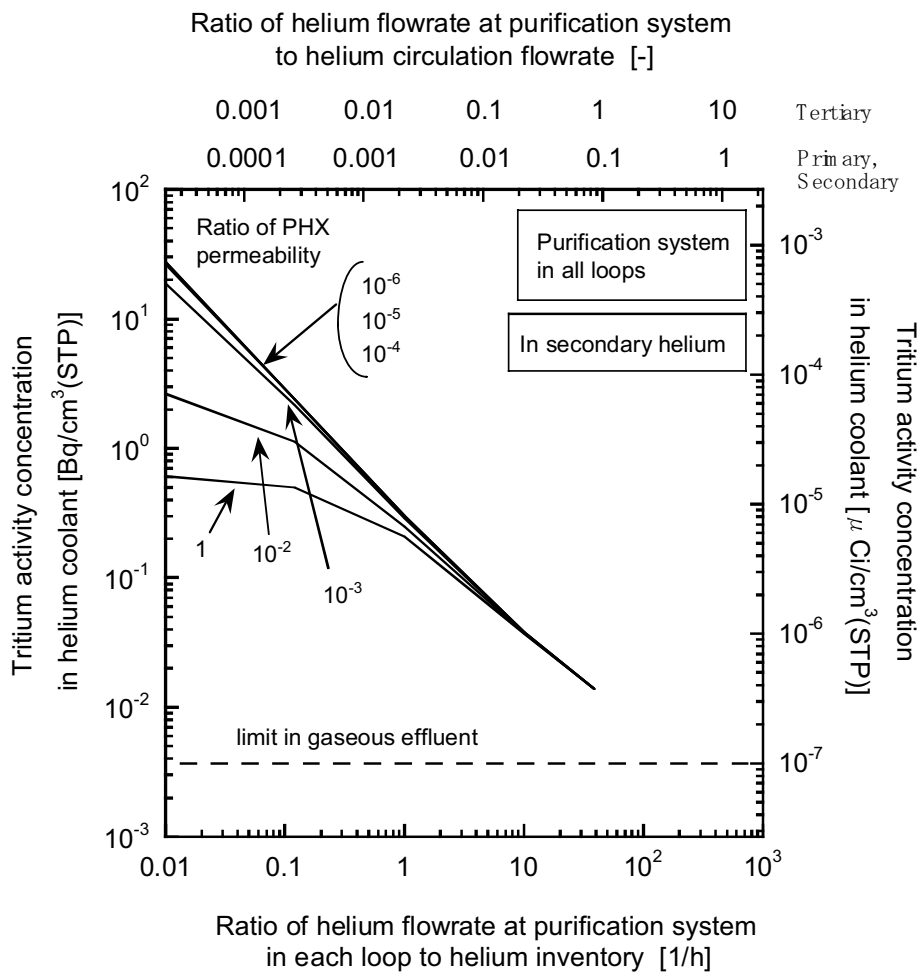

Figure 125. Effect of varying helium flow rate at the purification system in all loops on the tritium concentration in the secondary helium coolant for the Next Generation Nuclear Plant using the sulfur iodine process. 


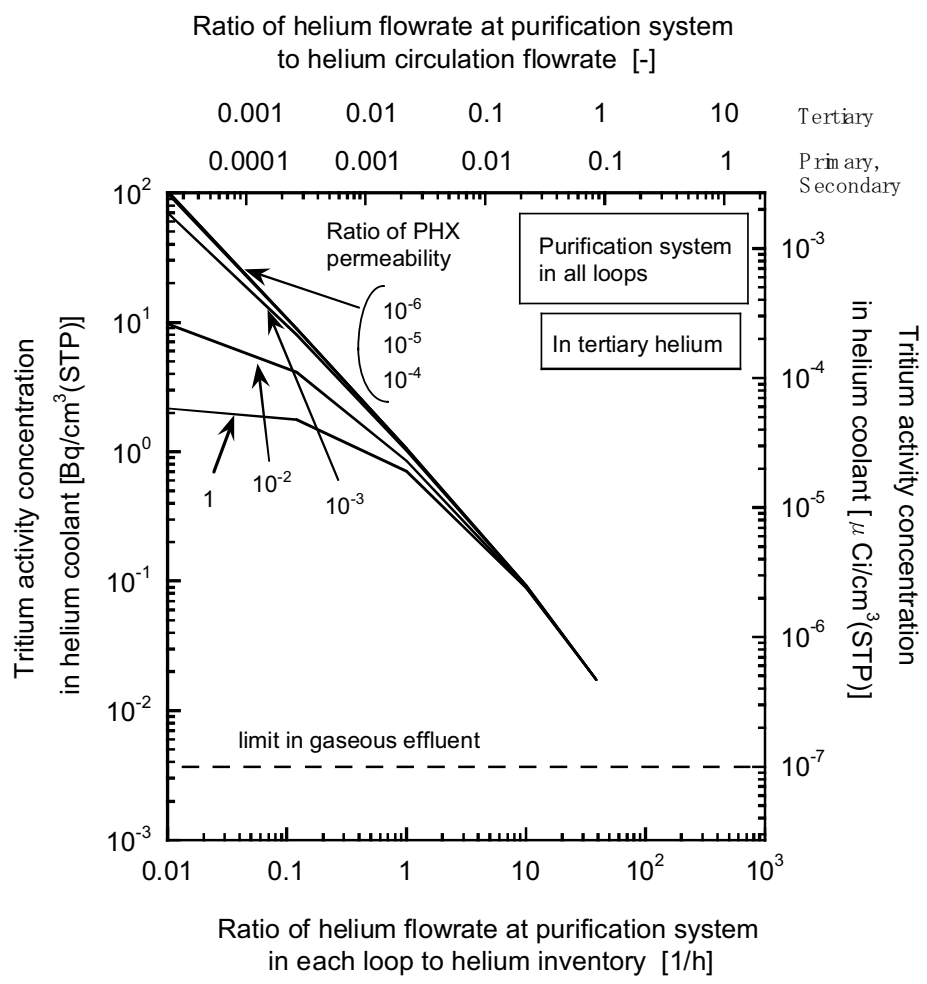

Figure 126. Effect of varying helium flow rate at the purification system in all loops on the tritium concentration in the tertiary helium coolant for the Next Generation Nuclear Plant using the sulfur iodine process.

\subsubsection{Effect of Pressure in Tertiary Loop}

Tritium concentration in product hydrogen. Figure 127 shows the effect of varying the pressure in the tertiary loop on the tritium concentration in product hydrogen. The tritium concentration decreases with a decrease of pressure in the tertiary loop, which is similar for an NGNP using the HTE process. However, the effect of the pressure is not significant. 


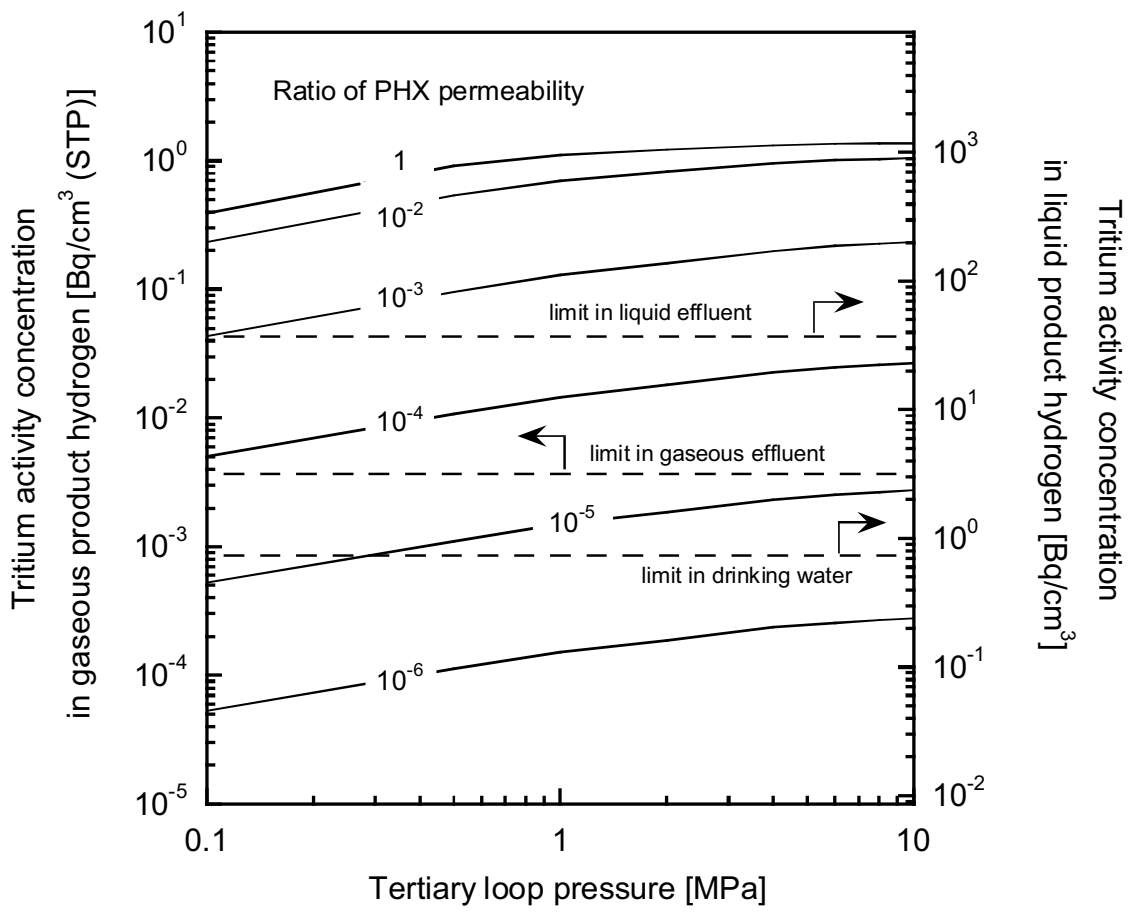

Figure 127. Effect of varying pressure in the tertiary loop on the tritium concentration in product hydrogen for the Next Generation Nuclear Plant using the sulfur iodine process.

Tritium concentration in a component of the sulfur iodine process. Figures 128 and 129 show the tritium concentration in gaseous process chemicals of the flash drum (S301) and in liquid process chemicals of the secondary $\mathrm{O}_{2}$ knockout drum (S105), respectively, in response to changing the tertiary loop pressure. The dependency of each tritium concentration on pressure in the tertiary loop is almost the same as for the tritium concentration in product hydrogen. The effect of the pressure is not significant.

Tritium concentration in helium coolant. Figures 130, 131, and 132 show tritium concentrations in the primary, secondary, and tertiary helium, respectively, in response to changing the tertiary loop pressure. With an increase of pressure in the tertiary loop, tritium concentrations in the primary and secondary loops increase, and the tritium concentration in the tertiary loop decreases due to an increase of the tritium permeation rate through SHX. However, the tritium concentration in the tertiary loop is much larger than the gaseous effluent limit in all cases. 


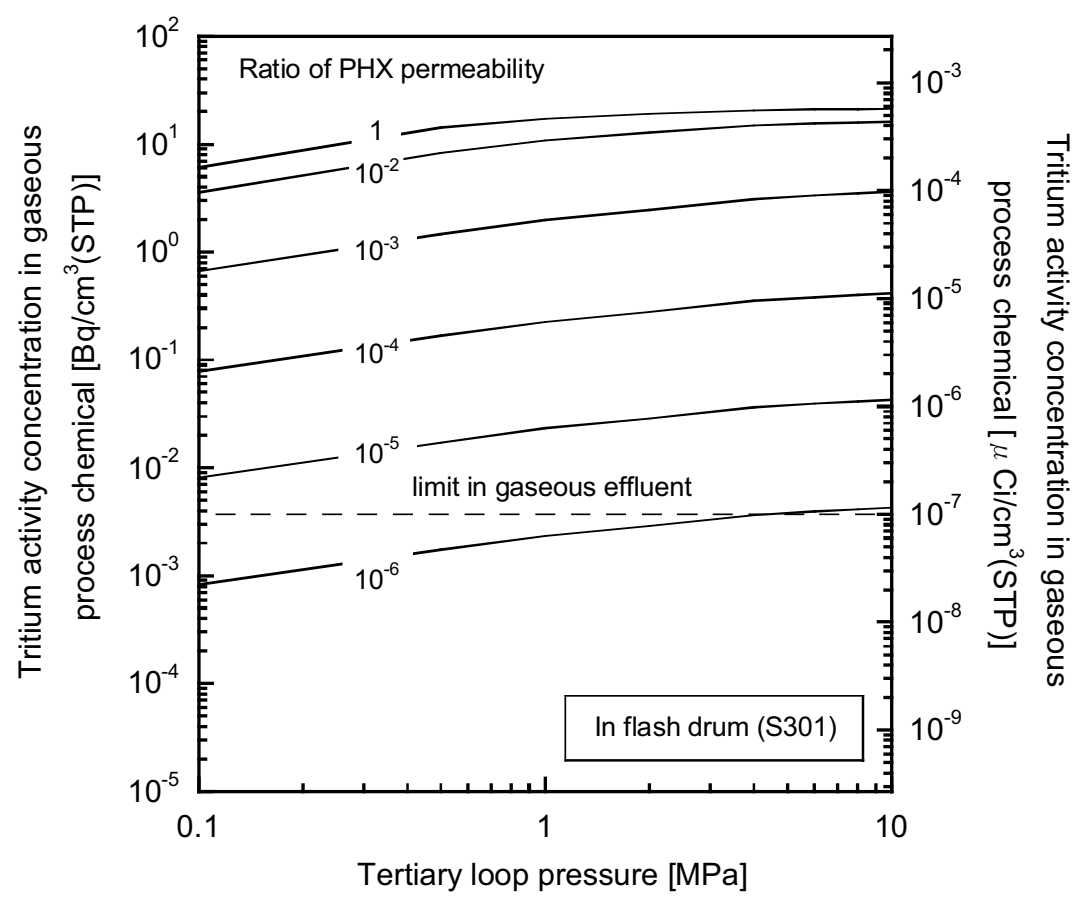

Figure 128. Effect of varying pressure in the tertiary loop on the tritium concentration in the gaseous process chemicals of the flash drum (S301) for the Next Generation Nuclear Plant using the sulfur iodine process.

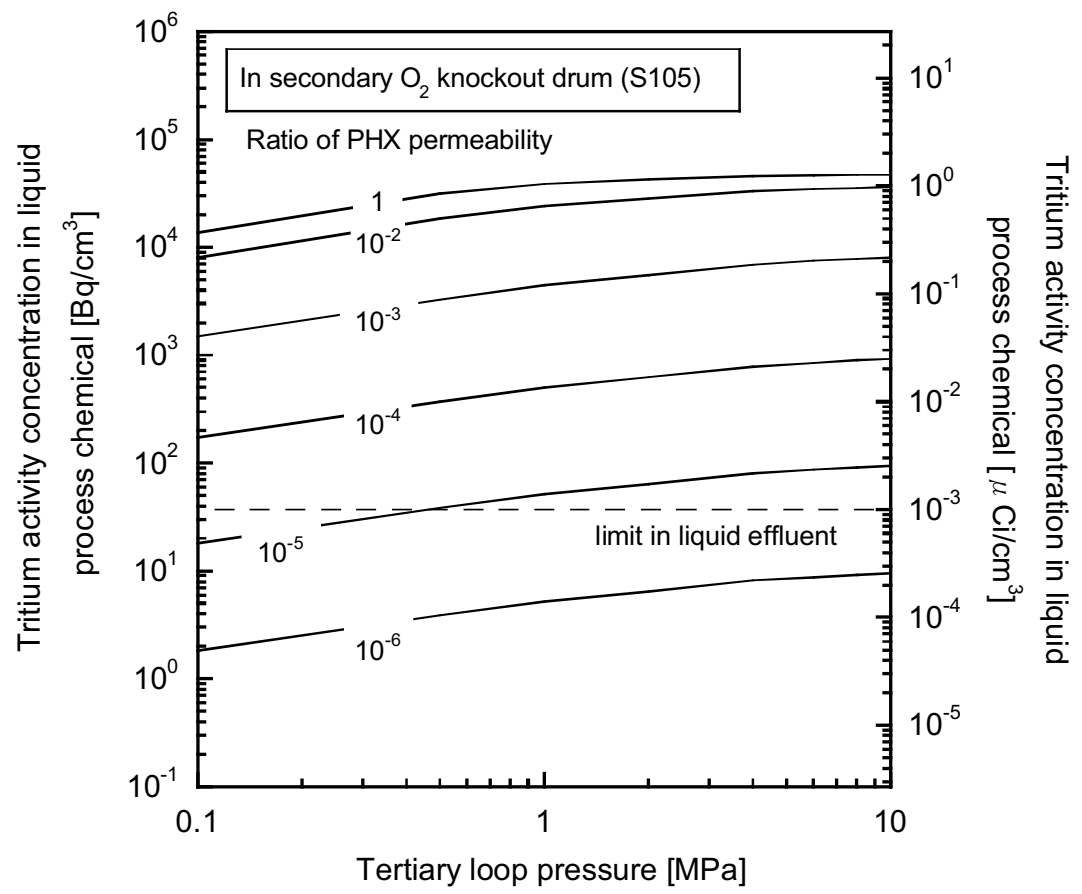

Figure 129. Effect of varying pressure in the tertiary loop on the tritium concentration in the liquid process chemicals of the secondary $\mathrm{O}_{2}$ knockout drum (S105) for the Next Generation Nuclear Plant using the sulfur iodine process. 


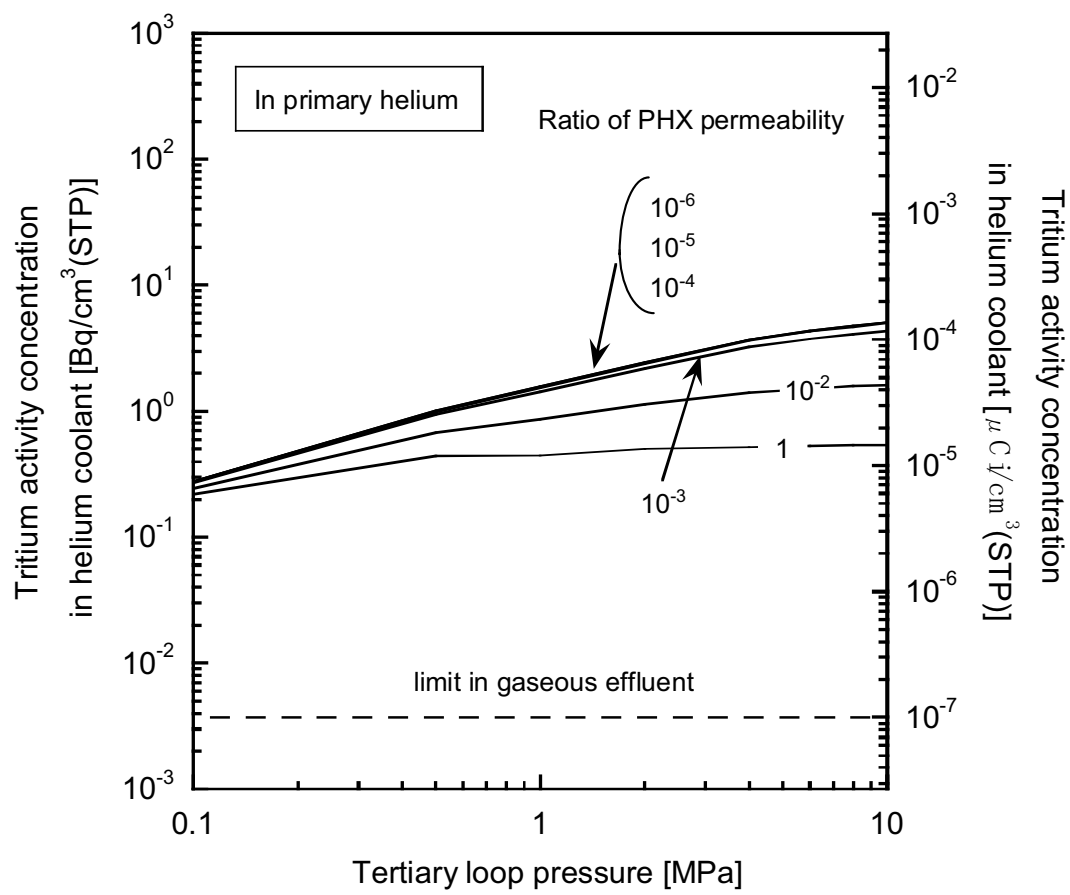

Figure 130. Effect of varying pressure in the tertiary loop on the tritium concentration in the primary helium coolant for the Next Generation Nuclear Plant using the sulfur iodine process.

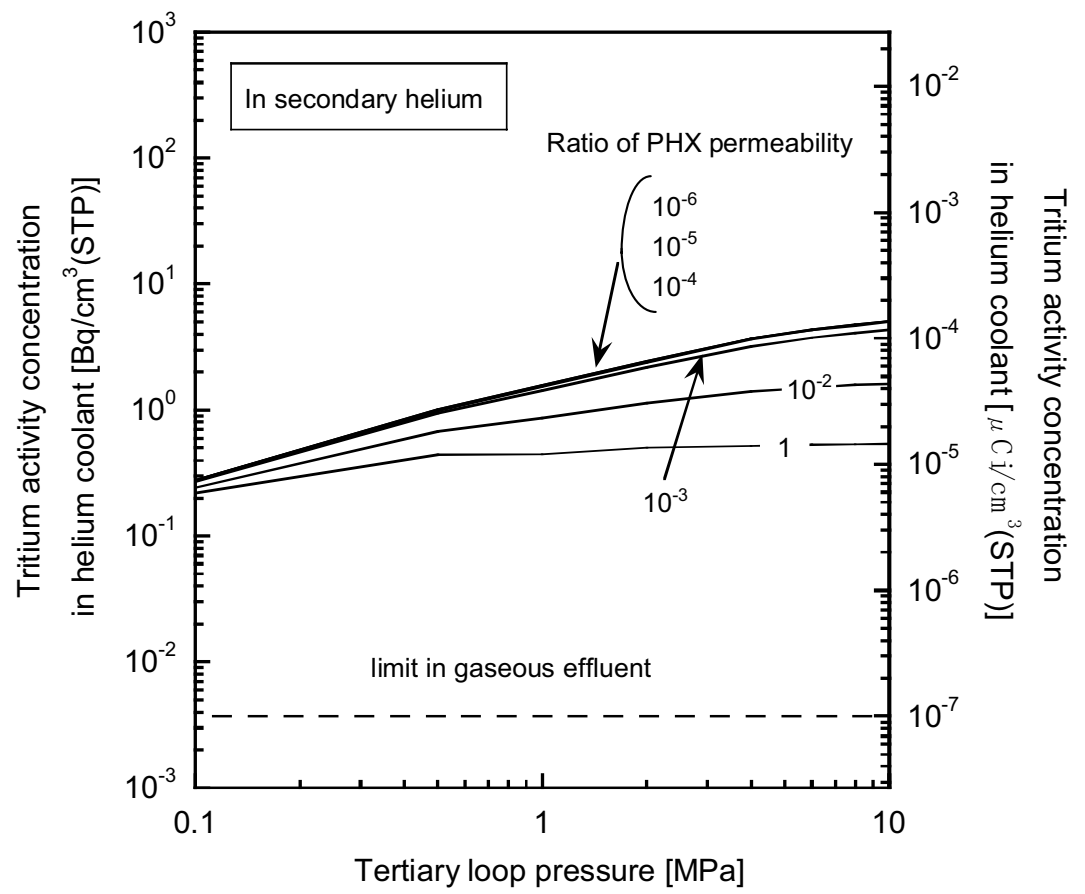

Figure 131. Effect of varying pressure in the tertiary loop on the tritium concentration in the secondary helium coolant for the Next Generation Nuclear Plant using the sulfur iodine process. 


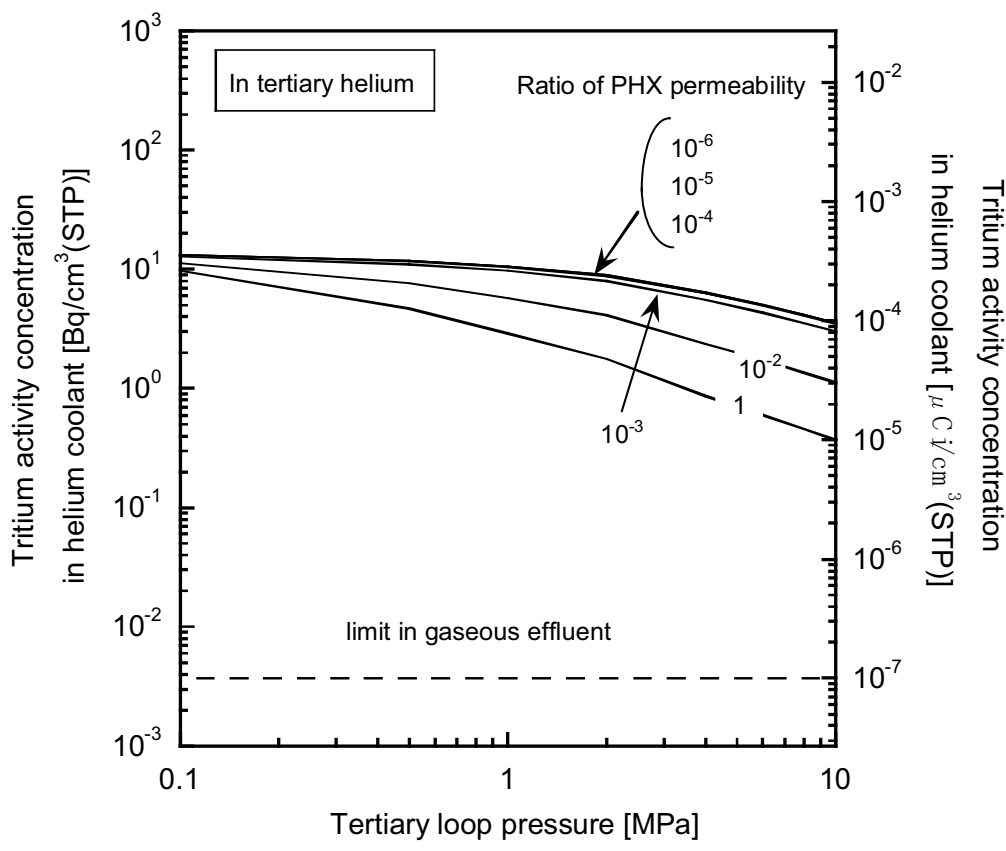

Figure 132. Effect of varying pressure in the tertiary loop on the tritium concentration in the tertiary helium coolant for the Next Generation Nuclear Plant using the sulfur iodine process.

\subsubsection{Effect of Hydrogen Injection in Helium Coolant}

Tritium concentration in product hydrogen. Figures 133, 134, and 135 show the effect of varying the hydrogen injection in the primary, secondary, and tertiary loops on the tritium concentration in the hydrogen product, respectively. The horizontal axis indicates the ratio of the hydrogen injection rate to the hydrogen production rate assuming the SI process is producing hydrogen at a rate of $3.03 \mathrm{~m}^{3}(\mathrm{STP}) / \mathrm{s}$. Due to the permeation of hydrogen between the primary, secondary, and tertiary loops, the point of injection does not appear to make a significant difference at steady state conditions. The tritium concentration in the hydrogen product decreases with an increase of the hydrogen injection rate, which is similar to the behavior experienced in an NGNP using the HTE process and hydrogen injection. However, the tritium concentration starts to decrease at a smaller injection rate when compared with an NGNP using the HTE process because there is not hydrogen in the loops prior to hydrogen injection. Figures 136, 137, and 138 show the changes in hydrogen concentration in the primary, secondary, and tertiary helium coolants, respectively, due to changes in the hydrogen injection rate in the primary helium coolant. The hydrogen concentration in the primary coolant of the Peach Bottom HTGR is reported as 10 ppmv (Burnette and Baldwin 1980). The hydrogen concentration of $10 \mathrm{ppmv}$ in the primary helium corresponds to the hydrogen injection rate of about $6 \times 10^{-4} \%$. Therefore, the effect of hydrogen injection at injection rates lower than $6 \times 10^{-4} \%$ is uncertain because there is no data available. However, the tritium concentration is certainly decreased by employing a hydrogen injection. At $1 \times 10^{-2}$ times the ratio of PHX permeability, the tritium concentration in the hydrogen product becomes less than the drinking water limit, which can be achieved by an injection rate of $5 \times 10^{-3} \%$ of the hydrogen production rate. At the base case permeability for the PHX, the tritium concentration in the hydrogen product is larger than the drinking water limit, even if the hydrogen injection rate is $1 \%$ of the hydrogen production rate. 


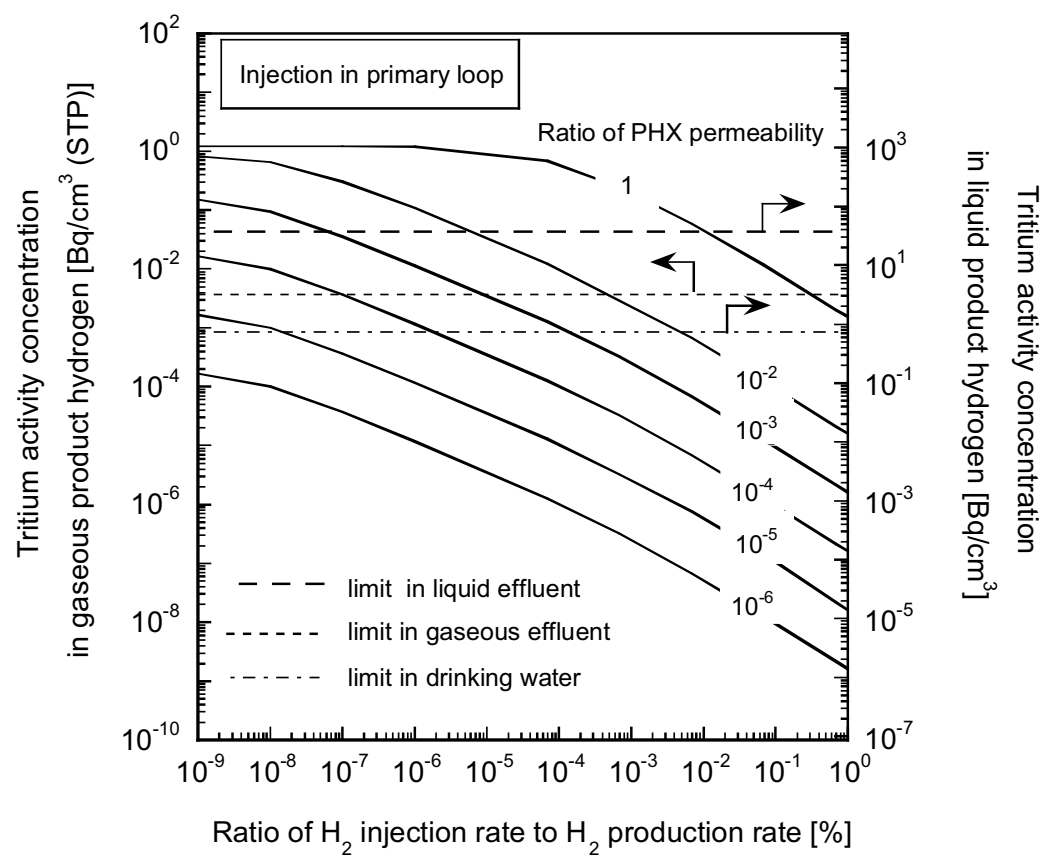

Figure 133. Effect of varying hydrogen injection in the primary helium coolant on the tritium concentration in the hydrogen product for the Next Generation Nuclear Plant using the sulfur iodine process.

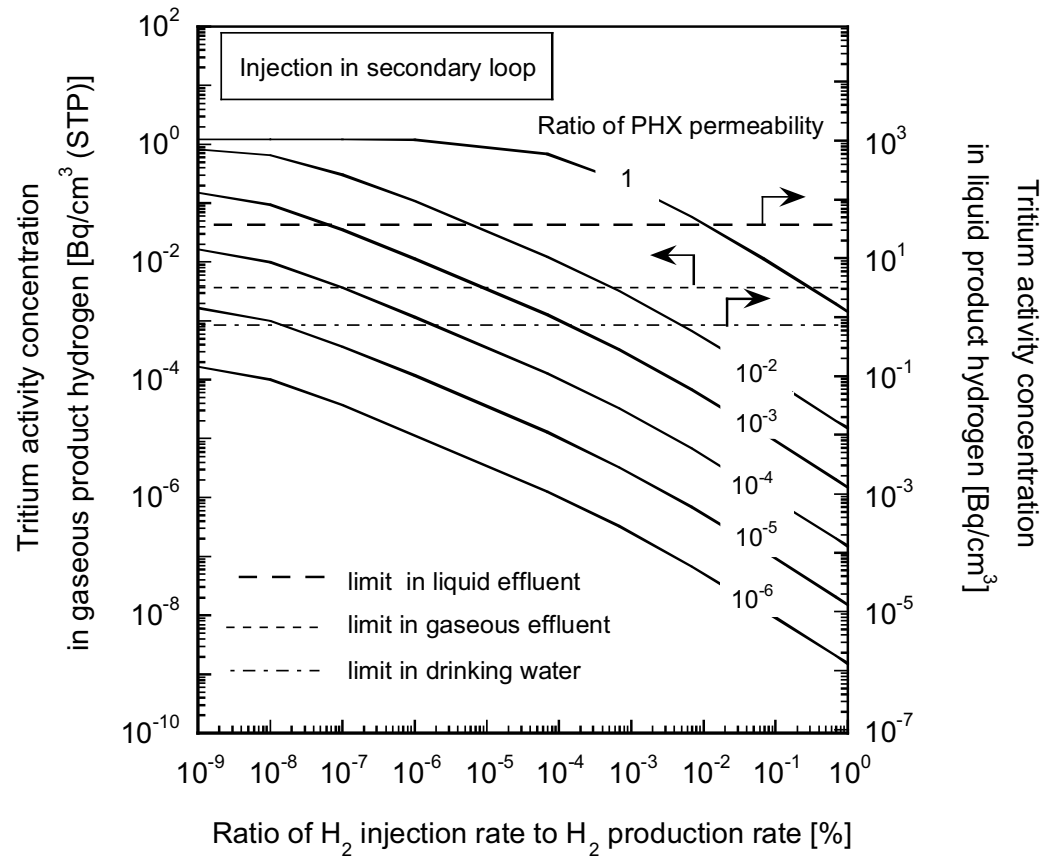

Figure 134. Effect of varying hydrogen injection in the secondary helium coolant on the tritium concentration in the hydrogen product for the Next Generation Nuclear Plant using the sulfur iodine process. 


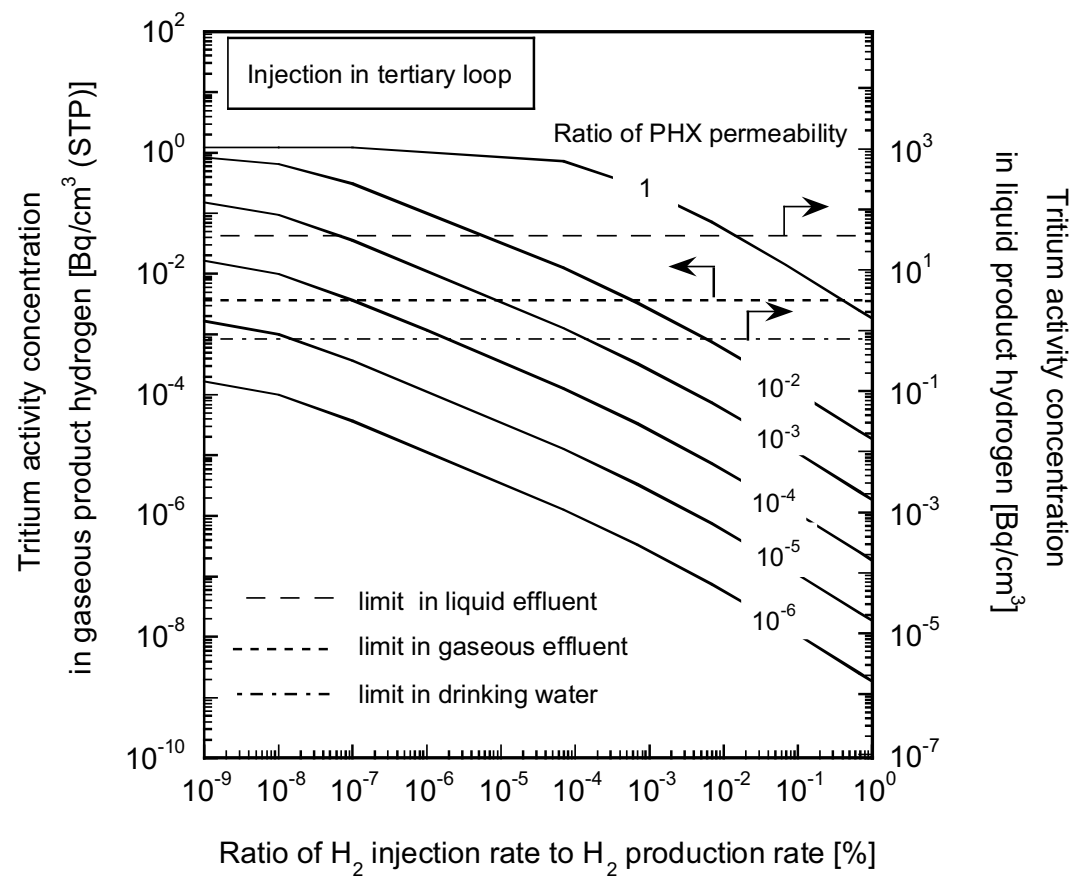

Figure 135. Effect of varying hydrogen injection in the tertiary helium coolant on the tritium concentration in the hydrogen product for the Next Generation Nuclear Plant using the sulfur iodine process.

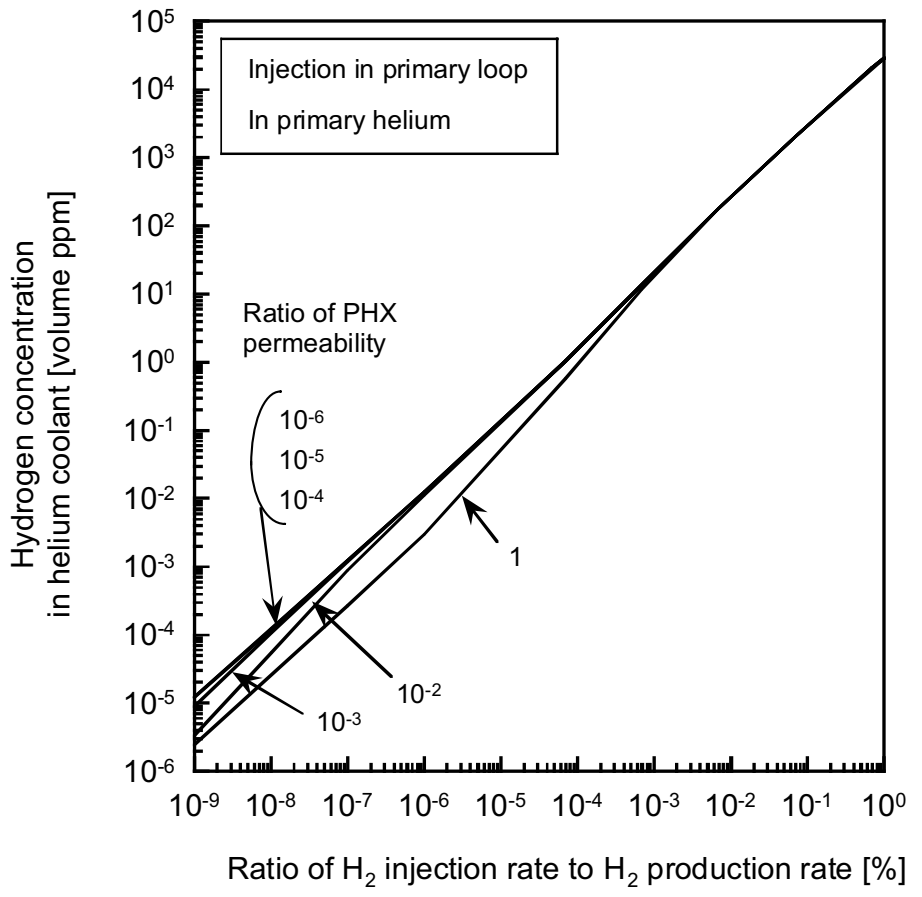

Figure 136. Effect of varying hydrogen injection in the primary helium coolant on the hydrogen concentration in the primary helium coolant for the Next Generation Nuclear Plant using the sulfur iodine process. 


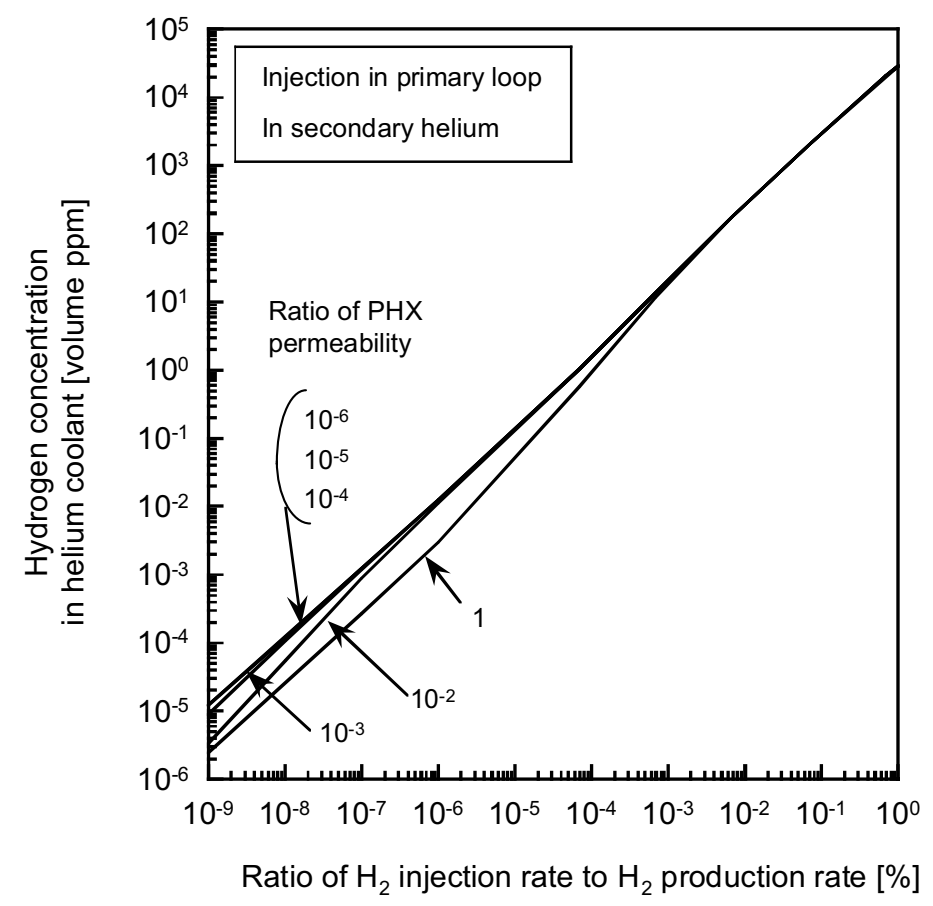

Figure 137. Effect of varying hydrogen injection in the primary helium coolant on the hydrogen concentration in the secondary helium coolant for the Next Generation Nuclear Plant using the sulfur iodine process.

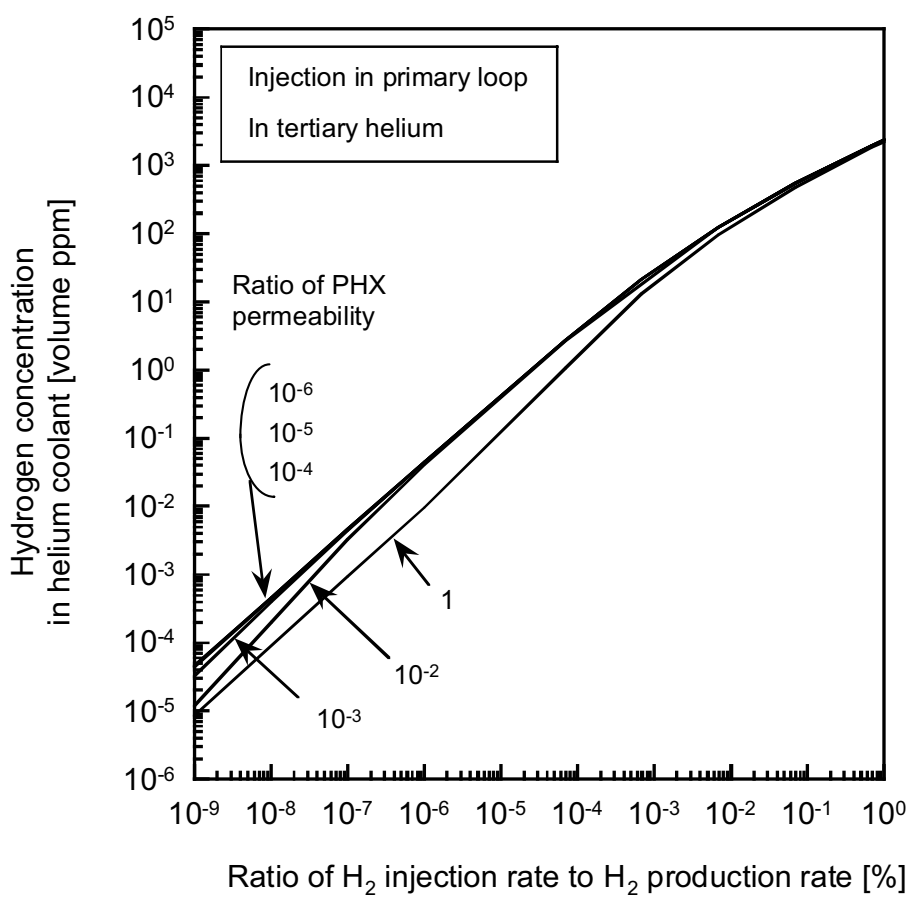

Figure 138. Effect of varying hydrogen injection in the primary helium coolant on the hydrogen concentration in the tertiary helium coolant for the Next Generation Nuclear Plant using the sulfur iodine process. 
Tritium concentration in a component of the sulfur iodine process. Figures 140 and 141 show the effect of varying the hydrogen injection rate in the primary helium coolant on the tritium concentration in gaseous process chemicals of the flash drum (S301) and in liquid process chemicals of the secondary $\mathrm{O}_{2}$ knockout drum (S105), respectively. The dependencies of tritium concentrations on hydrogen injection are the same as for hydrogen injection in the secondary and tertiary helium loops. The tritium concentration in gaseous process chemicals of the flash drum (S301) can be decreased less than the gaseous effluent limit by hydrogen injection of about $2 \times 10^{-5} \%, 1 \times 10^{-3} \%$ and $3 \times 10^{-2} \%$ against the hydrogen production rate if the PHX permeability is reduced by $1 \times 10^{-4}$ times, $1 \times 10^{-3}$ times, and $1 \times 10^{-2}$ times the base case, respectively. However, it cannot be decreased less than the gaseous effluent limit in the PHX permeability base case, even if the hydrogen injection rate is $1 \%$ of the hydrogen production rate.

The tritium concentration in liquid process chemicals of the secondary $\mathrm{O}_{2}$ knockout drum (S105) can be decreased less than the liquid effluent limit by hydrogen injection of about $1 \times 10^{-6} \%, 1 \times 10^{-4} \%$ and $3 \times 10^{-3} \%$ of the hydrogen production rate if the PHX permeability is also reduced by $1 \times 10^{-4}$ times, $1 \times 10^{-3}$ times, and $1 \times 10^{-2}$ times the base case permeability, respectively. For the PHX permeability base case, the tritium concentration is larger than the liquid effluent limit, even if the hydrogen injection rate is $1 \%$ of the hydrogen production rate.

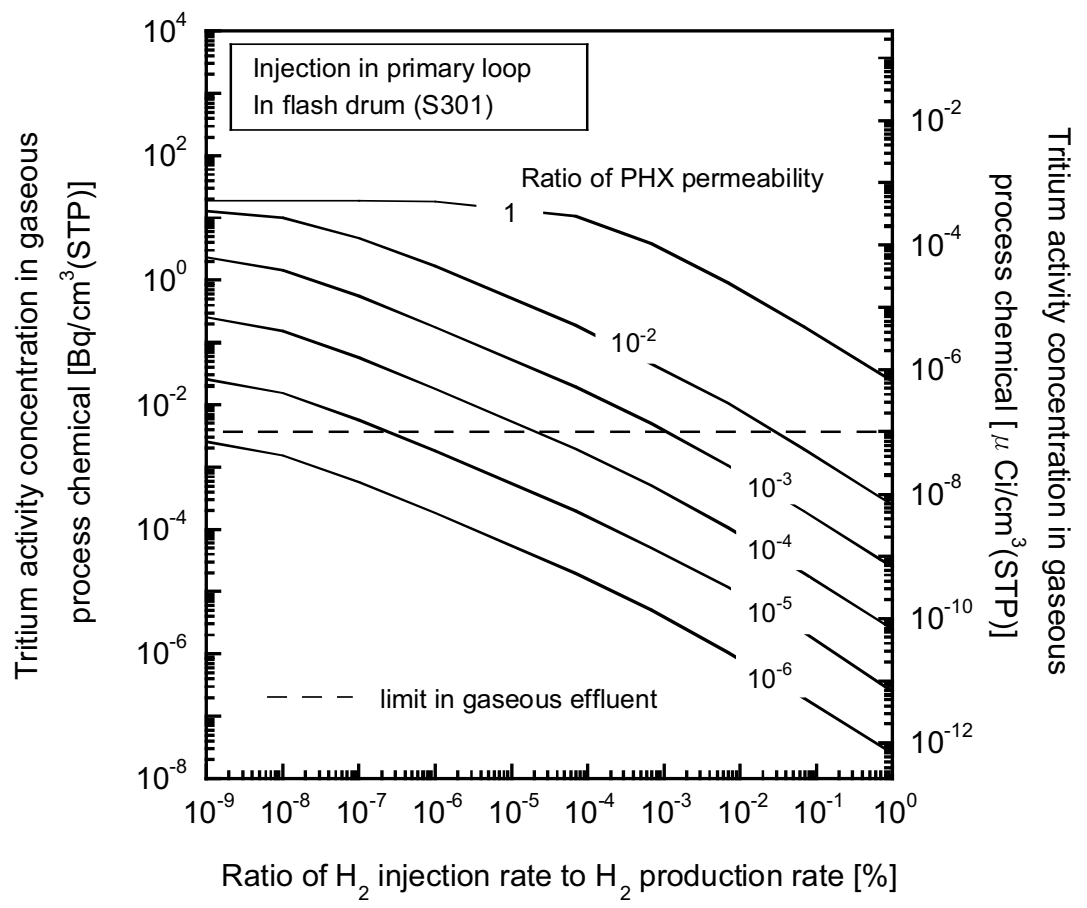

Figure 139. Effect of varying hydrogen injection in the primary helium coolant on the tritium concentration in gaseous process chemicals of the flash drum (S301) for the Next Generation Nuclear Plant using the sulfur iodine process. 


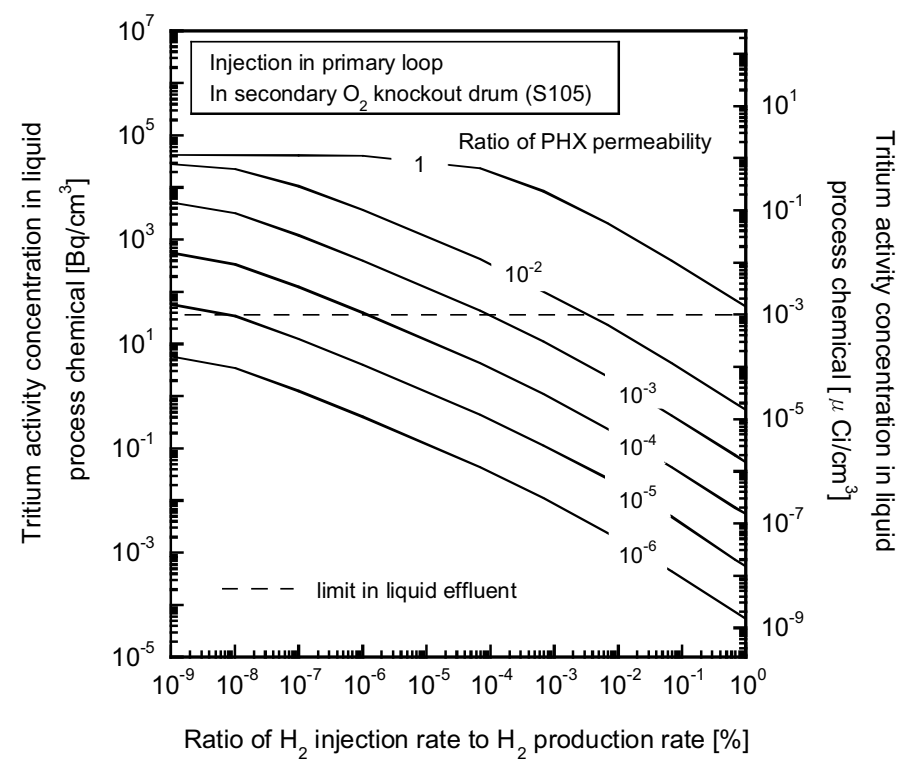

Figure 140. Effect of varying hydrogen injection in the primary helium coolant on the tritium concentration in liquid process chemicals of the secondary $\mathrm{O}_{2}$ knockout drum (S105) for the Next Generation Nuclear Plant using the sulfur iodine process.

Tritium concentration in helium coolant. Figures 141, 142, and 143 show the effect of varying the hydrogen injection rate in the primary helium coolant on the tritium concentration in primary, secondary, and tertiary helium coolants, respectively. Both tritium concentrations in the primary and secondary helium coolants slightly increase with an increase of the hydrogen injection rate, and show almost the same profiles. The tritium concentration in the tertiary helium coolant decreases with an increase of the hydrogen injection rate. However, the tritium concentration in the tertiary loop remains above the gaseous effluent limit, even if the hydrogen injection rate is $1 \%$ of the hydrogen production rate.

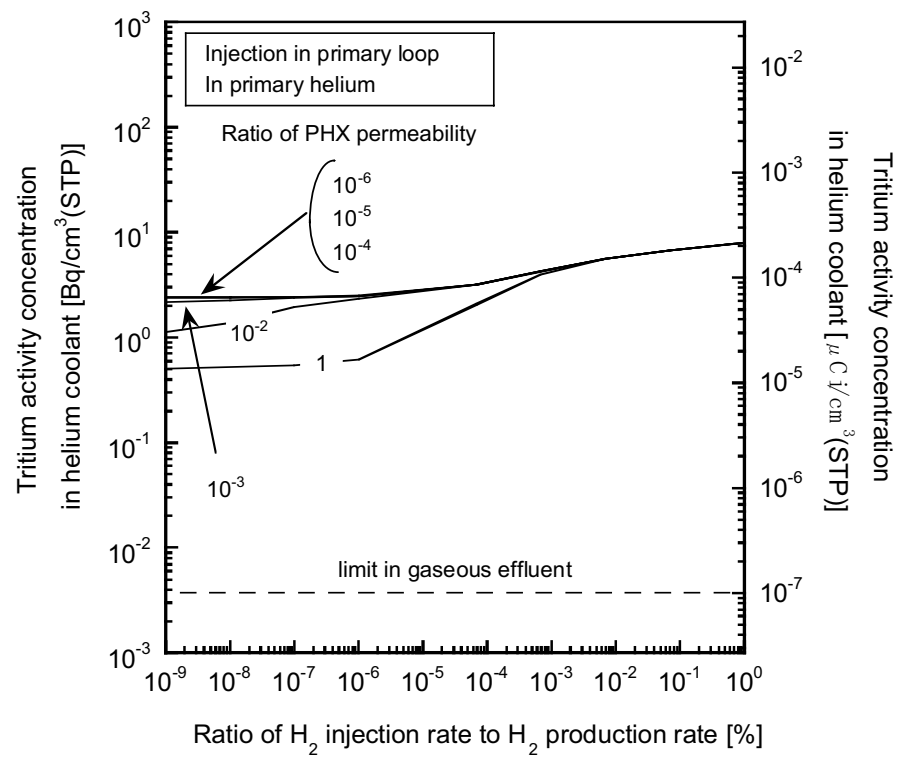

Figure 141. Effect of varying hydrogen injection in the primary helium coolant on the tritium concentration in the primary helium coolant for the Next Generation Nuclear Plant using the sulfur iodine process. 


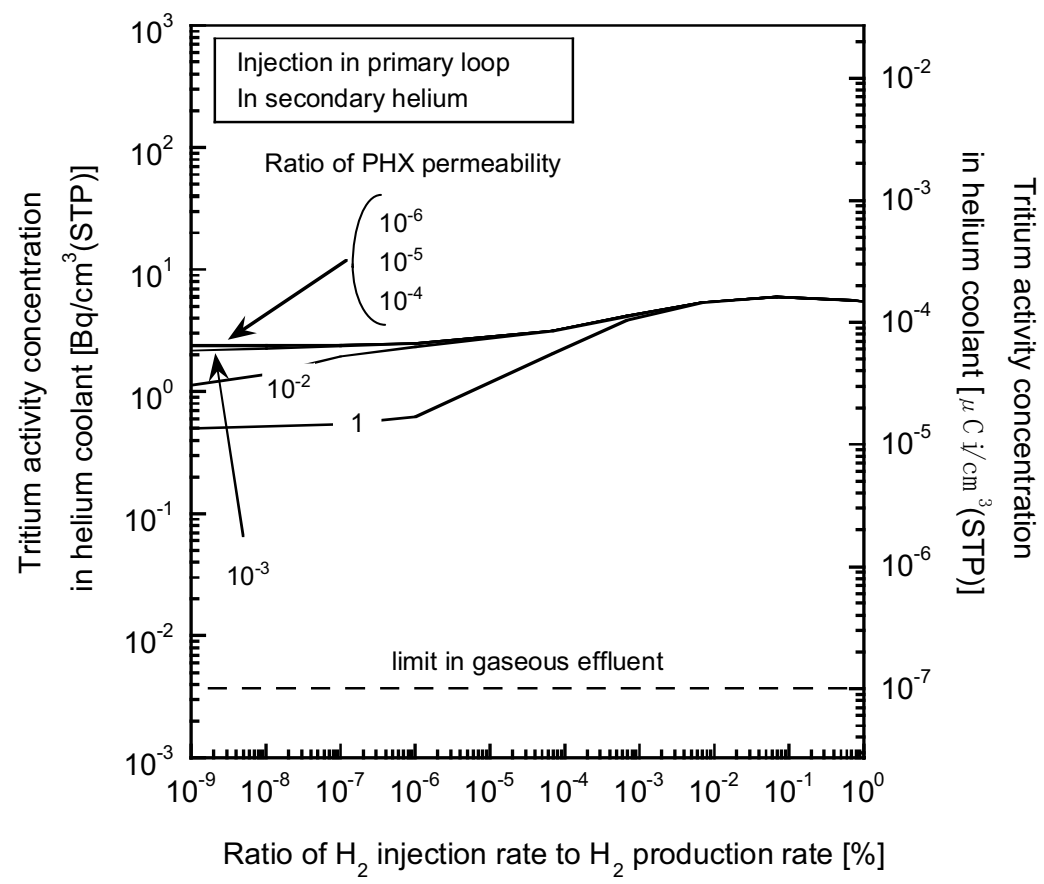

Figure 142. Effect of varying hydrogen injection in the primary helium coolant on the tritium concentration in the secondary helium coolant for the Next Generation Nuclear Plant using the sulfur iodine process.

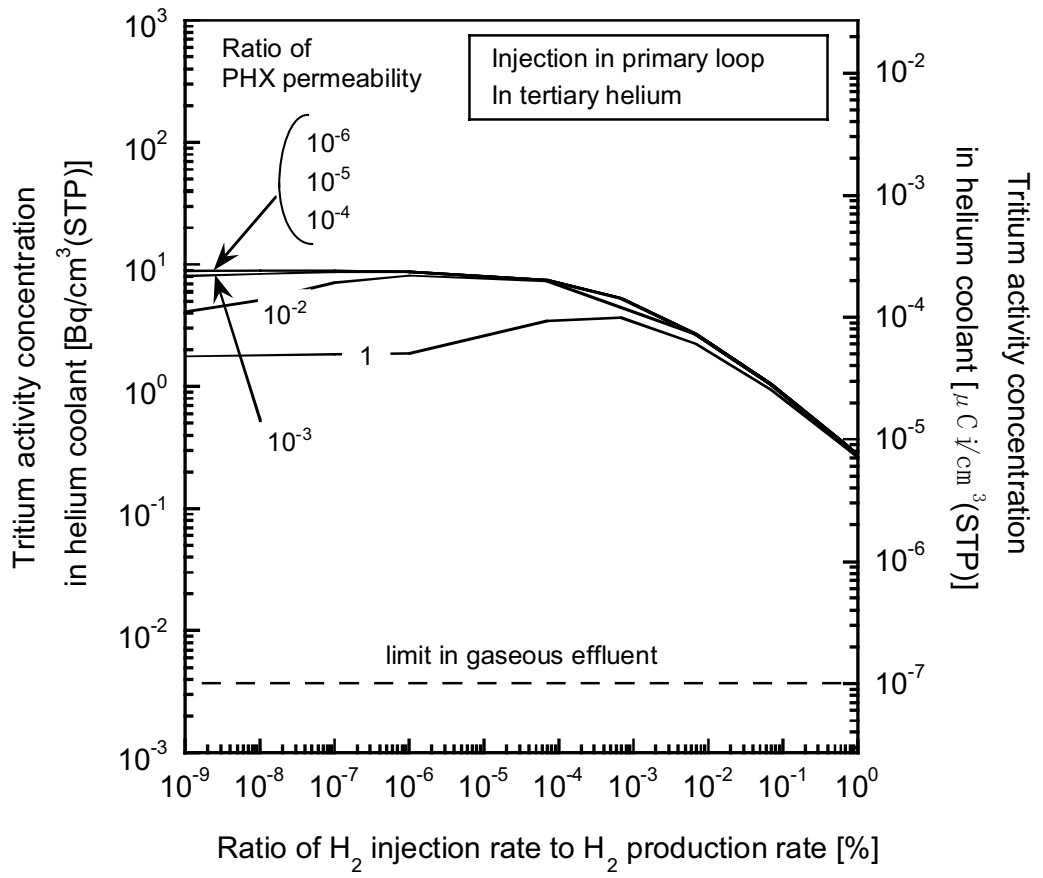

Figure 143. Effect of varying hydrogen injection in the primary helium coolant on the tritium concentration in the tertiary helium coolant for the Next Generation Nuclear Plant using the sulfur iodine process. 


\subsection{Summary}

Tritium concentrations in the hydrogen product and in process chemicals for an NGNP using the SI process are potentially larger than those for an NGNP using the HTE process. This is because the SI process uses only thermal energy (and, correspondlingly, a larger PHX), whereas the HTE process uses electricity and thermal energy to split water. For an NGNP using the SI process, there are three significant undetermined parameters (i.e., equilibrium constant of isotope exchange reaction between HT and $\mathrm{H}_{2} \mathrm{SO}_{4}$, permeability of PHX, and hydrogen concentration in helium coolants).

Tritium concentrations in product hydrogen and in the helium coolant are independent of the equilibrium constant of the isotope exchange reaction between $\mathrm{HT}$ and $\mathrm{H}_{2} \mathrm{SO}_{4}$. However, tritium concentrations in gaseous process chemicals in some components of Section 2 increase with an increase of the isotope exchange reaction. The tritium concentration in the flash drum (S301), which is independent of the equilibrium constant, and in the $\mathrm{H}_{2} \mathrm{SO}_{4}$ vaporizer 3 (H208B) show the maximum concentration below and above about 10 of the equilibrium constant. Tritium concentrations in liquid process chemicals of some components increase with an increase of the equilibrium constant. The tritium concentration in the secondary $\mathrm{O}_{2}$ knockout drum (S105), which stays almost constant, is the maximum for all process components below about 20 of the equilibrium constant. However, the tritium concentration in the $\mathrm{H}_{2} \mathrm{SO}_{4}$ vaporizer $2(\mathrm{H} 208 \mathrm{~A})$ increases with an increase of the equilibrium constant and becomes the maximum for all process components above about 20 of the equilibrium constant. Therefore, evaluation of the equilibrium constant of the isotope exchange reaction between HT and $\mathrm{H}_{2} \mathrm{SO}_{4}$ is significant for estimating tritium accumulation in SI process components.

The PHX permeability is uncertain because the current default technology for the sulfur-iodine PHX will employ ceramics, and there is incomplete data on the permeability of tritium through the ceramic materials of choice for this process unit (i.e., SiC). The effect of PHX permeability on the tritium concentration in the hydrogen product and in gaseous and liquid process chemicals is not significant above about $1 \times 10^{-2}$ times the ratio of PHX permeability for the base case (i.e., permeability of Incoloy 800). However, the tritium concentration decreases with a decrease of PHX permeability below $1 \times 10^{-2}$ times the ratio of PHX permeability. The tritium concentration in product hydrogen, gaseous process chemicals, and liquid process chemicals become less than the drinking water limit, gaseous effluent limit, and liquid effluent limit below about $5 \times 10^{-6}$ times, $1 \times 10^{-6}$ times, and $6 \times 10^{-6}$ times the PHX permeability ratio under the condition without adding any hydrogen in the helium coolant, respectively. Because the tritium concentration in tertiary helium increases with a decrease of PHX permeability, it is impossible to decrease the tritium concentration in tertiary helium less than the gaseous effluent limit by decreasing PHX permeability.

The hydrogen concentration in the helium coolants significantly affects tritium concentrations in the hydrogen product and in gaseous and liquid process chemicals because hydrogen restricts tritium permeation. For example, at $10 \mathrm{ppm}$ of hydrogen concentration, which is the same condition for the primary coolant of the Peach Bottom HTGR, tritium concentrations in product hydrogen are less than those without hydrogen by a factor of $0.25,2 \times 10^{-3}$, and $2 \times 10^{-3}$ at the PHX permeability ratio of $1,1 \times 10^{-3}$, and $1 \times 10^{-6}$ times, respectively. Therefore, it is important to evaluate the hydrogen concentration in helium coolants. However, the tritium concentration in tertiary helium is larger than the gaseous effluent limit by more than two orders of magnitude, even at 1,000 ppm of hydrogen concentration in the primary coolant.

The effects of other parameters (i.e., tritium release rate to the primary coolant, IHX and SHX permeability, helium flow rate at the purification system, and pressure in the tertiary loop) were also evaluated. Tritium concentrations in the hydroge product, gaseous and liquid process chemicals, and 
tertiary helium decrease proportionally with a decrease of the tritium release rate to the primary coolant. This indicates that evaluation of the tritium generation rate and release rate (i.e., evaluation of tritium chemisorption on core graphite) is significant. Removal of tritium in the stream between the core and IHX in the primary loop and between IHX and SHX in the secondary loop seems to have the same effect as a decrease of the tritium release rate. However, alternative technology should be developed because the conventional purification system cannot be installed for these streams if a co-axial hot pipe is employed.

The effect of IHX permeability on tritium concentrations is not significant when compared with the effect of PHX permeability. However, tritium concentrations in the hydrogen product, gaseous and liquid process chemicals, and tertiary helium decrease with a decrease of SHX permeability, which is the same as with PHX permeability. This indicates that the development of methods to decrease the tritium permeation rate though SHX is important (e.g., applying ceramic heat exchanger and developing alternate technology).

Tritium concentrations in the hydrogen product, gaseous and liquid process chemicals, and tertiary helium decrease with an increase of the helium flow rate at the purification system. However, the effect of the helium flow rate at the purification system is not significant. For example, the helium flow rate at the purification system in all loops should be increased about 100 times to decrease the tritium concentrations by factor of 0.1 . It is impossible to decrease the tritium concentration in tertiary helium less than the gaseous effluent limit under the reasonable helium flow rate condition.

Tritium concentrations in the hydrogen product, gaseous and liquid process chemicals, and tertiary helium decreases, decreases, and increases, respectively, with a decrease of pressure in the tertiary loop. However, the effect of pressure in the tertiary loop is not significant when compared with other parameters.

Hydrogen injection in helium coolants seems to be one possible measure for decreasing tritium concentrations. Tritium concentrations in the hydrogen product, gaseous and liquid process chemicals, and tertiary helium decrease with an increase of the hydrogen injection rate. However, it is difficult to decrease the tritium concentration in tertiary helium to less than the gaseous effluent limit in under the condition of a reasonable hydrogen injection rate. 


\section{CONCLUSION AND RECOMMENDATIONS}

Tritium concentrations for an NGNP using the HTE process and SI process (i.e., tritium concentration in product hydrogen, process chemicals in the component of the hydrogen plant, and tertiary helium) were evaluated using the numerical analysis code THYTAN.

The tritium concentration in the liquid process chemicals of the components for the HTE process is less than the liquid effluent limit for the tentative base case. Tritium concentrations in the hydrogen and in gaseous process chemicals for the components of the HTE process at the tentative base case are slightly larger than the drinking water limit and the gaseous effluent limit, respectively. However, the tritium concentration in the hydrogen product and the gaseous process chemicals can be decreased to less than each limit by using some system designs and operations under reasonable conditions (i.e., increase of helium flow rate at the purification system, decrease of temperature, and injection of hydrogen in the helium coolant). However, the tritium concentration in tertiary helium is much larger than the gaseous effluent limit for the tentative base case.

Also for an NGNP employing the HTE process, tritium concentration in the tertiary coolant can be decreased to less than the limit under conditions of low tritium release rate to helium coolant, low permeability of IHX or SHX, and large helium flow rate at all purification systems. The effect of IHX permeability is less than SHX permeability. Achievement of the effluent limits for the tertiary coolant, however, by manipulating the helium purification rate requirs capacity for the helium purification system that is unreasonable. Therefore, a decrease of the tritium permeation rate through SHX is the most effective and reasonable measure to decrease the tritium concentration in tertiary helium. The estimation of the tritium release rate (i.e., estimation of the amount of chemisorbed tritium on core materials) also is an important issue.

Tritium concentrations in product hydrogen and in process chemicals for an NGNP using the SI process are potentially larger than those for NGNP using the HTE process. Tritium concentrations in the hydrogen product and process chemicals of the components for the SI process are significantly affected by PHX permeability and the hydrogen concentration in helium coolants. The tritium concentration in the hydrogen product becomes less than the drinking water limit under the condition that PHX permeability is less than about $5 \times 10^{-6}$ times the base case. The tritium concentration in tertiary helium is larger than the gaseous effluent limit regardless of the PHX permeability. Because the maximum tritium concentration in the process chemicals of the component for the SI process increases with an increase of the equilibrium constant of the isotope exchange reaction between $\mathrm{HT}$ and $\mathrm{H}_{2} \mathrm{SO}_{4}$ under the condition that the equilibrium condition is above about 10 , evaluation of the equilibrium concentration is indispensable in order to obtain a more accurate estimate of tritium accumulation in the SI process. An increase of the helium flow rate at the purification system and the hydrogen injection rate can decrease tritium concentrations in the hydrogen product and process chemicals. However, it is impossible to decrease the tritium concentration in tertiary helium less than the gaseous effluent limit by manipulating only these parameters. However, a decrease of the tritium release rate and a decrease of SHX permeability can decrease the tritium concentration in the hydrogen product hydrogen, process chemicals, and also the tertiary helium. Therefore, a decrease of tritium permeation through the SHX, coupled with other measures, is an effective means to lower tritium concentrations in the system.

Areas where more work would be required are listed as follows:

1. Determination of the acceptable tritium concentration in the hydrogen product and in the various plant components must be performed to ensure customer acceptance of the hydrogen product, compliance with regulations, and the installation of proper tritium controls. For example, the concentration of tritium in the tertiary loop has been pointed out as a potential trouble spot for 
tritium release if a bulk coolant leak were to occur. To avoid exceeding the gaseous effluent limit for tritium in this situation, the proper combination of tritium controls must be enacted to limit the tritium concentration in the coolant to below the gaseous effluent limit.

2. The tritium permeability of key materials of construction (e.g., high-temperature alloys, ceramics) at the temperatures and chemical conditions of interest must be confirmed from the available literature and, where necessary, measured or remeasured in the laboratory.

3. A better understanding of the tritium release rate from the nuclear reactor core materials must be obtained. This information should also include an understanding of the time-dependent behaviors of the tritium release rate. Since the best means of controlling tritium in the hydrogen product is to reduce the amount of tritium manufactured and released from the core in the first place, it is vital to have a good understanding of the range of release rates for the various core materials and core operating conditions, so that suitable tritium response strategies can be formulated.

4. Basic information is needed on the equilibrium constant of the isotope exchange reaction between $\mathrm{HT}$ and $\mathrm{H}_{2} \mathrm{SO}_{4}$.

5. Basic information is needed on the chemisorption mechanisms and chemical equilibrium behavior of tritium and graphite.

6. Greater research into the methods to decrease tritium concentrations in the hydrogen product, hydrogen plant components, and in the tertiary helium. Since these components are intended to fall outside of the nuclear-regulated domain, it is important to have the ability to limit tritium concentration in these areas to below acceptable limits. As this study has shown, more work is needed in the area of tritium controls to achieve this goal.

7. Identification and development of suitable methods for detecting and measuring the concentrations of tritium-containing compounds in the hydrogen plant process streams, either in the form of offline or on-line instrumentation.

8. Further development of the THYTAN model or future models, so that the data obtained from the items identified above can be incorporated into the model(s), and to improve the capability of the model(s) to examine other NGNP configurations than the ones examined in this study. 


\section{ACKNOWLEDGEMENT}

This study is carried out under the Fujii-e Research Initiative by the U.S. Department of Energy. The authors wish to thank to Prof. Yoichi Fujii-e, former chairman of Atomic Energy Commission of Japan, for assistance. The authors also thank to Dr. Chang H. Oh (INL) and Dr. Steven Herring (INL) for their helpful comments and for providing information on the HTE process. 


\section{REFERENCES}

10 CFR 20, Subpart D, 2007, "Radiation Dose Limits for Individual Members of the Public," Code of Federal Regulations.

10 CFR 50, 2007, "Domestic Licensing of Production and Utilization Facilities," Code of Federal Regulations.

40 CFR 190, 2007, "Environmental Radiation Protection Standards for Nuclear Power Operations," Code of Federal Regulations.

Atomic Energy Society of Japan, 1982, Tritium no kagaku, Atomic Energy Society of Japan, Vol. 31 [in Japanese].

Billot, P. and D. Barbier, 2004, "Very high temperature reactor (VHTR) the French atomic energy commission (CEA) R\&D program," Proc. 2nd Int. Topical Meeting on High Temperature Reactor Technology, Beijing, China, September 22-24, 2004, pp. A01.

Burnette, R. D. and N. L. Baldwin, 1980, Primary Coolant Chemistry of the Peach Bottom and Fort St. Vrain High-Temperature Gas-Cooled Reactors, GA-A16163, General Atomic Company, November 1980.

Compere, E. L., S. H. Freid, and C. W. Nestor, 1974, Distribution and Release of Tritium in High-Temperature Gas-Cooled Reactors as a Function of Design, Operational, and Material Parameters, ORNL-TM-4303, Oak Ridge National Laboratory, June 1974.

Forsyth, N., 1972, “Tritium Production and Distribution in High Temperature Gas Cooled Reactors Part 1: Tritium Production, Migration and Removal in the Dragon Reactor Between Core 5 Charge III and Core 1 Charge IV," O.E.C.D. High Temperature Reactor Project DRAGON, DP-REPORT-799, June 1972.

Forsyth, N., 1974, "Tritium production and distribution in High Temperature Gas-Cooled Reactors: Tritium generation, retention, distribution, and environmental release in a national 1,500 MW(th) HTR," O.E.C.D. High Temperature Reactor Project DRAGON, DP-REPORT-905, October 1974.

Fujikawa, S., H. Hayashi, T. Nakazawa, K. Kawasaki, T. Iyoku, S. Nakagawa, N. Sakaba, 2004, "Achievement of reactor-outlet coolant temperature of $950^{\circ} \mathrm{C}$ in HTTR," J. Nucl. Sci. Technol., Vol. 41, pp. 1245.

Gainey, B. W., 1976, A Review of Tritium Behavior in HTGR Systems, GA-A13461, General Atomic Company, April 30, 1976.

General Atomic Company, 1978, Metallurgical examination of primary circuit components from the Peach Bottom HTGR, GA-A14506, General Atomic Company, February 1978.

Matzner, D., 2004, "PBMR Project Status and the Way Ahead," Proc. 2nd Int. Topical Meeting on High Temperature Reactor Technology, Beijing, China, September, 22-24, 2004, pp. A04.

Oh, C. H., Davis, C. B., Han, J., Barner, R., Sherman, S. R., Vilim, R., Lee, Y. J., Lee, W. J., 2006, HyPEP FY06 Report: Models and Methods, INL/EXT-06-011725, September 2006. 
Public Law 109-58, 2005, Energy Policy Act of 2005, August 8, 2005.

Richards, M. B., A. S. Shenoy, L. C. Brown, R. T. Buckingham, E. A. Harvego, K. L. Peddicord, S. M. Reza, and J. P. Coupey, 2006, H2-MHR Pre-Conceptual Design Report: SI-Based Plant, GA-A25401, General Atomics Company, April 2006.

Röhrig, H. D., R. Hecker, J. Blumensaat, and J. Schaefer, 1975, "Studies on the permeation of hydrogen and tritium in nuclear process heat installations," Nuclear Engineering and Design, Vol. 34, pp. $157-167$.

Scheffel, W. J., N. L. Baldwin, and R. W. Tomlin, 1976, Operating History Report for the Peach Bottom HTGR Volume I Reactor Operating History, GA-A13907, General Atomics Company, Volume I, August 31, 1976.

Shin, Y., J. Kim, J. Chang, W. Park, and J. Park, 2005, "Nuclear hydrogen production project in Korea," Proc. third information exchange meeting on the nuclear production of hydrogen, Oarai, Japan, October 5-7, 2005.

Steinwarz, W., H. D. Röhrig, and R. Nieder, 1980, Tritium Behavior in an HTR-System Based on AVR-Experience, IWGGCR2, International Atomic Energy Agency, Vienna (Austria), pp. 153-160.

Steinwarz, W., D. Stöver, R. Hecker, and W. Thiele, 1984, "Distribution of tritium in a nuclear process heat plant with HTR,” Nuclear Engineering and Design, Vol. 78, pp. 267-272.

Wichner, R. P. and F. F. Dyer, 1979, Distribution and Transport of Tritium in the Peach Bottom HTGR, ORNL-5497, Oak Ridge National Laboratory, August 1979.

Yang, L., W. A. Baugh, and N. L. Baldwin, 1977, Study of Tritium Permeation Through Peach Bottom Steam Generator Tubes, GA-A14376, General Atomics Company, June 1977.

Zhang, Z. and S. Yu, 2002, "Future HTGR developments in China after the criticality of the HTR-10," Nucl. Eng. Des., Vol. 218, pp. 249. 